\title{
Ocean acidification: Comparative impacts on the photophysiology of a temperate symbiotic sea anemone and a tropical coral
}




\title{
Ocean acidification: Comparative impacts on the photophysiology of a temperate symbiotic sea anemone and a tropical coral
}

\author{
Michael J. W. Doherty
}

A thesis submitted to Victoria University of Wellington in part fulfilment of the requirements of the degree of Master of Science in Marine Biology

VICTORIA UNIVERSITY OF WELLINGTON

Te Whare Wānanga o te Ūpoko o te Ika a Māui

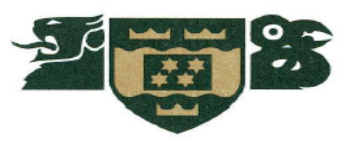

Victoria University

Wellington, New Zealand 


\section{Supervisor's Statement}

I can affirm that, to the best of my knowledge, Michael Doherty has carried out the research for his Masters thesis according to the requirements of the VUW Statutes as set out in the Calendar.

Michael has been solely supervised by myself. I have provided advice about methodology, research, resources and analysis.

Michael carried out his research project independently and therefore the thesis represents his own work.

5th January 2010 


\section{TABLE OF CONTENTS}

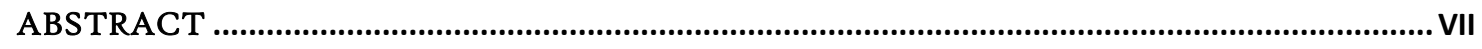

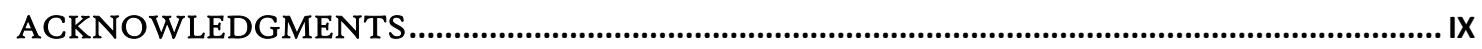

LIST OF FIGURES ……….............................................................................................................. XI

LIST OF TABLES …….................................................................................................................

\section{CHAPTER I}

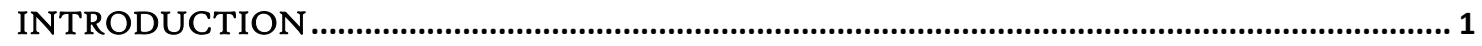

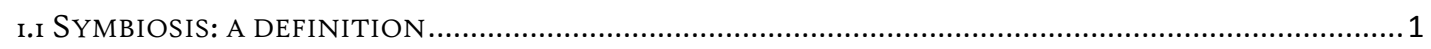

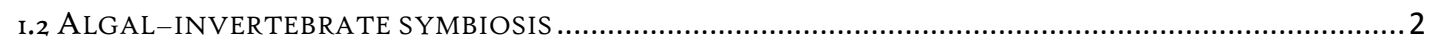

I.3 THE NATURE OF ANTHOZOAN-DINOFLAGELLATE SYMBIOSES ....................................................

I.4 PHOTOSYNTHESIS AND NUTRITIONAL INTERACTIONS IN ANTHOZOAN-DINOFLAGELLATE

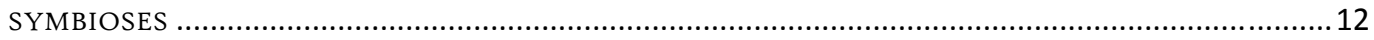

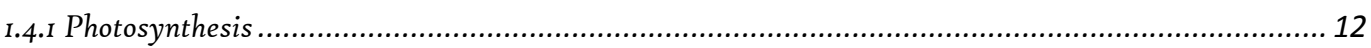

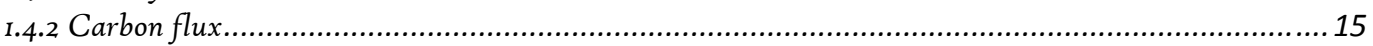

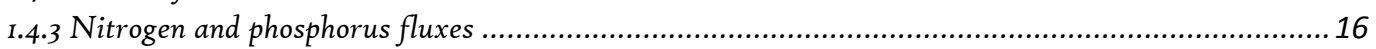

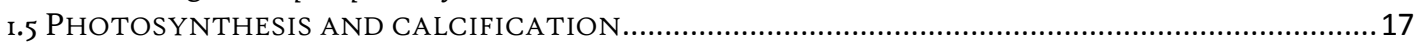

I.6 ENVIRONMENTAL THREATS TO ANTHOZOAN-DINOFLAGELLATE SYMBIOSES ..............................20

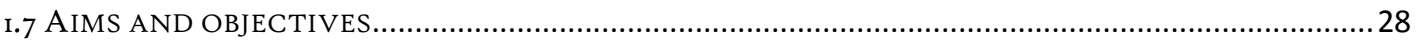

\section{CHAPTER II}

PHOTOPHYSIOLOGICAL RESPONSES OF THE RED SEA CORAL

STYLOPHORA PISTILLATA TO SEAWATER ACIDIFICATION ............................................... 30

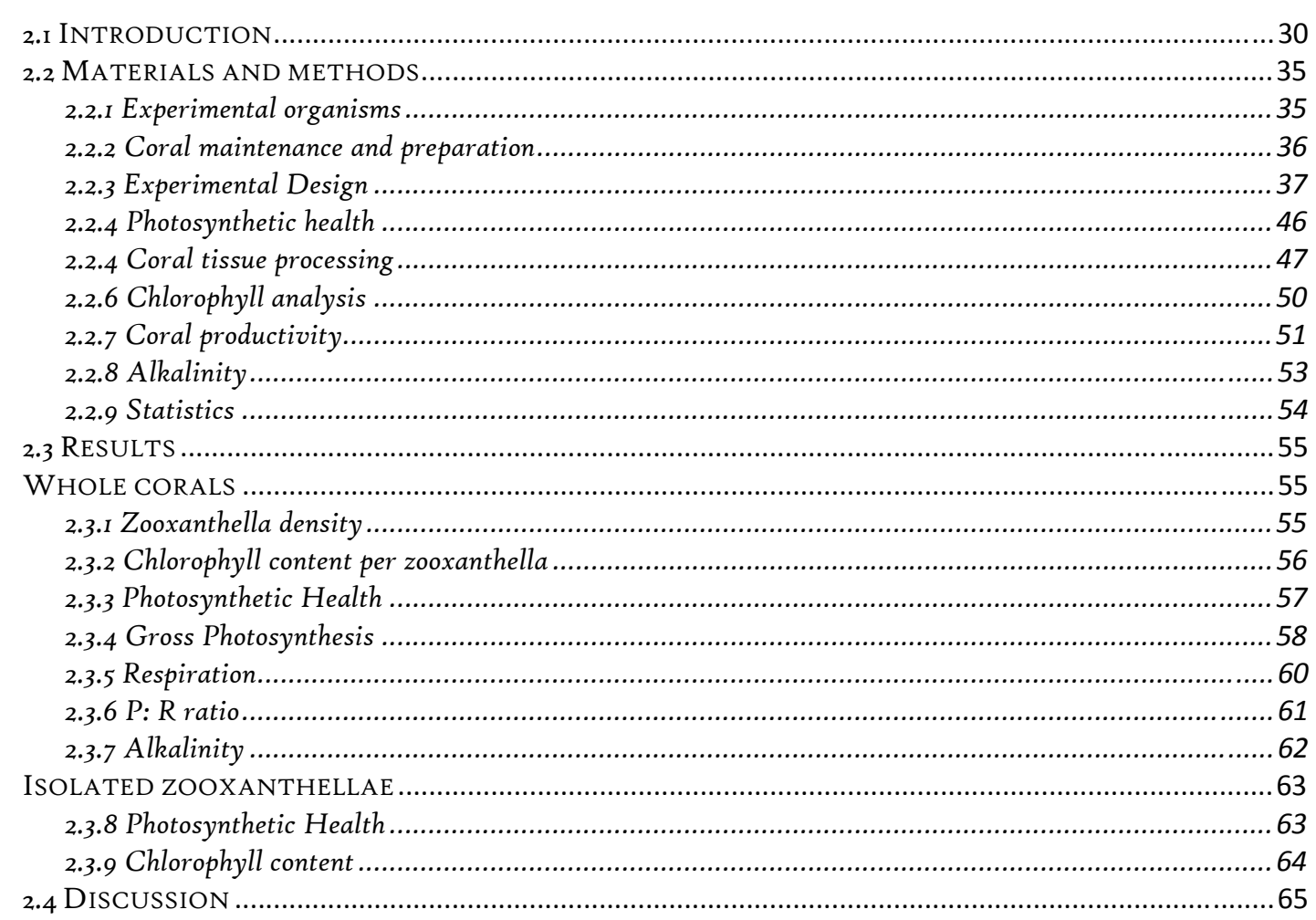




\section{CHAPTER III}

PHOTOPHYSIOLOGICAL RESPONSES OF THE TEMPERATE SEA

ANEMONE ANTHOPLEURA AUREORADIATA TO SEAWATER

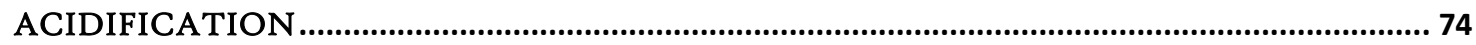

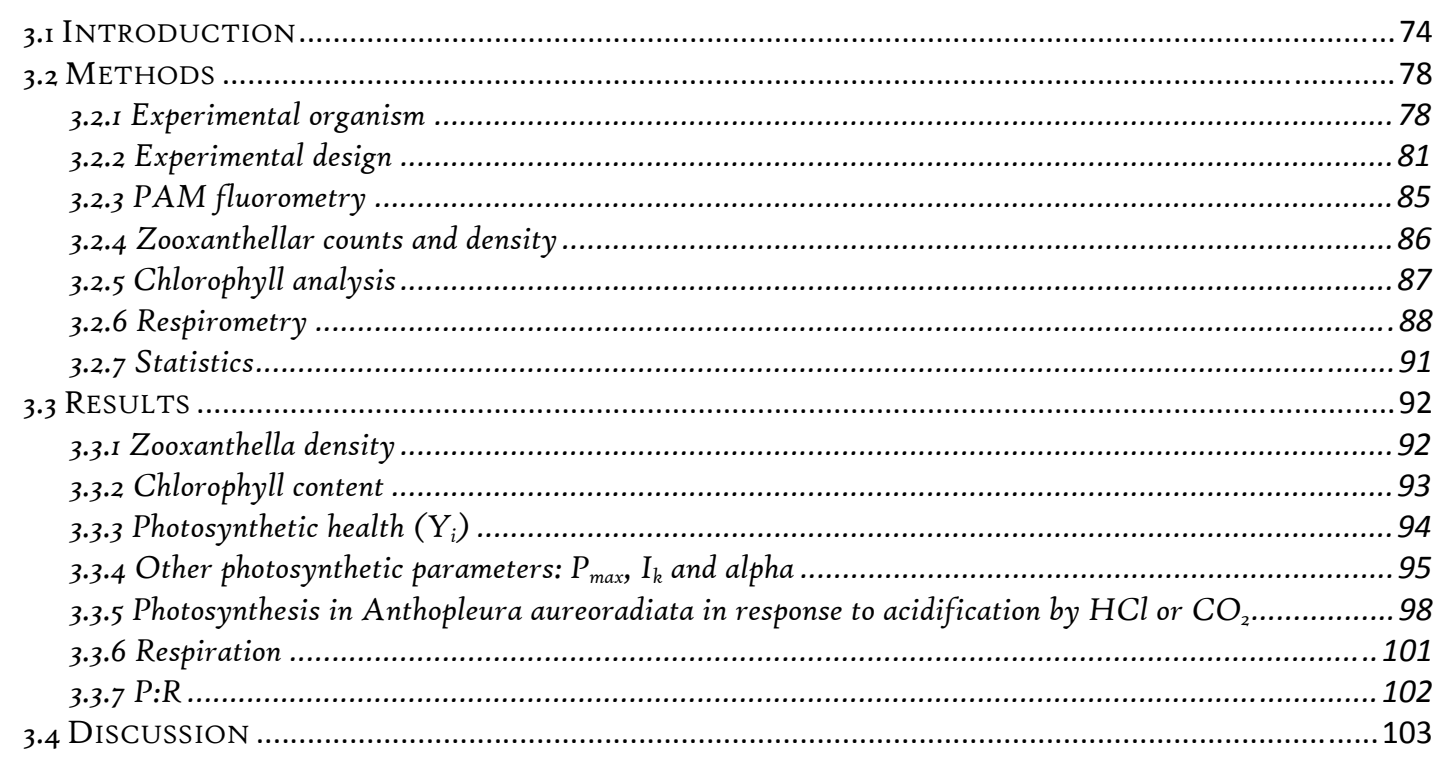

\section{CHAPTER IV}

PHOTOSYNTHETIC HEALTH OF THE TEMPERATE SEA ANEMONE

ANTHOPLEURA AUREORADIATA IN RESPONSE TO INCREMENTAL

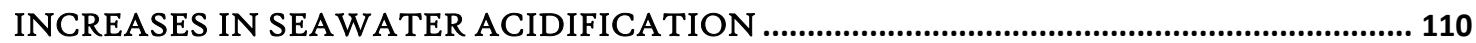

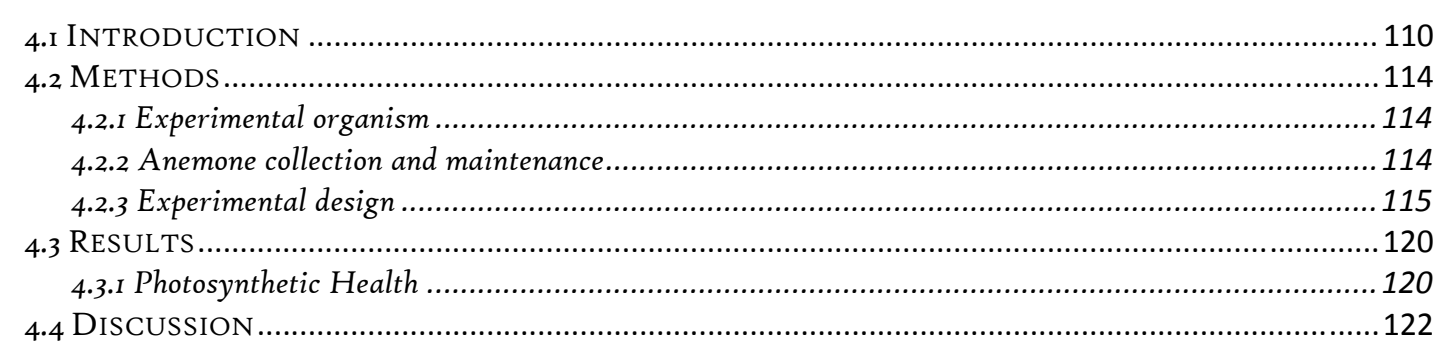

CHAPTER V

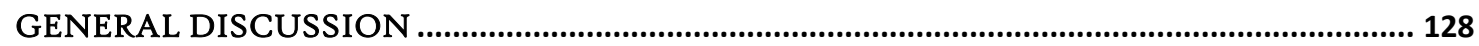

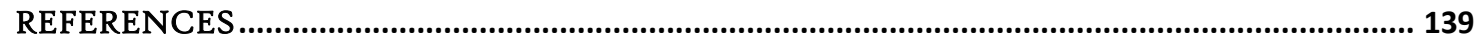

Please note that this thesis has been produced in paper format and therefore may have slight repetition through some chapters. This is intended and is attributable to various

sub-sections being, at least in part, reproduced for each chapter. Where possible, paraphrasing has been utilised in order to minimise the impact of this slight repetition. 


\section{Abstract}

Ocean acidification has the potential to drastically alter the coral reef ecosystem by reducing the calcification rate of corals and other reef-builders, and hence a considerable amount of research is now focused on this issue. It also is conceivable that acidification may affect other physiological processes of corals. In particular, acidification may alter photosynthetic physiology and hence the productivity of the coraldinoflagellate symbiosis that is pivotal to the reef's survival and growth. However, very little is known about the impacts of acidification on the photophysiology of corals or, indeed, other invertebrate-algal symbioses. This gap in our knowledge was addressed here by measuring the impacts of acidification $(\mathrm{pH} 7.6$ versus $\mathrm{pH} 8.1$ ) on the photophysiology and health of the tropical coral Stylophora pistillata and its isolated dinoflagellate symbionts ('zooxanthellae'), and the temperate sea anemone Anthopleura aureoradiata. The comparative nature of this study allowed for any differences between tropical and temperate symbioses, and zooxanthellae in a symbiotic or free-living state, to be assessed. Corals, anemones and cultured zooxanthellae were maintained in flowthrough seawater systems, and treated either with non-acidified (control) seawater at $\mathrm{pH}$ 8.1, or seawater acidified with $\mathrm{CO}_{2}$ or $\mathrm{HCl}$ to $\mathrm{pH}$ 7.6. A variety of parameters, including zooxanthellar density, chlorophyll content, photosynthetic health $\left(\mathrm{Y}_{\mathrm{i}}\right)$, and the ratio of gross photosynthetic production to respiration (P:R) were measured via cell counts, spectrophotometry, respirometry and PAM fluorometry, at a series of time-points up to a maximum of 42 days. Acidification generated by the addition of $\mathrm{CO}_{2}$ had no discernible effect on $\mathrm{Y}_{\mathrm{i}}$ of either the corals or anemones. However, in the coral, chlorophyll content per zooxanthella cell increased by $25 \%$, which was countered by a near-significant decline $(22 \%)$ in the rate of gross photosynthesis per unit chlorophyll; as zooxanthellar density remained unchanged, this led to a constant $\mathrm{P}: \mathrm{R}$ ratio. When acidified via $\mathrm{CO}_{2}$, the isolated zooxanthellae exhibited no impacts in recorded $Y_{i}$ or chlorophyll levels. The response of the anemone to acidification via $\mathrm{CO}_{2}$ was different to that observed in the 
coral, as the density of zooxanthellae increased, rather than the chlorophyll content per cell, leading to an increased rate of gross photosynthesis. However P:R again remained constant as the increased photosynthesis was matched by an increased rate of respiration. In contrast to the impacts of $\mathrm{CO}_{2}, \mathrm{HCl}$ adversely impacted the chlorophyll content per cell in both the isolated zooxanthellae and sea anemone, and $\mathrm{Y}_{\mathrm{i}}$, gross photosynthesis per cell, and overall gross photosynthesis in the sea anemone; however, despite the decline in gross photosynthesis, P:R remained constant due to the concurrent decline in respiration. Unfortunately, the corals in the $\mathrm{HCl}$ experiment died due to technical issues. There are two plausible reasons for this difference between $\mathrm{CO}_{2}$ and $\mathrm{HCl}$. Firstly, $\mathrm{HCl}$ may have caused intracellular acidosis which damaged chloroplast structure and photosynthetic function. Secondly, the increased levels of aqueous $\mathrm{CO}_{2}$ stimulated photosynthetic function and hence mitigated for the effects of lowered $\mathrm{pH}$. In addition, evidence is presented for a $\mathrm{pH}$ threshold for A. aureoradiata of between $\mathrm{pH} 6$ and $\mathrm{pH} 6.75$ (acidified with $\mathrm{HCl}$ ), at which point photosynthesis 'shuts-down'. This suggests that, even without the potentially beneficial effects from increased $\mathrm{CO}_{2}$ levels, it is likely that oceanic $\mathrm{pH}$ would need to decrease to less than $\mathrm{pH} 6.75$ for any acidosis effects to compromise the productivity of this particular symbiosis. Since acidification will have the benefits of increased $\mathrm{CO}_{2}$ and will reach nowhere near such low $\mathrm{pH}$ levels as those extremes tested here, it is proposed that ocean acidification via increased dissolution of $\mathrm{CO}_{2}$ into our oceans will have no impact on the photosynthetic production of symbiotic cnidarians. Indeed, it is entirely likely that increased $\mathrm{CO}_{2}$ will add some benefit to the usually carbon-limited symbiotic zooxanthellae. Ocean acidification is not likely to benefit corals however, with compromised calcification rates likely to undermine the viability of the coral. Symbiotic sea anemones, which do not bio-mineralise $\mathrm{CaCO}_{3}$, are better placed to take advantage of the increased $\mathrm{CO}_{2}$ as we move toward more acidic oceans.

Keywords Ocean acidification $\left|\mathrm{CO}_{2}\right|$ sea anemone $\mid$ coral $\mid$ zooxanthellae photosynthesis $\mid$ acidosis $\mid$ symbiosis $\mid$ dissolved inorganic carbon 


\section{ACKNOWLEDGMENTS}

"If I have seen further, it is by standing on the shoulders of giants". Isaac Newton, letter to Robert Hooke, February 5, 1675

It is well known that Newton and Hooke did not see eye to eye, and given Hooke was a short man, it is quite conceivable that in the above statement Newton had a humorous jab at his contemporary. While indeed humorous, it is the notorious modesty of Newton that resonates most with me. This thesis would not have been possible without the many scientists referenced within, and their countless support staff. Furthermore, this thesis cannot claim to be original in it's entirely, as with any piece of research we lean, to some degree, on previous studies and ideas. In line with Sir Isaac Newton's sentiment, I too have stood on the shoulders of others, and it has without doubt helped my research, and hopefully, it has allowed us to see just that little bit further. Thank you.

I must dedicate this thesis to the two leading ladies in my life. Not long after meeting Fiona, my darling, she convinced me to enrol at University; surprisingly this was not a blind chase of an attractive student into the abyss, but rather acting on a sound piece of advice from a lady who knew better (and always will). Fiona not only provided support, both financially and emotionally, she performed the occasional grammar check too. She is my rock/spellchecker. The other lady in my life, my Mum, is a tower of a lady and someone I look up to and admire immensely. My Mum has always been there for me, always supportive and gave me every chance to succeed. I must also thank my Dad, who never shied away from the countless, often special, questions I fired at him. He persevered with my blank expressions, often showing great restraint from pursuing a Homeresque-type strangle hold. As I grew, I increasingly asked why? Dad encouraged me to pursue this greater level of understanding; and in addition to football, trucks, and sweets, the word why quickly became a favourite - and consequently Dad's least favourite. 
I would like to thank the staff at the School of Biological Sciences, for their help, support and patience; my research undoubtedly benefited. In particular, Neville and Craig helped with my stubborn determination to pursue an experimental set up the way I had envisioned (in a dream). The blurry lines between reality and the dream world meant we countered many challenges, and if not for Neville and Craig, my experiment would have destroyed the School building. Thank you Sandra Taylor, Mary Murray, Patricia Stein and the naval commander Paul Marsden - all of whom made my time at university easier and conducive to good research. Thank you Dr. Shirley Pledger, whom against all odds, managed to conjure a smile when asked for help with my complicated statistics. Thank you to Dr. Joanne Davy for help with, among other things, anemone collection and permit writing and also to Dr. Ken Ryan for taking the time to explain the intricacies of PAM fluorometry. To the team at Centre Scientifique de Monaco, especially Denis Allemand, Christine Ferrier-Pages and Cecile Rottier, merci beaucoup and thank you for permitting a bright-eyed and fresh student into your world-class laboratory.

Finally, in what can only be described as rather repetitive, you cannot avoid the adulation and praise Dr. Simon Davy (Si) gets from his students in theses long since submitted. Despite my best efforts, and trust me I tried, I could not break with this annoying tradition - he is a great supervisor and also a friend. To Si, supervising is not limited to the textbook definition of the word; instead, it encompasses support, motivation, challenge, friendship, laughs, and the odd glass of red. With Si I could debate photosynthesis, calcification and argue how the two were linked, just as easily as arguing which David Bowie era was the greatest, the 70 's or the 80 's. Si has taught me much in two years, but for all you have taught me Si, I hope I have taught you one thing, it was the 70 's. Bon voyage, good day and thank you all. 


\section{LIST OF FIGURES}

\section{Chapter I - Introduction}

Figure 1.1: A) A scleractinian coral, Pocillopora sp., in the Central Pacific (photo: S. Davy). B) A temperate symbiotic sea anemone, Anemonia viridis, from northern Europe (photo: S. Davy). C) A bleached coral, Porites sp., on the reef flat at Heron Island, Great Barrier Reef (photo: S. Davy). D) A giant clam, Tridacna gigas, in the Central Pacific (photo: S. Davy) E) TEM showing Symbiodinium sp. in the tissues of the sea anemone Aiptasia pallida (photo: K. Lee and G. Muller-Parker), scale bar = $2 \mu \mathrm{m}, \mathrm{Ch}=$ chloroplast, $\mathrm{Nu}=$ nucleus, $\mathrm{Cs}=$ chromosomes, $\mathrm{Py}=$ pyrenoid, $\mathrm{L}=$ lipid, $\mathrm{Cw}=$ cellulose based cell wall, and $\mathrm{Mt}=$ mitochondrion. (Page 4)

$>$ Figure 1.2: A) A typical anthozoan polyp illustrating extended tentacles; B) a cross section of a polyp tentacle illustrating the various cellular layers and the location of the dinoflagellate symbionts. (Page 7)

$>$ Figure 1.3: A) Dinomastigote zooxanthella with anterior epicone, posterior hypocone, and two flagella (only transverse flagellum labelled). B) Coccoid zooxanthella. (Page 9)

$>$ Figure 1.4: Symbiodinium diversity. Schematic illustrating the multiple layers and complexity of Symbiodinium. Each of the 8 clades (A-H) are defined by sequencing conserved genes, however, due to adaptive radiation each of the clades have converged to a point where clade-specific traits are few. The within clade diversity is resolved by utilising more genetically variable molecules, which allows resolution of types within a clade, as the figure illustrates for Clade B. (Page 10)

$>$ Figure 1.5: The chemistry underpinning calcification (equation 1), bicarbonate conversion (equation 2), and photosynthesis (equation 3). Calcification, via bicarbonate conversion, provides carbon for photosynthesis. Using this source of carbon (and that from other sources), and during light hours, photosynthesis is able to provide energy which enhances calcification. Often equations 1-3 occur simultaneously, and this can result in net calcium carbonate accretion and energy to the coral (equation 4). (Page 19)

$>$ Figure 1.6: Ocean acidification and carbonate (aragonite/calcite depletion). As more and more $\mathrm{CO}_{2}$ is emitted more is absorbed by our oceans. As $\mathrm{CO}_{2}$ is absorbed by the oceans it reacts with water $\left(\mathrm{H}_{2} \mathrm{O}\right)$ to form a carbonic acid $\left(\mathrm{H}_{2} \mathrm{CO}_{3}{ }^{-}\right)$which readily releases $\mathrm{H}^{+}$protons that are able to react with carbonates $\left(\mathrm{CO}_{3}{ }^{2-}\right)$ decreasing the calcium carbonate $\left(\mathrm{CaCO}_{3}\right)$ saturation state of the oceans to below that required by corals. (Page 25)

$>$ Figure 1.7: Ocean acidification and carbonate (aragonite/calcite depletion). Changes in aragonite saturation $\left(\Omega_{\text {aragonite}}\right)$ are predicted to occur as atmospheric $\mathrm{CO}_{2}$ concentrations $(\mathrm{ppm}=$ number top left of each scenario panel) increase. Pre- 
industrial revolution (280 ppm), almost all shallow-water coral reefs had $\Omega_{\text {aragonite }}$ of $>3.25$ (blue regions in the figure), which is the minimum $\Omega_{\text {aragonite }}$ that coral reefs are associated with today.

$\mathrm{CO}_{2}$ is more readily absorbed in the colder water at the poles, therefore the southern and northern oceans are predicted to become further under-saturated with respect to aragonite, with this spreading to the equatorial regions. (Page 27)

\section{Chapter II - Photophysiological responses of the red sea coral Stylophora pistillata to seawater acidification}

$>$ Figure 2.1: Stylophora pistillata on a sandy reef. Photo taken by Paul Kay. (Page 35)

$>$ Figure 2.2: Stylophora pistillata coral nubbins suspended by nylon within their respective tank. (Page 36)

$>$ Figure 2.3: Experimental timeline. $\mathrm{pH} 8.1$ control conducted concurrently with the $\mathrm{pH} 7.6 \mathrm{HCl}$ and the $\mathrm{pH} 7.6 \mathrm{CO}_{2}$ treatments. Colour-coded boxes indicate what measurements were taken for each corresponding time-point, with twelve coral nubbins processed at time 0 and sixteen at time 18 for each treatment. (Page 39)

$>$ Figure 2.4: Coral experimental set-up. Experiment was run for 18 days, treatments were $\mathrm{pH} 8.1, \mathrm{pH} 7.6 \mathrm{HCl}$ and $\mathrm{pH} 7.6 \mathrm{CO}_{2}$. (Page 42)

$>$ Figure 2.5: Experimental set-up outlined in diagram figure 2.3. The photo was taken during the $\mathrm{pH} 8.1$ versus $\mathrm{pH} 7.6 \mathrm{HCl}$ and $\mathrm{pH} 7.6 \mathrm{CO}_{2}$ experiment. (Page 43)

$>$ Figure 2.6: Cultured zooxanthellae experimental set-up. Each trial was run for 35 days, with the treatments being $\mathrm{pH} 8.1$ versus $\mathrm{pH} 7.6 \mathrm{HCl}$, and $\mathrm{pH} 8.1$ versus $\mathrm{pH} 7.6$ $\mathrm{CO}_{2}$ experiments. (Page 44)

$>$ Figure 2.7: Photo of the experimental set-up outlined in diagram figure 1.4. The photo was taken during the $\mathrm{pH} 8.1$ versus $\mathrm{pH} 7.6 \mathrm{CO}_{2}$ experiment. (Page 45)

$>$ Figure 2.8: WinControl interface showing the light curve generated using the Diving Pulse Amplitude Modulated (Diving-PAM) Fluorometer. The photosynthetic parameter $Y_{i}$ was recorded. (Page 46)

Digure 2.9: Processing coral tissue. Coral tissue was removed from the skeleton using a waterpik, and isolated zooxanthellae were then used to measure algal density and chlorophyll levels. (Page 47)

$>$ Figure 2.10: Set-up for counting zooxanthellae. Software calculated algal density in the field of view (as shown on computer screen), before this value was used to calculate the density of zooxanthellae within the coral nubbin. (Page 48)

$>$ Figure 2.11: Standard curve of coral surface area versus tin-foil weight. The formula of the best fit line allowed surface area to be estimated from a given weight 
of tin foil. Black circle $=$ the set measured tin foil sizes, white circles $=$ the best fit predictions and the black line $=$ the linear best fit line. (Page 50)

$>$ Figure 2.12: Respirometry set-up for coral nubbins. A temperature of $25^{\circ} \mathrm{C}$ was maintained via a waterbath and light levels were manipulated with a halogen light attached to a movable rail. A computer recorded all changes in dissolved $\mathrm{O}_{2}$ and calculated rates of $\mathrm{O}_{2}$ depletion in $\mathrm{mg} \mathrm{O}_{2} \mathrm{~L}^{-1} \mathrm{~h}^{-1}$. (Page 52)

Figure 2.13: Density of zooxanthellae. Stylophora pistillata was treated at $\mathrm{pH} 8.1$ (blue) and $\mathrm{pH} 7.6 \mathrm{CO}_{2}$ (red). Densities were standardised per $\mathrm{cm}^{2}$ of coral skeleton surface. Values are means \pm SE. The experiment consisted of two time-points over the 18 days with $n=12$ at Day 0 and $n=16$ at Day 18. (Page 55)

$>$ Figure 2.14: Chlorophyll content per zooxanthella cell. Stylophora pistillata was treated with $\mathrm{pH} 8.1$ (blue) and $\mathrm{pH} 7.6 \mathrm{CO}_{2}$ (red). Values are means \pm SE. The experiment consisted of two time-points over the 18 day period with $n=12$ at 0 Days and $\mathrm{n}=16$ at 18 Days. (Page 56)

$>$ Figure 2.15: Photosynthetic health $\left(\mathrm{Y}_{\mathrm{i}}\right)$. Stylophora pistillata was treated with $\mathrm{pH}$ 8.1 (blue) and $\mathrm{pH} 7.6 \mathrm{CO}_{2}$ (red). Values are means \pm SE. The experiment consisted of two time-points over the 18 days, with $n=12$ at 0 Days and $n=16$ at 18 Days. (Page 57)

> Figure 2.16: Gross Photosynthesis. A) Gross photosynthetic rate per zooxanthella cell; B) Gross photosynthesis per unit chlorophyll; and C) Total gross photosynthesis. Stylophora pistillata was treated with $\mathrm{pH} 8.1$ (blue) and $\mathrm{pH} 7.6 \mathrm{CO}_{2}$ (red). Values are means $\pm \mathrm{SE}$. The experiment consisted of two time-points over the 18 days with $\mathrm{n}=12$ at Day 0 and $\mathrm{n}=16$ at Day 18. (Page 59)

$>$ Figure 2.17: Dark respiration rate (R). Stylophora pistillata was treated with $\mathrm{pH} 8.1$ (blue) and $\mathrm{pH} 7.6 \mathrm{CO}_{2}$ (red). Values are means $\pm \mathrm{SE}$. The experiment consisted of two time-points over the 18 days, with $n=12$ at Day 0 and $n=16$ at Day 18. (Page 60)

$>$ Figure 2.18: Gross photosynthesis $(\mathrm{P})$ to dark respiration $(\mathrm{R})$ ratio. Stylophora pistillata treated with $\mathrm{pH} 8.1$ (blue) and $\mathrm{pH} 7.6 \mathrm{CO}_{2}$ (red). Values are means $\pm \mathrm{SE}$. The experiment consisted of two time-points over the 18 days, with $\mathrm{n}=12$ at Day 0 and $\mathrm{n}=16$ at Day 18. (Page 61)

$>$ Figure 2.19: Seawater alkalinity. $\mathrm{pH} 8.1$ (blue), $\mathrm{pH} 7.6 \mathrm{CO}_{2}$ (red) and $\mathrm{HCl}$ (green). Values are means \pm SE. The experiment consisted of 4 time-points over an 18-day period; $\mathrm{n}=3$ per time-point. (Page 62)

$>$ Figure 2.20: Photosynthetic health $\left(\mathrm{Y}_{\mathrm{i}}\right)$ of isolated (i.e. cultured) zooxanthellae versus $\mathrm{pH}$. Zooxanthellae isolated from Stylophora pistillata were treated with A) $\mathrm{pH}$ 8.1 (blue) and $\mathrm{pH} 7.6 \mathrm{HCl}$ (red); and $\mathrm{B}$ ) $\mathrm{pH} 8.1$ (blue) and $\mathrm{pH} 7.6 \mathrm{CO}_{2}$ (red). Values are means \pm SE. The experiment consisted of 6 time-points over 35 days, with $n=6$ at Day 0 and $n=3$ at all other time-points. (Page 63) 
Digure 2.21: Chlorophyll concentrations per cell. Zooxanthella isolated from Stylophora pistillata were treated with A) $\mathrm{pH} 8.1$ (blue) and $\mathrm{pH} 7.6 \mathrm{HCl}$ (red) and B) $\mathrm{pH} 8.1$ (blue) and $\mathrm{pH} 7.6 \mathrm{CO}_{2}$ (red). Values are means $\pm \mathrm{SE}$, the experiment consisted of 6 time-points over 35 days, $n=6$ at time 0 , otherwise $n=3$. (Page 64)

Chapter III - Photophysiological responses of the temperate sea anemone Anthopleura aureoradiata to seawater acidification

$>$ Figure 3.1: Pauatahanui Inlet at low tide. A) Typical shallow pools of water that Anthopleura aureoradiata is found in once the tide had receded. B) A. aureoradiata with its tentacles above the sediment surface layer. Note that the body of the animal is buried beneath the sediment. C) The anemone in B) when removed from the sediment, attached to a deceased cockle. A further three anemones were also attached to this cockle. (Page 79)

$>$ Figure 3.2: Collection site. A) New Zealand; B) Pauatahanui Inlet, $33 \mathrm{~km}$ north of Wellington; C) magnified view of the collection site. Photo illustrates site at partial low tide. (Page 80)

$>$ Figure 3.3: Experimental set-up. Experiment was left for a duration of 42 days for both the $\mathrm{pH} 8.1$ versus $\mathrm{pH} 7.6 \mathrm{HCl}$ and $\mathrm{pH} 8.1$ versus $\mathrm{pH} 7.6 \mathrm{CO}_{2}$ experiments. (Page 82)

Figure 3.4: Photograph of the experimental set-up shown diagrammatically in figure 2.6. The photograph was taken during the $\mathrm{pH} 8.1$ versus $\mathrm{pH} 7.6 \mathrm{HCl}$ experiment, so the $\mathrm{CO}_{2}$ cylinders are not in use. The experimental set-up for the $\mathrm{pH} 8.1$ versus $\mathrm{pH}$ 7.6 $\mathrm{CO}_{2}$ experiment was otherwise the same, except that the $\mathrm{pH}$ controller triggered a $\mathrm{CO}_{2}$ solenoid and hence the delivery of dissolved $\mathrm{CO}_{2}$ to the reservoir tank, rather than triggering the peristaltic pump to add $10 \% \mathrm{HCl}$. (Page 83)

> Figure 3.5: Experimental timeline. $\mathrm{pH} 8.1$ control conducted in tandem with a specific treatment - either $\mathrm{pH} 7.6 \mathrm{HCl}$ or $\mathrm{pH} 7.6 \mathrm{CO}_{2}$. Colour-coded boxes indicate what measurements were taken for each corresponding time-point, with 5 anemones processed per time-point per treatment. (Page 84)

$>$ Figure 3.6: View of Anthopleura aureoradiata (5 anemones) under the IPAM fluorometer. The partial red ring encircling the anemones is light scatter from the Petri dish in which the anemones were placed. The black rectangles are the "areas of interest”. (Page 85)

> Figure 3.7: Respirometry. A) The respirometry set-up within the laboratory. B) Anthopleura aureoradiata in an $\mathrm{O}_{2}$ chamber, and the electrodes measuring the temperature and the dissolved $\mathrm{O}_{2}$ content. The chamber was illuminated at $300 \mu \mathrm{mol}$ photons $\mathrm{m}^{-2} \mathrm{~s}^{-1}$; and C) A. aureoradiata within its $\mathrm{O}_{2}$ chamber covered in tin foil, for measuring respiration rates in darkness. (Page 89) 
Figure 3.8: Zooxanthella density in response to seawater acidification by $\mathrm{HCl}$ and $\mathrm{CO}_{2}$. A) $\mathrm{pH} 8.1$ (blue) and $\mathrm{pH} 7.6 \mathrm{HCl}$ (red). B) $\mathrm{pH} 8.1$ (blue) and $\mathrm{pH} 7.6 \mathrm{CO}_{2}$ (red). Values are means \pm SE; $n=5$ per time-point. (Page 92)

$>$ Figure 3.9: Biomass-specific chlorophyll content versus $\mathrm{pH}$ in Anthopleura aureoradiata. A) pH 8.1 (blue) and $\mathrm{HCl}$-induced $\mathrm{pH} 7.6$ (red). B) pH 8.1 (blue) and $\mathrm{CO}_{2}$-induced $\mathrm{pH} 7.6$ (red). Values are means \pm SE, $\mathrm{n}=5$ per time-point. (Page 93)

Figure 3.10: Photosynthetic health $\left(\mathrm{Y}_{\mathrm{i}}\right)$ in response to acidification. A) $\mathrm{pH} 8.1$ (blue) and $\mathrm{HCl}$ induced $\mathrm{pH} 7.6$ (red). B) $\mathrm{pH} 8.1$ (blue) and $\mathrm{CO}_{2}$ induced $\mathrm{pH} 7.6$ (red). Values are means \pm SE, $n=5$ per time-point. (Page 94)

$>$ Figure 3.11: Photosynthetic parameters of Anthopleura aureoradiata in response to acidification by $\mathrm{HCl}$, as measured by IPAM fluorometry. Maximum rate of photosynthesis $\left(\mathrm{P}_{\max }, \mathrm{A}\right)$, saturation irradiance $\left(\mathrm{I}_{\mathrm{k}}, \mathrm{B}\right)$, and photosynthetic efficiency $(\alpha, \mathrm{C})$ were calculated using an exponential waiting-in-line fit curve, $\mathrm{pH} 8.1$ (blue) and $\mathrm{pH} 7.6$ (red). Values are means \pm SE, with $\mathrm{n}=5$ per time-point. (Page 96)

$>$ Figure 3.12: Photosynthetic parameters of Anthopleura aureoradiata in response to acidification by $\mathrm{CO}_{2}$, as measured by IPAM fluorometry. Maximum rate of photosynthesis $\left(\mathrm{P}_{\max }, \mathrm{A}\right)$, saturation irradiance $\left(\mathrm{I}_{\mathrm{k}}, \mathrm{B}\right)$, and photosynthetic efficiency $(\alpha, \mathrm{C})$ were calculated using an exponential waiting-in-line fit curve, $\mathrm{pH} 8.1$ (blue) and $\mathrm{pH} 7.6$ (red). Values are means \pm SE, with $n=5$ per time-point. (Page 97)

> Figure 3.13: Photosynthesis in Anthopleura aureoradiata in response to acidification by $\mathrm{HCl}$ or $\mathrm{CO}_{2}$. A) Biomass-specific gross photosynthesis $\left(\mathrm{mg} \mathrm{O}_{2} \mathrm{ng}^{-1}\right.$ $\left.\mathrm{h}^{-1}\right)$, B) Cell-specific gross photosynthesis $\left(\mathrm{mg} \mathrm{O}_{2} \mathrm{zoox}^{-1} \mathrm{~h}^{-1}\right)$ and C) Chlorophyllspecific gross photosynthesis $\left(\mathrm{mg} \mathrm{O}_{2} \mathrm{mg}^{-1}\right.$ chlorophyll $\left.\mathrm{h}^{-1}\right)$. Treatments were $\mathrm{pH} 8.1$ control (blue); $\mathrm{pH} 7.6$ generated with either $\mathrm{HCl}$ or $\mathrm{CO}_{2}$ (red). Note that anemones at Day 0 were removed from the same control $(\mathrm{pH} 8.1)$ stock tank and analysed, prior to further anemones being placed in either the control or two acidification treatments; hence there is only one bar at this first time-point. Values are means $\pm \mathrm{SE}, \mathrm{n}=5$ per time-point. (Page 99/100)

Figure 3.14: Respiration of Anthopleura aureoradiata in response to acidification of seawater by $\mathrm{HCl}$ or $\mathrm{CO}_{2}$. $\mathrm{pH} 8.1$ control (blue); $\mathrm{pH} 7.6$ generated with either $\mathrm{HCl}$ or $\mathrm{CO}_{2}$ (red). Note that anemones at Day 0 were removed from the same control $(\mathrm{pH}$ 8.1) stock tank and analysed, prior to further anemones being placed in either the control or two acidification treatments; hence there is only one bar at this first timepoint. Values are means $\pm \mathrm{SE}, \mathrm{n}=5$ per time-point. (Page 101)

$>$ Figure 3.15: The ratio of gross photosynthesis $(\mathrm{P})$ to respiration $(\mathrm{R})$ of Anthopleura aureoradiata at the different $\mathrm{pH}$ values. $\mathrm{pH} 8.1$ (blue) were independent samples recorded at time 0 and twice at time 42 for both experiments. $\mathrm{pH} 7.6$, induced with either $\mathrm{HCl}$ or $\mathrm{CO}_{2}$ (red) was recorded at time-point 42 only, as indicated on the axis. Values are means $\pm \mathrm{SE}, \mathrm{n}=5$ per time-point. (Page 102) 
Chapter IV - Photosynthetic health of the temperate sea anemone Anthopleura aureoradiata in response to incremental increases in seawater acidification

Figure 4.1: Anthopleura aureoradiata settled in a $15 \mathrm{ml}$ Falcon tube, in seawater of the desired pH. (Page 115)

$>$ Figure 4.2: Experimental set-up, consisting of 25 treatment tubes placed in a waterbath at $16 \pm 1^{\circ} \mathrm{C}$, and illuminated from the side by a halogen lamp. The position of the tubes was randomly re-assigned twice daily to prevent bias caused by the single light source. (Page 117)

Figure 4.3: View of Anthopleura aureoradiata (20 of the total 25 anemones) under the IPAM fluorometer showing chlorophyll fluorescence $(F)$. The black rectangle represents an 'area of interest'. (Page 118)

$>$ Figure 4.4: Photosynthetic health $\left(\mathrm{Y}_{\mathrm{i}}\right)$ of Anthopleura aureoradiata in response to seawater acidification. Treatments: A) $\mathrm{pH} 8.1$ (blue); $\mathrm{pH} 7.6$ (red); $\mathrm{pH} 7.25$ (black); pH 7 (yellow); and pH 6.75 (orange). B) pH 8.1 (blue); pH 7.6, as a reference from Chapter 3 results (red dash); $\mathrm{pH} 7.25$ (orange); $\mathrm{pH} 6.75$ (black); $\mathrm{pH} 6$ (purple); and $\mathrm{pH} 5$ (green). Treatments were acidified using $10 \% \mathrm{HCl}$. Values are means $\pm \mathrm{SE}, \mathrm{n}=$ 5 per time-point, with the same anemones measured repeatedly throughout the experiment. (Page 121)

$>$ Figure 4.5: Free-energy profile of a typical enzymatic reaction. Points 1 (initial substrate); 2 (enzyme active site binds onto substrate and initial conversion); and 3 (enzyme and product at up to $10^{19}$ increased efficiency) represent optimal function of an enzyme under optimal conditions (for example, specific $\mathrm{pH}$, temperature and alcohol concentrations). The free energy made available by the enzyme (e) either allows the most efficient conversion rate of the substrate (A) to the product (B), or even permits the conversion to occur at all. Points 4 (initial substrate); 5 (enzyme binding on to substrate and initial conversion (e. B) or no binding occurs (e. A)); and 6 (enzyme and product catalysed at a reduced rate $(\mathrm{e}+\mathrm{B})$ or not at all $(\mathrm{A})$ represent what is likely to occur should an enzyme operate out of optimal conditions or become denatured. In the chloroplast, the substrate for the enzyme $\mathrm{RuBisCO}$ is $\mathrm{CO}_{2}$ or $\mathrm{O}_{2}$ combined with $\mathrm{H}_{2} \mathrm{O}$; if $\mathrm{RuBisCO}$ fixes $\mathrm{CO}_{2}$ the product produced is the intermediate photosynthetic product 3-keto-2-carboxyarabinitol 1,5-bisphosphate. If RuBisCO decreased in efficiency or ceased to function there would be dire consequences for photosynthetic health. (Page 124) 


\section{Chapter V - General Discussion}

$>$ Figure 5.1: Key changes to carbon oceanic chemistry as a result of ocean acidification. Using information from the IPCC and assuming scenario IS92a, by $2100 \mathrm{pH}$ is predicted to fall to $7.8-7.6, \mathrm{CO}_{3}{ }^{2-}$ will drop by $50 \%$, there will be significantly increased dissolved $\mathrm{CO}_{2}$, and total DIC will increase. (Page 137) 


\section{LIST OF TABLES}

Table 1.1: Environmental impacts on coral reefs. The table outlines the various environmental impacts known to affect coral reefs. The table lists these impacts in ascending order; from small scale, high frequency, and short term impacts to those impacts which are large scale, low frequency and longer term. (Page 22) 


\section{Chapter I}

\section{INTRODUCTION}

\section{I.I Symbiosis: a definition}

In the late nineteenth century, de Bary coined the term symbiosis and defined it as the living together of two dissimilar organisms, regardless of the nature of their interactions. This broad definition of 'living together' can be broken down further and used to construct a continuum of potential fitness outcomes to the partners in the symbiosis. This symbiotic continuum can be thought of as a progression from a mutualistic symbiosis, where the fitness of both members is positively affected, to a parasitic symbiosis, where the fitness of one partner is positively affected at the expense of the other. Theoretically, at the midpoint between these two extremes, is commensalism, where one partner benefits while there is no benefit or cost for the other partner. A symbiosis can be defined as either endosymbiotic or ectosymbiotic, the former referring to a smaller organism (the 'symbiont') living within a larger organism (the 'host'), and the latter referring to a symbiont living on the host. Finally, if the symbiotic relationship is vital for the survivorship of one or both of the partners, then it is considered as obligate; otherwise it is facultative. 


\section{I.2 Algal-invertebrate symbiosis}

Phototrophic symbioses are abundant in the marine environment, with numerous taxa of marine invertebrates forming endosymbiotic relationships with photosynthetic prokaryotes and eukaryotes. For example, many diatoms, dinoflagellates, sponges, cnidarians (including corals), ascidians and echiuroid worms may contain prokaryotic cyanobacterial symbionts (Usher et al. 2007). Symbiotic photosynthetic eukaryotes include a variety of unicellular microalgae, including chlorophytes, rhodophytes, prasinophytes, diatoms or dinoflagellates. Unicellular chlorophytes are found in a variety of invertebrates including cnidarians, molluscs, sponges, protozoans and foraminiferans, single-celled rhodophytes are found exclusively in foraminiferans, and symbiotic prasinophytes are known from flatworms, radiolarians and dinoflagellates (Trench 1993). Diatoms commonly form symbioses with foraminiferans (Lee et al. 1982) as well as larger dinoflagellates such as Dinothrix paradoxa, Gymnodinium quadrilobatum and Peridinium quinquecorne (Inagaki et al. 2000; Horiguchi and Takano 2006); such dinoflagellate-diatom symbioses are thought to provide some insight into chloroplast evolution, given that extant photosynthetic algae are thought to have originated from the engulfment of a photosynthetic alga by a larger and colourless protist (Chesnick et al. 1996). Some flatworms and sponges also harbour symbiotic diatoms, with sponge-diatom symbioses being especially common in Antarctic waters (Bavestrello et al. 2000). A small number of invertebrate species also form symbioses with macroalgal seaweeds, for example, the sponge Haliclona cymiformis envelopes the rhodophyte Ceratodictyon spongiosum and is never found outside of this symbiosis (Davy et al. 2002). 
Unquestionably the most well known and ecologically important phototrophic symbionts are, however, the dinoflagellates. These symbiotic dinoflagellates are commonly known as zooxanthellae and largely belong to the genus Symbiodinium, though other symbiotic genera include Amphidinium, Scripsiella, Gloeodinium, Pyrocystis and Prorocentrum (Trench 1993). Zooxanthellae form mutualistic symbioses with an array of marine invertebrate taxa, including the scleractinian (= hard) corals (fig 1.1A and C), soft corals, sea anemones (fig 1.1B), jellyfish, molluscs (e.g. giant clams, nudibranchs) (fig 1.1D), sponges, protists (e.g. foraminiferans) and turbellarian flatworms. The dinoflagellates may reach densities of several million or more per $\mathrm{cm}^{2}$ of host tissue in these organisms (LaJeunesse 2002).

The highest diversity and abundance of invertebrates that contain symbiotic dinoflagellates are found in tropical marine ecosystems, and especially on coral reefs (LaJeunesse 2002). Indeed, reef-building ( = hermatypic) scleractinian corals all contain zooxanthellae of the genus Symbiodinium, where this association of primary producer and heterotrophic consumer enables polytrophy and the tight recycling of nutrients in nutrient-poor waters (Hoegh-Guldberg 1999; see section 1.4); it also accelerates the rate of coral skeletogenesis.

Coral reefs calcify at $2-6 \mathrm{~kg} \mathrm{CaCO}_{3} \mathrm{~m}^{-2} \mathrm{yr}^{-1}$ over an area of approximately $284,300 \mathrm{~km}^{2}$ (Allemand et al. 2004). This makes coral reefs the most extensive bioconstruction on the planet (Allemand et al. 2004). This structure resists hydrodynamic stress (Schuhmacher and Zibrowius 1985) and so helps to protect shorelines from erosion, which is crucial for shoreline stability, especially of small island nations but also of larger countries (HoeghGuldberg 1999; Allemand et al. 2004; Cornish and DiDonato 2004). This in turn protects 

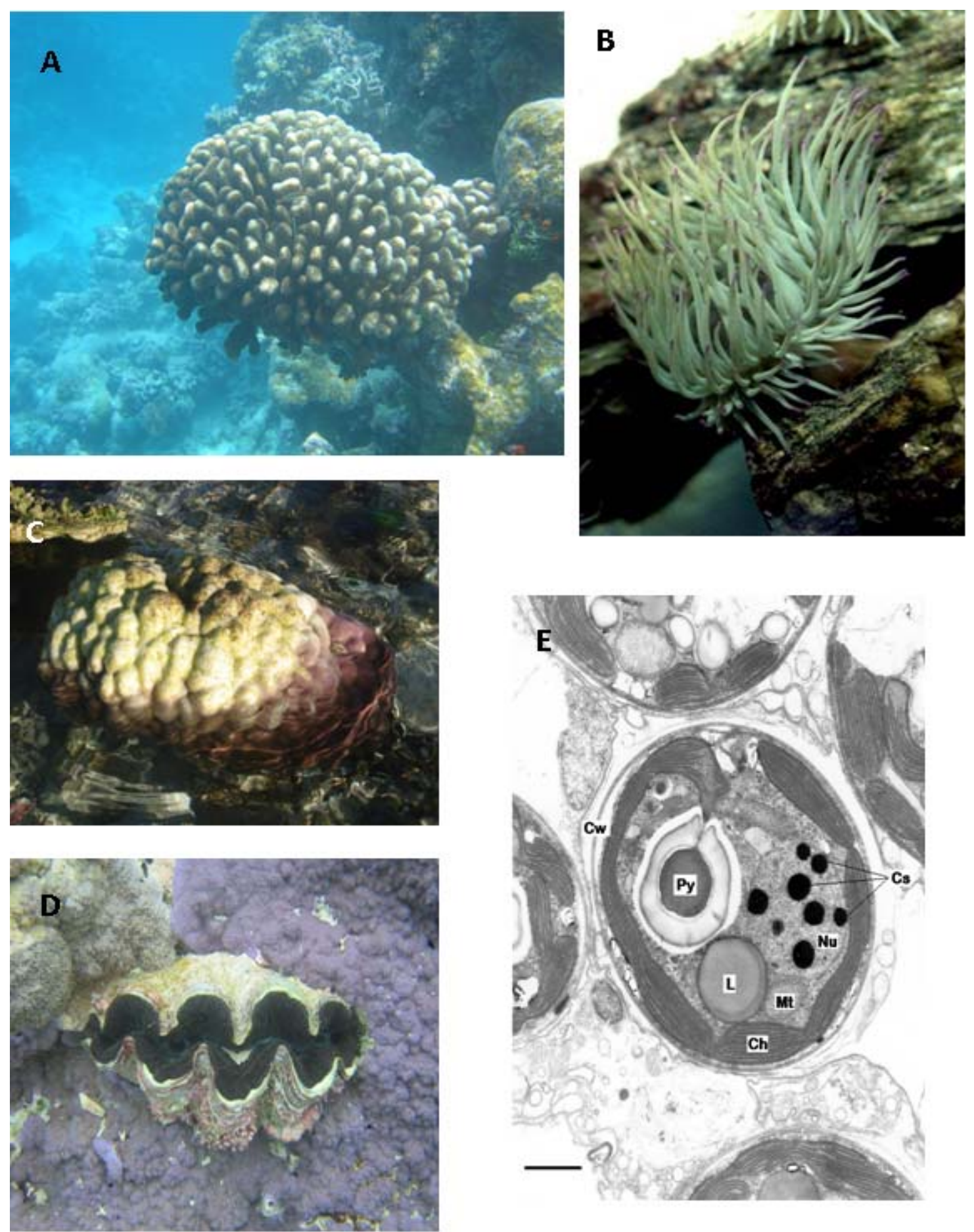

Figure 1.1: A) A scleractinian coral, Pocillopora sp., in the Central Pacific (photo: S. Davy). B) A temperate symbiotic sea anemone, Anemonia viridis, from northern Europe (photo: S. Davy). C) A bleached coral, Porites sp., on the reef flat at Heron Island, Great Barrier Reef (photo: S. Davy). D) A giant clam, Tridacna gigas, in the Central Pacific (photo: S. Davy) E) TEM showing Symbiodinium sp. in the tissues of the sea anemone Aiptasia pallida (photo: K. Lee and G. Muller-Parker), scale bar $=2 \mu \mathrm{m}, \mathrm{Ch}=$ chloroplast, $\mathrm{Nu}=$ nucleus, $\mathrm{Cs}=$ chromosomes, $\mathrm{Py}=$ pyrenoid, $\mathrm{L}=$ lipid, $\mathrm{Cw}=$ cellulose based cell wall, and $\mathrm{Mt}=$ mitochondrion. 
other coastal ecosystems such as mangroves and seagrass beds (Hoegh-Guldberg 1999). The growth of coral reefs in otherwise nutrient-poor regions also creates biodiversity hotspots, supporting much more life than would otherwise be supported in their absence and much more life than in most other ecosystems on the planet (Sebens 1994; HoeghGuldberg 1999; Allemand et al. 2004). In the open sea surrounding coral reefs, productivity can be as little as $0.01 \mathrm{~g} \mathrm{C} \mathrm{m}^{-2} \mathrm{day}^{-1}$, while productivity within the reef can be thousands of times higher (algal turfs: $280 \mathrm{~g} \mathrm{C} \mathrm{m}^{-2}$ day $^{-1}$; corals: $40 \mathrm{~g} \mathrm{C} \mathrm{m}^{-2}$ day $^{-1}$; benthic microalgae: $363 \mathrm{~g} \mathrm{C} \mathrm{m}^{-2}$ day $^{-1}$ (Hoegh-Guldberg 1999)). This high productivity, combined with the complex reef architecture afforded by coral skeletogenesis, supports about 9 million species worldwide (Knowlton 2001a). Indeed, corals alone support a third of all known species of fish (Allemand et al. 2004) and hundreds of thousands of other taxa (Hoegh-Guldberg 1999). This rich biodiversity and high biomass are of immense socio-economic value, with approximately $15 \%$ of the world's population living within $100 \mathrm{~km}$ of a coral reef (Pomerance 1999; Hoegh-Guldberg 1999). In particular, coral reefs support industries associated with tourism, fishing and other marine harvests, building materials, and pharmaceutical production (Carte 1996; Hoegh-Guldberg 1999; Allemand et al. 2004). In the case of fisheries alone, coral reefs yield at least 6 million metric tonnes of fish catches world-wide and provide employment for millions of fishers (Roberts et al. 1998; Hoegh-Guldberg 1999). None of this would exist without the symbiosis between corals and their dinoflagellate symbionts.

Many soft corals (the Octocorallia) on reefs also contain zooxanthellae. After the scleractinian corals, soft corals are the second-most abundant macroinvertebrates on many Indo-Pacific and Caribbean coral reefs. Soft corals lack the ability to produce calcium carbonate structures so they are neither reef-building nor able to lay platforms for 
future coral (van Alstyne et al. 1992). Nevertheless, they are abundant on many reefs, ranging from $50 \%$ to $95 \%$ cover (van Oppen et al. 2005), provide habitat for other organisms, and are important for the health and ecological balance of a coral reef (Cornish and DiDonato 2004). As in the scleractinian corals, the symbiosis between soft corals and zooxanthellae plays an important role in promoting this ecological significance.

The other conspicuous reef invertebrates to commonly form a symbiosis with zooxanthellae are the giant clams (Blidberg et al. 2000) and sea anemones (Scott and Harrison 2007), though these taxa are less crucial to the structure and biodiversity of reefs than are the hard and soft corals. A small number of sponge species, which are very important for the consolidation of reefs, also form symbioses with zooxanthellae (Garson et al. 1998). Symbiotic sea anemones perhaps become more significant at higher latitudes, where they may be locally abundant and contribute markedly to community productivity in intertidal and shallow sub-tidal locations (Fitt et al. 1982; Davy et al. 1997; Davy and Turner 2003; Rodriguez-Lanetty et al. 2003). For instance the North American sea anemone Anthopleura elegantissima is a locally dominant member of intertidal communities of the Pacific Northwest; this anemone contains not only zooxanthellae but also unicellular chlorophytes (zoochlorellae) that contribute to its ecological success (Muller-Parker et al. 2007). 


\section{I.3 The nature of anthozoan-dinoflagellate symbioses}

Anthozoans are diploblastic animals with two tissue layers, the ectodermis which faces the ambient seawater, and the endodermis which faces the gastrovascular cavity or coelenteron (Fig 1.2) (Furla et al. 2005). The zooxanthellae are, for the most part, located in the endodermal cells of the host, where a perisymbiont membrane of animal origin forms a vacuolar compartment isolating the dinoflagellate from the animal cytoplasm

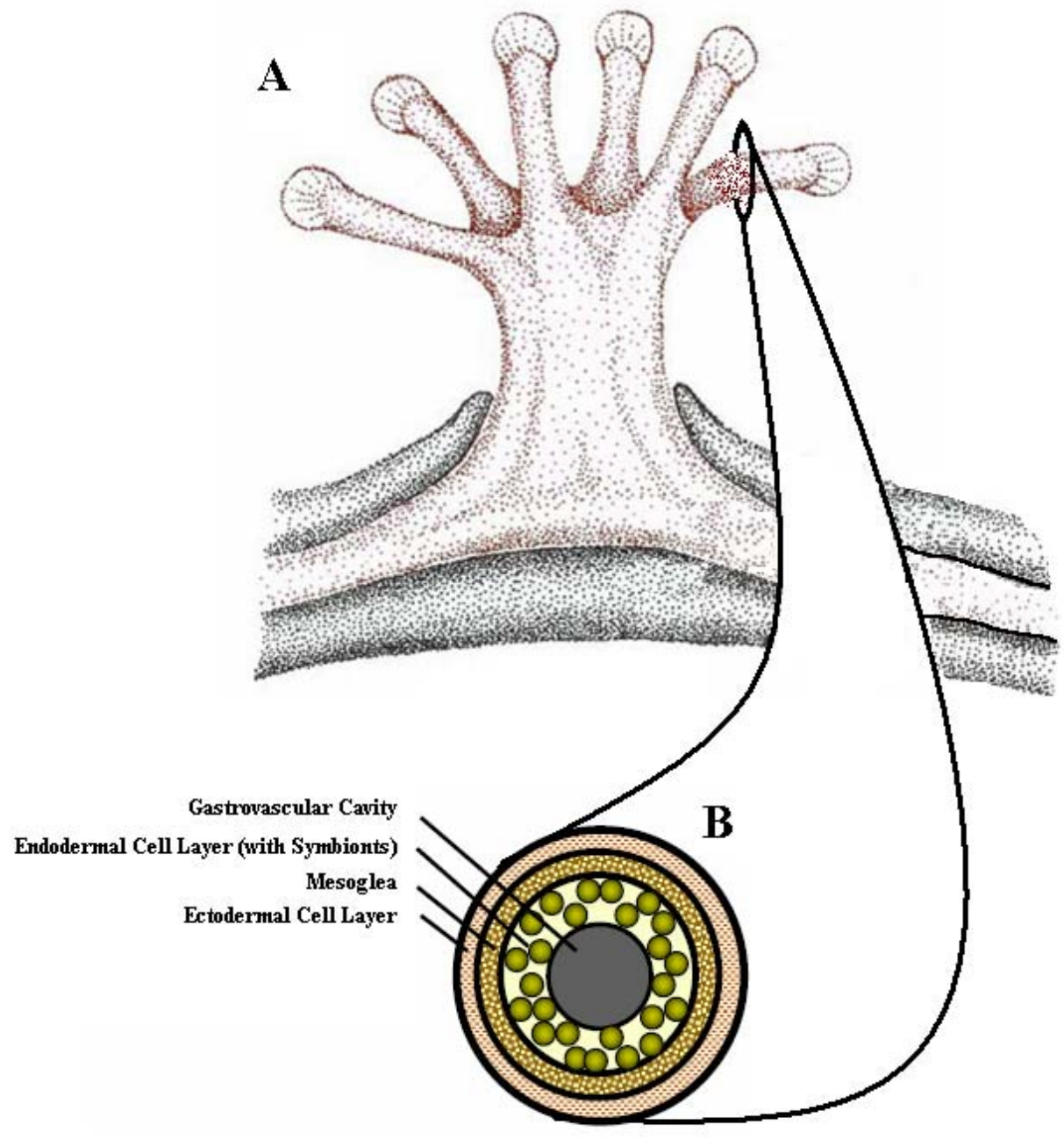

Figure 1.2: A) A typical anthozoan polyp illustrating extended tentacles; B) a cross section of a polyp tentacle illustrating the various cellular layers and the location of the dinoflagellate symbionts.

Source: Adapted from Hauck (2007) 
(Fig 1.2) (Furla et al. 2005). This compartment also contains multiple layers of additional membranes (most likely of algal origin) that surround the 'pellicle' or cell wall of the dinoflagellate, and together this entire compartment and all of its inclusions (including the symbiont itself) comprise what is termed the 'symbiosome' (Wakefield and Kempf 2001)

Zooxanthellae are acquired via the parent colony (vertical transmission) or via the environment (horizontal transmission) (Marlow and Martindale 2007; Gomez-Cabrera et al. 2008). In the former case, the zooxanthellae are acquired during embryogenesis by maternal inheritance, while in the latter case the zooxanthellae must be phagocytosed by the gastrodermal cells, while the host anthozoan is either in its planktonic planula stage or soon after it has settled (Marlow and Martindale 2007). The mechanisms that enable the host anthozoan to recognise the zooxanthellae as friend rather than foe are not well understood, but likely include the recognition of specific glycoprotein patterns on the surface of the dinoflagellate cell and the subsequent down-regulation of the host's immune system (Weis et al. 2008).

The morphology of the zooxanthellae is quite similar across all species or types within the genus Symbiodinium (phylum Dinophyta, order Gymnodiniales) (Blank 1987). They are typically $5-10 \mu \mathrm{m}$ in diameter and are encompassed by a cellulose-based cell wall (fig 1.1E) (Black 1987; Reimer et al. 2007) and when inside the host they take the coccoid form (spherical) and lack flagella (Fig. 1.3B) (Blank 1987). Internally, zooxanthellae possess a dominant nucleus containing permanently-condensed chromosomes, and a peripheral chloroplast(s) which displays a stalked pyrenoid, a structure containing the $\mathrm{CO}_{2}$-fixing enzyme ribulose-1,5-bisphosphate carboxylase (fig 1.1E) (RuBisCO; Leggat 
et al.1999). To aid in photosynthesis, zooxanthellae contain chlorophylls $a$ and $c$ in combination with accessory pigments such as peridinin and diadinoxanthin (Gantt 1996). While most zooxanthellar cells stay in the their coccoid form while within their host cells,

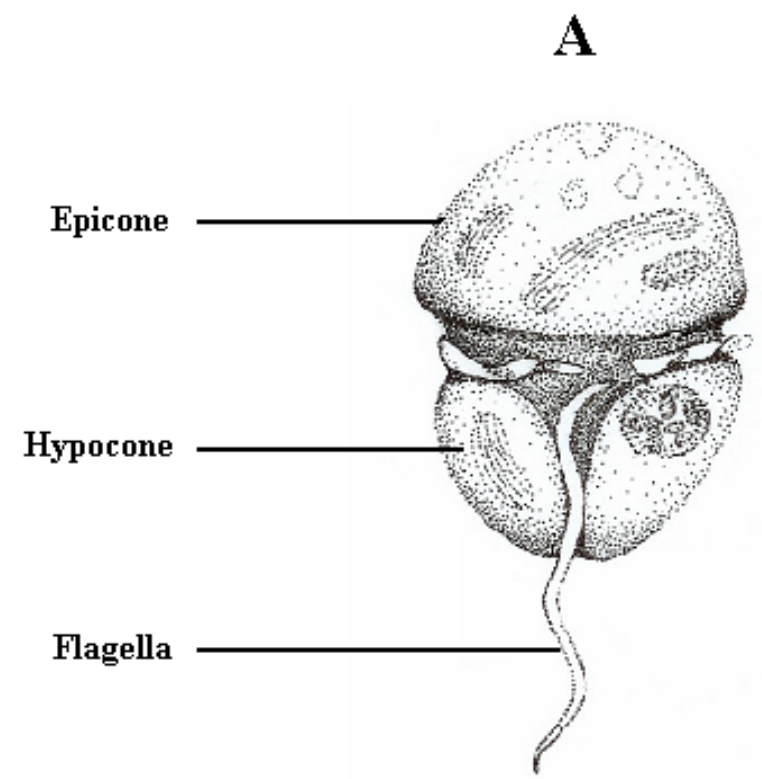

B

Figure 1.3: A) Dinomastigote zooxanthella with anterior epicone, posterior hypocone, and two flagella (only transverse flagellum labelled). B) Coccoid zooxanthella.

Source: Adapted from Hauck (2007)

when outside the animal host they develop two flagella and all the structural elements of free-living dinoflagellates, including the epicone and hypocone - this is known as the dinomastigote stage (Fig. 1.3A) (Titlyanov and Titlyanova 2002). It is well documented that zooxanthellae exhibit asexual reproduction through mitosis (Goh and Chou 1990; Strychar et al. 2004; Porto et al. 2008), though there is little evidence for sexual recombination. However recent evidence indicating high allelic diversity does suggest sexual reproduction (Porto et al. 2008). 
Advances in genetic sequencing have enabled a deeper, more accurate, interpretation of zooxanthellar diversity. Originally all zooxanthellae were classified as one species, Symbiodinium microadriaticum (Coffroth and Santos 2005). However, molecular methods based on small and large ribosomal subunits (SSUrDNA and LSUrDNA) and, more recently, the internal transcribed spacer (ITS) region have led to a proliferation in the number of described members of the genus Symbiodinium (LaJeunesse 2002). Indeed, it is now known that there are at least eight clades of Symbiodinium ranging from Clade A through Clade H (LaJeunesse 2002; Coffroth and Santos 2005; Gomez-Cabrera et al. 2008), of which clades A, B, C, D and F only occur in symbiosis with corals (GomezCabrera et al. 2008). Moreover, there are numerous (100+) sub-clades within these clades; these sub-clades are often referred to as 'types' (Fig. 1.4) (Coffroth and Santos 2005).

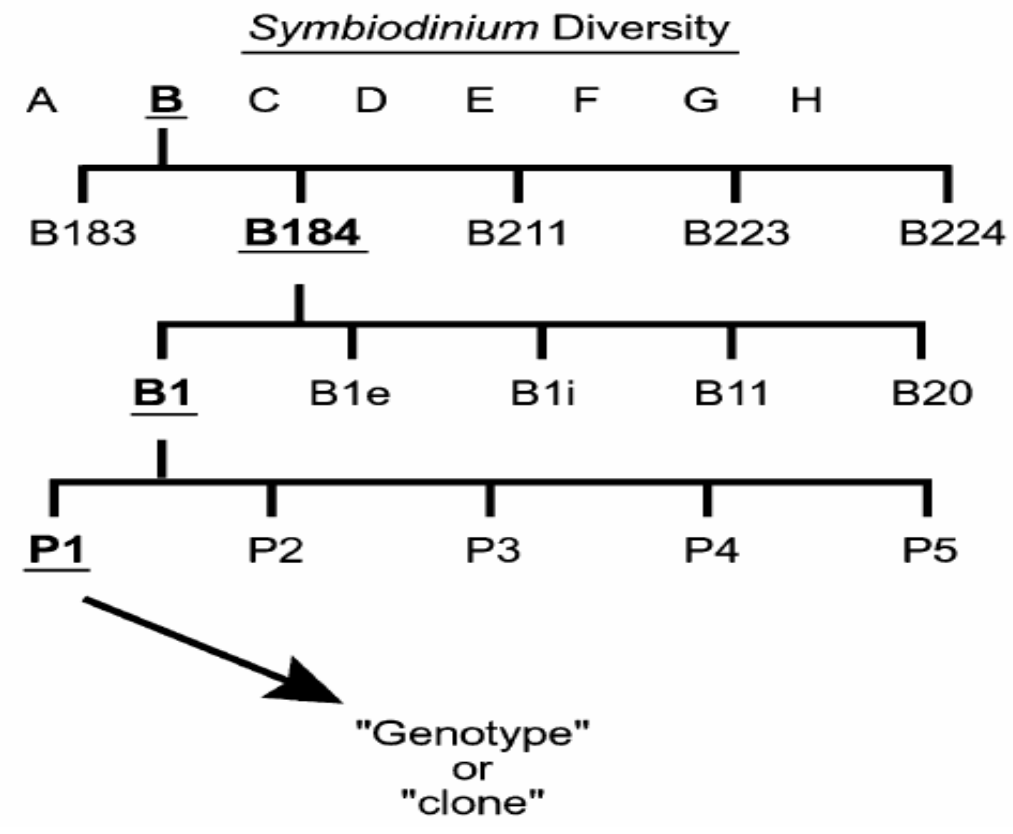

Figure 1.4: Symbiodinium diversity. Schematic illustrating the multiple layers and complexity within the genus Symbiodinium. Each of the 8 clades $(\mathrm{A}-\mathrm{H})$ are defined by sequencing conserved genes, however, due to adaptive radiation each of the clades have converged to a point where clade-specific traits are few. The within-clade diversity is resolved by utilising more genetically variable molecules, which allows resolution of types within a clade, as the figure illustrates for Clade B.

Source: from Coffroth and Santos (2005) 
The various types of Symbiodinium show various levels of specificity for their host corals (Baker 2003): certain Symbiodinium types are noted as 'specialists' (found in a single taxon of coral) while others are known as 'generalists' (found in a large number of coral taxa). For example, LaJeunesse et al. (2003) found that on the Great Barrier Reef, Symbiodinium type C8a occurs only in the coral Stylophora pistillata, while types C1, C3 and $\mathrm{C} 21$ were found in a range of different coral species. Corals themselves can also be considered as 'specialists' or 'generalists', whereby some coral species are able to harbour numerous types of Symbiodinium (often simultaneously), and others may only form symbioses with a single type or a sub-set of closely related types (LaJeunesse 2002; Baker 2003).

The environmental regime of a given location has considerable influence on the types of Symbiodinium found there and their abundance. This stems from the physiological suitability of the Symbiodinium type to its environment. For instance, various types belonging to Clade $\mathrm{C}$ tend to be more prevalent in more stable conditions, while those types belonging to Clade B become more abundant in harsher, colder conditions. Indeed, Clade C dominates Pacific reefs and Clade B is more common on Caribbean reefs, possibly because it was favoured over Clade $\mathrm{C}$ by the relatively tough conditions experienced in the Caribbean during the Pliocene-Pleistocene transition (Baker 2003; LaJeunesse et al. 2003). Likewise, the widespread Indo-Pacific coral Plesiastrea versipora performs a latitudinal shift from Clade $\mathrm{C}$ to Clade $\mathrm{B}$ as one moves south from the tropical waters of the Great Barrier Reef to the temperate, more variable waters of southern Australia (Rodriguez-Lanetty et al. 2001). Moreover, some zooxanthellae are more suited to high-temperature/high-turbidity environments, allowing them to persist in stressful locations such as the Persian Gulf where seawater temperatures regularly exceed 
$33{ }^{\circ} \mathrm{C}$ (Baker et al. 2004); such zooxanthellae mostly belong to Clade D (Fabricius et al. 2004; Berkelmans and Van Oppen 2006).

Physiological diversity also explains within-site distributions of different Symbiodinium types, with Rowan and Knowlton (1995) discovering that the composition and relative abundance of Clades A, B and C in the Caribbean corals Montastraea annularis and $M$. faveolata changes with depth (i.e. light regime); in particular, Clade $\mathrm{C}$ became more abundant relative to the other clades as depth increases.

\section{I.4 Photosynthesis and nutritional interactions in anthozoan-dinoflagellate symbioses}

\section{I.4.I Photosynthesis}

The principal method by which zooxanthellae photosynthesise has been a contentious issue, with earlier works advocating that the presence of phosphoenol-pyruvate carboxylase and malate dehydrogenase activity was indicative of the $\mathrm{C}_{4}$ pathway (Bil et al. 1992). More recently, however, conclusive evidence for the presence of a form II RuBisCO, amongst other biochemical evidence, has led to a consensus that the primary pathway for $\mathrm{CO}_{2}$ fixation in zooxanthellae is the $\mathrm{C}_{3}$ Calvin-Benson Cycle (Bil et al. 1992; Streamer et al. 1993; Leggat et al. 1999). In $C_{3}$ photosynthesis, there are two main stages that are worth briefly expanding upon. Firstly there are the light-dependent reactions that occur in photosystems II and I, and secondly there are the light-independent reactions of the Calvin-Benson cycle. Photosystem II absorbs reddish light around $680 \mathrm{~nm}$ and photosystem I absorbs red light at around $700 \mathrm{~nm}$; a photon arriving at the respective 
wavelength at either photosystem II or I is captured by antenna pigments and transferred to the reaction centre where it raises the energy of an electron. At photosystem II, electrons excited by photons at the $680 \mathrm{~nm}$ wavelength are accepted by the primary electron acceptor plastoquinone; plastoquinone transfers the excited electron to the $\mathrm{b}_{6}-\mathrm{f}$ complex which creates a positive $\mathrm{H}^{+}$gradient within the thylakoid by the pumping $\mathrm{H}^{+}$ from the stroma. As the thylakoid membrane is impermeable to $\mathrm{H}^{+}$protons, the $\mathrm{H}^{+}$ protons must pass through the channels provided by ATP synthase, and as the protons pass through ATP synthase, ADP is phosphorylated to make ATP - a process known as photophosphorylation. In non-cyclic electron flow, photosystem II must replace the deficit in electrons created by this process; electrons are replaced by the splitting of $\mathrm{H}_{2} \mathrm{O}$, a process that releases $\mathrm{O}_{2}$. At photosystem $\mathrm{I}$, electrons excited by photons at the $700 \mathrm{~nm}$ wavelength are accepted by the primary electron acceptor ferredoxin; ferredoxin transfers excited electrons to NADP reductase, NADP reductase creates NADPH by transferring protons to an NADP acceptor. As with photosystem II, photosystem I must also replace electrons lost in this process. Photosystem I differs from photosystem II in that is does not split water to liberate electrons, but rather replaces lost electrons with the spent electrons from the $b_{6}-f$ complex from photosystem II. Photophosphorylation is required to create the necessary energy to drive the light-independent reactions. Using RuBisCO, the light independent-reactions fix $\mathrm{CO}_{2}$ and utilise 18 ATP and 12 NADPH molecules, created by the light-dependent reactions and mitochondrion respiration, in the synthesis of photosynthate.

At low light levels photosynthesis increases linearly with increased light before steadily reaching a plateau (i.e. photosynthetic saturation) and eventually tapering (Long et al. 1994; Beer et al. 1998). For marine organisms photosynthetic saturation can vary, but for 
coral it typically occurs at an irradiance of approximately $200-300 \mu \mathrm{mol}$ photons $\mathrm{m}^{-2} \mathrm{~s}^{-1}$ (S. K. Davy, VUW, personal communication); $200-300 \mu \mathrm{mol}$ photons $\mathrm{m}^{-2} \mathrm{~s}^{-1}$ can be considered a low irradiance in comparison to the surface irradiance of $>2000 \mu \mathrm{mol}$ photons $\mathrm{m}^{-2} \mathrm{~s}^{-1}$ experienced on a clear day in equatorial regions (Muller-Parker and Davy 2001). At any given moment the irradiance is at its highest levels at the surface of the water and decreases exponentially with depth, meaning that photosynthetic organisms that span different depths must contend with varying light levels (Titlyanov et al. 2001; Anthony and Hoegh-Guldberg 2003). To counter the low light levels experienced at greater depths, corals for example can employ a number of methods to optimise the use of light. The principal tool that zooxanthellae are known to use is photoacclimation, where, in response to reduced light, the zooxanthella may increase the size of the photosynthetic units (PSUs) and in doing so increase the amount of chlorophyll $a$ per zooxanthella (Falkowski and La Roche 1991; Titlyanov et al. 2001; Anthony and HoeghGuldberg 2003; Suggett et al. 2007).

While under reduced irradiances, the increased PSU size enables greater light harvesting efficiency; under high irradiances, the PSUs are smaller and less efficient, but more numerous, meaning that the maximum rate of carbon fixation is greater (Falkowski and La Roche 1991; Titlyanov et al. 2001; Major and Dunton 2002; Suggett et al. 2007). The increased chlorophyll content, as a result of the photoacclimatory response, is thought to explain why shade-adapted corals are visibly darker than light-adapted corals. For instance, Falkowski and Dubinsky (1981) noted that shade- and light-adapted colonies of S. pistillata contained similar densities of zooxanthellae, but visibly darker shade-adapted colonies contained $>7$ times more chlorophyll $a$ per unit biomass than the more pale light-adapted colonies; these findings were later corroborated by Stambler and Dubinsky 
(2005). Increasing the size of the PSU is the practical evolutionary response to overcoming low light levels, as increasing the chlorophyll concentration in the coral's tissues by increasing the density of zooxanthellae would result in self-shading and little gain in overall light harvested (McCloskey and Muscatine 1984; Fitt and Cook 2001; Stambler and Dubinsky 2005). A further way in which corals have evolved to cope with declining light availability is by forming symbioses with specific zooxanthella types that have adapted to low light levels. As noted earlier in this chapter (section 1.3) Rowan and Knowlton (1995) identified that, out of clades A, B, and C, Clade C becomes more dominant with increasing depth. A less known photoacclimatic adaptation involves the coral positioning fluorescent pigments in a manner that enhances the light available to the zooxanthellae - the pigments do this by scattering light onto the zooxanthellae (Salih et al. 2000; Mazel et al. 2003). However, in high light conditions, alternative fluorescent pigments, that emit light at non-useable wavelengths, are situated above the zooxanthellae so reflecting potentially damaging light (Dodds et al. 1999) away from the zooxanthellae (Salih et al. 2000).

\section{I.4.2 Carbon flux}

In the symbiosis between Anthozoa and their intracellular dinoflagellates, the photosynthate is, in part, used by the zooxanthella to satisfy its own respiratory and growth demands, but by far the majority (up to $95 \%$ or so) is released (translocated) to the host animal (Muscatine et al. 1981; Davies 1984; Davy and Cook 2001a). The photosynthate is a cocktail of glycerol, glucose, amino acids (e.g. alanine), and perhaps lipids (Muscatine et al. 1994; Ishikura et al. 1999; Davy and Cook 2001a). In contrast to when in symbiosis, isolated zooxanthellae release very little $(<5 \%)$ photosynthate to the 
surrounding seawater, leading many physiologists to believe that the host animal 'induces' the release of photosynthate via chemical stimuli known as host release factors (HRFs) (Muscatine 1967; Grant et al. 1998; Davy and Cook 2001a). The organic carbon translocated to the host is then used to support its respiration, growth and reproduction, or is released to the seawater as dissolved organic matter (DOM) or mucus (Crossland et al. 1980; Muscatine et al. 1984; Stimson 1987; Palardy et al. 2006). This autotrophic carbon source can meet more than all of the host's metabolic carbon needs, at least under well-lit conditions such as those in shallow coral reef waters (Davies 1991). For this reason, this nutritional interaction is one of the key reasons for the success of corals and other symbiotic invertebrates in the nutrient- and hence food-poor waters of the tropics.

\section{I.4.3 Nitrogen and phosphorus fluxes}

For symbiotic anthozoans to make full use of their zooxanthellar photosynthate, which is nutrient-poor, they must obtain key nutrients from the surrounding seawater, such as nitrogen and phosphorus (Burris 1984). Nitrogen is essential in the formation of amino acids, which in turn are essential for the synthesis of proteins. Hence, acquisition of exogenous nutrients is essential for physiological function, growth and reproduction. Anthozoans can acquire nitrogen from the water as: 1) dissolved nitrogen, either in organic form as amino acids or inorganic form as ammonium $\left(\mathrm{NH}_{4}{ }^{+}\right)$, nitrate $\left(\mathrm{NO}_{3}{ }^{-}\right)$and perhaps nitrite $\left(\mathrm{NO}_{2}^{-}\right)$; or 2) particulate nitrogen, for example in the form of sediment or by heterotrophic feeding on zooplankton (Meyer et al. 1983). As seawater in the tropics is typically nitrogen limited (Meyer et al. 1983), zooxanthellae play a pivotal role in the acquisition, conservation and recycling of this essential nutrient. Firstly, there is strong evidence to suggest that inorganic nitrogen, primarily as $\mathrm{NH}_{4}{ }^{+}$, can only be acquired and 
retained in the presence of zooxanthellae and light, largely because the synthesis of amino acids requires an organic carbon skeleton as an acceptor for $\mathrm{NH}_{4}^{+}$(Muscatine and D'Elia 1978). Secondly, the translocation of photosynthetic carbon provides a freely available respiratory substrate for the host that is utilised in favour of more 'precious' amino acids, so conserving nitrogen (Wang and Douglas 1998). Finally, the zooxanthellae assimilate excretory $\mathrm{NH}_{4}{ }^{+}$from the host (the product of cellular catabolism) and convert it to amino acids. These amino acids are then either used by the zooxanthellae (e.g. for growth) or are translocated back to the host anthozoan where they are eventually catabolised once again to $\mathrm{NH}_{4}{ }^{+}$(Rees 1986; Rees \& Ellard 1989; Wang and Douglas 1998; Lipschultz and Cook 2002). This serves to recycle the nitrogen between the host and zooxanthellae, so preventing its loss to the surrounding seawater.

Phosphorus fluxes in anthozoan-dinoflagellate symbioses are poorly understood when compared to nitrogen fluxes. However, it is known that uptake is once again light-driven (D'Elia 1977). The role of the zooxanthellae in phosphorus acquisition was further supported by Dean and O'Brien (1981), who found that zooxanthellae cultured in isolation were able to assimilate phosphorus from the ambient medium.

\section{I.5 Photosynthesis and calcification}

The coral skeleton is made of two primary components, 1) the organic matrix and 2) calcium carbonate (aragonite) crystals. The organic matrix is a composite of proteins, glycoproteins, mucopolysaccharides and calcium-binding phospholipids (Goreau 1959; Constantz and Weiner 1988; Allemand et al. 1998; Muscatine et al. 2005). The organic matrix is synthesised by the calicoblastic epithelium at which point it is secreted into the 
underlying sub-epithelial space; the matrix then facilitates $\mathrm{CaCO}_{3}$ nucleation and provides a framework for the aragonite crystals (Muscatine et al. 2005). While a heterotrophic food supply provides much of the nutrients needed for the formation of the organic matrix, including being the primary source for nitrogenous components, (Allemand et al. 1998; Houlbreque et al. 2004), zooxanthellae also contribute to the synthesis of the organic matrix through the provision of organic carbon (Muscatine and Cernichiari 1969; Pearse 1971; Pearse and Muscatine 1971). Unlike the contribution that zooxanthellae make to the synthesis of the organic matrix, the role that the zooxanthellae play in $\mathrm{CaCO}_{3}$ deposition (i.e. calcification) is poorly understood and furthermore a topic that is keenly debated. There is, however, some strong circumstantial evidence which suggests that zooxanthellae do play a key role in calcification: 1) In $>90 \%$ of cases $\mathrm{CaCO}_{3}$ secretion is much faster in symbiotic corals than in non-symbiotic corals (Gattuso et al. 1999); and 2) symbiotic corals secrete $\mathrm{CaCO}_{3}$ at a higher rate in the light as opposed to in the dark (Gattuso et al. 1999). To illustrate these points, Gattuso et al. (1999) provided radioactive calcium $\left({ }^{45} \mathrm{Ca}\right)$ to the coral Manicina areolata and found that the incorporation of ${ }^{45} \mathrm{Ca}$ was approximately 6 times faster in the light than in the dark, and 16 times faster in the light when zooxanthellae were present than when they were absent. Furla et al. (2000) also found the incorporation of ${ }^{45} \mathrm{Ca}$ to be 4 times greater in the light as in the dark in the coral S. pistillata.

There is a clear link, albeit circumstantial, between photosynthesis and calcification. What is not so clear, however, is the precise mechanism by which these two biological processes interact. In the middle of the twentieth century, Goreau (1959) proposed the 'light-enhanced calcification' hypothesis, where photosynthesis removes $\mathrm{CO}_{2}$, so reducing the partial pressure of $\mathrm{CO}_{2}$ within the coral's tissues, and causing an equilibrium 
shift in favour of $\mathrm{CaCO}_{3}$ secretion. Smith and Douglas (1987) highlighted a major flaw in this theory however: coral calcification occurs at the fastest rate as the tips of the coral branches where the zooxanthellae are considered to be the least dense. More recent research, such as McConnaughey (1991), McConnaughey and Whelan (1997), and Cohen and McConnaughey (2003), has led to the prominence of the 'trans-calcification' hypothesis, where $\mathrm{Ca}^{2+}$-ATPase delivers $\mathrm{Ca}^{2+}$ to the calcification site and carries $\mathrm{H}^{+}$ released during $\mathrm{CaCO}_{3}$ precipitation to the coelenteron, where $2 \mathrm{x} \mathrm{H}^{+}$protons reduce $2 \mathrm{x}$ $\mathrm{HCO}_{3}{ }^{-}$and hence generate $\mathrm{CO}_{2}$ (fig 1.5, equation 2). During calcification, it is this step that researchers believe, through increased $\mathrm{CO}_{2}$ availability, can enhance photosynthesis. This could explain why calcification increases during daylight hours, if the coral has

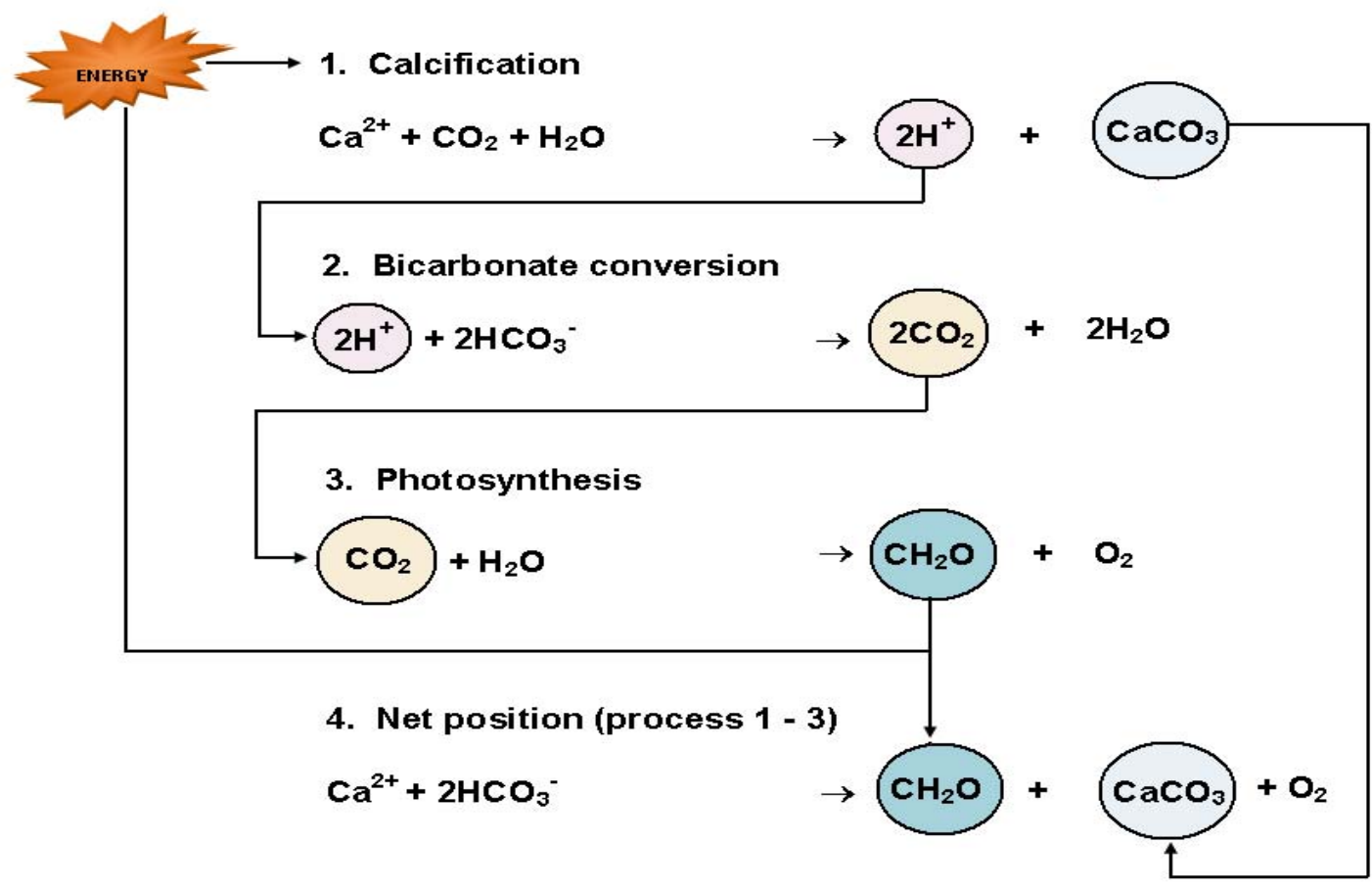

Figure 1.5: The chemistry underpinning calcification (equation 1), bicarbonate conversion (equation 2), and photosynthesis (equation 3). Calcification, via bicarbonate conversion, provides carbon for photosynthesis. Using this source of carbon (and that from other sources), and during light hours, photosynthesis is able to provide energy which enhances calcification. Often equations 1-3 occur simultaneously, and this can result in net calcium carbonate accretion and energy to the coral (equation 4).

Source: Adapted from Gattuso et al. (1999). 
adapted to increase its $\mathrm{CaCO}_{3}$ deposition rate (thus increasing $\mathrm{CO}_{2}$ availability) at times when the zooxanthellae most need this carbon source i.e. for photosynthesis. As with 'light-enhanced' calcification, the 'trans-calcification' hypothesis has its doubters. For instance, Gattuso et al. (2000) inhibited calcification in the coral S. pistillata, to test whether or not photosynthesis is impacted as predicted by trans-calcification, yet they found no effect. It may well be a collection of mechanisms, some of which are not mentioned, which together explain how zooxanthellae help to increase the rates of $\mathrm{CaCO}_{3}$ deposition.

\section{I.6 Environmental threats to anthozoan-dinoflagellate symbioses}

Marine systems, including coral reefs, can be affected by both localised and global impacts. Some local impacts, which affect an area, large or small, in the vicinity of the source of the impact, have been impacting upon coral reef ecosystems for as long as those ecosystems have existed (Nystrom et al. 2000). These impacts have naturally ranged from frequent but minor pulses, such as grazing and predation, to larger more infrequent events, like overwhelming predator populations and hurricanes (Nystrom et al. 2000), and are part of a natural disturbance regime that allows for new evolutionary opportunities and renewal of reef ecosystems (Nystrom et al. 2000). However, anthropogenic stresses are now exacerbating these local impacts, with often drastic consequences. For example, the proliferation and intensity of the outbreaks of coral predators, such as the crown-of-thorns starfish (Acanthaster planci) or the predatory sea urchin (Echinometra mathaei) has been linked to human-induced algal growth resulting from nutrient run-off from agricultural land, and eutrophication (McClanahan and Mutere 
1994; Bell and Elmetri 1995; Nystrom et al. 2000; Knowlton 2001a). Nutrient run-off and sedimentation can reduce light penetration in the water column, decreasing photosynthetic rates and indirectly reducing energy production. The problem is further compounded given that additional energy is required to remove the sediment from the surface of the coral (Rogers 1990; Riegl and Brancha 1995; Nystrom et al. 2000). The fishing and tourism industries also have significant local impacts. For instance, cyanide fishing for the aquarium trade is associated with localised bleaching (i.e. loss of photosynthetic pigments or zooxanthellae) in corals, especially in Southeast Asia (HoeghGuldberg 1999; Jones and Hoegh-Guldberg 1999; Mous et al. 2000), overfishing leads to excessive removal of grazers and hence algal overgrowth of corals (Tanner 1995; Lirman 2001), and the development of hotel resorts in and around coral reef locations has enormous potential for reduction in reef health and cover (Hawkins and Roberts 1994).

While localised environmental impacts can have severe consequences for reasonably large areas of reef habitat, it is perhaps the global impacts which ultimately pose the most complete and irreversible threat (see table 1.1 for comparison of local/global impacts). These impacts, such as sea level rise, increased seawater temperature and ocean acidification, which all result from climate change and/or the associated emissions of $\mathrm{CO}_{2}$, could alter reef ecosystems beyond current recognition (Hoegh-Guldberg 1999; Walther et al. 2002; Hoegh-Guldberg et al. 2007). $\mathrm{CO}_{2}$ acts like an insulator heating the planet by trapping the Sun's energy. This is an entirely natural process, but with excessive amounts of $\mathrm{CO}_{2}$ being released by human activity, the planet is now heating up far quicker, and with more intensity, than has been seen in the last 10,000 years, or possibly longer (Petit et al. 1999; Epstein 2001). 
Table 1.1: Environmental impacts on coral reefs. The table outlines the various environmental impacts known to affect coral reefs. The table lists these impacts in ascending order, from small scale, high frequency, and short term impacts to those impacts which are large scale, low frequency and longer term.

Source: adapted from Nystrom et al. (2000)

\begin{tabular}{|c|c|c|c|}
\hline Environmental impacts & Spatial extent & Frequency & Duration \\
\hline Predation and grazing & $1-10 \mathrm{~cm}$ & Weeks/months & Minutes/days \\
\hline Coral collapse & $1 \mathrm{~m}$ & Monthsiyears & Days/weeks \\
\hline $\begin{array}{c}\text { Individual bleaching or } \\
\text { coral disease }\end{array}$ & $1 \mathrm{~m}$ & Monthsiyears & Daysiweeks \\
\hline Storms & $1-100 \mathrm{~km}$ & Weeks/Years & Days \\
\hline Hurricanes & $10-10000 \mathrm{~km}$ & Months/decades & Days \\
\hline Mass Bleaching & $10-10000 \mathrm{~km}$ & Yearsidecades & We eks/months \\
\hline $\begin{array}{c}\text { Crowil-of-Thorn } \\
\text { outbreaks }\end{array}$ & $10-10000 \mathrm{~km}$ & Yearsidecades & Month/Years \\
\hline Epidemic disease & $10-10000 \mathrm{~km}$ & Months/Century & Years \\
\hline Sea lewel rise & Global & $10^{4}-10^{5}$ years & $10^{3}-10^{4}$ years \\
\hline Temperature change & Global & $10^{4}-10^{5}$ years & $10^{3}-10^{4}$ years \\
\hline Ocean acidification & Global & $?$ & $?$ \\
\hline
\end{tabular}

The oceans act as a climate regulator, storing heat that reaches the planet and releasing it when temperatures are cooler; as the planet warms, the oceans will store increasing amounts of heat energy (Clark et al. 2002). Increased stored heat will result in the oceans increasing in temperature, which is likely to have both direct and indirect effects on corals. Together with rising atmospheric temperatures, increased sea surface temperatures will act to destabilise ice sheets, such as the Antarctic ice sheet, which has an area of 13.6 million $\mathrm{km}^{2}$ and averaging over $2 \mathrm{~km}$ in thickness (Barker et al. 1999). The huge 
Antarctic ice sheet contains a volume of freshwater equivalent to $4 \%$ of the modern ocean which if melted in its entirety would equate to approximately a $66 \mathrm{~m}$ rise in global sealevel (Barker et al. 1999). Through melting of the ice sheets and thermal expansion of water, global sea levels have already risen by $0 \cdot 1-0.2 \mathrm{~m}$ in the past one hundred years (Houghton et al. 2001; Hulme 2005) and levels are projected to rise by 0.09 to $0.88 \mathrm{~m}$ between 1990 and 2100 (Houghton et al. 2001); this could have indirect and dire consequences for coral reefs. Coral reefs and the atolls they form are particularly vulnerable to sea level rise (Barnett and Adger 2003; Church et al. 2006), it is believed that corals will not be able to accrete enough reef (at the rate required by the rise in sea level) to enable them to maintain access to light levels to which they are currently adapted (Woodroffe 1990), causing bleaching and reduced calcification (Knowlton 2001b; Barnett and Adger 2003; Church et al. 2006).

It is thought that rising sea surface temperatures can directly promote coral disease, and the loss of symbiotic algae and/or their photosynthetic pigments (bleaching) (Walther et al. 2002; Hughes et al. 2003). This thermal bleaching arises because of loss of photosynthetic function, which means that the rate of light (i.e. energy) capture in photosynthesis exceeds the rate of light utilisation, so causing photoinhibition and the build-up of toxic reactive oxygen species (ROS) (Hoegh-Guldberg 1999; Weis 2008). Coral bleaching is perhaps the most widely recognised global threat to coral reefs with, for example, the 1998 mass bleaching event killing 16\% of corals worldwide, and the frequency and duration of bleaching events becoming ever greater (Hoegh-Guldberg 1999; Hoegh-Guldberg et al. 2007). Moreover, bleaching can act synergistically with more localised impacts, worsening the impacts that humans place upon reefs (Buddemeier et al. 2004; Hoegh-Guldberg et al. 2007; Nicholls et al. 2008). Increased 
levels of $\mathrm{CO}_{2}$ not only accumulate in the atmosphere, but in the oceans too. Indeed the oceans act, as they have done for millennia, as a considerable reservoir for carbon, readily exchanging $\mathrm{CO}_{2}$ with the atmosphere and absorbing about 2 gigatons $(\mathrm{Gt})$ of $\mathrm{CO}_{2}$ more than they release (Royal Society 2005; Pelejero et al. 2005). Indeed, it has been estimated that the oceans have absorbed approximately half of the total anthropogenic emissions of $\mathrm{CO}_{2}$ released since the industrial revolution (Sundquist 1993; Royal Society 2005). The $\mathrm{CO}_{2}$ absorbed by the oceans reacts with water to form a carbonic acid, which then readily releases $\mathrm{H}^{+}$ions into the seawater and in doing so reduces the $\mathrm{pH}$ of the seawater. The oceans naturally buffer against this by using carbonate $\left(\mathrm{CO}_{3}{ }^{2-}\right)$ to react with the $\mathrm{H}^{+}$ions to form bicarbonate $\left(\mathrm{HCO}_{3}{ }^{-}\right)$, so neutralising any adverse drop in $\mathrm{pH}$ (Royal Society 2005). This is an entirely natural process, but with elevated levels of $\mathrm{CO}_{2}$, this carbonate buffer is becoming overwhelmed, resulting in a decrease in seawater $\mathrm{pH}$ of 0.1 of a $\mathrm{pH}$ unit since pre-industrial times; $\mathrm{pH}$ is predicted to drop a further $0.3-0.4$ units by the end of this century (Royal Society 2005; Orr et al. 2005; Lovejoy 2006; Miles et al. 2007; Turley et al. 2007). The decrease in $\mathrm{pH}$ is accompanied by a decrease in $\mathrm{CO}_{3}{ }^{2-}$, so reducing its availability for the formation of calcium carbonate $\left(\mathrm{CaCO}_{3}\right)$, either as aragonite or calcite (Royal Society 2005; Calderia 2007). For calcification (refer to section 1.5) to take place, seawater must be saturated with respect to $\mathrm{CaCO}_{3}$ (more specifically, aragonite and calcite) (Orr et al. 2005; Royal Society 2005; Schneider and Erez 2006); if the seawater becomes under-saturated with respect to these molecules, then it becomes increasingly difficult to form and maintain $\mathrm{CaCO}_{3}$ structures, with implications such as weakened coral skeletons and the reef structures they create (Orr et al. 2005; Royal Society 2005; Schneider and Erez 2006). 
In the field of ocean acidification, the vast majority of research has focused on coral reefs and pelagic coccolithophores, and more specifically $\mathrm{CaCO}_{3}$ depletion and its effects on calcification (Blackford et al. 2007; Fabry et al. 2008). Much of the research states that, at atmospheric $\mathrm{CO}_{2}$ concentrations of around $550 \mathrm{ppm}$ (today atmospheric $\mathrm{CO}_{2}$ stands at $380 \mathrm{ppm}$ ), coral calcification will be reduced by $40 \%$, primarily due to the undersaturation of aragonite/calcite (fig 1.6) (Hoegh-Guldberg et al. 2007). Indeed, empirical research suggests that calcification rates may decline by: $25 \%$ for mussels by 2100

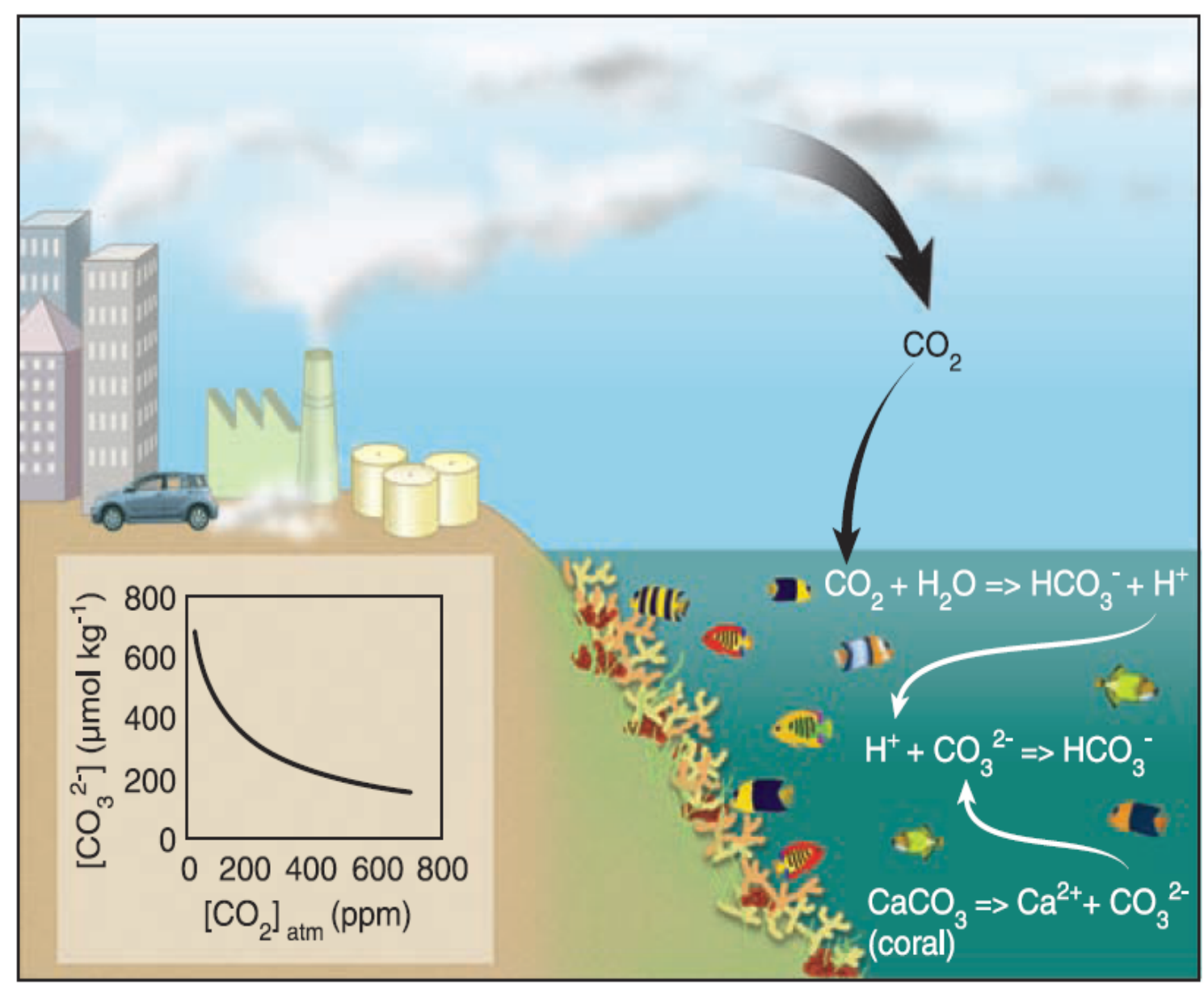

Figure 1.6: Ocean acidification and carbonate (aragonite/calcite depletion). As more and more $\mathrm{CO}_{2}$ is emitted more is absorbed by our oceans. As $\mathrm{CO}_{2}$ is absorbed by the oceans it reacts with water $\left(\mathrm{H}_{2} \mathrm{O}\right)$ to form a carbonic acid $\left(\mathrm{H}_{2} \mathrm{CO}_{3}{ }^{-}\right)$which readily releases $\mathrm{H}^{+}$ protons that are able to react with carbonates $\left(\mathrm{CO}_{3}{ }^{2-}\right)$ decreasing the calcium carbonate $\left(\mathrm{CaCO}_{3}\right)$ saturation state of the oceans to below that required by corals.

Source: Hoegh-Guldberg et al. (2007) 
(Gazeau et al. 2007); 21\% for scleractinian corals by 2065 (Leclercq et al. 2000); 59\% for the scleractinian coral Acropora cervicornis (Renegar and Riegl 2005); $18 \%$ and $66 \%$ for the coccolithophorids Emiliania huxleyi and Gephyrocapsa oceanica, respectively (Riebesell et al. 2000); and a much lower 6 to $14 \%$ for the Foraminifera (Bijma et al. 2002; Spero et al. 1997). Initially the impact from carbonate under-saturation will not be uniform. $\mathrm{CO}_{2}$ is more readily absorbed by colder water, and therefore it is predicted that much of the Southern Ocean will become under-saturated with respect to aragonite by 2050 , and by 2100 this under-saturation is predicted to spread to the entire Southern Ocean and into the subarctic Pacific Ocean (Orr et al. 2005). Furthermore, changes in ocean acidity will not only vary with respect to latitude but also within similar ecosystems, with some ecosystems, such as the Great Barrier Reef, Coral Sea, and the Caribbean Sea, attaining risky levels of aragonite saturation more rapidly than other tropical ecosystems (Fig. 1.7) (Hoegh-Guldberg et al. 2007). This predicted pattern in carbonate chemistry leads researchers to believe that calcification rates will initially decrease in colder water low-latitude corals (Gattuso et al. 1998 Kleypas et al. 1999 Langdon et al. 2003), which form reefs/skeletal structures from aragonite, and in low latitudinal phytoplankton that form their tests (shells, such as coccolithophores) out of calcite (Riebesell et al. 2000; Zondervan et al. 2001). 

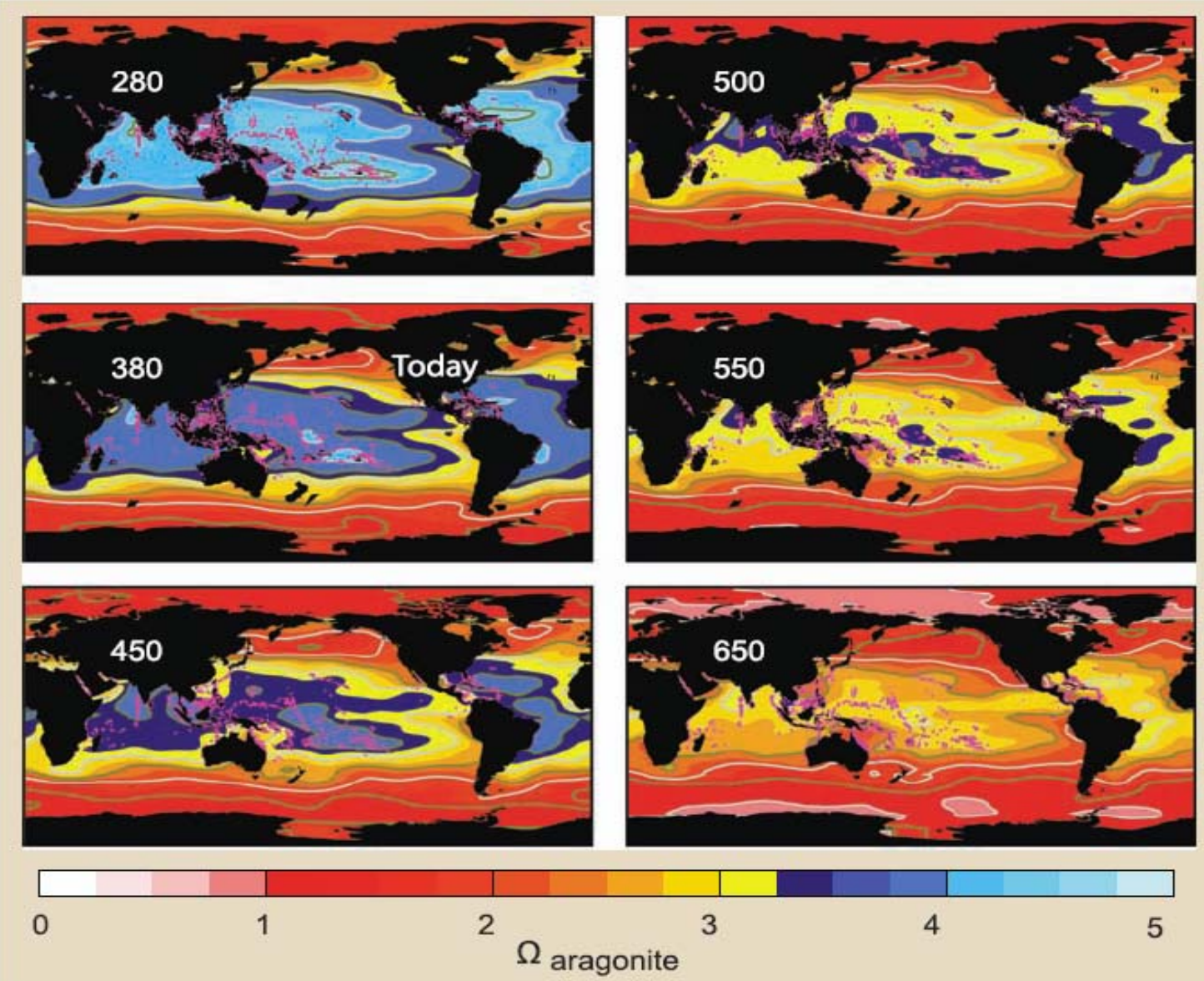

Figure 1.7: Ocean acidification and carbonate (aragonite/calcite depletion). Changes in aragonite saturation $\left(\Omega_{\text {aragonite }}\right)$ are predicted to occur as atmospheric $\mathrm{CO}_{2}$ concentrations $(\mathrm{ppm}=$ number top left of each scenario panel $)$ increase. Pre-industrial revolution (280 ppm), almost all shallow-water coral reefs had $\Omega_{\text {aragonite }}$ of $>3.25$ (blue regions in the figure), which is the minimum $\Omega_{\text {aragonite }}$ that coral reefs are associated with today.

$\mathrm{CO}_{2}$ is more readily absorbed in the colder water at the poles, therefore the southern and northern oceans are predicted to become further under-saturated with respect to aragonite, with this spreading to the equatorial regions.

Source: Hoegh-Guldberg et al. (2007)

Little information, however, is available on other physiological processes, such as growth, development, reproduction, metabolism, and $\mathrm{pH}$ balance under predicted acidic conditions (Fabry et al. 2008). Indeed, research on the biological implications of ocean acidification is in its infancy. This thesis will address one of the major gaps in our knowledge: what are the impacts of $\mathrm{CO}_{2}$-induced seawater acidification on the 
photosynthetic physiology and productivity of anthozoan-dinoflagellate symbioses? In particular, the research described here focuses on two model anthozoans, the tropical coral Stylophora pistillata and the temperate sea anemone Anthopleura aureoradiata, the comparison of which allows for unique insights into how the photophysiology of temperate and tropical symbioses may differ in response to seawater acidification. Furthermore, this thesis considers impacts on zooxanthellae isolated from S. pistillata, to discern any impacts that living inside the host might have. Lastly, this thesis compares the impacts of acidification caused by $\mathrm{CO}_{2}$ versus $\mathrm{HCl}$, in order to determine whether any positive relationship between photophysiology and $\mathrm{CO}_{2}$ availability can potentially overcome any negative impacts of cellular acidosis.

\section{I.7 Aims and objectives}

This study aimed to determine the potential impact that seawater acidification may have on: 1) the photophysiological health of zooxanthellae both in hospite and while isolated from the symbiosis; and 2) the health of the symbiosis itself. Furthermore, comparisons were made between tropical and temperate symbiotic organisms.

In particular, this study aimed to:

1. Determine whether the tropical scleractinian coral S. pistillata and the temperate mudflat sea anemone A. aureoradiata exhibited any negative photophysiological impacts when the seawater was acidified to levels forecast for 2100 .

2. Establish whether the zooxanthellar photophysiology in both S. pistillata and A. aureoradiata is enhanced by an increased availability of DIC (i.e. $\mathrm{CO}_{2}$ ), and whether this might moderate any negative impacts of acidification. 
3. Compare and contrast the photophysiological impacts of seawater acidification (if any) on zooxanthellae from S. pistillata, when both inside the host coral (i.e. in hospite), and when in isolation.

4. Identify the $\mathrm{pH}$ threshold (if any) at which A. aureoradiata suffers a marked and potentially irreversible loss of photosynthetic function.

Ultimately this study will contribute to the growing body of research on the impacts of ocean acidification on marine flora and fauna. Only recently has the central focus shifted from calcification to other physiological impacts, and this study is uniquely placed to compare and contrast the potential impacts of ocean acidification on the photosynthetic function of temperate and tropical symbiotic algae. Furthermore, this is the first ever study to compare the impacts on algal symbionts when inside and outside their hosts. 


\section{Chapter II}

\section{PhOTOPHYSIOLOGICAL RESPONSES OF THE RED SEA CORAL STYLOPHORA PISTILLATA TO SEAWATER ACIDIFICATION}

\section{I Introduction}

A common ecosystem analogy places coral reefs alongside rainforests, with regards to the abundance of life, species diversity and species density (Knowlton 2001a; Barneah et al. 2007; Sale 2008). The capacity of a coral reef to support such a huge volume and array of life is due, at least in part, to the niches created - and filled - by highly specific symbiotic relationships (Knowlton 2001a; Barneah et al. 2007). Invertebrates such as corals and sea anemones can form various symbiotic relationships, often simultaneously. The symbiotic relationship may involve one partner, or a combination of different partners, such as vertebrates (e.g. fish), other invertebrates, bacteria or algae (Buddemeier et al. 2004). With regards to reef-building corals and other cnidarians, the most common symbiotic relationship is with photosynthetic dinoflagellates of the genus Symbiodinium, known commonly as zooxanthellae. These dinoflagellates also form symbioses with members of the Porifera, Mollusca, Platyhelminthes and Protozoa (Barneah et al. 2007), though their symbiosis with corals is the most important ecologically (Gierck 2007; Weis et al. 2008). Generally, tropical waters are high in sunlight, but have low levels of nutrients and dissolved $\mathrm{O}_{2}$ (Muller- 
Parker \& Davy 2001); they should be unable to sustain the abundance of life that is currently present. However, as a result of the coral-dinoflagellate symbiosis, and its capacity for tight nutrient recycling and primary production, coral reefs are able to persist and grow in these conditions (Shick and Dykens 1985). In addition, the symbiosis accelerates the deposition of calcium carbonate by corals, so enabling the construction of the reef which in turn creates a biodiversity hotspot, through the provision of food and habitat for a multitude of organisms (Lough 2008). These reefs can also protect shorelines from coastal erosion (Richmond 1993).

Climate change, which is the shift in global climatic patterns arising from excessive amounts of atmospheric $\mathrm{CO}_{2}$, poses a real threat to the long term survival of coral reefs. $\mathrm{CO}_{2}$ acts like an insulator heating the planet by trapping the Sun's energy. This is an entirely natural process, but with excessive amounts of anthropogenic $\mathrm{CO}_{2}$ released, the planet is heating up much faster, and to a greater degree, than has been observed in the last 10,000 years - possibly longer (Petit et al. 1999; Epstein 2001). Rising sea surface temperatures can promote coral disease and the loss of symbiotic dinoflagellates and/or their photosynthetic pigments from corals (i.e. bleaching) (Walther et al. 2002; Hughes et al. 2003). In $1997 / 98$ it was estimated that as much as $16 \%$ of the world's coral reefs were damaged by human induced coral bleaching, whereas, pre-1980s, widespread coral bleaching was largely unheard of (Buddemeier et al. 2004; Gierck 2007). This increased bleaching, and cases of coral disease, are not solely attributable to climate change, but rather a synergistic relationship with non-climatic stresses which humans also place upon reefs (Buddemeier et al. 2004; Hoegh-Guldberg et al. 2007; Nicholls et al. 2008). 
There is potentially an even greater threat to the world's coral reefs: ocean acidification. Not only is $\mathrm{CO}_{2}$ a greenhouse gas heating the planet, but it also dissolves into the ocean. Therefore, as the rate at which it is being pumped into the atmosphere has intensified, so has the amount being absorbed by the world's oceans; this is likely to overwhelm natural systems. $\mathrm{CO}_{2}$, when dissolved in water, undergoes a chain of simple chemical reactions and, when combined with $\mathrm{H}_{2} \mathrm{O}$, it forms a carbonic acid which readily releases $\mathrm{H}^{+}$ions to the water, making it more acidic (Royal Society 2005). When an acid, such as carbonic acid, is added to seawater, the additional hydrogen ions react with available $\mathrm{CO}_{3}{ }^{2-}$ ions and convert them to $\mathrm{HCO}_{3}{ }^{-}$. This acts to reduce the concentration of hydrogen ions, so preventing acidification of the seawater (Royal Society 2005); this process is known as the carbonate buffer. However, with the ever increasing amount of $\mathrm{CO}_{2}$ added to seawater, the ability of the carbonate buffer to maintain a constant $\mathrm{pH}$ is reduced, as the availability of $\mathrm{CO}_{3}{ }^{2-}$ ions becomes less (Royal Society 2005). Crucially, this reduced availability of $\mathrm{CO}_{3}{ }^{2-}$ ions has serious implications for the numerous marine organisms, including reef corals that utilise carbonate for building their skeletons and shells.

Oceans have already decreased 0.1 of a $\mathrm{pH}$ unit since the industrial revolution (lateeighteenth to mid-nineteenth centuries) and are predicted to drop to $\mathrm{pH} 7.6$ by 2100 and beyond (Caldeira and Wickett 2003; Orr et al. 2005; Wood et al. 2008; Zeebe et al. 2008; Doney et al. 2009). As a result, the future for marine calcifiers is bleak (Orr et al. 2005; Hoegh-Guldberg et al. 2007). How ocean acidification may affect other physiological processes is, however, much less clear. Of particular interest is photosynthesis, as the addition of $\mathrm{CO}_{2}$ and cellular acidosis (i.e. acidification and disruption of the intracellular environment) could have quite different, and opposing, effects. For example, HallSpencer et al. (2008), using volcanic $\mathrm{CO}_{2}$ vents which locally acidified the water off the 
coast of Italy, found that seagrass production was highest in areas of $\mathrm{pH}$ 7.6. This suggests that, rather than causing physiological dysfunction, photosynthetic production can in fact be increased with acidification by $\mathrm{CO}_{2}$. Similarly, in a mesocosm experiment performed by Palacios and Zimmerman (2007), the seagrass Zostera marina photosynthesised more at elevated $\mathrm{CO}_{2}$ levels, leading to increased biomass production. Likewise, increases in dissolved inorganic carbon (DIC) to 750 parts per million or the equivalent decrease to a $\mathrm{pH}$ of 7.7 , at least doubled the rate of photosynthesis in the coccolithophore Emiliania huxleyi (Iglesias-Rodriguez et al. 2008); this finding is particularly interesting in the context of corals, as coccolithophores also produce $\mathrm{CaCO}_{3}$ structures and suffer reduced calcification in acidified water (Zondervan et al. 2002; Riebesell 2004).

It is therefore conceivable that ocean acidification could benefit coral photosynthesis, if not calcification, though this topic has received little attention to date. In particular, given that zooxanthellae are present at high densities within the coral's tissues, it has been suggested that they are carbon limited (Leggat et al. 2000) and hence an increased availability of $\mathrm{CO}_{2}$ may be especially valuable. Alternatively, zooxanthellae in corals may not respond to elevated $\mathrm{CO}_{2}$ levels as readily as do the likes of seagrasses and phytoplankton, because they are isolated from the seawater reservoirs of DIC by their endosymbiotic habitat (Weis and Reynolds 1999; Leggat et al. 2002). Increased levels of $\mathrm{CO}_{2}$ and increased acidification could therefore cause different photosynthetic responses in symbiotic zooxanthellae than in other marine phototrophs, and quite different responses in symbiotic zooxanthellae than in ones isolated from their host coral. Clearly, there is a need to better understand the effects of acidification via $\mathrm{CO}_{2}$ on the photophysiology of corals and their endosymbionts. 
This experiment aimed to identify the photophysiological effects of seawater acidification on the symbiotic zooxanthellae contained within the tropical coral Stylophora pistillata. In addition, the photophysiological effects of acidification on cultured zooxanthellae, originally isolated from the same coral species, were measured. It was hypothesised that seawater acidified using $\mathrm{CO}_{2}$ would have a positive effect on the photophysiology of the zooxanthellae contained within S. pistillata, due to their carbon limitation in the coral's tissues. Conversely, it was hypothesised that the cultured (i.e. isolated) zooxanthellae would experience less marked photophysiological benefits, if any, as they were less likely to be carbon limited as a result of having ready access to DIC in their culture medium. It was further hypothesised that seawater acidified with $\mathrm{HCl}$ rather than $\mathrm{CO}_{2}$ would have a negative effect on the photophysiology of both the zooxanthellae in symbiosis with $S$. pistillata and in isolation, due to a decrease in $\mathrm{pH}$ with no associated increase in DIC availability that could potentially help the cell to counter any cellular impacts of acidosis. 


\subsection{Materials and methods}

\subsubsection{Experimental organisms}

Experiments were conducted on the branching scleractinian coral S. pistillata (fig 2.1). S. pistillata is a shallow-water Indo-Pacific coral, and is the most common of the 100 or more coral species found in the Gulf of Aqaba, situated between Saudi Arabia and the Sinai Peninsula in the north-eastern arm of the Red Sea. S. pistillata is pervasive along the light continuum: from full sunlight to almost complete shade. Small colonies can be removed from the substratum, without damaging the coral's living tissue; this makes them ideal as a study species. Corals had previously been collected by researchers at the Centre Scientifique de Monaco (CSM) from the Gulf of Aqaba (Latitude: $29^{\circ} 0$ Min, 0 Sec. Longitude: $34^{\circ} 40 \mathrm{Min} .1 .2 \mathrm{Sec}$.). The corals were then maintained in culture at CSM for several years.

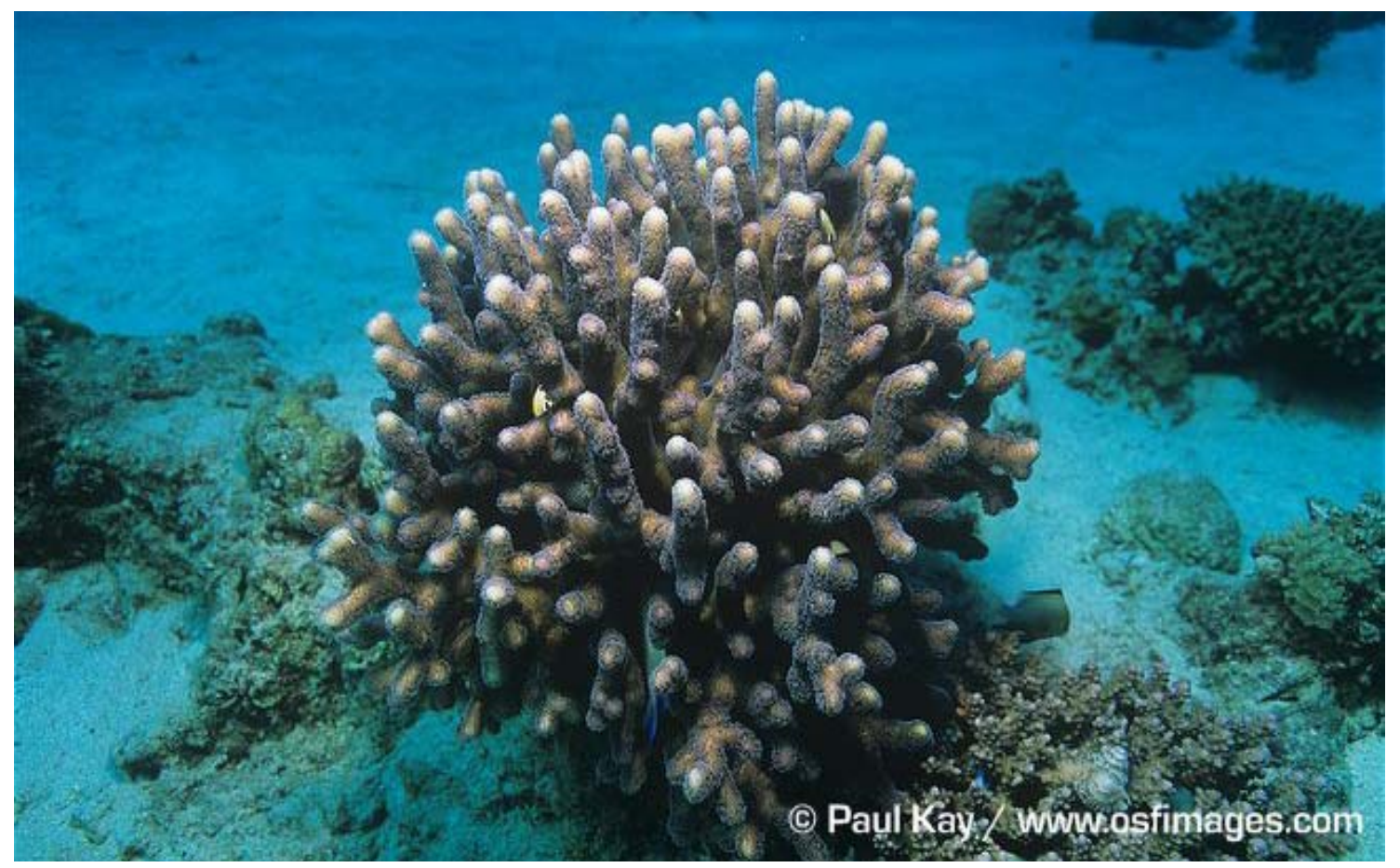

Figure 2.1: Stylophora pistillata on a sandy reef. Photo taken by Paul Kay, photo accessed online at www.arkive.org. 
Experiments were also conducted on the zooxanthellae originally isolated from $S$. pistillata and cultured long-term ( $>5$ years) in F/2 culture medium at the CSM. The zooxanthellar clade or type (i.e. sub-clade) was not identified.

\subsubsection{Coral maintenance and preparation}

Corals were stored in $300 \mathrm{~L}$ tanks which were supplied with nutrient-poor Mediterranean seawater (pumped from a depth of $50 \mathrm{~m}$ ) at an exchange rate of $6 \mathrm{~L} \mathrm{~h}^{-1}$ in an open water system. Temperature $\left(26.0 \pm 1{ }^{\circ} \mathrm{C}\right)$, salinity $(38 \mathrm{ppt})$ and light $\left(300 \mu \mathrm{mol}\right.$ photons $\left.\mathrm{m}^{-2} \mathrm{~s}^{-1}\right)$ were all held constant; light was provided using two $400 \mathrm{~W}$ metal halide lamps (Philips, HPIT) on a $12 \mathrm{~h}$ light:12 h dark cycle. Corals were fed using a mix of Artemia salina

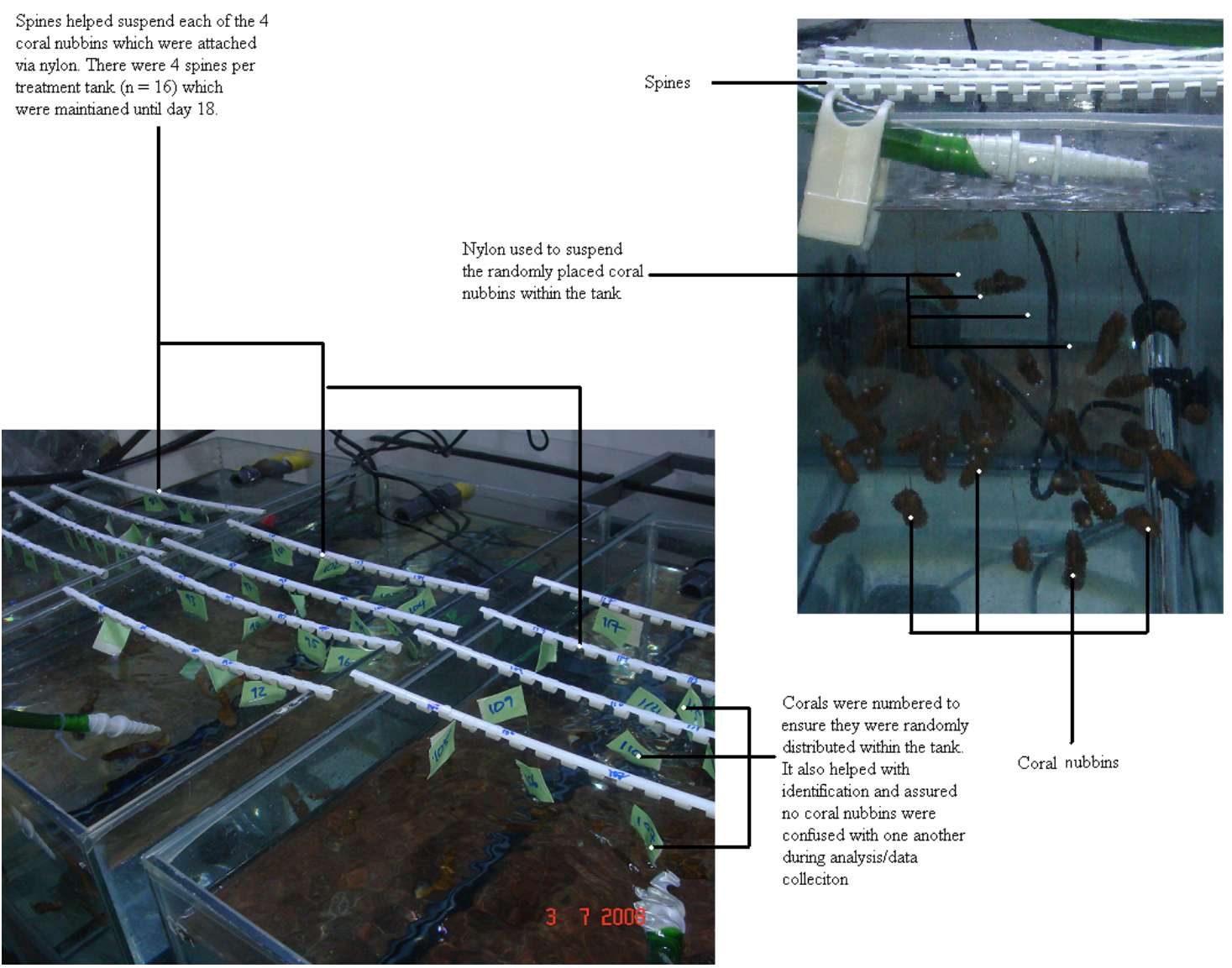

Figure 2.2: Stylophora pistillata coral nubbins suspended by nylon within their respective tanks. 
nauplii, A. salina frozen adults, and frozen krill. Corals were fed twice per week up until experimentation began (last feeding the day before experimentation), at which time feeding was discontinued. Four weeks before experimentation, coral fragments or 'nubbins' (20 - $30 \mathrm{~mm}$ in length) were cut with bone-cutting pliers from the terminal branches of coral colonies. The nubbins were suspended with nylon line in a $30 \mathrm{~L}$ aquarium and subjected to the same environmental regime as the parent colony (fig 2.2). Approximately 4 weeks later, nubbin tissue had overgrown the cut region leaving no areas of exposed skeleton, and nubbins were ready for experimental use.

\subsubsection{Experimental Design}

\section{Coral nubbins}

The impact of acidified seawater on the photophysiology of S. pistillata was assessed; including any differing impacts of acidification with $\mathrm{HCl}$ or $\mathrm{CO}_{2}$. The seawater naturally had a $\mathrm{pH}$ of 8.1 and this was considered as the control treatment. However, the $\mathrm{pH}$ adjusted tanks required acidification to attain a $\mathrm{pH}$ of 7.6 (Fig. 2.4). The $\mathrm{pH} 7.6 \mathrm{HCl}$ treatment involved the addition of $\mathrm{HCl}$ via a peristaltic pump, whereas the $\mathrm{pH} 7.6 \mathrm{CO}_{2}$ treatment involved the addition of industrial-grade gaseous $\mathrm{CO}_{2}$. In both cases, to achieve and maintain a lowered $\mathrm{pH}$, a PINPOINT ${ }^{\circledR} \mathrm{pH}$ controller (American Marine Inc.) was used. This $\mathrm{pH}$ controller consisted of a probe that, upon detecting an abnormally high $\mathrm{pH}$, would switch on either the peristaltic pump delivering $10 \% \mathrm{HCl}$ into the reservoir tank or the $\mathrm{CO}_{2}$ solenoid which delivered dissolved $\mathrm{CO}_{2}$ to the reservoir tank via the Red Sea Pro System. The Red Sea Pro System is a commercially available aquarium tool for $\mathrm{CO}_{2}$ control - how the system works is elaborated in the following steps: 
1. Pinpoint $\mathrm{pH}$ controller registers a deviation (rise) in $\mathrm{pH}$ and switches on power to the solenoid.

2. Upon being initiated the solenoid allows $\mathrm{CO}_{2}$, from the tank, to pass through its valve.

3. $\mathrm{CO}_{2}$ enters the piping of the Red Sea Pro System and into the highly efficient $\mathrm{CO}_{2}$ Reactor 500 which can dissolve over 180 bubbles of $\mathrm{CO}_{2}$ per min.

4. Seawater, supersaturated with $\mathrm{CO}_{2}$, is contained within the Reactor 500 and released into the water. The process stops when the pinpoint $\mathrm{pH}$ monitor registers a return to the desired $\mathrm{pH}$ range, resulting in the power supply to the solenoid being turned off and the cessation of $\mathrm{CO}_{2}$ flow.

The coral nubbins were housed in a wet lab at CSM (fig. 2.5). The three $30 \mathrm{~L}$ treatment tanks were fed from three $200 \mathrm{~L}$ reservoir tanks, which were constantly supplied at a rate of $1 \mathrm{~L} \mathrm{~min}{ }^{-1}$ with nutrient-poor and unfiltered Mediterranean seawater pumped from a depth of $50 \mathrm{~m}$. The seawater had a natural salinity of $38 \mathrm{ppt}$ and the reservoir tanks were wrapped in foil to retard algal growth. For the duration of the experiment, seawater was pumped from the bottom of the reservoir tank into the bottom of the respective treatment tank at a rate $600 \mathrm{ml} \mathrm{h}^{-1}$. The overflow from the treatment and reservoir tanks was returned to the Mediterranean Sea. A powerful $35 \mathrm{~W}$ pond pump was used to ensure complete mixing within each reservoir tank, to ensure that the $\mathrm{pH}$ was maintained at a constant level throughout. Furthermore, each treatment tank had a small pump within it to ensure continuous mixing of newly added water with older water. A $12 \mathrm{~h}$ light: $12 \mathrm{~h}$ dark regime was used, with $400 \mathrm{~W}$ metal halide lamps (Philips, HPIT) generating an irradiance of $300 \pm 15 \mu \mathrm{mol}$ photons $\mathrm{m}^{-2} \mathrm{~s}^{-1}$. 
Coral nubbins $(\mathrm{n}=60)$ were transferred from the stock aquaria to the $\mathrm{pH} 8.1$ treatment tank to allow acclimation to experimental (light and temperature) conditions for 6 days; they were not fed during this time. After this acclimation period, 12 nubbins were removed for initial processing; this was considered as time zero $(t=0 \mathrm{~d})$. A further 16 nubbins were transferred to each of the $\mathrm{pH} 7.6 \mathrm{HCl}$ and $\mathrm{pH} 7.6 \mathrm{CO}_{2}$ experimental tanks, leaving 16 nubbins in the $\mathrm{pH} 8.1$ control tank. The coral nubbins remained undisturbed in their treatment tanks for 18 days, with temperature and $\mathrm{pH}$ being measured three times per day to ensure environmental stability; nubbins were not fed for the duration of the experiment. At each time-point ( $0 \mathrm{~d}$ and $18 \mathrm{~d}$, fig 2.3), photosynthetic health,

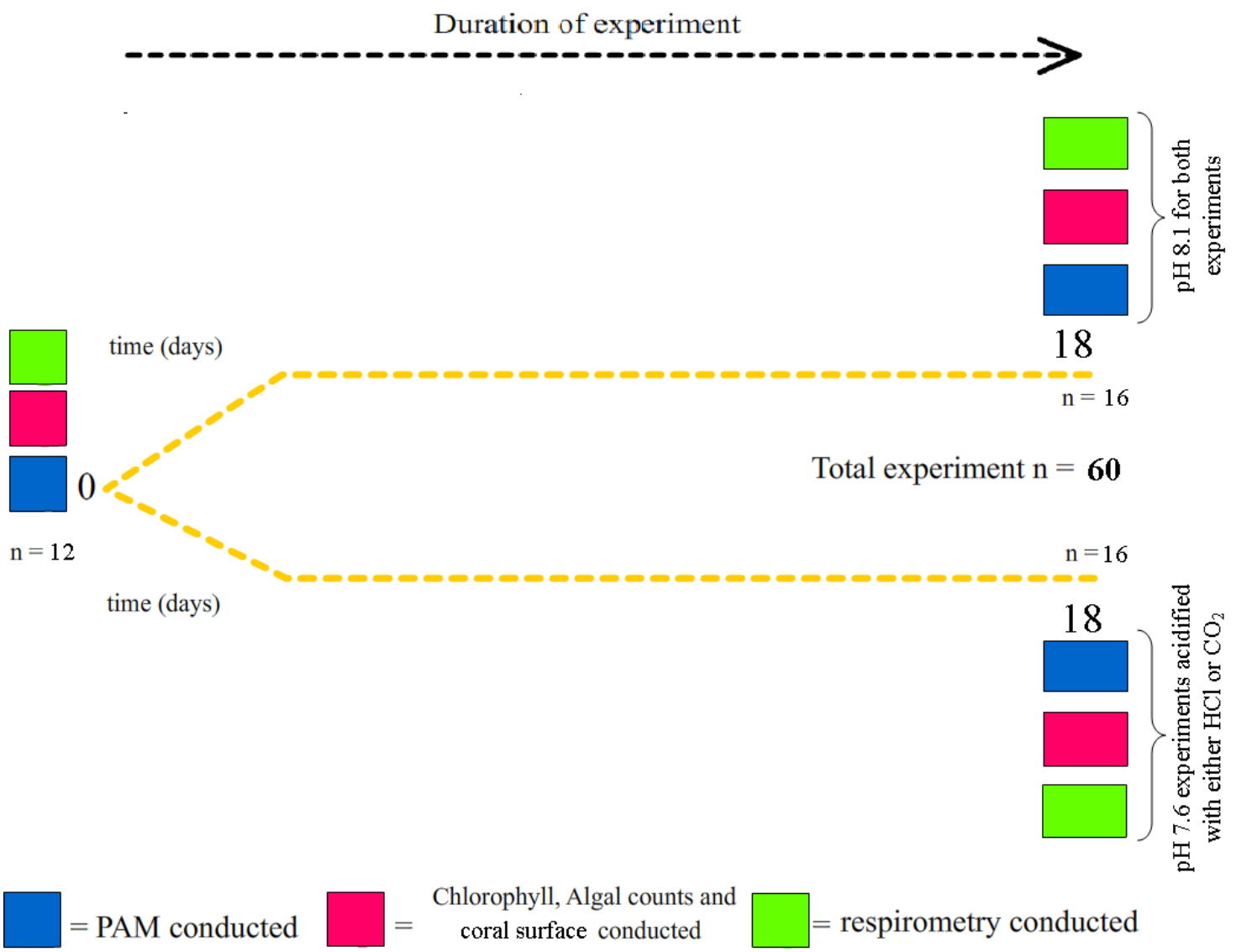

Figure 2.3: Experimental timeline. $\mathrm{pH} 8.1$ control conducted concurrently with the $\mathrm{pH}$ $7.6 \mathrm{HCl}$ and the $\mathrm{pH} 7.6 \mathrm{CO}_{2}$ treatments. Colour-coded boxes indicate what measurements were taken for each corresponding time-point, with twelve coral nubbins processed at time 0 and sixteen at time 18 for each treatment. 
chlorophyll content per zooxanthella, and zooxanthella density were measured. Furthermore, as a measure of autotrophic potential, the ratio of photosynthesis to respiration was measured (see below for methods).

For $\mathrm{pH} 8.1$ and $\mathrm{pH} 7.6 \mathrm{CO}_{2}$, the temperature remained at $26 \pm 1^{\circ} \mathrm{C}$ for both and $\mathrm{pH}$ was constant at $8.1 \pm 0.01$ and $7.6 \pm 0.01$, respectively. However, due to a major problem with the water inflow system, on Day 17 the $\mathrm{pH}$ of the $\mathrm{pH} 7.6 \mathrm{HCl}$ treatment dropped to $\mathrm{pH} 4$. Unfortunately, as a result, the corals died and no data could be collected for the final time-point $(\mathrm{t}=18 \mathrm{~d})$. This particular treatment is therefore not considered further here.

\section{Cultured zooxanthellae}

The impact of acidified seawater on the photophysiology of zooxanthellae isolated from $S$. pistillata was measured, again including any differential impacts arising from acidification with $\mathrm{HCl}$ or $\mathrm{CO}_{2}$ (fig 2.6). Due to space limitations, this experiment was completed in two stages, with $\mathrm{HCl}$ first being used and then $\mathrm{CO}_{2}$. The experiment was conducted in a temperature controlled room (fig. 2.7) and each $\mathrm{pH} 7.6$ treatment, acidified with either $\mathrm{HCl}$ or $\mathrm{CO}_{2}$, was run concurrently with a $\mathrm{pH} 8.1$ treatment. The zooxanthella cultures were maintained in $150 \mathrm{ml}$ conical flasks held within a waterbath. Each flask was fed with $1 \mu \mathrm{m}$-filtered seawater (FSW), via dialysis tubing connected to one of two $50 \mathrm{~L}$ reservoir tanks (one containing acidified water and one containing nonacidified water). The seawater flowed into each flask, by gravity, at a rate $50 \mathrm{ml} \mathrm{h}^{-1}$. The overflow from each flask filled the waterbath, from where it flowed into the drain before it could reach the tops of the flasks; to ensure a continuous flow of FSW, the reservoir tanks were topped up as needed. A $20 \mathrm{~W}$ pond pump was used to ensure complete 
mixing within each reservoir tank to maintain a constant temperature and $\mathrm{pH}$, while the tank was completely blacked-out to prevent growth of algal contaminants Furthermore, the waterbath contained a small pump to ensure mixing of recently overflowed seawater with older seawater, so maintaining an even temperature. Irradiance was on a $12 \mathrm{~h}$ light: $12 \mathrm{~h}$ dark regime at $275 \pm 25 \mu \mathrm{mol}$ photons $\mathrm{m}^{-2} \mathrm{~s}^{-1}$; light was provided via a light bank containing thirty-five 5 W LED lamps (Green Lights, Taiwan)

In total, 6 culture flasks were used for each 35-day trial. All culture flasks were initially fed for 6 days via the $\mathrm{pH} 8.1$ reservoir tank, allowing for acclimation to experimental conditions. Subsequently $(\mathrm{t}=0 \mathrm{~h})$, physiological measurements (see below) were taken for all 6 flasks, before 3 of them were transferred to either the $\mathrm{pH} 7.6 \mathrm{HCl}$ (first trial) or pH 7.6 $\mathrm{CO}_{2}$ (second trial) treatments. Photosynthetic health was measured at 0,3 and 7 days, and every 7 days until Day $35(t=0,3,7,14,21,28,35 \mathrm{~d})$. Chlorophyll content per zooxanthella was measured at the same time-points, except for $\mathrm{t}=3 \mathrm{~d}$. Temperature and $\mathrm{pH}$ were recorded once a day over the course of the experiment to ensure a constant environment: in the $\mathrm{pH} 8.1$ and $\mathrm{pH} 7.6 \mathrm{CO}_{2}$ and $\mathrm{HCl}$ treatments temperature remained at $26 \pm 1{ }^{\circ} \mathrm{C}$ and $\mathrm{pH}$ remained at $8.1 \pm 0.01$ and $7.6 \pm 0.01$, respectively. 
Water intake system. Delivers water pumped from the Mediterranean, sourced at $50 \mathrm{~m}$ depth, and delivers it to the $200 \mathrm{~L}$ reservoir tanks.

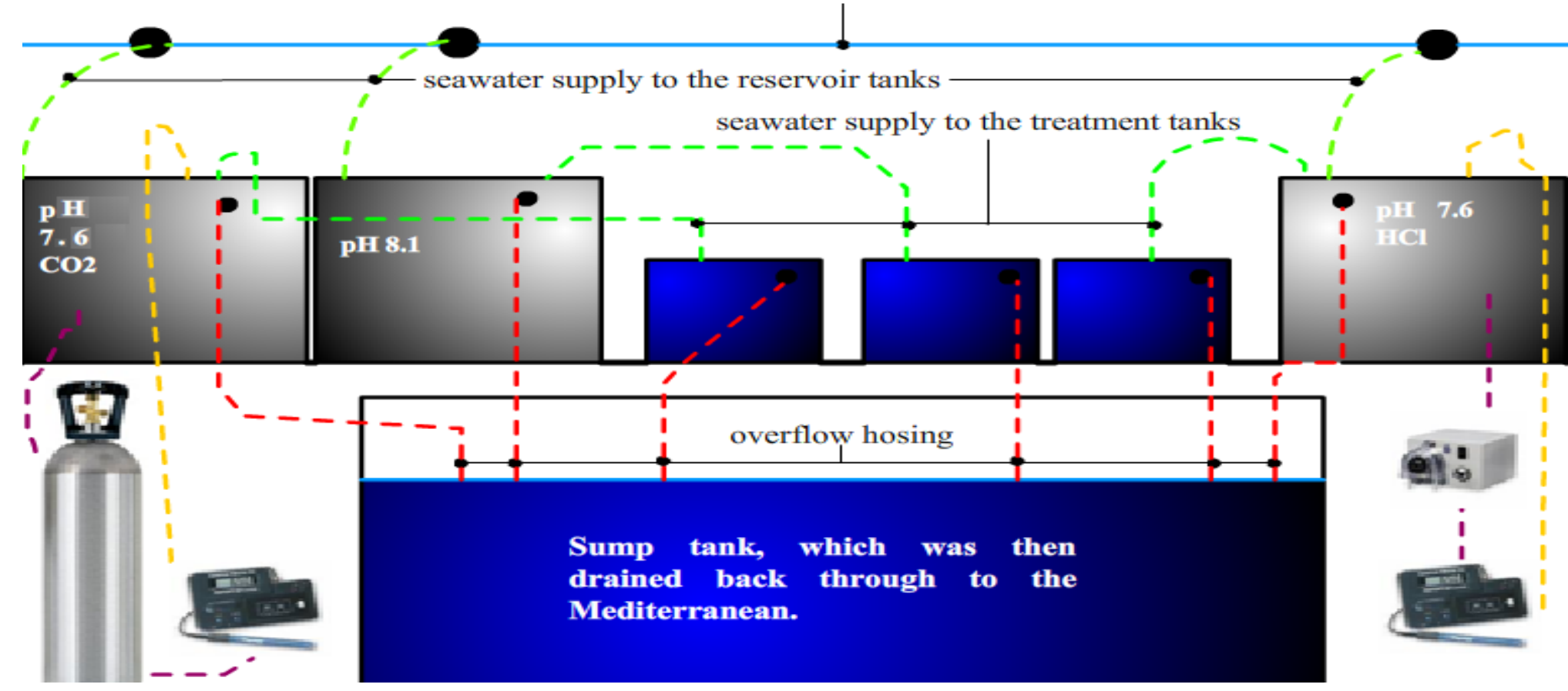

Figure 2.4:

Cora

experimental

set-up.

Experiment

was run for

18 days,

treatments were $\mathrm{pH} 8.1$, $\mathrm{pH} 7.6 \mathrm{HCl}$ and $\mathrm{pH} 7.6$

$\mathrm{CO}_{2}$.

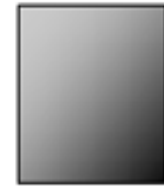

$200 \mathrm{~L}$ reservoir tank, in which $\mathrm{pH}$ was controlled. This then fed the
reatment tanks

Q1' $\begin{aligned} & \text { Represents } \mathrm{HCl} \\ & \text { and its delivery } \\ & \text { system }\end{aligned}$

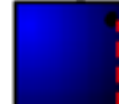

$30 \mathrm{~L}$ treatment tamk with dilled

overflow hole

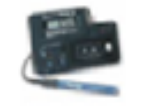

Pinpoint $\mathrm{pH}$ controller and probe, regulates $\mathrm{pH}$ 'suntching on' the $\mathrm{HCl}$ delimen systers
Represents carbo dioxide and its delivery system

Fresh seawater from the | Acidification of Mediterravean pumped in an continuous open system into the reservoir tark. Seswater would then be acidified with either caton dioxide or $\mathrm{HCl}$ or left H 81 and fed into pHe.1 and fed into and intiates addition of $\mathrm{HCl}$ or carbon dioxide when reguired reservoir tanks, with either carbon dioxide or $\mathrm{HCl}$

Overflow from reservoir and treatment tanks. Retumed back te the Mediteranean Sea
Permunent piping contuining fresh Mediterranean seawater, hosing directed se awater into the reservoir tanks (green dotted lines) 


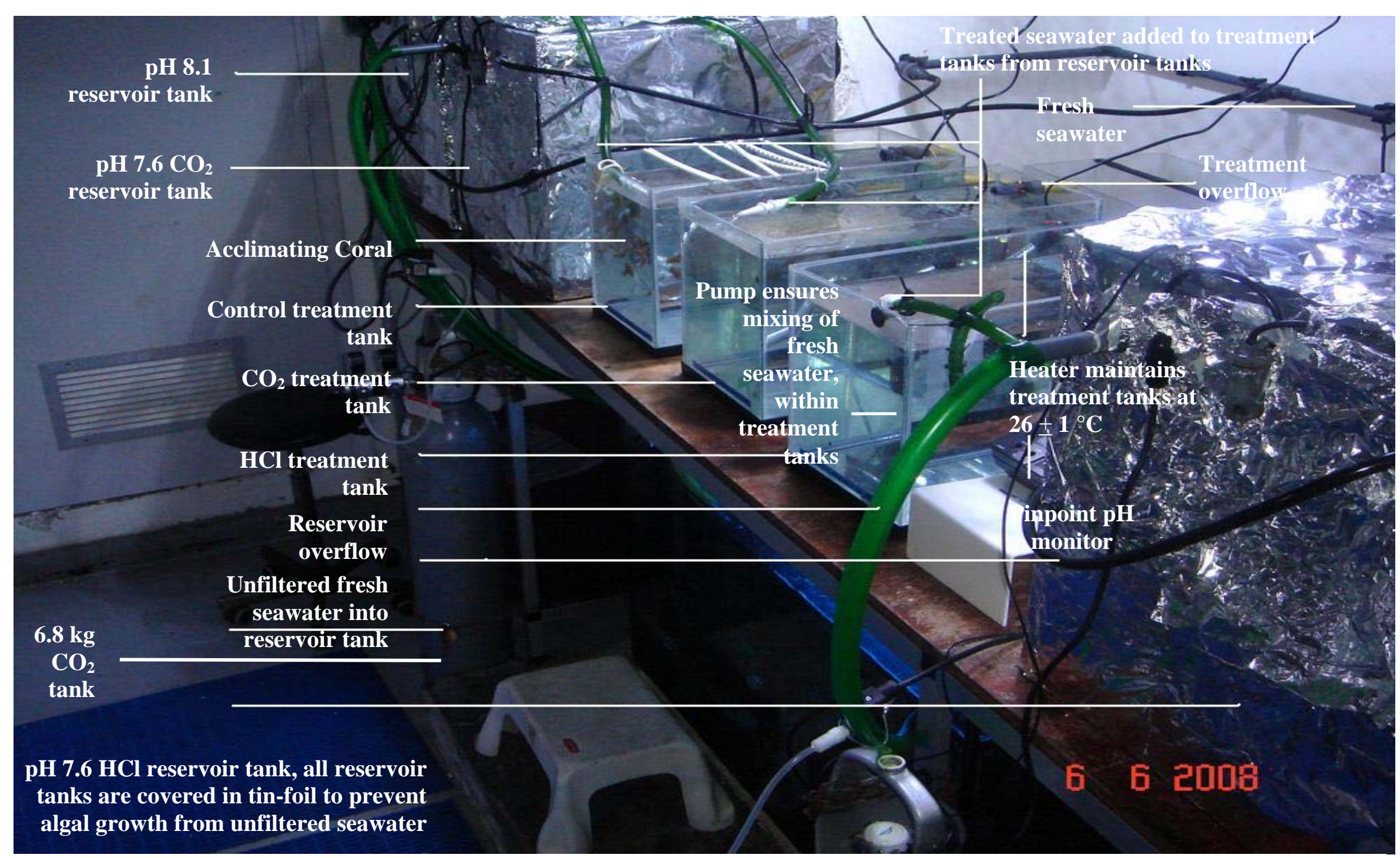

Figure 2.5: Experimental set-up outlined in diagram figure 2.3. The photo was taken during the $\mathrm{pH} 8.1$ versus $\mathrm{pH} 7.6 \mathrm{HCl}_{\text {and }} \mathrm{pH} 7.6 \mathrm{CO}_{2}$ experiment. 

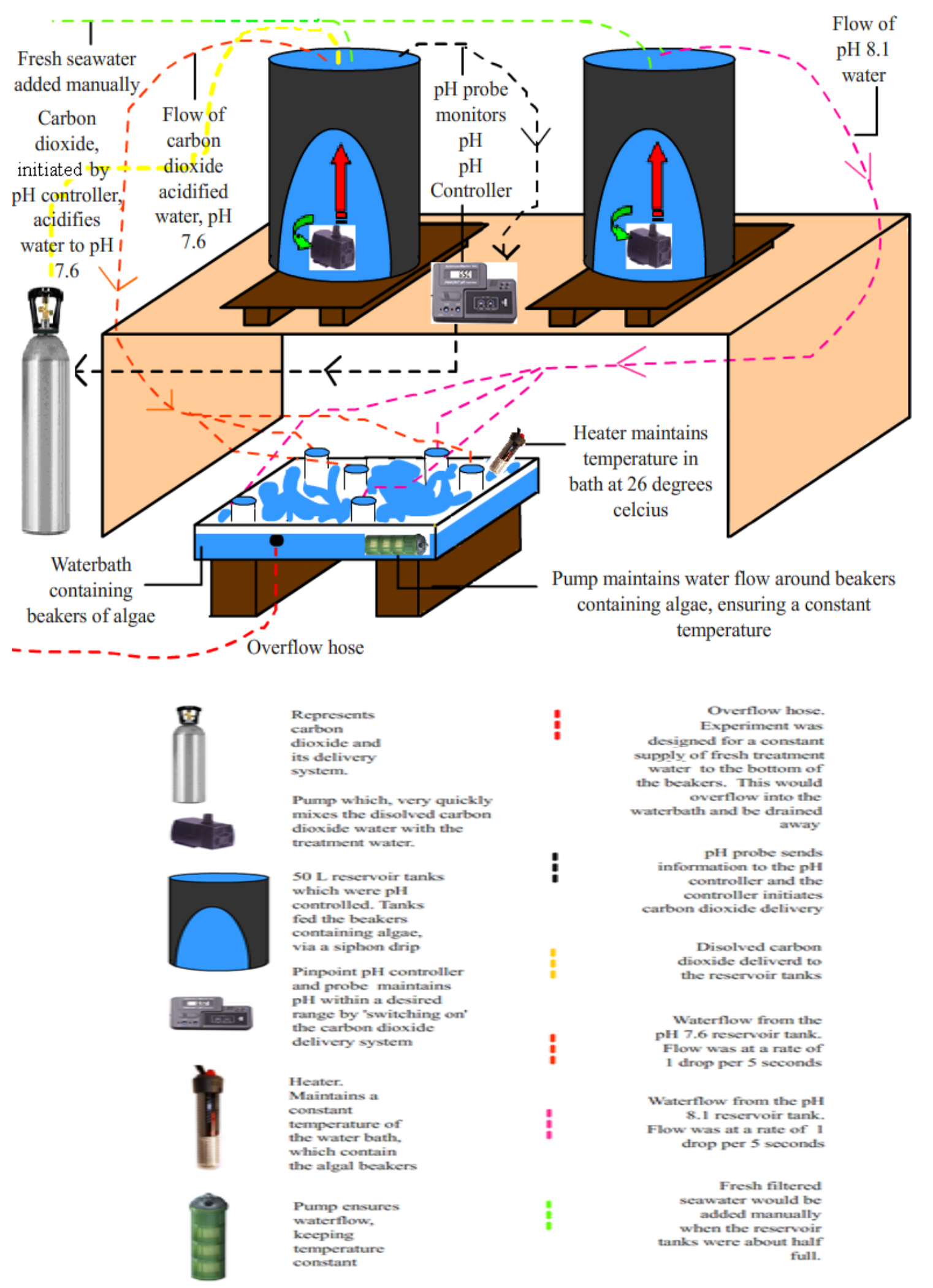

Fresh filtered adder mould be addod manually tanks were about half
full.

Figure 2.6: Cultured zooxanthellae experimental set-up. Each trial was run for 35 days, with the treatments being $\mathrm{pH} 8.1$ versus $\mathrm{pH} 7.6 \mathrm{HCl}$, and $\mathrm{pH} 8.1$ versus $\mathrm{pH} 7.6 \mathrm{CO}_{2}$ 


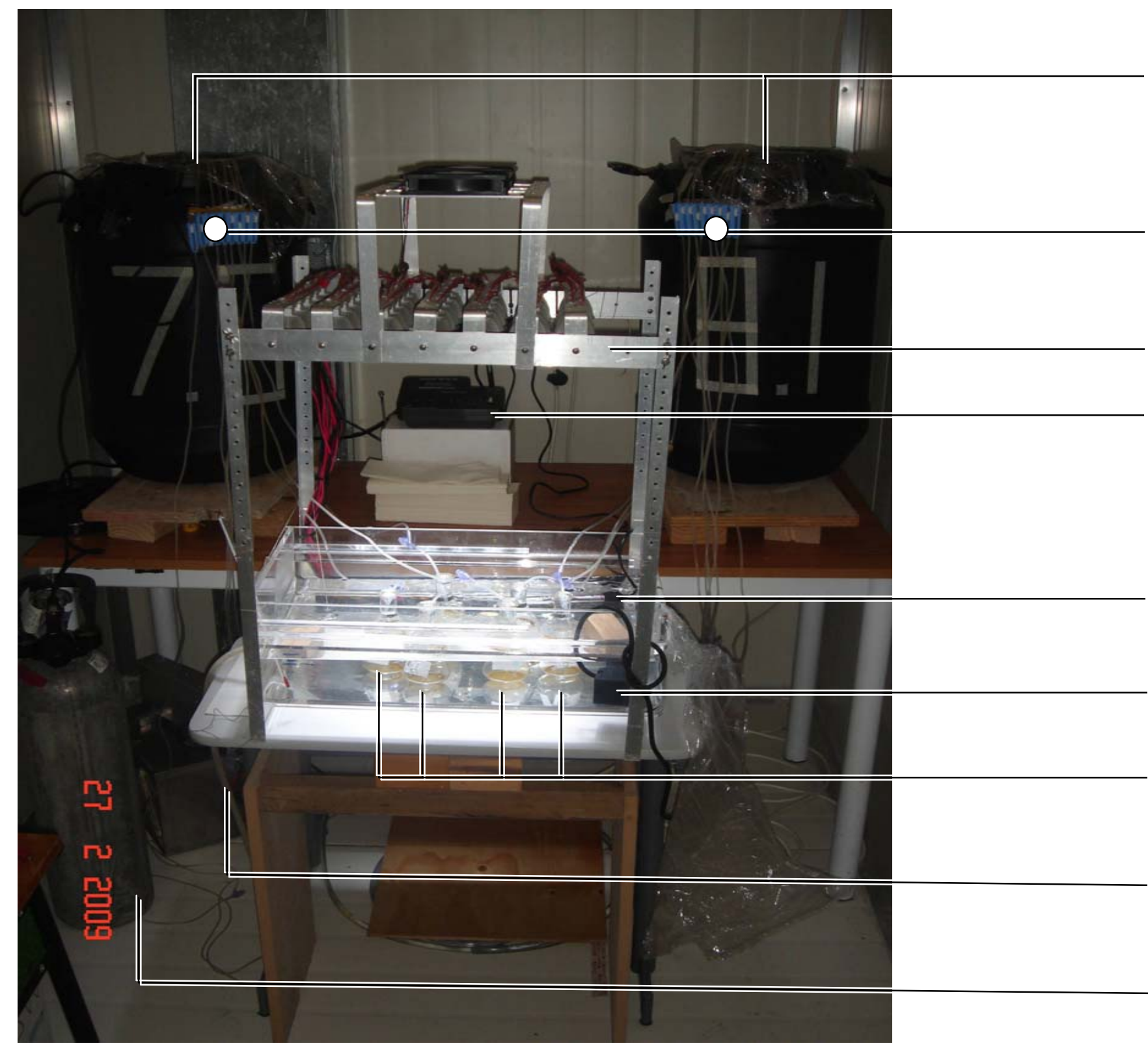

$50 \mathrm{~L}$ reservoir tanks (pH 7.6 left, $\mathrm{pH} 8.1$ right) fed the zooxanthellar cultures via dialysis tubing. Seawater added as needed and acidified when $\mathrm{pH}$ probe measured increased $\mathrm{pH}$ levels.

Rate controlled drips. Fed treatment water from the reservoir tanks to the zooxanthellar cultures

Lights, $12 \mathrm{~h}$ light: $12 \mathrm{~h}$ dark regime at $275 \pm 25 \mu \mathrm{mol}$ photons $\mathrm{m}^{-2} \mathrm{~s}^{-1}$.

Pinpoint $\mathrm{pH}$ controller, regulated $\mathrm{pH}$ via a probe and initiated the addition of either $\mathrm{CO}_{2}$ or $\mathrm{HCl}$ as required.

Heater, maintained temperature at $26 \pm$ $1{ }^{\circ} \mathrm{C}$

Lights, $12 \mathrm{~h}$ light: $12 \mathrm{~h}$ dark regime at $275 \pm 25 \mu \mathrm{mol}$ photons $\mathrm{m}^{-2} \mathrm{~s}^{-1}$.

$150 \mathrm{ml}$ flasks contained cultures.

Overflow water flowed into the waterbath.

Overflow hose from bath to drain

$\mathrm{CO}_{2}$ tank bubbled $\mathrm{CO}_{2}$ into the seawater when triggered by the Pinpoint $\mathrm{pH}$ controller. Or $\mathrm{HCl}$ was added.

Figure 2.7: Photo of the experimental set-up outlined in diagram figure 1.4. The photo was taken during the $\mathrm{pH} 8.1$ versus $\mathrm{pH} 7.6 \mathrm{CO}_{2}$ experiment. 


\subsubsection{Photosynthetic health}

Using a Diving PAM (Walz, Germany), and the interface WinControl v2.08, photosynthetic health $\left(\mathrm{Y}_{\mathrm{i}}\right.$, light-adapted yield) of the zooxanthellae was measured, while both in hospite (i.e. in the coral) and in culture (fig 2.8). Coral nubbins from each treatment and time-point $(\mathrm{t}=0 \mathrm{~h}, \mathrm{n}=12 ; \mathrm{t}=18 \mathrm{~h}, \mathrm{n}=16)$ were immediately placed into a beaker containing their specific treatment seawater, and $Y_{i}$ measured while using a shade cloth to prevent excessive natural light reaching them from nearby windows. For each flask containing cultured zooxanthellae ( $n=6$ at $0 \mathrm{~h}, \mathrm{n}=3$ per treatment thereafter), three $\mathrm{Y}_{\mathrm{i}}$ measurements were taken in different regions of the culture, and averaged; this accounted for any spatial variability in photosynthetic health associated with the growth and ageing of the culture. After PAM (and respirometry if required), coral nubbins and isolated zooxanthellae were placed in the freezer $\left(-20 \pm 1.5^{\circ} \mathrm{C}\right)$ until a time when further processing of the samples was undertaken. Diving PAM was set as follows: Measuring light intensity 8; Saturation Pulse Intensity 5; Gain 5; Damping 4 and 30 second intervals between measuring light pulses.

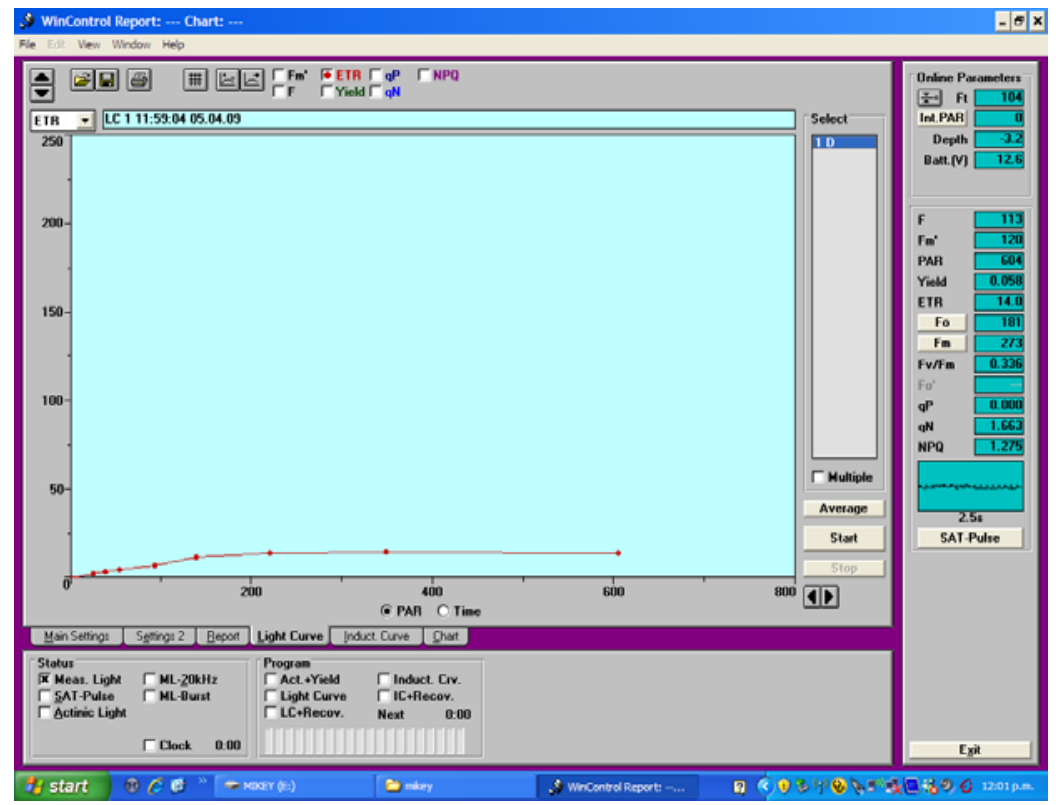

Figure 2.8: WinControl interface showing the light curve generated using the Diving Pulse Amplitude

Modulated (DivingPAM) Fluorometer. The photosynthetic parameter $\mathrm{Y}_{\mathrm{i}}$ was recorded. 


\subsubsection{Coral tissue processing}

To measure total chlorophyll levels, the zooxanthellae were first isolated from the coral. Coral tissue was removed from defrosted corals, using an Oral B waterpik type 4803 (fig. 2.9) and $50 \mathrm{ml}$ of FSW. The resulting tissue slurry was mixed using a vortex, and $400 \mu \mathrm{l}$ removed for zooxanthellar counts (section 2.2.5). The remaining slurry was centrifuged at $5^{\circ} \mathrm{C}$ and $\mathrm{x} 11,000 \mathrm{~g}$ for $12 \mathrm{~min}$. The supernatant was discarded and the remaining zooxanthellar pellet was re-suspended in FSW and re-centrifuged for 6 minutes at the same temperature and $g$. The supernatant was again discarded and the remaining zooxanthellar pellet was frozen for later chlorophyll analysis (section 2.2.6).

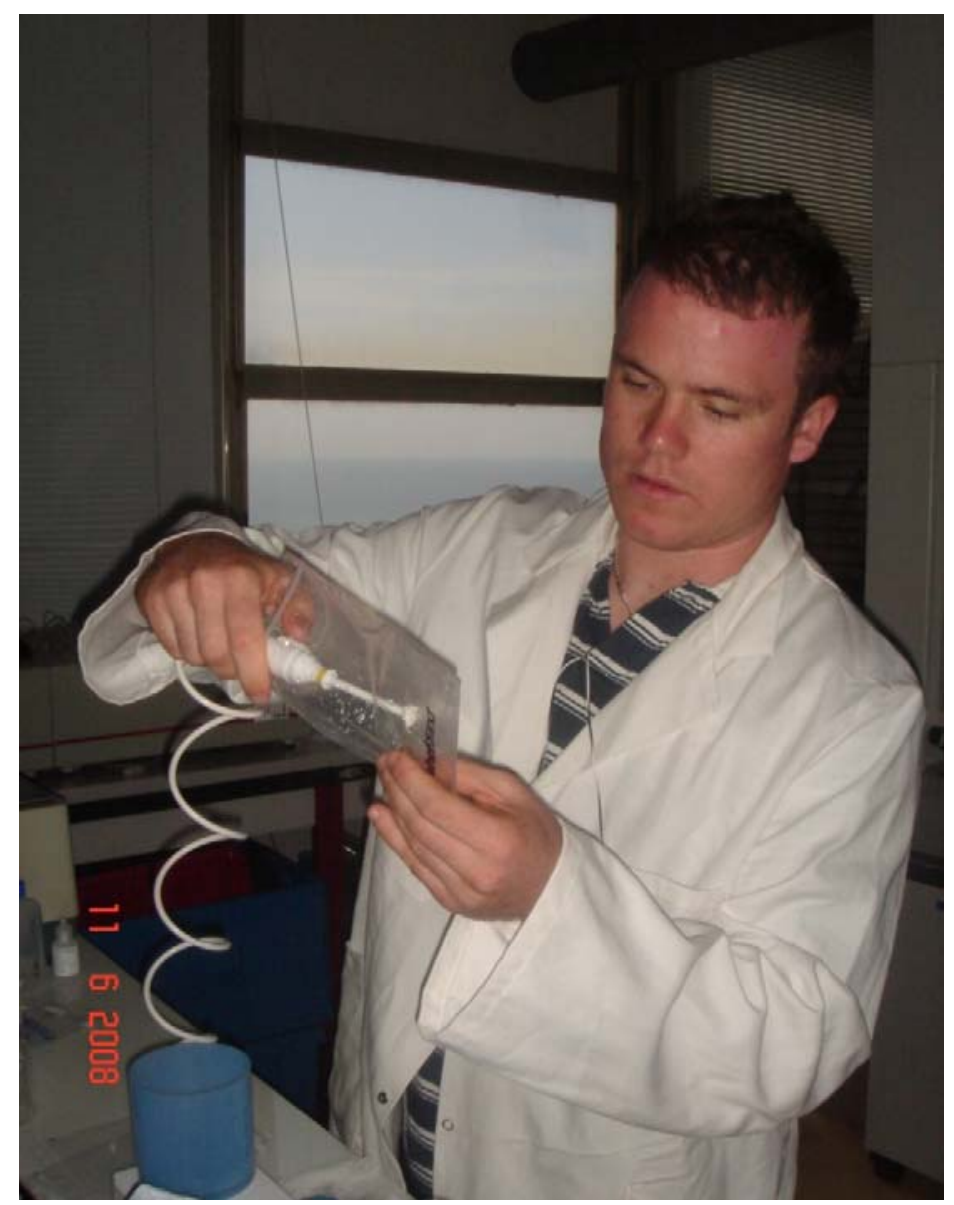

Figure 2.9. Processing coral tissue. Coral tissue was removed from the skeleton using a waterpik, and isolated zooxanthellae were then used to measure algal density and chlorophyll levels. 


\subsubsection{Zooxanthellar counts and densities}

Numbers of zooxanthellae were necessary for subsequent calculations of chlorophyll per cell and cell density (i.e. zooxanthellae per $\mathrm{cm}^{2}$ coral). Zooxanthellae were counted using an automated computer system running Histolab v6.02 by Microvision Instruments (fig. 2.10). Each coral tissue slurry sub-sample $(400 \mu l)$ was placed into a Hydro Bios Kiel Chamber and a further $2.5 \mathrm{ml}$ of FSW added to fill the chamber. A coverslip was then placed over the chamber, forming a bubble-free, air-tight seal. The Histolab software estimated the number of cells within the field of view (fig. 2.10, computer screen), with 16 random fields of view used per sample. The number of zooxanthellae per $\mathrm{ml}$ and hence in the total $50 \mathrm{ml}$ extracted from each coral nubbin was then calculated, as described in equation 2.1 .

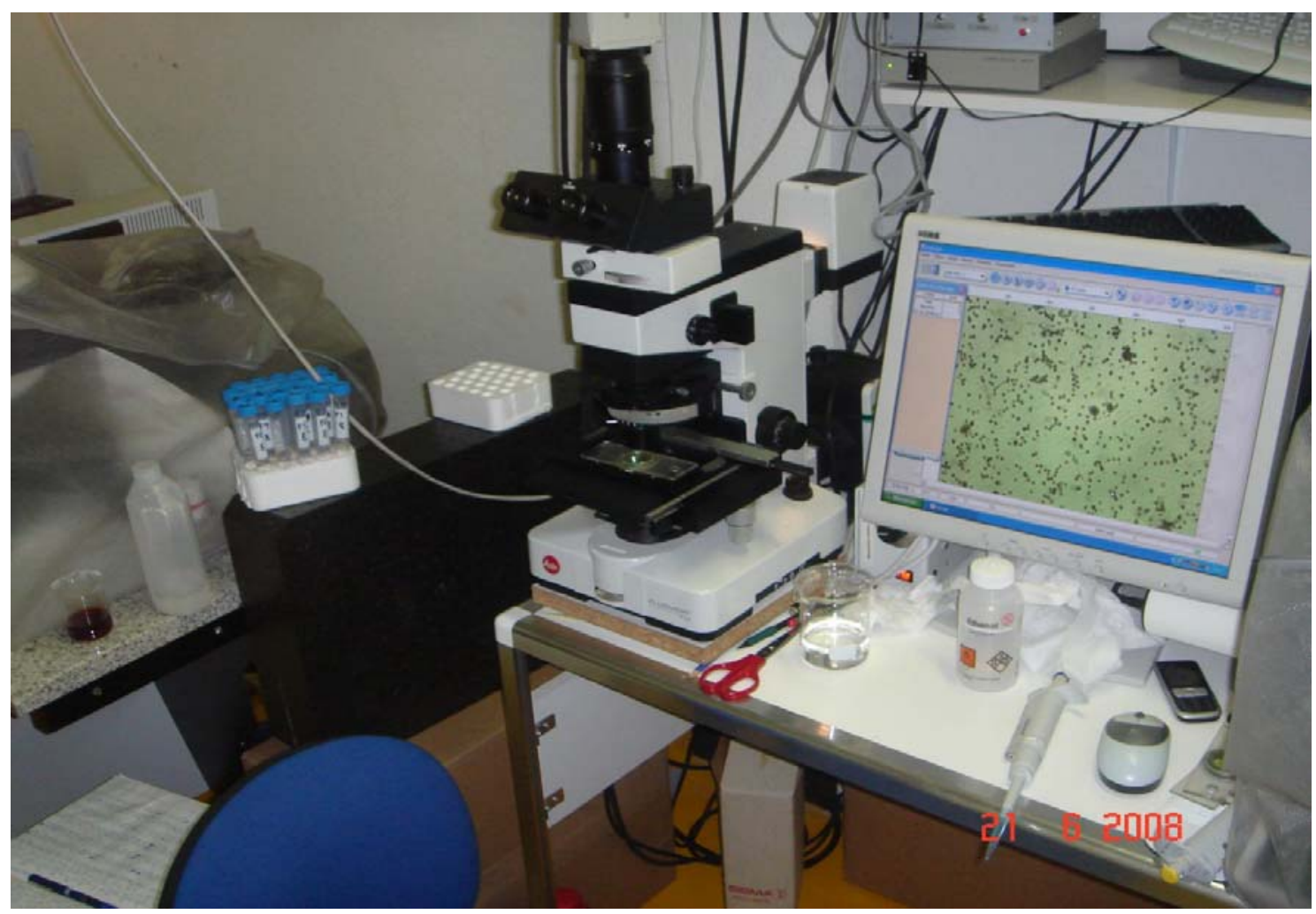

Figure 2.10: Set-up for counting zooxanthellae. Software calculated algal density in the field of view (as shown on computer screen), before this value was used to calculate the density of zooxanthellae within the coral nubbin. 


$$
X=1753 \times(Z / C) \times 50
$$

[equation 2.1]

\section{Where:}

$\mathrm{X}=$ number of zooxanthellae per $\mathrm{ml}$

$\mathrm{Z}=$ number of zooxanthellae per field of view

$\mathrm{C}=$ volume of original suspension used for counting $(400 \mu \mathrm{l})$

Cultured zooxanthellae were counted via a different method, as the software described above was not available. For each flask and time-point, $2.3 \mathrm{ml}$ of seawater + zooxanthellae were removed, of which $800 \mu \mathrm{l}$ were used for cell counts and the remaining $1.5 \mathrm{ml}$ were frozen for subsequent chlorophyll analysis (section 2.2.6). Eight

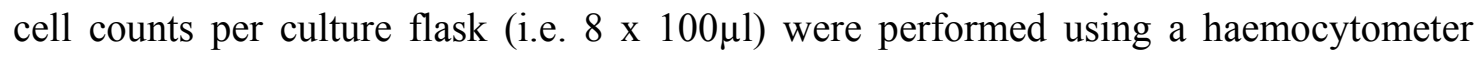
(Weber Scientific Instruments, England). These counts were then averaged and the number of zooxanthellae per ml estimated (equation 2.2). Total chlorophyll was then standardised to the number of zooxanthellae present in the $1.5 \mathrm{ml}$ of algal suspension from which chlorophyll was extracted (section 2.2.6), to give chlorophyll content per cell.

\section{$\mathrm{X}=\mathrm{A} * \mathrm{C} \quad$ [equation 2.2]}

Where:

$\mathrm{X}=$ Cells per $\mathrm{ml}$

$\mathrm{A}=$ Number of cells in haemocytometer field of view

$\mathrm{C}=$ Haemocytometer coefficient $(10,000)$

Coral surface area was estimated using the standard tin-foil method. Coral skeletons were wrapped in tin foil, ensuring a single layer of foil that enveloped the entire coral nubbin. The tin foil was removed and weighed, and the weight converted to surface area $\left(\mathrm{cm}^{2}\right)$ using a previously generated standard curve (fig. 2.11). 


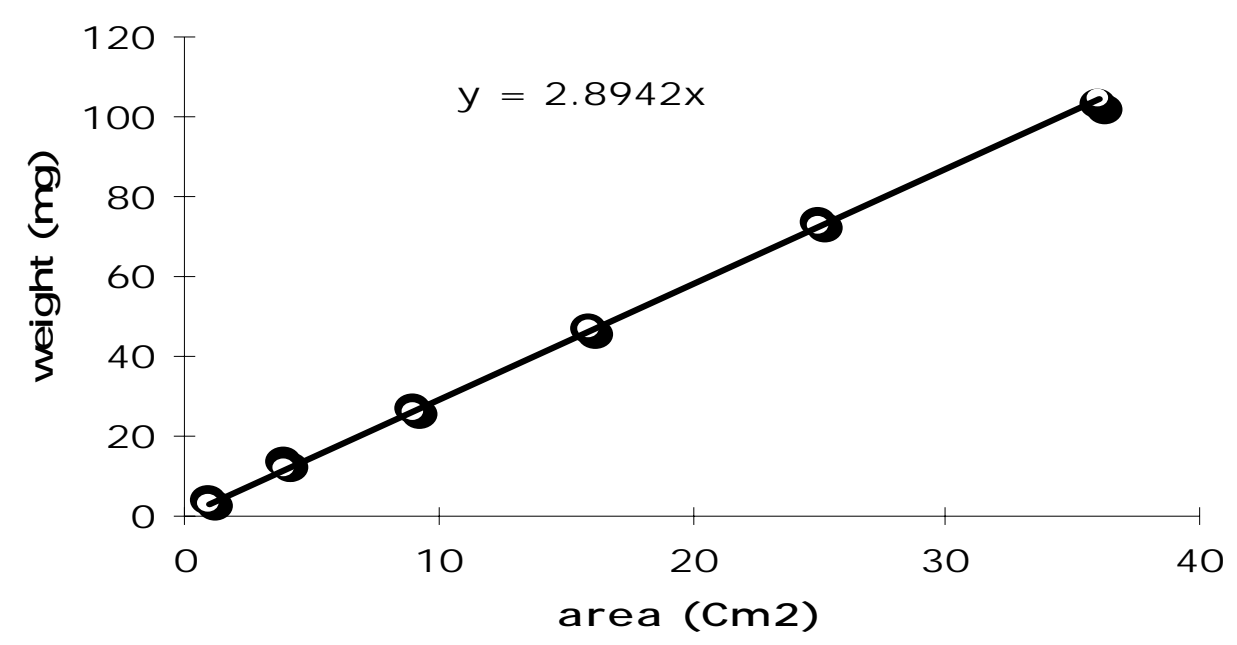

Figure 2.11: Standard curve of coral surface area versus tin-foil weight. The formula of the best fit line allowed surface area to be estimated from a given weight of tin-foil. Black circle $=$ the set measured tin-foil sizes, white circles $=$ the best fit predictions and the black line $=$ the linear best fit line.

Once the surface area and total number of zooxanthellae per nubbin were measured, the density of zooxanthellae was expressed as number of cells $\mathrm{cm}^{-2}$.

\subsubsection{Chlorophyll analysis}

Chlorophyll levels were normalised per algal cell and/or per $\mathrm{cm}^{2}$ coral. The tubes containing the zooxanthellar pellet $(50 \mathrm{ml}$ Falcon tubes for the coral experiment; $2 \mathrm{ml}$ Eppendorf tubes for the cultured zooxanthellae) were wrapped in tin foil to prevent light entering the tube. Acetone $(5 \mathrm{ml}$ for coral experiment and $1.5 \mathrm{ml}$ for the cultured zooxanthellae) was added to each tube and the tubes placed in a fridge $\left(3 \pm 1^{\circ} \mathrm{C}\right)$ for $24 \mathrm{~h}$, during which time the solvent extracted the chlorophyll. The following day the tubes were centrifuged at $5^{\circ} \mathrm{C}$ and $\mathrm{x} 11,000 \mathrm{~g}$ for $12 \mathrm{~min}$ to pellet cellular debris, and the acetone/extracted chlorophyll $(3 \mathrm{ml}$ for the coral experiment; $1 \mathrm{ml}$ for the cultured 
zooxanthellae) pipetted into an acetone-proof cuvette. Using a spectrophotometer, absorbance readings were taken at the wavelengths $630 \mathrm{~nm}, 663 \mathrm{~nm}$ and $750 \mathrm{~nm}$, where absorbance at $750 \mathrm{~nm}$ was indicative of background turbidity. Chlorophyll concentration, and hence the total amount chlorophyll extracted, was then calculated from the standard equations:

\section{[equation 2.3]}

\section{Chlorophyll $a(\mathrm{mg}$ per $\mathrm{ml})=\left(11.43 \times\left(\mathrm{A}_{663}-\mathrm{A}_{750}\right)\right)-\left(0.64 \times\left(\mathrm{A}_{630}-\mathrm{A}_{750}\right)\right)$}

\section{[equation 2.4]}

\section{Chlorophyll $c_{2}(\mathrm{mg}$ per $\mathrm{ml})=\left(27.09 \times\left(\mathrm{A}_{630}-\mathrm{A}_{750}\right)\right)-\left(3.63 \times\left(\mathrm{A}_{663}-\mathrm{A}_{750}\right)\right)$}

Total chlorophyll was calculated by adding together the amounts of chlorophylls $a$ and $c_{2}$, and total chlorophyll content per algal cell and per $\mathrm{cm}^{2}$ coral were estimated by normalising to the cell densities and surface areas measured before.

\subsubsection{Coral productivity}

A Strathkelvin 928,6 channel $\mathrm{O}_{2}$ v.2 system was used for respirometry readings. At 0 days and 18 days, each coral nubbin was placed in a transparent $60 \mathrm{ml}$ Perspex chamber (fig. 2.12), containing FSW. A bung was placed firmly into the chamber, expelling any air and forming an air-tight seal. An $\mathrm{O}_{2}$ electrode entered the chamber through the side, and water pre-heated in a waterbath was pumped into the jacket surrounding the chamber; this maintained a constant temperature inside the chamber $\left(26^{\circ} \mathrm{C}\right)$. Once in the chamber, the coral nubbin was allowed to settle for $10 \mathrm{~min}$, before the chamber was blacked-out 


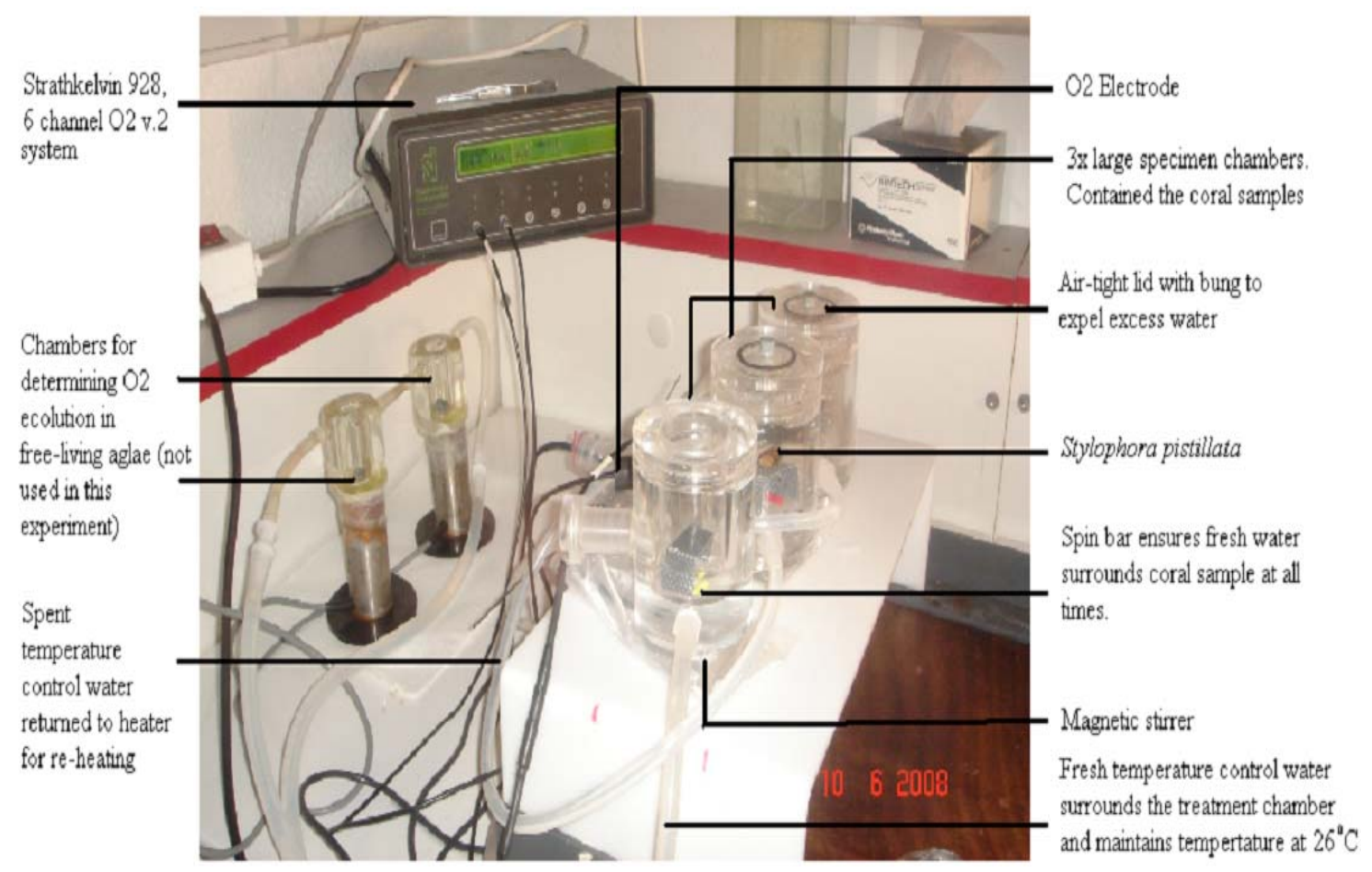

Figure 2.12: Respirometry set-up for coral nubbins. A temperature of $25^{\circ} \mathrm{C}$ was maintained via a waterbath and light levels were manipulated with a halogen light attached to a movable rail. A computer recorded all changes in dissolved $\mathrm{O}_{2}$ and calculated rates of $\mathrm{O}_{2}$ depletion in $\mathrm{mg} \mathrm{O}_{2} \mathrm{~L}^{-1} \mathrm{~h}^{-1}$.

completely by placing a sheet over it; a light meter was used to test the validity of this method. Dissolved $\mathrm{O}_{2}$ content (\% saturation) was measured in darkness for a minimum of 10 min (i.e. until a steady rate was observed), to obtain the dark respiration rate. The sheet was then removed and the chamber illuminated at $135 \mu \mathrm{mol}$ photons $\mathrm{m}^{-2} \mathrm{~s}^{-1}$ for at least $10 \mathrm{~min}$, after which the chamber was illuminated with a photosynthesis-saturating irradiance of $400 \mu \mathrm{mol}$ photons $\mathrm{m}^{-2} \mathrm{~s}^{-1}$ for a further $10 \mathrm{~min}$ or more. Dissolved $\mathrm{O}_{2}$ content was measured at 135 and $400 \mu \mathrm{mol}$ photons $\mathrm{m}^{-2} \mathrm{~s}^{-1}$ to obtain rates of mid- to maximum photosynthesis. To enable the $\mathrm{O}_{2}$ electrode to calculate the $\mathrm{O}_{2}$ saturation of the seawater surrounding the coral, the $\mathrm{O}_{2}$ electrode needed to be calibrated to the upper $\left(100 \% \mathrm{O}_{2}\right.$ saturation) and lower $\left(0 \% \mathrm{O}_{2}\right.$ saturation $) \mathrm{O}_{2}$ saturation extremes. In order to calibrate the $\mathrm{O}_{2}$ electrode to an environment of $100 \% \mathrm{O}_{2}$ saturation, FSW used for calibration was 
supplied with continuous air via a pump for $20 \mathrm{~min}$. Subsequent $\mathrm{O}_{2}$ saturation readings were assumed to be indicative of seawater at $100 \% \mathrm{O}_{2}$ saturation. To calibrate the $\mathrm{O}_{2}$ electrode to an environment of $0 \% \mathrm{O}_{2}$ saturation, $\mathrm{FSW}$ used for calibration was supplied with nitrogen from a compression tank, for $20 \mathrm{~min}$. Subsequent $\mathrm{O}_{2}$ saturation readings were assumed to be indicative of seawater at $0 \% \mathrm{O}_{2}$ saturation. All seawater used during the calibration process was maintained at $26^{\circ} \mathrm{C}$, by placing the beakers containing the calibration seawater in a waterbath.

Once provided with values for temperature, salinity and the volume of water in the chamber, the Strathkelvin software automatically calculated the rate of $\mathrm{O}_{2}$ consumption or net production $\left(\mathrm{mg} \mathrm{O}_{2} \mathrm{~h}^{-1}\right)$ within the chamber. Water volume was measured at the end of the incubation by decanting the water into a measuring cylinder, so allowing for the various sizes of the coral nubbins in the $60 \mathrm{ml}$ chamber. Respiration, and gross photosynthesis (i.e. net photosynthesis + respiration) at $135 \mu \mathrm{mol}$ photons $\mathrm{m}^{-2} \mathrm{~s}^{-1}$ and 400 $\mu \mathrm{mol}$ photons $\mathrm{m}^{-2} \mathrm{~s}^{-1}$ were then divided by the surface area $\left(\mathrm{cm}^{2}\right)$ of the coral nubbin, to give rates in $\mathrm{mg} \mathrm{O}_{2} \mathrm{~cm}^{-2} \mathrm{~h}^{-1}$. Finally, the maximum $\mathrm{P}: \mathrm{R}$ ratio was calculated by dividing the maximum rate of gross photosynthesis (i.e. the rate at $400 \mu \mathrm{mol}$ photons $\mathrm{m}^{-2} \mathrm{~s}^{-1}$ ) by the respiration rate. This ratio was indicative of the potential for autotrophy, with a $\mathrm{P}: \mathrm{R}>1$ indicating autotrophy and a $\mathrm{P}: \mathrm{R}<1$ indicating a requirement for a heterotrophic carbon source.

\subsubsection{Alkalinity}

To understand how seawater acidification, via addition of $\mathrm{CO}_{2}$ versus $\mathrm{HCl}$, affects seawater chemistry, measurements of alkalinity were performed. A Mettler DL 70 titrator, 
with the addition of $0.01 \mathrm{~N} \mathrm{HCl}$ (containing 38 grams per $\mathrm{L}$ of $\mathrm{NaCl}$ ), was used to determine the alkalinity of the different seawater treatments. Alkalinity was measured 3 times per treatment on each of 4 days across the duration of the experiment, resulting in a total of 12 alkalinity measurements per treatment; more frequent measures of alkalinity were prevented by intermittent availability of the titrator.

\subsubsection{Statistics}

For the coral $\mathrm{CO}_{2}$-acidification experiment, significant changes in the various photophysiological parameters between 0 and 18 days were determined with a Student's T-test, with the test statistic calculated by hand. For the cultured zooxanthellae, simple linear regression was used to analyse indiscrete data with multiple time-points. The statistical software package $\mathrm{R}$ was used to perform this latter analysis, and diagnostic graphs were checked for normality and equal variance. T-tests were also utilised to gain a more detailed perspective on any differences between the various parameters at specific time-points. 


\subsection{Results}

\section{Whole corals}

\subsection{Zooxanthella density}

Over the 18-day trial, zooxanthella density remained constant for both the $\mathrm{pH} 8.1$ and $\mathrm{pH}$ 7.6 $\mathrm{CO}_{2}$ treatments (T-test, $\mathrm{p}>0.05$ ). At 18 days, the $\mathrm{pH} 7.6 \mathrm{CO}_{2}$ treatment had a $4 \%$ higher zooxanthella density than did the $\mathrm{pH} 8.1$ treatment, though this difference was insignificant (T-test, $\mathrm{p}>0.05)$ (fig. 2.13).

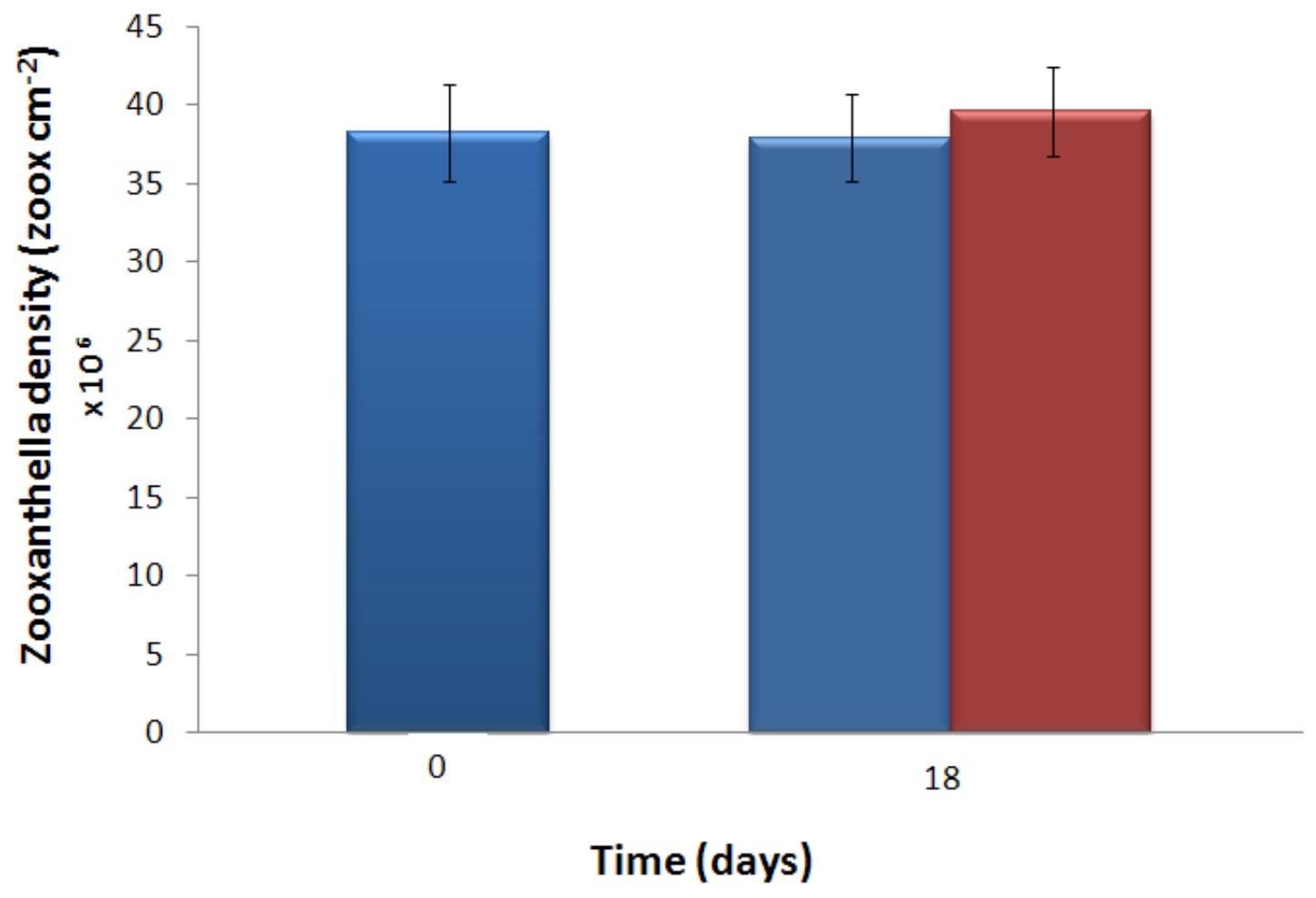

Figure 2.13: Density of zooxanthellae. Stylophora pistillata was treated at $\mathrm{pH} 8.1$ (blue) and $\mathrm{pH} 7.6 \mathrm{CO}_{2}$ (red). Densities were standardised per $\mathrm{cm}^{2}$ of coral skeleton surface. Values are means \pm SE. The experiment consisted of two time points over the 18 days with $n=12$ at Day 0 and $n=16$ at Day 18 . 


\subsubsection{Chlorophyll content per zooxanthella}

Over the duration of the experiment, chlorophyll concentration at $\mathrm{pH} 8.1$ did not change significantly (T-test, $\mathrm{p}>0.05$ ), despite a $15 \%$ increase between 0 and 18 days. However, in the $\mathrm{pH} 7.6 \mathrm{CO}_{2}$ treatment, there was a significant $25 \%$ increase in chlorophyll per zooxanthella between 0 and 18 days (T-test, $\mathrm{p}<0.01)$. Nevertheless, at 18 days, there was no distinguishable difference between the chlorophyll content per zooxanthella in the two treatments (T-test, $\mathrm{p}>0.05)$ (fig 2.14).

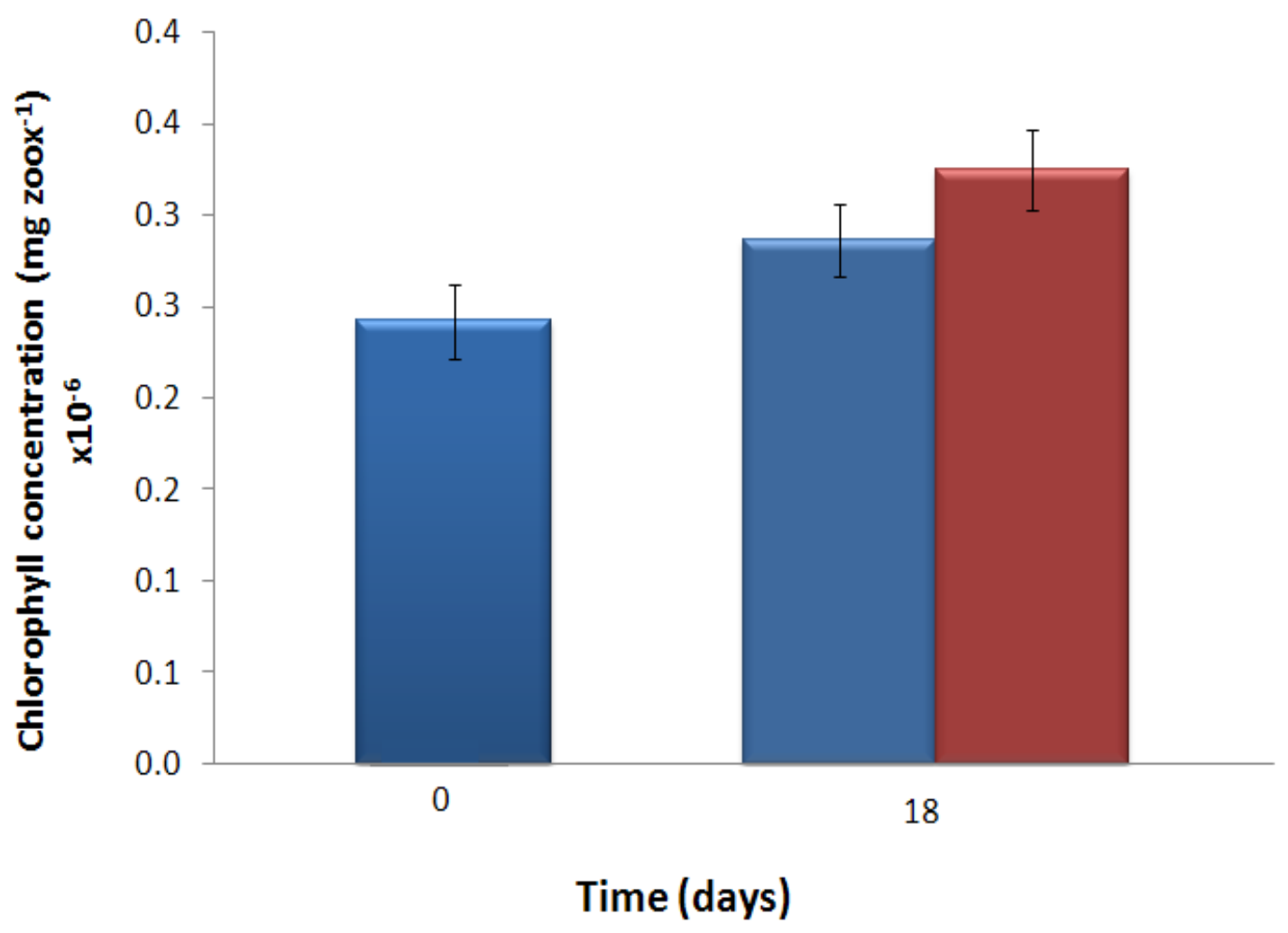

Figure 2.14: Chlorophyll content per zooxanthella cell. Stylophora pistillata was treated with $\mathrm{pH} 8.1$ (blue) and $\mathrm{pH} 7.6 \mathrm{CO}_{2}$ (red). Values are means \pm SE. The experiment consisted of two time points over the 18 day period with $n=12$ at 0 Days and $n=16$ at 18 Days. 


\subsubsection{Photosynthetic Health}

Photosynthetic yield $\left(\mathrm{Y}_{\mathrm{i}}\right)$ did not change over the 18 day experiment for either $\mathrm{pH} 8.1$ or $\mathrm{pH}$ 7.6 $\mathrm{CO}_{2}$ (T-test, $\left.\mathrm{p}>0.05\right)$. Moreover, there was no difference in $\mathrm{Y}_{\mathrm{i}}$ between the two treatments at 18 days (T-test, $\mathrm{p}>0.05$ ) (fig 2.15). At Day 0 , the average $\mathrm{Y}_{\mathrm{i}}$ of S. pistillata was 0.623 , while at Day 18 the average $\mathrm{Y}_{\mathrm{i}}$ was 0.622 and 0.622 for the $\mathrm{pH} 8.1$ and $\mathrm{pH} 7.6$ $\mathrm{CO}_{2}$ treatments, respectively.

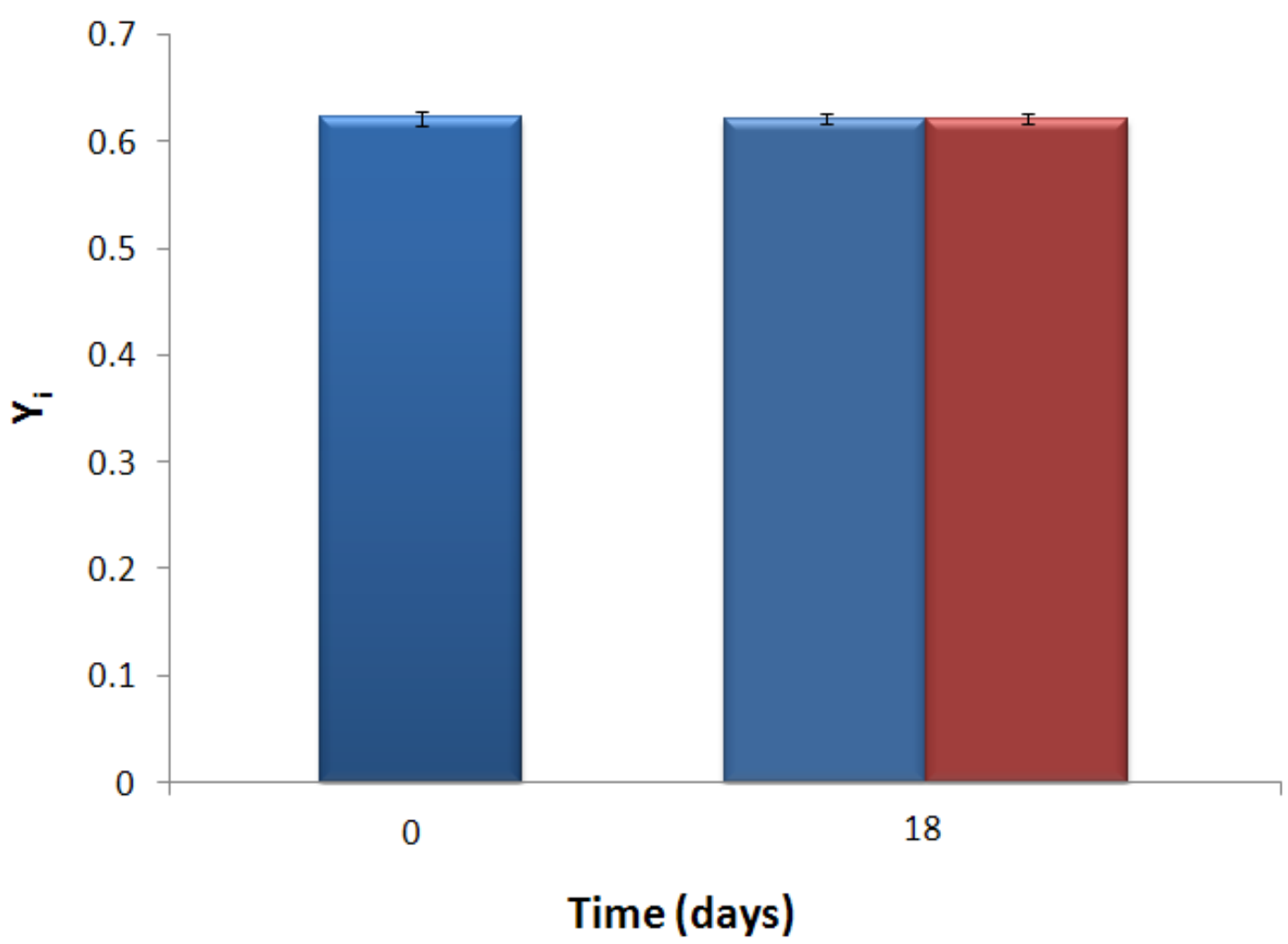

Figure 2.15: Photosynthetic health $\left(\mathrm{Y}_{\mathrm{i}}\right)$. Stylophora pistillata was treated with $\mathrm{pH} 8.1$ (blue) and $\mathrm{pH} 7.6 \mathrm{CO}_{2}$ (red). Values are means $\pm \mathrm{SE}$. The experiment consisted of two time points over the 18 days, with $n=12$ at 0 Days and $n=16$ at 18 Days. 


\subsubsection{Gross Photosynthesis}

There was no change in gross photosynthesis per zooxanthella for either of the $\mathrm{pH} 7.6$ $\mathrm{CO}_{2}$ or $\mathrm{pH} 8.1$ treatments (T-test, $\mathrm{p}>0.05$ ). Indeed, at 18 days, gross photosynthetic rates per cell were not significantly different between the two treatments (T-test, $p>0.05)$ (fig 2.16A).

There was no change in the rate of chlorophyll-specific gross photosynthesis for either treatment over 18 days (T-test, $\mathrm{p}>0.05$ ), despite measurements at Day 18 for the $\mathrm{pH} 7.6$ $\mathrm{CO}_{2}$ treatment being $22 \%$ lower than at the start of the treatment. Furthermore, at Day 18 , there was no significant difference in gross photosynthetic rate per unit chlorophyll between the two treatments (T-test, $\mathrm{p}>0.05)$ (fig 2.16B).

Despite an $11 \%$ higher gross photosynthetic rate in the $\mathrm{pH} 7.6 \mathrm{CO}_{2}$ treatment at 18 days than at the start of the experiment, there was no significant change with time for either $\mathrm{pH}$ treatment (T-test, $p>0.05)$. Similarly, total gross photosynthesis at the end of the experiment was $8 \%$ higher in the $\mathrm{pH} 7.6 \mathrm{CO}_{2}$ treatment than in the control, but this difference was again insignificant (T-test, $\mathrm{p}>0.05)$ (fig 2.16C). 

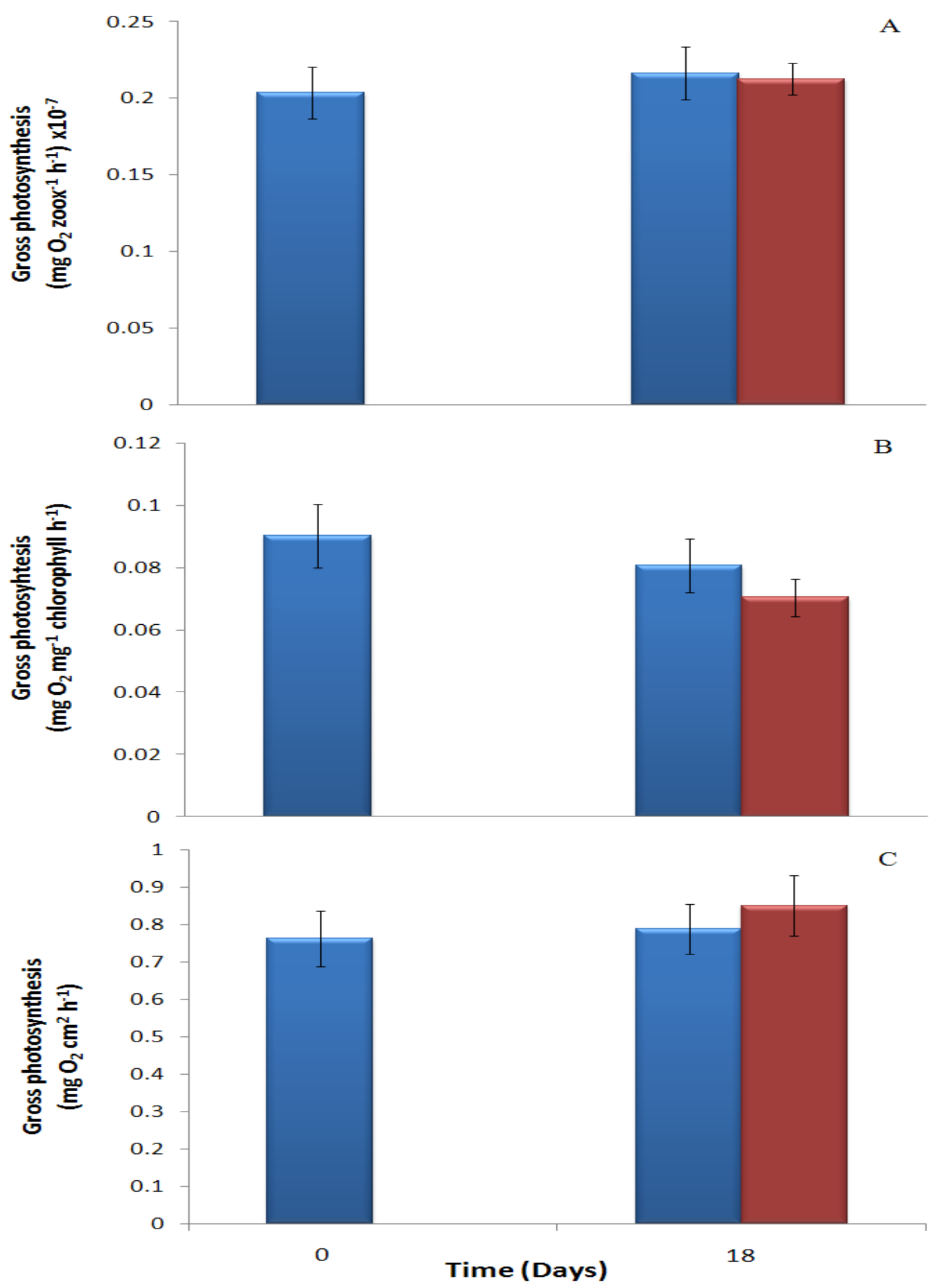

Figure 2.16: Gross Photosynthesis. A) Gross photosynthetic rate per zooxanthella cell; B) Gross photosynthesis per unit chlorophyll; and C) Total gross photosynthesis. Stylophora pistillata was treated with $\mathrm{pH} 8.1$ (blue) and $\mathrm{pH} 7.6 \mathrm{CO}_{2}$ (red). Values are means $\pm \mathrm{SE}$. The experiment consisted of two time points over the 18 days with $\mathrm{n}=12$ at Day 0 and $n=16$ at Day 18 . 


\subsubsection{Respiration}

There was no significant change in dark respiration rate between 0 and 18 days, at either $\mathrm{pH}$ (T-test, $\mathrm{p}>0.05$ for both treatments). However, at 18 days, the respiration rate of corals at $\mathrm{pH} 7.6 \mathrm{CO}_{2}$ was $19.5 \%$ higher than at the control $\mathrm{pH}$, and was hence significantly different (T-test, $\mathrm{p}<0.05)$ (fig. 2.17).

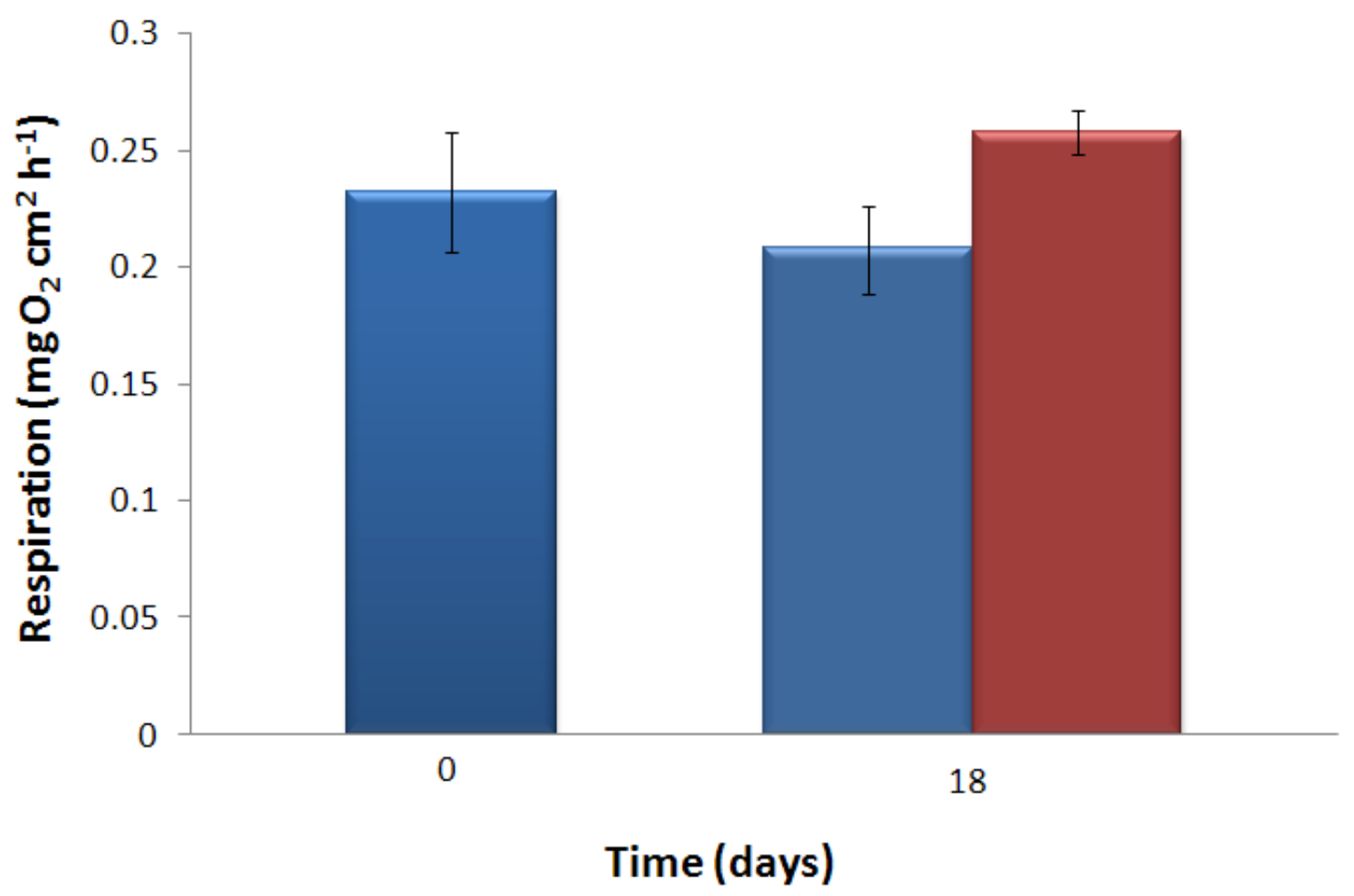

Figure 2.17: Dark respiration rate (R). Stylophora pistillata was treated with $\mathrm{pH} 8.1$ (blue) and $\mathrm{pH} 7.6 \mathrm{CO}_{2}$ (red). Values are means $\pm \mathrm{SE}$. The experiment consisted of two time points over the 18 days, with $\mathrm{n}=12$ at Day 0 and $n=16$ at Day 18. 


\subsubsection{P: $\mathrm{R}$ ratio}

Over the duration of the experiment, P:R increased markedly, by $17 \%$, at $\mathrm{pH} 8.1$ (T-test, $\mathrm{p}<0.05)$, but remained unchanged in the $\mathrm{pH} 7.6 \mathrm{CO}_{2}$ treatment (T-test, $\left.\mathrm{p}>0.05\right)$. Furthermore, in the $\mathrm{pH} 8.1$ treatment, $\mathrm{P}: \mathrm{R}$ was $20 \%$ higher at 18 days than it was in the $\mathrm{pH} 7.6 \mathrm{CO}_{2}$ treatment (T-test, $\mathrm{p}<0.05$ ). In all cases though, $\mathrm{P}: \mathrm{R}$ exceeded 1.5 , indicating that the corals remained potentially autotrophic with respect to carbon irrespective of the $\mathrm{pH}$ (fig 2.18).

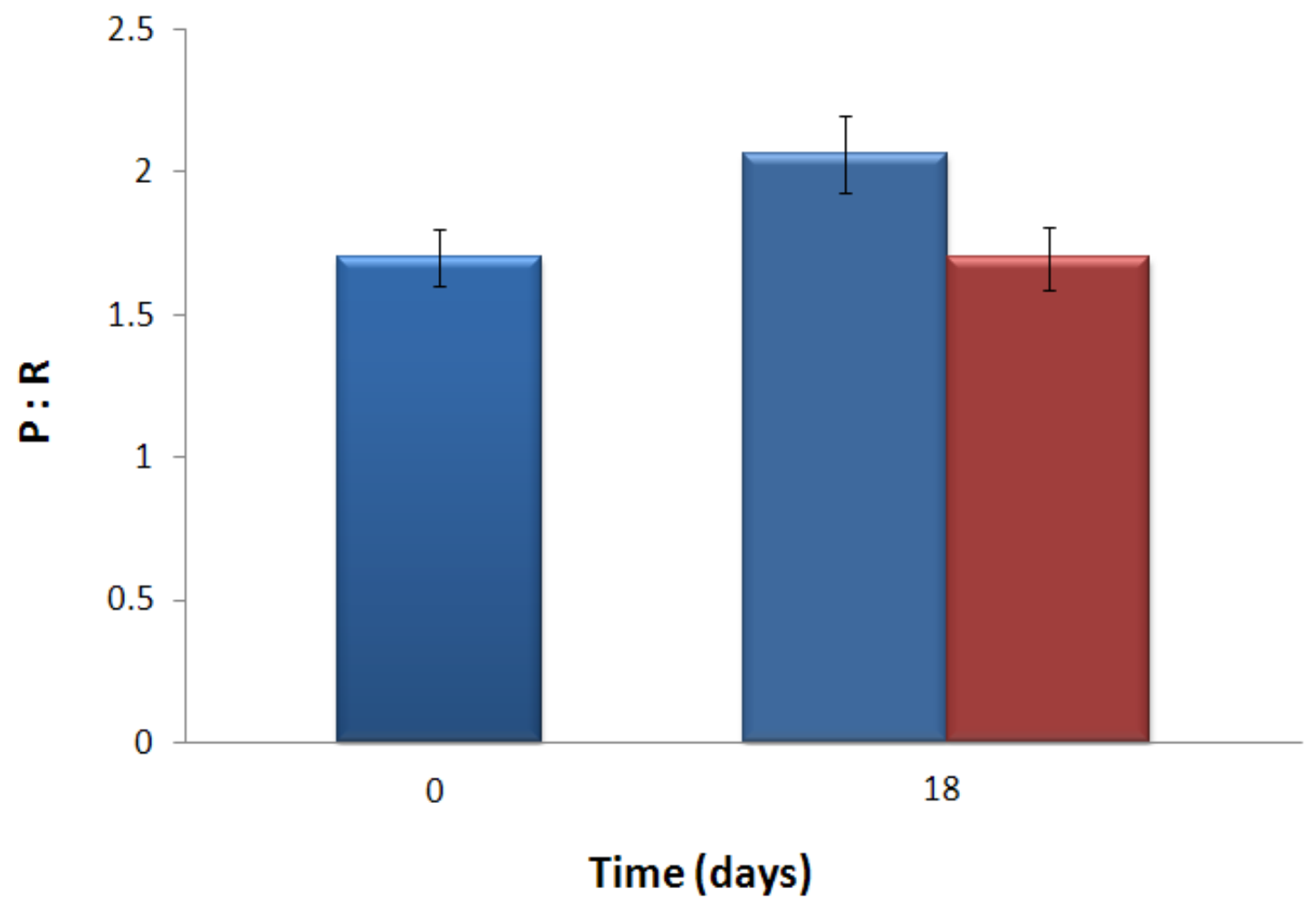

Figure 2.18: Gross photosynthesis $(\mathrm{P})$ to dark respiration (R) ratio. Stylophora pistillata treated with $\mathrm{pH} 8.1$ (blue) and $\mathrm{pH} 7.6 \mathrm{CO}_{2}$ (red). Values are means $\pm \mathrm{SE}$. The experiment consisted of two time points over the 18 days, with $\mathrm{n}=12$ at Day 0 and $\mathrm{n}=16$ at Day 18 . 


\subsubsection{Alkalinity}

The alkalinity of the $\mathrm{pH} 8.1$ and $\mathrm{pH} 7.6 \mathrm{CO}_{2}$ treatments did not differ significantly over the duration of the experiment (multiple T-test, $p>0.05$ ). At every time-point during the 18-day trial, the alkalinity of the $\mathrm{pH} 7.6 \mathrm{HCl}$ treatment averaged $12 \%$ lower than in the control and $\mathrm{pH} 7.6 \mathrm{CO}_{2}$ treatments (multiple T-test, $\mathrm{p}<0.001$ ) (fig 2.19).

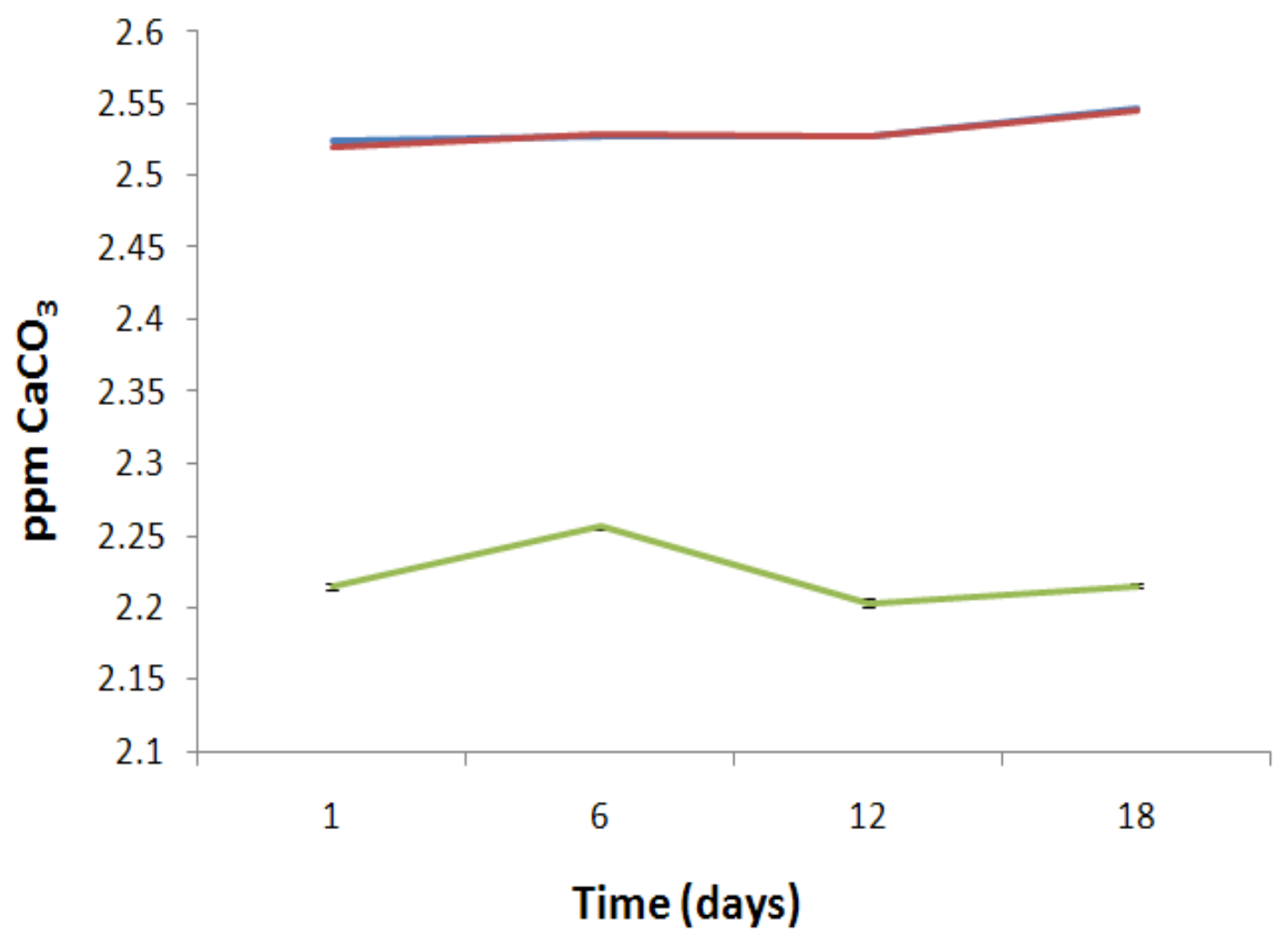

Figure 2.19: Seawater alkalinity. $\mathrm{pH} 8.1$ (blue), $\mathrm{pH} 7.6 \mathrm{CO}_{2}$ (red) and $\mathrm{HCl}$ (green). Values are means \pm SE. The experiment consisted of 4 time-points over an 18-day period; $\mathrm{n}=3$ per time-point. 


\section{Isolated zooxanthellae}

\subsubsection{Photosynthetic Health}

In both the $\mathrm{HCl}$ and $\mathrm{CO}_{2}$ trials, photosynthetic health $\left(\mathrm{Y}_{\mathrm{i}}\right)$ was consistent throughout at both $\mathrm{pH} 8.1$ and $\mathrm{pH} 7.6$ (linear regression $\mathrm{p}>0.05$ for both trials). Furthermore, the linear trends for the two $\mathrm{pH}$ levels did not differ in either trial ( $\mathrm{p}>0.05)$ (fig. 2.20).

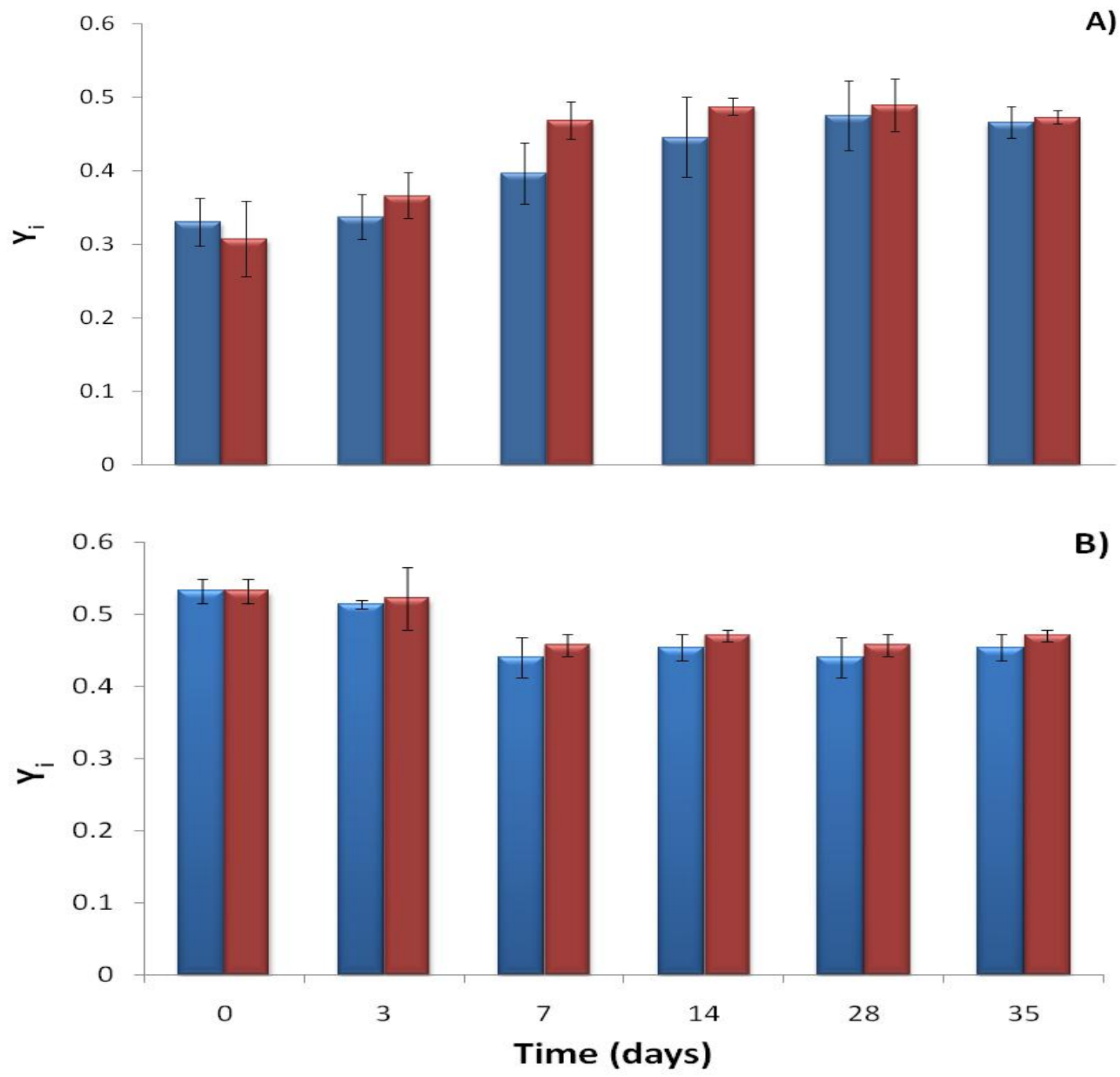

Figure 2.20: Photosynthetic health $\left(\mathrm{Y}_{\mathrm{i}}\right)$ of isolated (i.e. cultured) zooxanthellae versus $\mathrm{pH}$. Zooxanthellae isolated from Stylophora pistillata were treated with A) $\mathrm{pH} 8.1$ (blue) and $\mathrm{pH} 7.6 \mathrm{HCl}$ (red); and $\mathrm{B}$ ) $\mathrm{pH} 8.1$ (blue) and $\mathrm{pH} 7.6 \mathrm{CO}_{2}$ (red). Values are means \pm SE. The experiment consisted of 6 time-points over 35 days, with $n=6$ at Day 0 and $n=3$ at all other time-points. 


\subsubsection{Chlorophyll content}

In the $\mathrm{HCl}$ trial (fig 2.21A), chlorophyll per algal cell remained constant over time at $\mathrm{pH}$ 7.6 (linear regression, $\mathrm{p}>0.05$ ). In contrast, in the corresponding $\mathrm{pH} 8.1$ treatment, chlorophyll per algal cell increased with time (linear regression, $\mathrm{p}<0.05$ ), with the concentration being $64 \%$ higher at 35 days than at Day 0 . These opposing trends meant that, at the final two time-points, the chlorophyll concentration was 48 and 35\% lower, respectively, at $\mathrm{pH} 7.6$ than at the control $\mathrm{pH}$ (T-test, $\mathrm{p}<0.05)$.

In the $\mathrm{CO}_{2}$ trial (fig 2.21B), chlorophyll concentration per cell did not change significantly with time, at either the treatment or control $\mathrm{pH}$ (linear regression $\mathrm{p}>0.05$ ). However, there were differences between the chlorophyll concentrations in two treatments, largely because a slight but insignificant decline in the control. In particular, at Days 28 and 35, the chlorophyll concentration in the $\mathrm{pH} 7.6$ treatment was 41 and $45 \%$ higher, respectively, than in the $\mathrm{pH} 8.1$ control (T-test, $\mathrm{p}<0.05$ for both time-points).

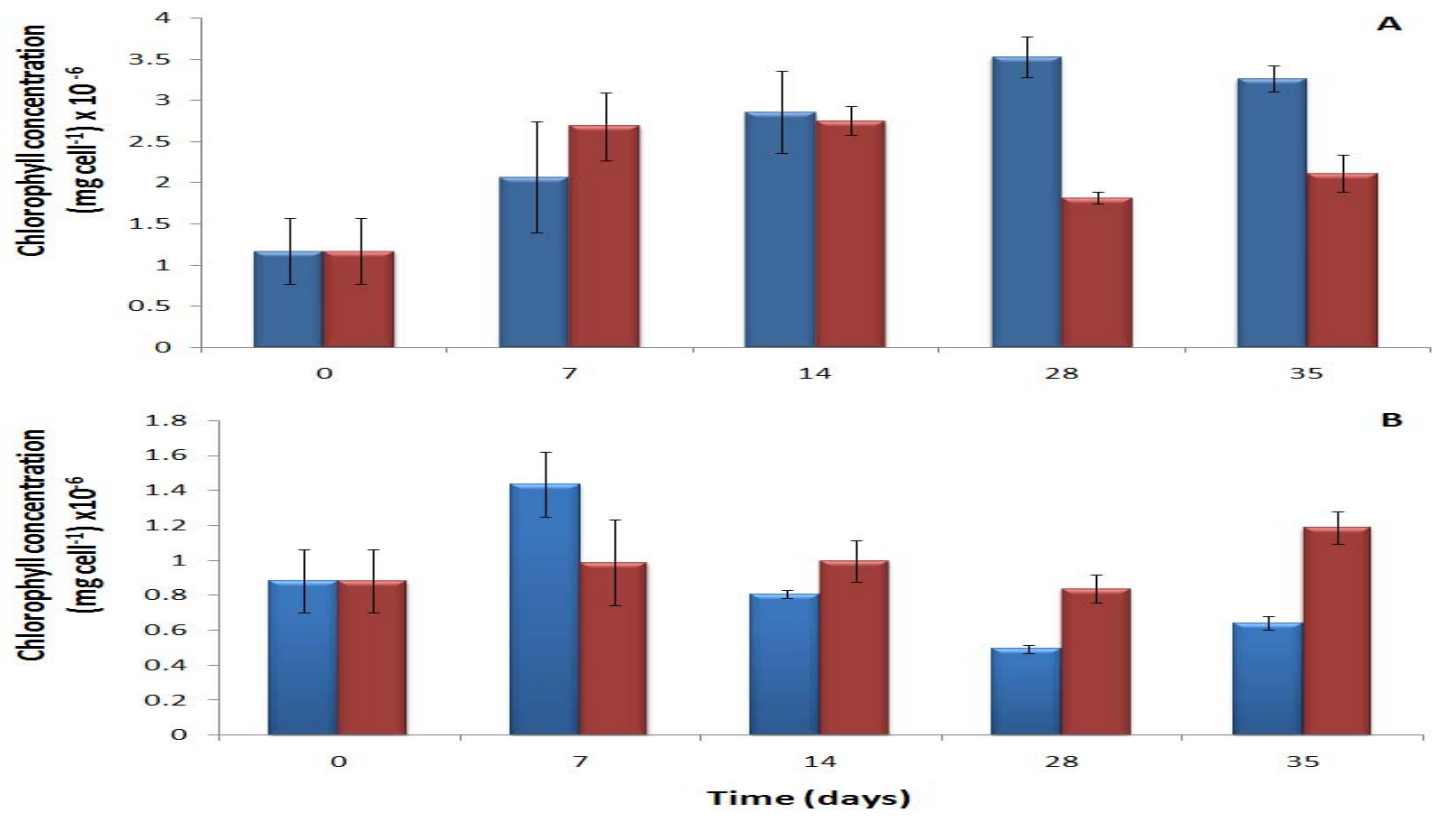

Figure 2.21: Chlorophyll concentrations per cell. Zooxanthella isolated from Stylophora. pistillata were treated with A) $\mathrm{pH} 8.1$ (blue) and $\mathrm{pH} 7.6 \mathrm{HCl}$ (red) and B) $\mathrm{pH} 8.1$ (blue) and $\mathrm{pH} 7.6 \mathrm{CO}_{2}$ (red). Values are means $\pm \mathrm{SE}$, the experiment consisted of 6 time-points over 35 days, $n=6$ at time 0 , otherwise $n=3$. 


\subsection{Discussion}

The experiments in this chapter were designed to assess any impact of acidification on the photophysiology of zooxanthellae in the coral S. pistillata, both while in symbiosis and in isolation (i.e. in culture). Moreover, as the addition of $\mathrm{HCl}$ affects seawater chemistry differently to the addition of $\mathrm{CO}_{2}$ (Kikkawa et al. 2003; Atkinson and Cuet 2008; Fabry 2008; Iglesias-Rodriguez et al. 2008), the experiments demonstrated any differential effects of these two treatments. Unfortunately, due to unforeseen circumstances, the $7.6 \mathrm{pH} \mathrm{HCl/intact} \mathrm{coral} \mathrm{trial} \mathrm{could} \mathrm{not} \mathrm{be} \mathrm{completed,} \mathrm{limiting} \mathrm{the}$ conclusions that can be drawn here, however the remaining experiments still revealed some interesting patterns.

\section{$\mathrm{CO}_{2}$ impacts on whole corals}

In S. pistillata, zooxanthella density did not change and chlorophyll levels per zooxanthella increased in the 18-day $\mathrm{pH} 7.6 \mathrm{CO}_{2}$ treatment. Similarly, in a 4-day study by Crawley et al. (2009), the coral Acropora formosa showed increased chlorophyll levels per zooxanthella and no increase in overall zooxanthella density. Due to the high densities of zooxanthellae within their host, it has been suggested that zooxanthellae could be carbon limited in hospite (Goiran et al. 1996), and since the $\mathrm{pH} 7.6 \mathrm{CO}_{2}$ treatment acted to increase carbon availability in the current experiment, this may help explain the increased chlorophyll concentration per zooxanthella. In S. pistillata, however, this did not translate into increased gross photosynthesis per cell or total gross photosynthesis, most likely because of the near-significant $(22 \%)$ decline in 
photosynthetic rate per unit chlorophyll. The reason for this chlorophyll-specific decline is unknown and in fact this trend seems inconsistent with the PAM data where the photosynthetic health $\left(\mathrm{Y}_{\mathrm{i}}\right)$ was amongst the least variable of all parameters measured. Indeed, there is current debate among photophysiologists about whether data recorded via PAM, which measures electron transport rate, are directly comparable with data recorded via an $\mathrm{O}_{2}$ electrode. Electrons sourced for the key stages of the dark reactions of photosynthesis are sourced from the splitting of water (Jones et el. 1999), and PAM quantifies this and allows for a rapid and non-invasive assessment of the photochemical efficiency of photosystem II (Jones et al. 1999). In these experiments, gross photosynthesis was derived by correcting net oxygen evolution rate for the corresponding rate of dark respiration. PAM fluorometry assumes that gross photosynthetic rate is represented by the electron transport rate at photosystem II, therefore omitting lightdependent alternative electron pathways, such as the oxygen-consuming Mehler reaction, mitochondrial respiration or the electron cycle around photosystem II (Wagner et al. 2006; Jakob et al. 2007). The range of alternative electron pathways, which are not detected by PAM, could explain why Jakob et al. (2007) highlighted that measuring gross photosynthesis, by detecting evolution of $\mathrm{O}_{2}$, includes the activity of "alternative" electron consuming reactions, and it is for this reason results obtained via an $\mathrm{O}_{2}$ electrode cannot be directly compared with results obtained via PAM fluorometry. More detailed biochemical assessment is necessary to reveal why gross photosynthesis per unit chlorophyll declined while photosynthetic health remained constant.

The autotrophic potential of $S$. pistillata when acidified was determined by the P:R ratio. Given that the rates of gross photosynthesis and respiration remained unchanged between 
0 and 18 days, $\mathrm{P}: \mathrm{R}$ also remained unchanged in the $\mathrm{pH} 7.6 \mathrm{CO}_{2}$ treatment. Somewhat surprisingly, however, $\mathrm{P}: \mathrm{R}$ increased in the control $\mathrm{pH} 8.1$ treatment and at 18 days it was $17 \%$ higher than in the $\mathrm{pH} 7.6 \mathrm{CO}_{2}$ treatment. This increase was not related to any increase in gross photosynthesis, which remained unchanged at this $\mathrm{pH}$ too, but instead to a small drop in the respiration rate. While this temporal drop was statistically insignificant, it was sufficient to result in the respiration rate at 18 days being $\sim 20 \%$ different between the two $\mathrm{pH}$ treatments. Why the respiration rate dropped in the control treatment is not obvious. One possibility, however, is that the coral nubbins were continuing to recover from their initial handling even after the start of the experimental period. This decline in respiratory rate may not have been seen in the acidified treatment because it was countered by a degree of physiological stress to the animal and/or algae, resulting in enhanced respiration. Importantly though, in both the control and acidified treatments, P:R remained considerably above the autotrophic threshold value of 1 . As a result, it seems that $S$. pistillata can continue to survive autotrophically (with respect to carbon at least) even under the long-term projections for ocean acidification. In a comparable study by Anthony et al. (2008), productivity (P:R) in the corals Acropora intermedia and Porites lobata, and the coralline alga Porolithon onkodes was reduced by doses of $\mathrm{CO}_{2}$ that resulted in acidification levels similar to those used here. These authors also tested for the synergistic effects of increased acidification and increased temperature. In marked contrast to the current study, using the 3 different coral species, they showed between a $30 \%$ (P. lobata) and almost $100 \%$ (A. intermedia and P. onkodes) reduction in productivity at the lowest experimental $\mathrm{pH}(\mathrm{pH} 7.60-7.70)$ and the lowest experimental temperature $\left(26^{\circ} \mathrm{C}\right)$; notably, the low $\mathrm{pH}$ and temperature were comparable to those used here. While at the same $\mathrm{pH}$, but the highest temperature $\left(29^{\circ} \mathrm{C}\right)$, productivity levels dropped even further, from a decrease of almost $100 \%$ (P. lobata and A. intermedia) to a 
decrease of $160 \%$ ( $P$. onkodes) (i.e. removing the alga's capacity for complete autotrophy). Also contrary to the current study, Anthony et al. (2008) claimed that these negative effects on productivity were a function of decreased photosynthesis rather than any major increase in respiration, which fluctuated by $<10 \%$. However, more similarly to S. pistillata, all three species described by Anthony et al. (2008) remained autotrophic while at a similar temperature and $\mathrm{pH}$ as used in the current experiment. Furthermore, two out of three species remained autotrophic when at the same $\mathrm{pH}$ but at the higher temperature. From this published study and this current work, it appears that corals and other coralline phototrophs have distinct physiological responses to acidification, with $S$. pistillata (this study) and P. lobata (Anthony et al. 2008) both showing relatively limited photophysiological responses to acidification ( $\mathrm{pH}$ 7.6) when compared to some other species. It is important to note though that more prolonged exposure to acidification could have induced more marked impacts in S. pistillata, and that Anthony et al.'s (2008) study ran for 8 weeks, rather longer than the 18 days of this current investigation.

\section{$\mathrm{CO}_{2}$ and isolated zooxanthellae}

Unlike the zooxanthellae in symbiosis, chlorophyll levels per cell in the isolated zooxanthellae did not increase with the addition of $\mathrm{CO}_{2}$ over the duration of the experiment, even after 35 days. However, chlorophyll levels declined by $27 \%$ in the $\mathrm{pH}$ 8.1 control treatment. This decline, although not significant, was enough to lead to a significantly lower chlorophyll concentration at $\mathrm{pH} 8.1$ than at $\mathrm{pH} 7.6$ towards the end of the experiment, suggesting that the zooxanthellae were beginning to bleach under the control conditions. Indeed, being maintained in seawater rather than a nutrient-enriched 
culture medium or inside the nutrient-rich intracellular environment of the host (i.e. in hospite), most likely led to physiological stress or nutrient-limitation for these algae. Indeed, the open ocean is subject to large fluctuations and low overall concentration of key critical nutrients such as nitrogen, but within the cytoplasm of the host coral, zooxanthellae avoid such fluctuations and can experience nutrient levels an order of magnitude higher than those available in the open ocean (Miller and Yellowlees 1989; Cook et al. 1994). Given this, it seems likely that the maintenance of steady chlorophyll concentrations in the $\mathrm{CO}_{2}$-treated zooxanthellae was assisted by this additional inorganic carbon supply. However, why this same decline was not seen in the control treatment in the $\mathrm{HCl}$ trial is unknown; indeed, the cellular chlorophyll content actually increased. This inconsistency between the two trials warns of drawing strong conclusions from a single experimental run and a single set of algal cultures.

\section{$\mathrm{HCl}$ and isolated zooxanthellae}

Acidification via $\mathrm{HCl}$ resulted in no negative effect on the photosynthetic health $\left(\mathrm{Y}_{\mathrm{i}}\right)$ of zooxanthellae isolated from S. pistillata, contrary to an expected impact of cellular acidosis. In comparison, chlorophyll levels per zooxanthella fluctuated and were significantly lower when compared to the controls, though there was no significant overall decrease. It was initially predicted that the lower alkalinity arising from acidification via $\mathrm{HCl}$ rather than $\mathrm{CO}_{2}$, and shown during the course of these experiments, would have greater potential for causing intracellular acidosis than acidification via $\mathrm{CO}_{2}$ - which by comparison maintains similar alkalinity levels to normal seawater but with higher levels of DIC. In turn, it was expected that acidosis would negatively impact upon 
the healthy operation of photosynthesis, with impacts for example on the function of ribulose-1,5-bisphosphate carboxylase $(\mathrm{RuBisCO})$ and membranes such as the thylakoid membranes of the chloroplast (May et al. 1986; Reaich et al. 1992; Mitch et al. 1994 and May et al. 1996; Patel et al. 2001; Doerr et al. 2005). Even in less extreme cases, a lowered $\mathrm{pH}$ may not necessarily denature an enzyme but may move it out of its optimal range of efficiency, thus reducing its activity (Irwin et al. 1994; Laffey et al. 2000; Wildbrett et al. 2003). There are many examples in the literature detailing how acidosis affects protein function. In animals it has been shown that denaturation of proteins in skeletal muscle and increased oxidation of amino acids, such as leucine, occurs with acidosis (May et al. 1986; Reaich et al. 1992; Mitch et al. 1994 and May et al. 1996); moreover, membrane function and repair may be hindered by extreme acidosis (Patel et al. 2001; Doerr et al. 2005) and the increased $\left[\mathrm{H}^{+}\right]$may cause lipid peroxidation (Hall et al. 1995). Further effects of acidosis have been reported in plants. For example, cytosolic acidification in plants triggers a reduction of carbon flow along the glycolytic pathway (Sakano 2001; Nocito 2008). Acidosis in plants has also been found to affect the enzyme L-galactono-gamma-lactone dehydrogenase (GAL), which is important for the formation of ascorbic acid, which acts as an antioxidant in plants, removing free radicals and preventing cellular damage (Ostergaard et al. 1997; Blokhina et al. 2003). The failure of these isolated zooxanthellae to show any signs of acidosis, at least in terms of their photosynthetic health $\left(\mathrm{Y}_{\mathrm{i}}\right)$, may well be related to their usual habitat inside the symbiosome membrane complex of their coral host. Indeed, very recently (Venn et al. 2009) it has been discovered, via the use of $\mathrm{pH}$-specific fluorescent probes and confocal microscopy, that the $\mathrm{pH}$ in $S$. pistillata, in the region surrounding the zooxanthellae, is just 7.13 in the dark and 7.41 in the light. Likewise, these same authors found that the $\mathrm{pH}$ in the symbiotic sea anemone Anemonia viridis was only 7.01 in the dark and 7.29 in the 
light. This important finding strongly suggests that the zooxanthellae are adapted to living in an acidic environment, and hence it is not as surprising as it first seemed that acidification had no impact on photosynthetic health in these isolated algae.

It is unfortunate that the failure to complete the whole coral/ $\mathrm{HCl}$ experiment prevented comparison with the isolated zooxanthellae $/ \mathrm{HCl}$ trial. In particular, on Day 17 of the whole coral experiment (i.e. less than 24 hours before the planned endpoint and just before the tanks were accidentally over-acidified), it was noted that the coral nubbins were extremely pale and showing signs of tissue or mucus sloughing. It may well be that the coral animal itself is more susceptible to acidification with $\mathrm{HCl}$ than are its zooxanthellae, and if so then degradation of the coral's tissues might introduce a secondary source of stress for the zooxanthellae. This interesting topic warrants further study.

\section{Ecological implications}

Whether in isolation or symbiosis, zooxanthellae from S. pistillata suffered no negative effects on photosynthetic health $\left(\mathrm{Y}_{\mathrm{i}}\right)$ in response to acidification caused by increased levels of $\mathrm{CO}_{2}$. Furthermore, in the intact corals, an increased concentration of chlorophyll at elevated $\mathrm{CO}_{2}$ levels was countered by a decrease in the chlorophyll-specific rate of photosynthesis, meaning that there was no impact on the total gross photosynthetic capacity of the coral. All of this suggests that acidification of the seawater to the longterm projected value of $\mathrm{pH} 7.6$ would have negligible impacts on the photophysiology of S. pistillata unless, as stated previously, impacts on the coral itself have secondary impacts on the zooxanthellae. However, if the coral itself was impacted and bleached as a 
consequence of acidification, this study indicates that the expelled zooxanthellae might retain their photosynthetic viability and the potential to infect new hosts. Such a scenario would be consistent with the so-called Adaptive Bleaching Hypothesis, where zooxanthellae form new symbioses after stress events that are better suited to the new environmental regime (Buddemeier and Fautin 1993).

It is of course important to discriminate between the impacts on symbiont photophysiology and other physiological impacts, especially those involving calcification. Zooxanthellae, like all dinoflagellates, have no calcium carbonate-based structures, so will remain unaffected by acidification in this respect. However their coral hosts will have to contend with reduced aragonite and calcite concentrations, and hence reduced rates of skeletogenesis. This fact means that coral reefs are still unlikely to persist in the face of acidification, and that the zooxanthellae would lose their endosymbiotic habitat. Indeed, even now zooxanthellae are rarely found in the free-living state, and when they are they tend to be close to their hosts, in low numbers and transient (Carlos et al. 1999; Savage et al. 2002). It would therefore seem likely that, unless symbiotic zooxanthellae rapidly evolve the ability to persist in the free-living state (which is highly improbable given the extent of host-symbiont integration), then they would become extinct along with their coral hosts.

To gain a better understanding of how S. pistillata and its zooxanthellae could be affected in the long term by seawater acidification, a longer-term study should be performed. This current study evaluated the effects arising from seawater acidification in the short term, and it would appear that some effects occur quite quickly. However, some other patterns, 
such as those relating to cellular chlorophyll content, were only just becoming apparent or were inconsistent between trials and over time. Clarification of these patterns requires longer-term study. Furthermore, the synergistic impacts of acidification and other environmental stressors (e.g. temperature) should be considered (Anthony et al. 2008). If environmental predictions are true, then seawater will become more acidic and warmer in the future (Hoegh-Guldberg et al. 2007), which may prove too much for most of the world's coral. Moreover, when global warming and acidification are considered alongside other environmental impacts such as sediment runoff, poorly managed tourism, destructive fishing practices and sea-level rise, then the future for S. pistillata, and other corals around the world looks bleak. Modelling the synergistic impacts of these various stressors is a major challenge for coral reef scientists in the immediate future. 


\section{Chapter III}

\section{PhOTOPHySiOLOGICAL RESPONSES OF THE TEMPERATE SEA ANEMONE ANTHOPLEURA AUREORADIATA TO SEAWATER ACIDIFICATION}

\section{I Introduction}

Climate change, which is the shift in global climatic patterns arising from excessive amounts of atmospheric $\mathrm{CO}_{2}$, poses a real threat to the long term survival of coral reefs. $\mathrm{CO}_{2}$ acts like an insulator heating the planet by trapping the Sun's energy. This process is natural, but with excessive anthropogenic $\mathrm{CO}_{2}$ emissions the planet is now heating at a much faster rate than what has been recorded in the last 10,000 years possibly longer (Petit et al. 1999; Epstein 2001). Rising sea surface temperatures can potentially promote coral disease and loss of the symbiotic algae from corals (bleaching) (Walther et al. 2002; Hughes et al. 2003). In 1997/98, it was estimated that as much as $16 \%$ of the world's coral reefs were damaged by human induced coral bleaching whereas, pre-1980s, widespread coral bleaching was considered uncommon (Buddemeier et al. 2004; Gierck 2007). This increased bleaching, and cases of coral disease, are not solely attributable to climate change, but rather a synergistic relationship with non-climatic stresses which humans also place upon reefs (Buddemeier et al. 2004; Hoegh-Guldberg et al. 2007; Nicholls et al. 2008). 
There is potentially an even greater threat to the world's coral reefs: ocean acidification. As already mentioned $\mathrm{CO}_{2}$ is a greenhouse gas which acts to alter the climate of the planet, but in addition to atmospheric storage $\mathrm{CO}_{2}$ also dissolves into the ocean. Therefore, as the rate at which $\mathrm{CO}_{2}$ is released to the atmosphere has intensified, so to has the amount being absorbed by the world's oceans, and there are early signs that this is beginning to overwhelm natural systems. $\mathrm{CO}_{2}$, when dissolved in water, undergoes a chain of simple chemical reactions and, when combined with $\mathrm{H}_{2} \mathrm{O}$, forms a carbonic acid which readily releases $\mathrm{H}^{+}$ions to the water, making it more acidic (Royal Society 2005). When an acid, such as carbonic acid, is added to seawater, the additional hydrogen ions react with available $\mathrm{CO}_{3}{ }^{2-}$ ions and convert them to $\mathrm{HCO}_{3}{ }^{-}$. This acts to reduce the concentration of hydrogen ions and hence limit the acidification that would have otherwise occurred (Royal Society 2005); this process is known as the carbonate buffer. However, with the ever increasing amount of $\mathrm{CO}_{2}$ added to seawater, the ability of the carbonate buffer to maintain a constant $\mathrm{pH}$ is reduced. This is due to the fact that, as more and more $\mathrm{CO}_{2}$ dissolves into seawater, the $\mathrm{CO}_{3}{ }^{2-}$ ions used to buffer against acidification are reduced in number, and so are not as readily available for maintaining the seawater's buffering capacity (Royal Society 2005).

As a result of this overwhelming of the carbonate buffer, oceans have decreased 0.1 of a $\mathrm{pH}$ unit since the Industrial Revolution (late-eighteenth to mid-nineteenth centuries), and are predicted to drop to $\mathrm{pH} 7.6$ by 2100 and beyond (Caldeira and Wickett 2003; Orr et al. 2005; Wood et al. 2008; Zeebe et al. 2008; Doney et al. 2009). This decrease in pH will make it very difficult for marine calicifiers to form their calcium carbonate structures, which are integral to their physiology (Orr et al. 2005; Hoegh-Guldberg et al. 2007). 
Since ocean acidification was highlighted by the Royal Society (2005), research in the area of ocean acidification impacts on marine calcification has grown exponentially; as a result it has left other potential physiological impacts of acidification somewhat understudied.

Contrary to the situation with calcification, increased levels of dissolved $\mathrm{CO}_{2}$ may increase rates of photosynthesis and algal/plant production. For example, Hall-Spencer et al. (2008) used volcanic $\mathrm{CO}_{2}$ vents, which locally acidified the water off the coast of Italy, as a natural in situ simulation of ocean acidification. Results identified that seagrass production was highest in areas of $\mathrm{pH} 7.6$ (i.e. acidified). Similarly, in a mesocosm (Palacious and Zimmerman 2007), the seagrass Zostera marina exhibited increased photosynthetic rates when exposed to elevated levels of dissolved $\mathrm{CO}_{2}$ for 45 days; over longer periods of time ( 1 year) increased production was manifested as increased belowground biomass and improved reproductive output. Also of note, an increase in dissolved inorganic carbon (DIC) concentration to 750 parts per million by volume (ppmv) (causing a decrease to $\mathrm{pH}$ 7.7) at least doubled the rate of photosynthesis in the coccolithophore Emiliania huxleyi (Iglesias-Rodriguez et al. 2008). Clearly it seems as though increased levels of $\mathrm{CO}_{2}$ may have the potential to enhance photosynthetic production of symbiotic algae in corals and other invertebrates, though little is known about this. While there has been a small amount of recent work on this issue in reef corals (Chapter 2, this study; Anthony et al. 2008; Crawley et al. 2009), there have been no such studies on other zooxanthellate invertebrates, either in the tropics or at other latitudes. 
At temperate latitudes, the same environmental factors that favour cnidariandinoflagellate symbiosis in tropical regions are not present. For instance, there are greater fluctuations of irradiance and temperature, and greater supplies of inorganic nutrients and particulate food. However, cnidarian-dinoflagellate symbiosis, exhibited mostly in sea anemones, is still ecologically dominant and very productive at some locations (MullerParker \& Davy 2001; Rodriguez-Lanetty et al. 2003), even though far fewer cnidarian species form such symbioses at high latitudes than in the tropics (Muller-Parker \& Davy 2001; Davy and Turner 2003). The biogeographical distribution of temperate zooxanthellate anemones in the Pacific Basin extends from Alaska $\left(60^{\circ} \mathrm{N}\right)$ to New Zealand $\left(45^{\circ} \mathrm{S}\right)$, and in the eastern Atlantic Basin extends from south and west Europe and as far north as Scotland (Muller-Parker \& Davy 2001). Temperate anemones have lower densities of zooxanthellae than their tropical counterparts, while the symbiosis seems to be more resistant to fluctuations in light and temperature (Muller-Parker \& Davy 2001; Muller-Parker et al. 2007). However, how these temperate symbioses respond to acidification is completely unknown. This is of interest given both their aforementioned robustness to environmental fluctuations, and the fact that high latitudes are predicted to suffer the effects of ocean acidification before the tropics (HoeghGuldberg et al. 2007; Sheppard 2008).

The aim of this study was to identify the photophysiological effects of seawater acidification on temperate zooxanthellae. Using a model organism, the temperate sea anemone Anthopleura aureoradiata sourced locally from the Wellington region (fig 3.6), it was hypothesised that seawater acidified using $\mathrm{CO}_{2}$, due to increased availability of photosynthetically important DIC, would have a positive effect on the photophysiology 
of $A$. aureoradiata, but that seawater acidified with $\mathrm{HCl}$, due to the decrease in $\mathrm{pH}$ and no corresponding increase in available DIC, would have a negative effect.

\subsection{Methods}

\subsection{Experimental organism}

A. aureoradiata is a common sea anemone found on mudflats throughout New Zealand, although it also frequents rocky shores. Due to a lack of hard substrate on mudflats, the anemone attaches itself to the shells of common bivalves (fig 3.1), especially the cockle Austrovenus stutchburyi, a filter-feeding bivalve that can occur at very high densities (up to $200 \mathrm{~m}^{-2}$ ). A. aureoradiata can reach an average height of up to $2-3 \mathrm{~cm}$ when fully extended and attaches to the cockle using its basal disk. Typically the cockle is a few centimetres or less from the sediment surface, allowing the anemone's tentacles to surface at high tide.

A. aureoradiata $(\mathrm{n}=150)$ was collected from Pauatahanui Inlet (Latitude: $-41^{\circ} 05 \mathrm{Min}$. 50 Sec. Longitude: $174^{\circ} 52 \mathrm{Min} .54 \mathrm{Sec}$; fig 3.2) at low tide during October 2008. Once brought back to Victoria University of Wellington, the anemones were housed in a $2 \mathrm{~L}$ specimen bowl, filled with $1-\mu \mathrm{m}$ filtered seawater (FSW). The anemones were maintained at $16 \pm 1^{\circ} \mathrm{C}$ and an irradiance of $250-300 \mu \mathrm{mol}$ photons $\mathrm{m}^{-2} \mathrm{~s}^{-1}$ on a $12 \mathrm{~h}$ light: $12 \mathrm{~h}$ dark cycle; light and temperature control was provided via a standard incubator. The anemones were fed on a diet of Great Salt Lake Artemia sp. nauplii (MacKay Marine 


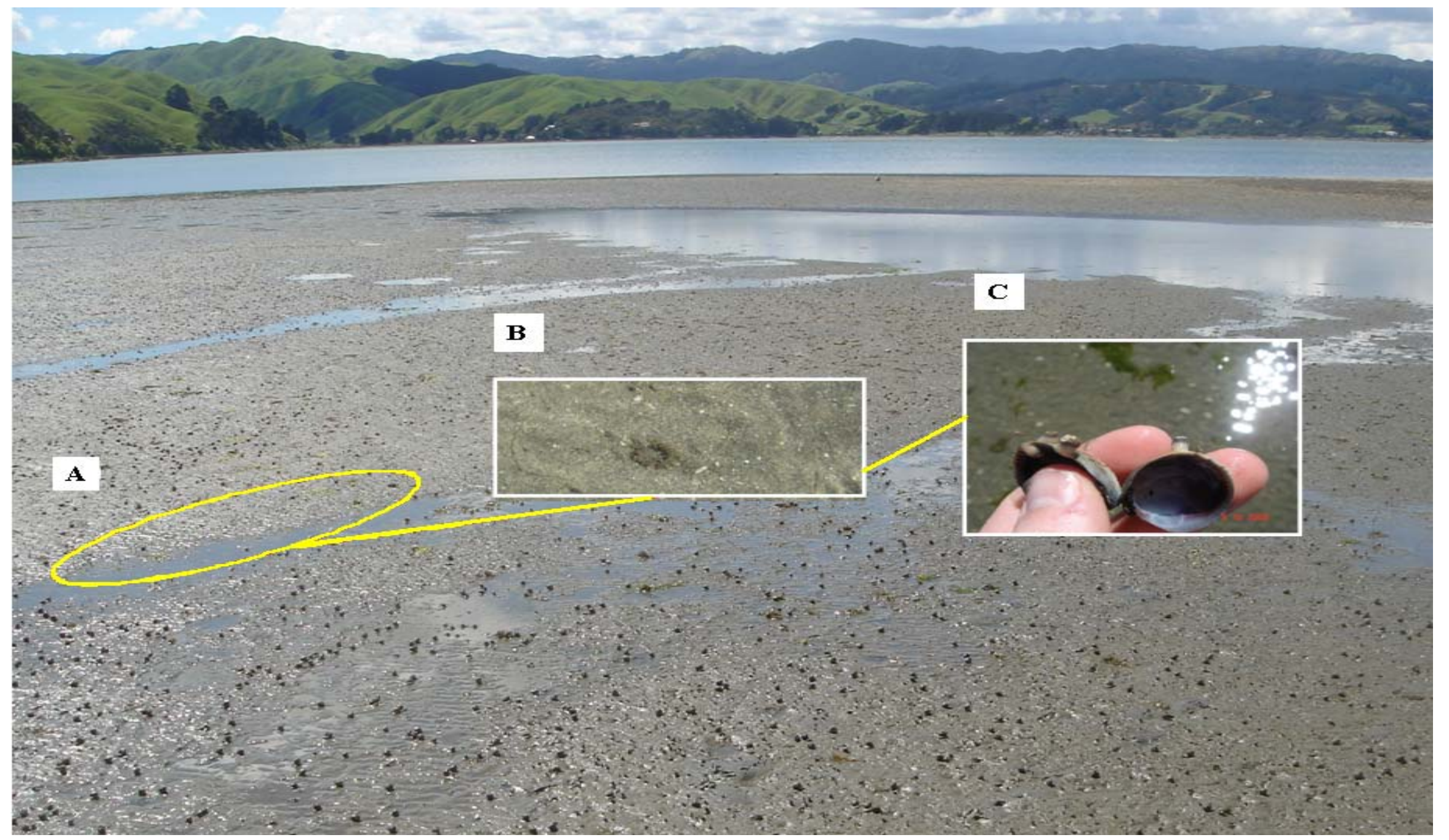

Figure 3.1: Pauatahanui Inlet at low tide. A) Typical shallow pools of water that Anthopleura aureoradiata is found in once the tide had receded. B) A. aureoradiata with its tentacles above the sediment surface layer. Note that the body of the animal is buried beneath the sediment. C) The anemone in B) when removed from the sediment, attached to a deceased cockle. A further three anemones were also attached to this cockle. 


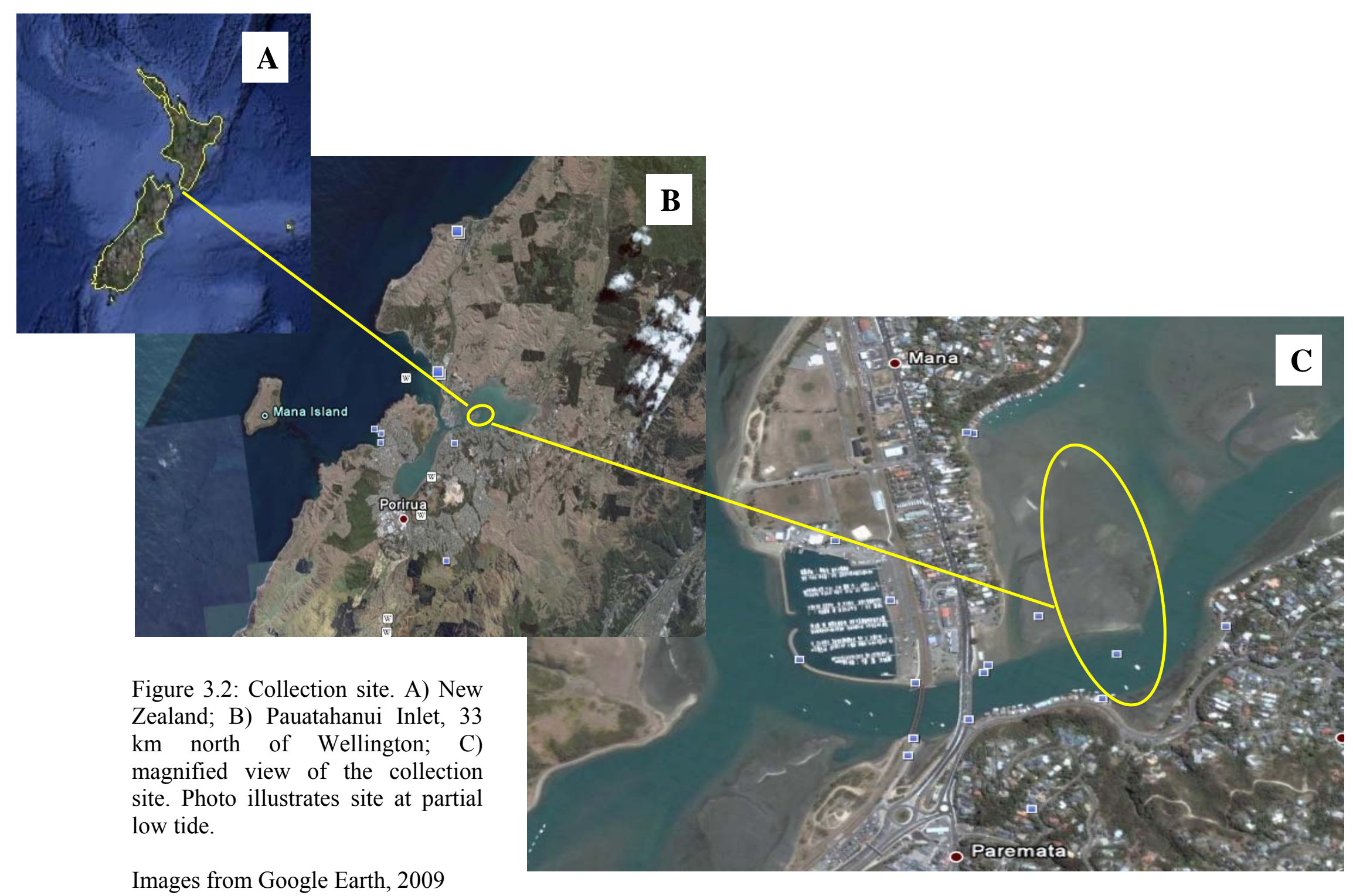


USA), with feeding every 5 days. The anemones were left to acclimate to this environment for 10 days before the commencement of any experimentation.

\subsubsection{Experimental design}

The whole set-up was housed in a temperature-controlled room. Two $200 \mathrm{~L}$ black plastic reservoir tanks were filled with FSW and each led to a single glass aquarium containing a further $25 \mathrm{~L}$ of FSW. Water was pumped from the bottom of each reservoir tank into the bottom of the corresponding aquarium, at a rate of $1 \mathrm{~L} \mathrm{~min}^{-1}$; the overflow from each aquarium was then returned to the surface of the reservoir tank. One reservoir tank contained untreated seawater at $\mathrm{pH} 8.1$ (the control) while the other contained acidified seawater at $\mathrm{pH} 7.6$; in the first experiment this $\mathrm{pH}$ was achieved by adding $\mathrm{HCl}$ while in the second experiment it was achieved by adding gaseous $\mathrm{CO}_{2}$. To acidify the seawater in the reservoir tank, a PINPOINT ${ }^{\circledR} \mathrm{pH}$ controller (American Marine Inc.) switched on either: 1) a peristaltic pump (fig 3.3) which triggered the addition of $10 \% \mathrm{HCl}$; or 2) a $\mathrm{CO}_{2}$ solenoid (Red Sea Pro) that delivered dissolved industrial-grade $\mathrm{CO}_{2}$ from a $6.8 \mathrm{~kg}$ cylinder. A powerful $35 \mathrm{~W}$ pond pump ensured complete mixing within each reservoir tank, while each aquarium had a small pump/filter within it to ensure further mixing; the pump also filtered out any debris and created a slight current that favoured anemone expansion. The $\mathrm{pH}$ of both the treatment and reservoir tanks was checked twice-daily with an independent $\mathrm{pH}$ probe, to ensure a $\mathrm{pH}$ of $7.6 \pm 0.01$, and all probes were recalibrated weekly. Temperature was maintained at $16 \pm 1^{\circ} \mathrm{C}$ via the temperature controlled room and a light regime of $12 \mathrm{~h}$ light:12 $\mathrm{h}$ dark regime at $275 \pm 25 \mu \mathrm{mol}$ photons $\mathrm{m}^{-2} \mathrm{~s}^{-1}$ was maintained via a light bank containing thirty-five $5 \mathrm{~W}$ LED lamps (Green Lights, Taiwan) (fig 3.4). 


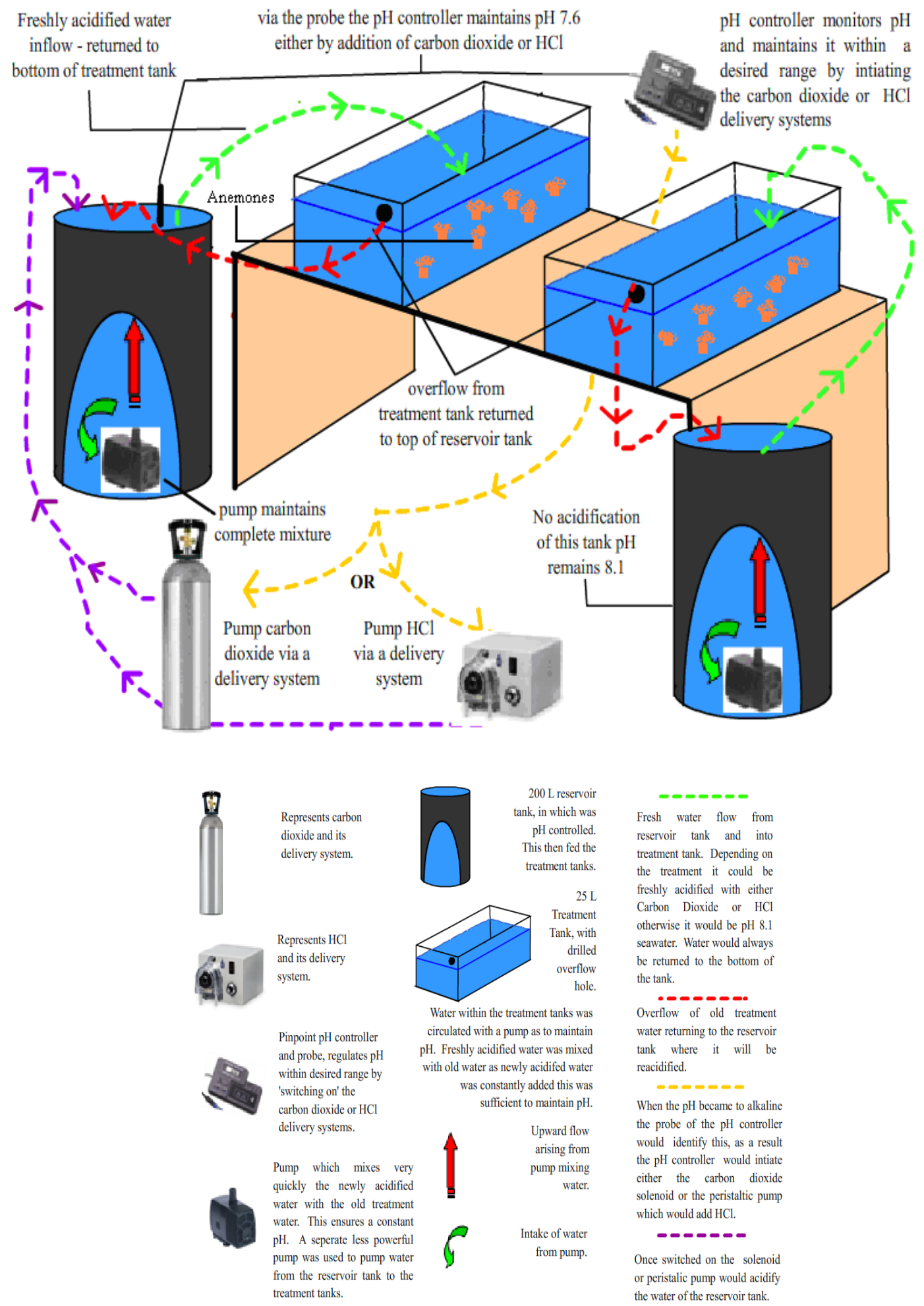

Figure 3.3: Experimental set-up. Experiment was left for a duration of 42 days for both the $\mathrm{pH} 8.1$ versus $\mathrm{pH} 7.6 \mathrm{HCl}$ and $\mathrm{pH} 8.1$ versus $\mathrm{pH} 7.6 \mathrm{CO}_{2}$ experiments. 


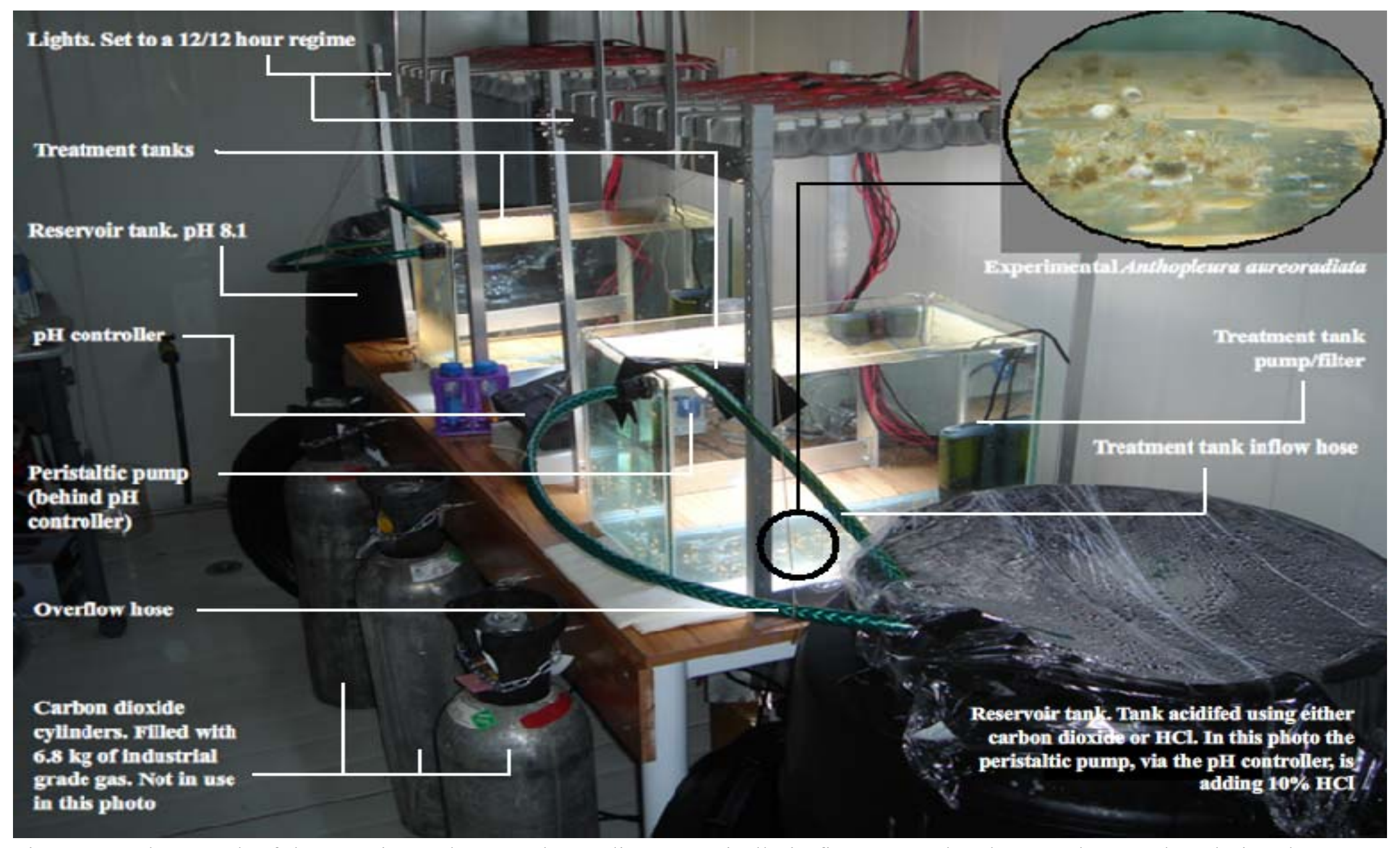

Figure 3.4: Photograph of the experimental set-up shown diagrammatically in figure 2.6. The photograph was taken during the $\mathrm{pH} 8.1$ versus $\mathrm{pH} 7.6 \mathrm{HCl}$ experiment, so the $\mathrm{CO}_{2}$ cylinders are not in use. The experimental set-up for the $\mathrm{pH} 8.1$ versus $\mathrm{pH} 7.6 \mathrm{CO}_{2}$ experiment was otherwise the same, except that the $\mathrm{pH}$ controller triggered a $\mathrm{CO}_{2}$ solenoid and hence the delivery of dissolved $\mathrm{CO}_{2}$ to the reservoir tank, rather than triggering the peristaltic pump to add $10 \% \mathrm{HCl}$. 
Once a steady $\mathrm{pH}$ was established, all experimental anemones $(\mathrm{n}=75)$ were placed in the pH 8.1 control aquarium for 10 days, after which 5 anemones were immediately sampled, and 35 were transferred into the $\mathrm{pH} 7.6$ aquarium (leaving 35 anemones at $\mathrm{pH} 8.1$ ). Anemones ( $\mathrm{n}=5$ per time-point per treatment) were sampled at 0,4 , and 7 days, and then every 7 days until Day 42. At each time-point, photosynthetic health, chlorophyll content per zooxanthella, and zooxanthellar density were measured as described below. The ratio of photosynthesis to respiration (P:R, a measure of autotrophic potential) was measured at 0 and 42 days only (fig 3.5).

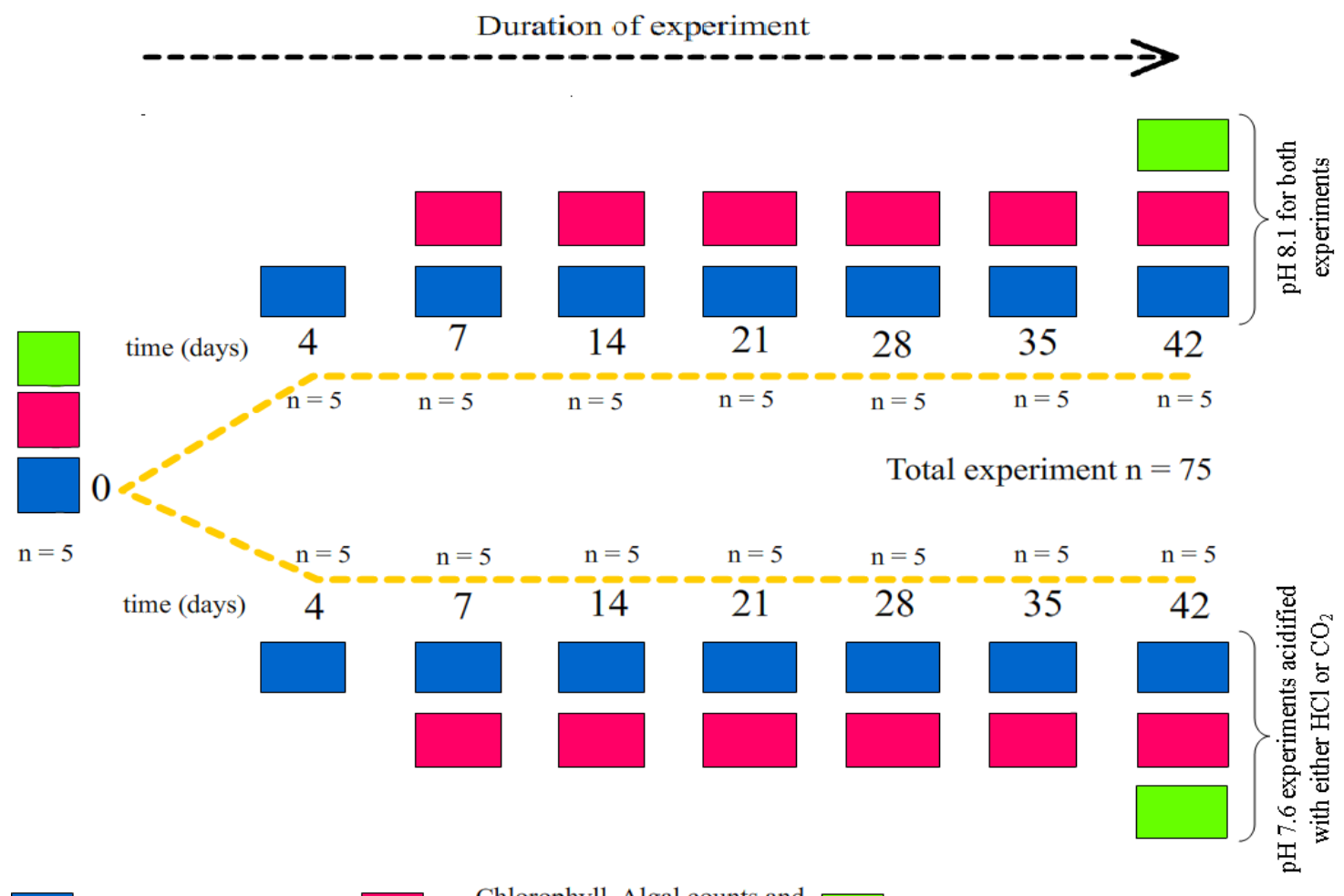

$=$ PAM conducted

protein algal counts and $=$ respirometry conducted

Figure 3.5: Experimental timeline. $\mathrm{pH} 8.1$ control conducted in tandem with a specific treatment - either $\mathrm{pH} 7.6 \mathrm{HCl}$ or $\mathrm{pH} 7.6 \mathrm{CO}_{2}$. Colour-coded boxes indicate what measurements were taken for each corresponding time-point, with 5 anemones processed per time-point per treatment. 


\subsubsection{PAM fluorometry}

Photosynthetic parameters of the zooxanthellae were measured with an Imaging Pulse Amplitude Modulated (IPAM) Fluorometer (Walz, model IAMG-MAX/1, Germany). Anemones from each treatment and time-point $(n=5)$ were placed into the IPAM immediately after treatment, without dark adaptation (fig 3.6). Light curves were constructed using exponential waiting-in-line fit, and the light curves used to estimate the light-saturated rate of photosynthesis $\left(\mathrm{P}_{\max }\right)$, the saturation irradiance $\left(\mathrm{I}_{\mathrm{k}}\right)$, and the photosynthetic efficiency (alpha, $\alpha$ ) for each anemone (via a standardised "area of interest"). The average of each of these parameters was then calculated for each timepoint and treatment. Imagaing PAM was set as follows: Measuring light intensity 2; Saturation Pulse Intensity 10; Gain 5; Damping 4 and 30 second intervals between measuring light pulses.

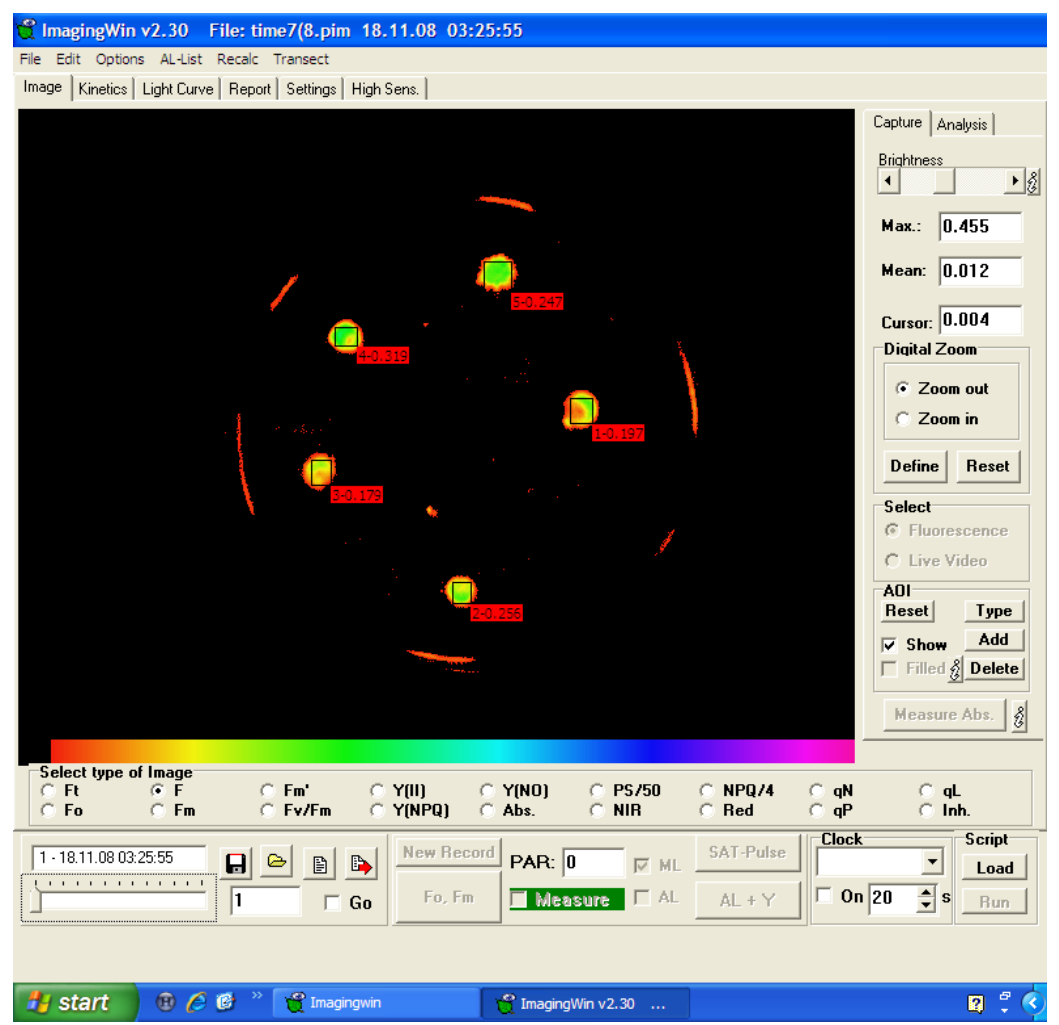

Figure 3.6: View of Anthopleura aureoradiata anemones) under the IPAM fluorometer. The partial red ring encircling the anemones is light scatter from the Petri dish in which the anemones were placed. The black rectangles are the "areas of interest". 


\subsubsection{Zooxanthellar counts and density}

Each anemone was ground in $10 \mathrm{ml}$ of FSW in a hand-held glass tissue grinder and, using a vortexer, the resulting slurry was thoroughly mixed. Sub-samples $(n=8 \times 100 \mu 1)$ of each slurry were taken for algal counts, conducted via light microscopy with a haemocytometer (Weber Scientific Instruments, England). These numbers were then used to calculate: 1) density of algae per ng of anemone protein; 2) concentration of chlorophyll per algal cell; and 3) gross photosynthesis per algal cell.

To enable calculation of the zooxanthellar density (to test for evidence of photoacclimatory changes or bleaching) it was necessary to measure the protein content of each anemone. To do this, the remaining $9.2 \mathrm{ml}$ of slurry were centrifuged at $\times 7,500 \mathrm{~g}$ for 5 minutes. A sub-sample $(5 \mathrm{ml})$ of the supernatant (animal fraction) was then pipetted off and kept aside. The algal pellet was re-suspended in the remaining $4.2 \mathrm{ml}$ of supernatant, to further remove animal contamination from the algal cells, and centrifuged at $\mathrm{x} 7,500 \mathrm{~g}$ for another 5 minutes. The secondary supernatant was added to the primary supernatant and made up to $10 \mathrm{ml}$ by the addition of $\sim 800 \mu \mathrm{l}$ of FSW. Two $1.5 \mathrm{ml}$ subsamples were taken from this $10 \mathrm{ml}$ sample and frozen in Eppendorf microfuge tubes; the pellet of zooxanthellae was also frozen, and the remaining $7 \mathrm{ml}$ solution was discarded. One of the two $1.5 \mathrm{ml}$ animal fraction samples (the other was kept as a back-up) was defrosted, poured into a $10 \mathrm{ml}$ tube, and diluted 6-fold with FSW. The solution was thoroughly mixed with a vortexer, decanted into a glass quartz cuvette, and the absorbances at 235 and $280 \mathrm{~nm}$ measured with a spectrophotometer. Equation 3.1 was used to calculate the protein content of the original $10 \mathrm{ml}$ solution (i.e. the total protein content of the sea anemone): 
Where:

$\mathrm{P}=$ protein content of original $10 \mathrm{ml}$ solution (total protein of anemone in $\mathrm{ng}$ )

$\mathrm{DF}=$ dilution factor

$\mathrm{V}=$ Volume of original supernatant

$\mathrm{A}_{235} / \mathrm{A}_{280}=$ Absorbance at either 235 or $280 \mathrm{~nm}$

In addition to calculating zooxanthellar density, the protein content was also used for standardising the chlorophyll content of each anemone, and rates of photosynthesis and respiration.

\subsubsection{Chlorophyll analysis}

Chlorophyll concentration, when normalised per algal cell or per ng of anemone protein, provided further insight into the impacts of acidification on photophysiology. Falcon tubes $(15 \mathrm{ml})$ containing the algae isolated from each anemone (as per section 3.2.4) were wrapped in tin foil, to prevent light-induced degradation of chlorophyll. Acetone $(2 \mathrm{ml})$ was added to each tube, and the tubes shaken and then placed in a fridge $\left(3 \pm 1{ }^{\circ} \mathrm{C}\right)$ for 24 hours. The following day, the tubes were centrifuged at $5^{\circ} \mathrm{C}$ and $\mathrm{x} 7,500 \mathrm{~g}$ for 12 minutes, to pellet cellular debris, and $1.2 \mathrm{ml}$ of the resulting supernatant was pipetted from each tube into an acetone-proof cuvette. Using a spectrophotometer, absorbance was measured at $630 \mathrm{~nm}, 663 \mathrm{~nm}$ and $750 \mathrm{~nm}$, where absorbance at $750 \mathrm{~nm}$ was indicative of background turbidity. The concentrations of chlorophylls $a$ and $c 2$ were then calculated according to Equations 3.2 and 3.3. 
Chlorophyll $a(\mathrm{mg}$ per $\mathrm{ml})=\left(11.43 \times\left(\mathrm{A}_{663}-\mathrm{A}_{750}\right)\right)-\left(0.64 \times\left(\mathrm{A}_{630}-\mathrm{A}_{750}\right)\right)$ [Equation 3.2]

Chlorophyll $c_{2}(\mathrm{mg}$ per $\mathrm{ml})=\left(27.09 \times\left(\mathrm{A}_{630}-\mathrm{A}_{750}\right)\right)-\left(3.63 \times\left(\mathrm{A}_{663}-\mathrm{A}_{750}\right)\right)[\mathrm{Eq} .3 .3]$

Chlorophyll $a$ and $c 2$ per anemone were calculated from these concentrations and the total volume of acetone in which the extraction occurred $(2 \mathrm{ml})$, and total chlorophyll was calculated by adding together the amounts of these two chlorophylls. Chlorophyll per algal cell and chlorophyll per ng of anemone protein were then calculated by dividing the total chlorophyll content by the total algal numbers or the protein content of each anemone.

\subsubsection{Respirometry}

The ratio of maximum gross photosynthesis to respiration (P:R, an indicator of autotrophic potential) was measured at 0 and 42 days. At these time-points, each anemone was placed individually in a $30 \mathrm{ml}$ transparent Perspex respirometry chamber (fig 3.7B) with FSW. The anemone sat on a piece of plastic mesh above a magnetic spin bar, and the whole chamber was placed on a submersible magnetic stirrer (Variomag Compact) in a transparent water bath at $16^{\circ} \mathrm{C}$. A rubber bung was placed firmly into the chamber, forming an air-tight seal, and a temperature probe and $\mathrm{O}_{2}$ electrode were placed through the bung and into the water. 


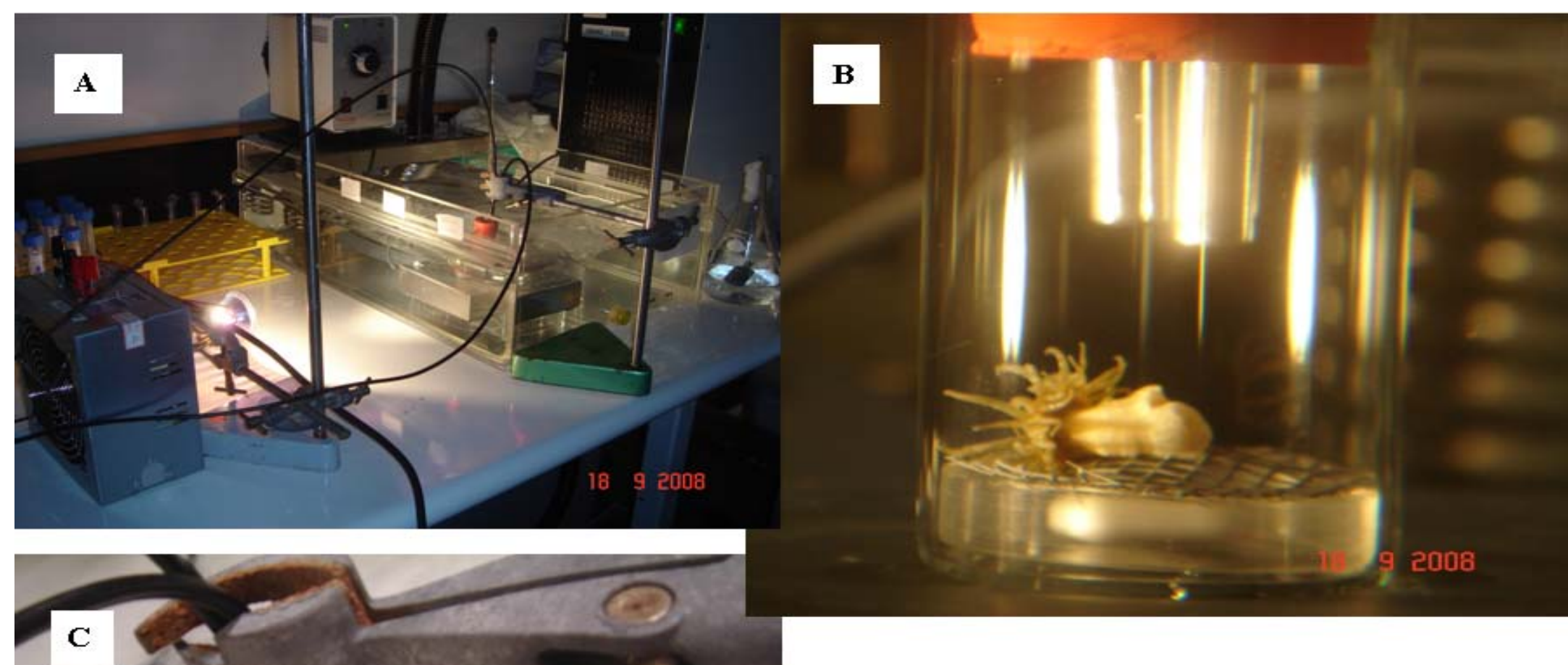

Figure 3.7: Respirometry. A) The respirometry set-up within the laboratory. B) Anthopleura aureoradiata in an $\mathrm{O}_{2}$ chamber, and the electrodes measuring the temperature and the dissolved $\mathrm{O}_{2}$ content. The chamber was illuminated at $300 \mu \mathrm{mol}$ photons $\mathrm{m}^{-2}$ $\mathrm{s}^{-1}$; and C) A. aureoradiata within its $\mathrm{O}_{2}$ chamber covered in tin foil, for measuring respiration rates in darkness. 
The oxygen and temperature sensors were calibrated to a $0 \%$ oxygen state using $1 \mathrm{~g}$ $\mathrm{Na}_{2} \mathrm{SO}_{3}$ per $100 \mathrm{ml} \mathrm{FSW}$, and stirring for 30 seconds. Alternatively, preparation for oxygen-saturated state involved using an air pump to circulate air through $500 \mathrm{ml}$ of FSW for an hour to provide surplus oxygenated FSW for measurements. To measure dark respiration, aluminium foil was wrapped around the $\mathrm{O}_{2}$ chamber to ensure that no light entered (fig 3.7C), and the anemone was allowed to settle for 10 minutes. The Fibox 3 temperature-compensated oxygen meter (PreSens, Germany) was then switched on and the dissolved $\mathrm{O}_{2}$ content $\left(\% \mathrm{O}_{2}\right.$ saturation) of the seawater was measured for at least 20 minutes, to obtain a constant respiration rate. The foil was then removed and the chamber illuminated at a photosynthesis-saturating irradiance of $300 \mu \mathrm{mol}$ photons $\mathrm{m}^{-2} \mathrm{~s}^{-1}$ (Fig 3.7A); the dissolved $\mathrm{O}_{2}$ content was then measured for a further 20 minutes to obtain the rate of maximum net photosynthesis.

These respiratory and net photosynthetic fluxes were then converted to rates of $\mathrm{mg} \mathrm{O}_{2}$ anemone $\mathrm{e}^{-1} \mathrm{~h}^{-1}$, by measuring the exact volume of FSW in the chamber with a measuring cylinder, and using standard conversion factors $\left(\% \mathrm{O}_{2}\right.$ to $\left.\mathrm{mg} \mathrm{O} \mathrm{O}_{2}\right)$ for seawater at $35 \mathrm{ppt}$ and $16^{\circ} \mathrm{C}$. Gross photosynthesis was calculated by adding the respiratory rate to the net photosynthetic rate, and this value was divided by the respiratory rate to give P:R. A P:R of $>1$ was indicative of autotrophy with respect to carbon. The gross photosynthetic rate was divided by the number of zooxanthellae in the anemone, to give gross photosynthesis per cell $\left(\mathrm{mg} \mathrm{O}_{2} \mathrm{zoox}^{-1} \mathrm{~h}^{-1}\right)$. This value was of use for comparing with changes in chlorophyll content and overall photosynthetic production, to gain more detailed insight into any photophysiological responses to acidification. 


\subsubsection{Statistics}

Simple linear regression was used to analyse data with multiple time-points, and hence to identify any temporal trends and significant differences (if any) between these trends. The simple linear regression was performed using the statistical software package $\mathrm{R}$, and diagnostic graphs were checked for normality and equal variance. Student's T-test was used as an effective way of comparing two means that were discrete from each other; this test statistic was calculated by hand. 


\subsection{Results}

\subsection{Zooxanthella density}

In the $\mathrm{HCl}$ acidification experiment, there was a decrease in zooxanthella density over the 42-day period at both $\mathrm{pH} 8.1$ and $\mathrm{pH} 7.6$ ( $\mathrm{p}<0.0001$ for both treatments; fig. 3.8A). There was no difference between these trends $(p>0.05)$. There was also a decrease in zooxanthella density in the $\mathrm{CO}_{2}$ acidification experiment, in both the $\mathrm{pH} 8.1(\mathrm{p}<0.0001)$ and $\mathrm{pH} 7.6 \mathrm{CO}_{2}(\mathrm{p}<0.0001)$ treatments $($ fig. 3.8B), though of considerable note the decline was less marked in the $\mathrm{CO}_{2}$ treatment than in the control $(\mathrm{p}<0.05)$.

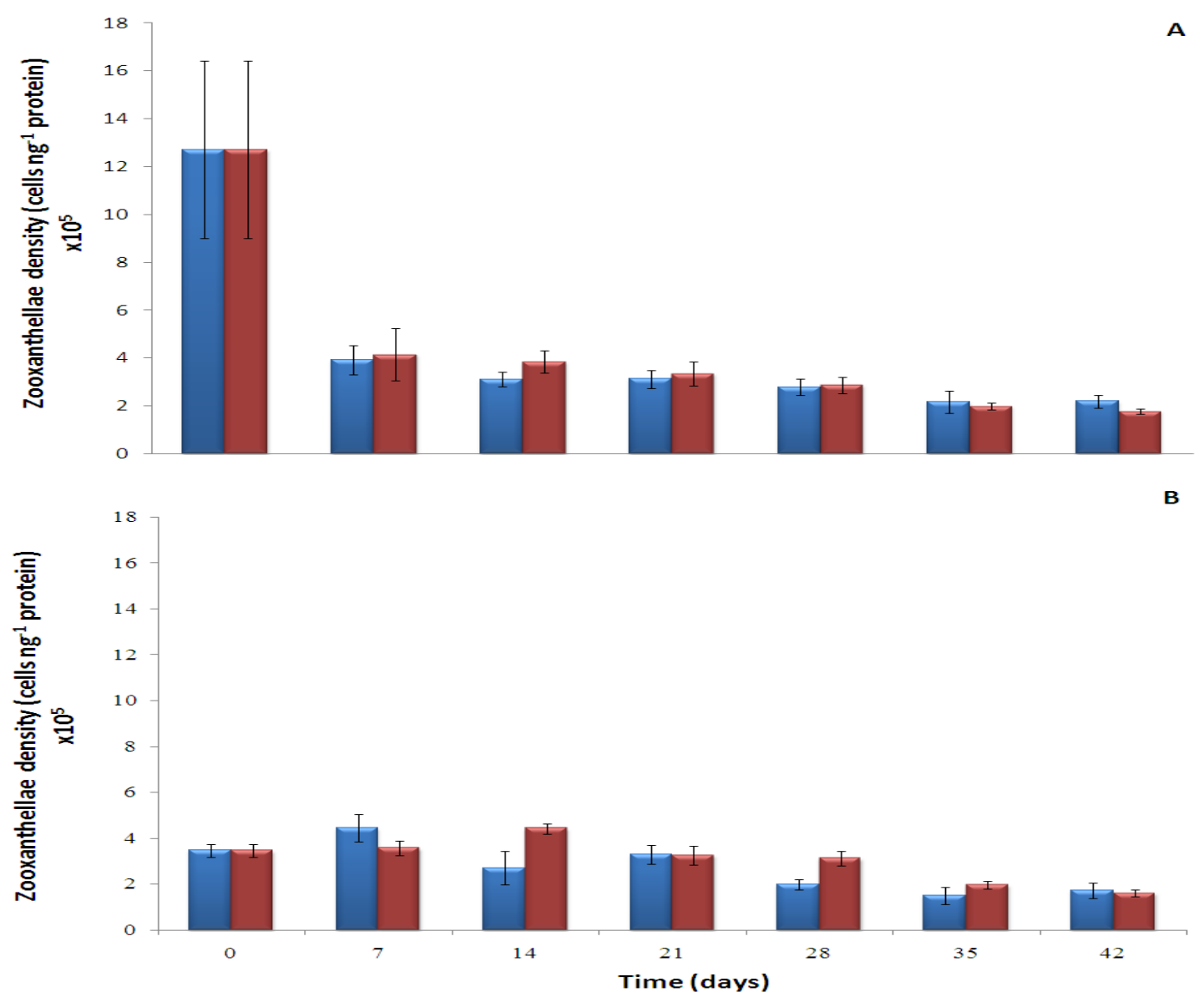

Figure 3.8: Zooxanthella density in response to seawater acidification by $\mathrm{HCl}$ and $\mathrm{CO}_{2}$. A) $\mathrm{pH} 8.1$ (blue) and $\mathrm{pH} 7.6 \mathrm{HCl}$ (red). B) $\mathrm{pH} 8.1$ (blue) and $\mathrm{pH} 7.6 \mathrm{CO}_{2}(\mathrm{red})$. Values are means $\pm \mathrm{SE} ; \mathrm{n}=5$ per time-point. 


\subsubsection{Chlorophyll content}

When acidified to $\mathrm{pH} 7.6$ with $\mathrm{HCl}$, there was no significant change in chlorophyll per ng anemone protein, even though on average it declined markedly, by $46 \%$ (fig. 3.9A). This was the same at $\mathrm{pH} 8.1$ in this same experiment, where no significant change was identified in the chlorophyll content $(\mathrm{p}>0.05)$; consequently the two trends were not significantly different $(\mathrm{p}>0.05)$. Figure $3.9 \mathrm{~B}$ shows that there was a significant decrease in chlorophyll content per ng anemone protein at both $\mathrm{pH} 7.6 \mathrm{CO}_{2}(\mathrm{p}<0.05)$ and $\mathrm{pH} 8.1$ in this experiment $(\mathrm{p}<0.001)$; of note, the rates of chlorophyll loss were similar in both treatments $(p>0.05)$.

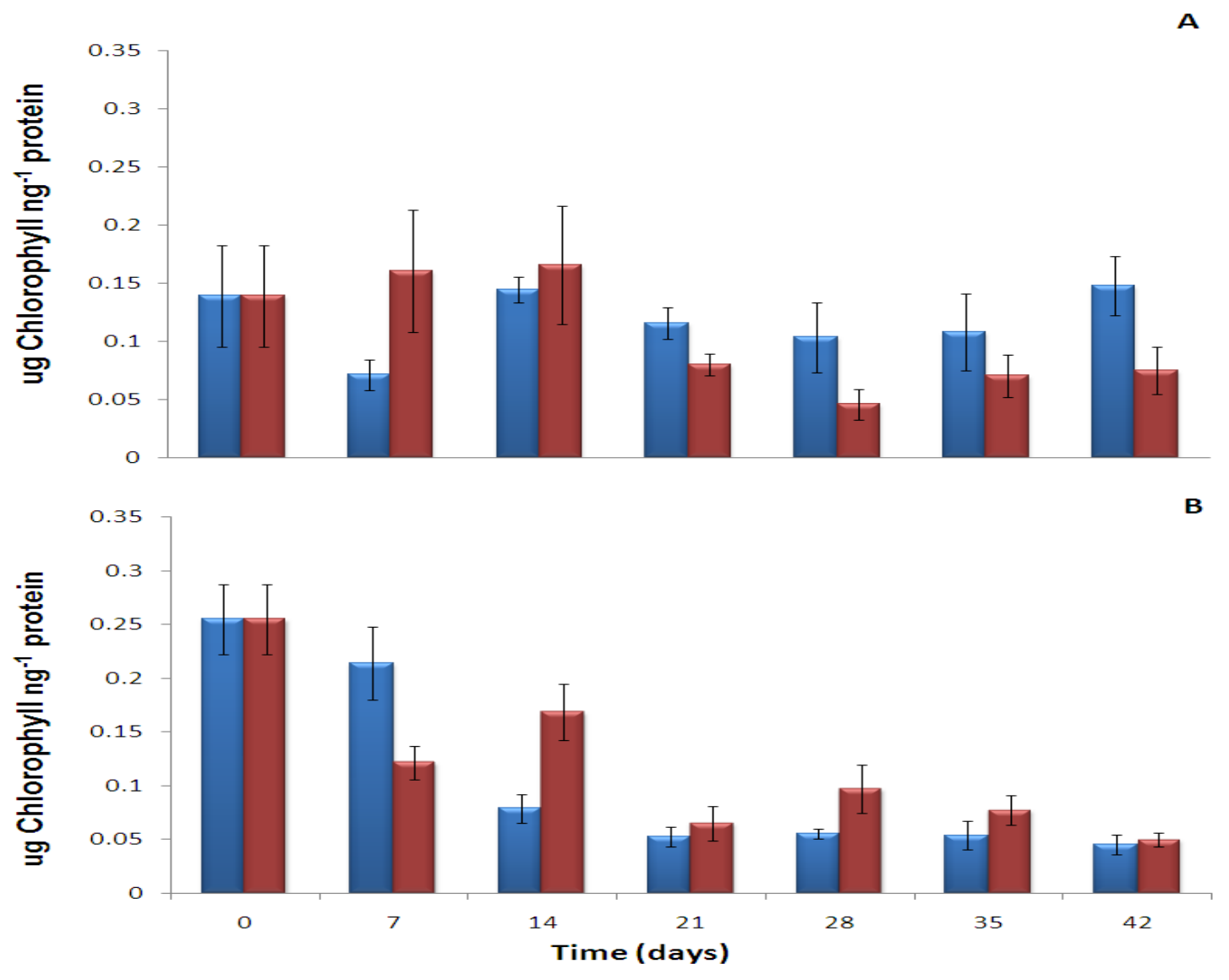

Figure 3.9: Biomass-specific chlorophyll content versus $\mathrm{pH}$ in Anthopleura aureoradiata. A) $\mathrm{pH} 8.1$ (blue) and $\mathrm{HCl}$-induced $\mathrm{pH} 7.6$ (red). B) $\mathrm{pH} 8.1$ (blue) and $\mathrm{CO}_{2}$-induced $\mathrm{pH} 7.6$ (red). Values are means $\pm \mathrm{SE}, \mathrm{n}=5$ per time-point. 


\subsubsection{Photosynthetic health $\left(Y_{i}\right)$}

In the $\mathrm{HCl}$ treatment, photosynthetic health $\left(\mathrm{Y}_{\mathrm{i}}\right)$ was consistent throughout the experiment at $\mathrm{pH} 8.1(\mathrm{p}>0.05)$, but declined by $23 \%$ at $\mathrm{pH} 7.6(\mathrm{p}<0.0001)$; indeed, the trends at the two $\mathrm{pH}$ values were significantly different $(\mathrm{p}<0.0001)($ Fig 3.10A). In the $\mathrm{CO}_{2}$ experiment there was no significant change in $\mathrm{Y}_{\mathrm{i}}$ at either $\mathrm{pH} 7.6$ or $\mathrm{pH} 8.1$, and these trends were not significantly different ( $p>0.05$ for all comparisons) (Fig 3.10B).
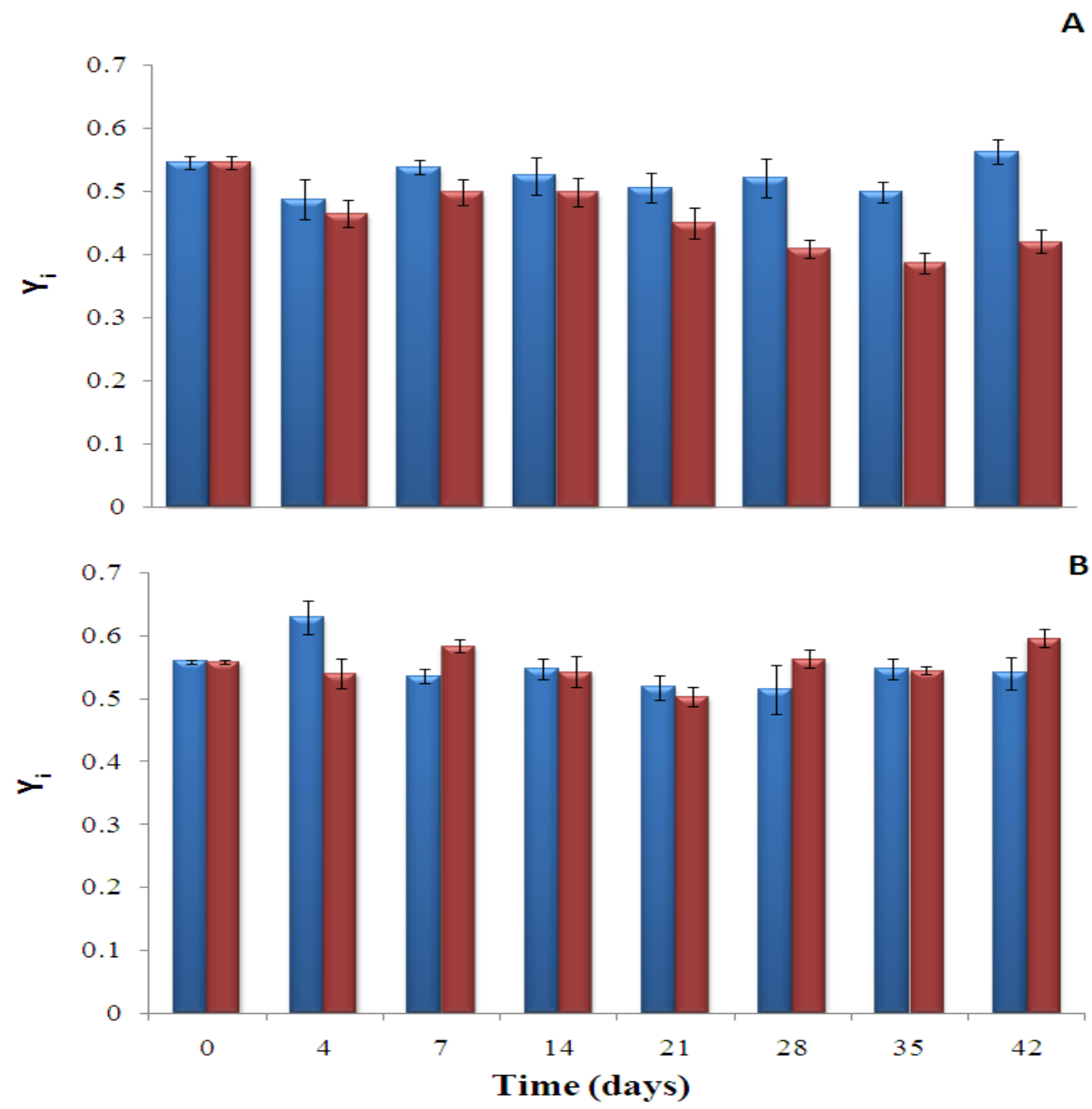

Figure 3.10: Photosynthetic health $\left(\mathrm{Y}_{\mathrm{i}}\right)$ in response to acidification. A) $\mathrm{pH}$ 8.1 (blue) and $\mathrm{HCl}$ induced $\mathrm{pH} 7.6$ (red). B) $\mathrm{pH} 8.1$ (blue) and $\mathrm{CO}_{2}$ induced $\mathrm{pH} 7.6$ (red). Values are in means $\pm \mathrm{SE}, \mathrm{n}=5$ per time-point. 


\subsubsection{Other photosynthetic parameters: $\mathrm{P}_{\max }, \mathrm{I}_{\mathrm{k}}$ and alpha}

When acidified to $\mathrm{pH} 7.6$ with $\mathrm{HCl}$, the maximum rate of photosynthesis $\left(\mathrm{P}_{\max }\right)$ declined significantly, by $23 \%$, over the 42 -day trial $(\mathrm{p}<0.05)$. In the $\mathrm{pH} 8.1$ control of this same experiment, $\mathrm{P}_{\max }$ also decreased significantly, but only by $7 \%(\mathrm{p}<0.05)$. However, these two trends were not significantly differently from one another $(p>0.05)$, perhaps reflecting the considerable variability in some of the data (fig 3.11A). At both $\mathrm{pH} 8.1$ and $\mathrm{pH} 7.6$ in the $\mathrm{HCl}$ experiment, the saturation irradiance $\left(\mathrm{I}_{\mathrm{k}}\right)$ remained constant, and the trends were not significantly between these two treatments $(p>0.05$ for all comparisons; fig 3.11B). Similarly, at pH 8.1 in this same experiment, photosynthetic efficiency (alpha) did not change $(\mathrm{P}>0.05)$. At $\mathrm{pH} 7.6$, however, there was a significant decline in alpha of $26 \%$ over the 42 -day period $(\mathrm{p}<0.05)$, though the trends at $\mathrm{pH} 7.6$ and $\mathrm{pH} 8.1$ were not significantly different $(\mathrm{p}>0.05$; fig 3.11C).

In comparison, in the $\mathrm{CO}_{2}$ experiment, $\mathrm{P}_{\max }$ did not change significantly at either $\mathrm{pH} 8.1$ or $\mathrm{pH} 7.6$, despite a $55-62 \%$ increase in the mean rate being observed, and both trends were statistically similar ( $\mathrm{p}>0.05$ for all comparisons; fig 3.12A). Likewise, $\mathrm{I}_{\mathrm{k}}$ did not change significantly in this experiment at either $\mathrm{pH}$ value, even though the mean value did increase by about $30 \%$, and the trends were not significantly different between the two treatments ( $p>0.05$ for all comparisons; fig 3.12B). Alpha also did not change significantly at either $\mathrm{pH}$, with the trends being the same in both cases $(\mathrm{p}>0.05$ for all comparisons; fig 3.12C). 

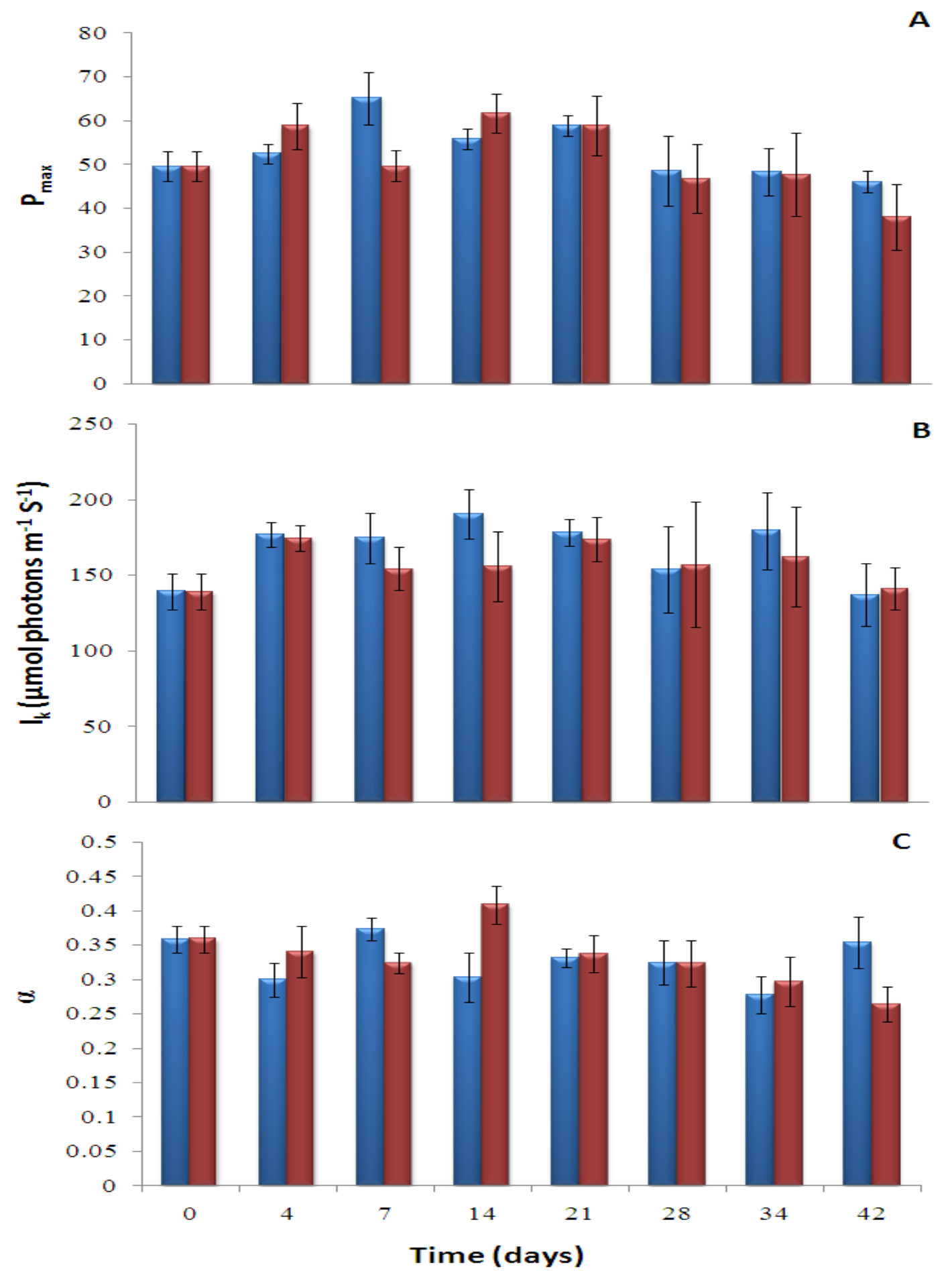

Figure 3.11: Photosynthetic parameters of Anthopleura aureoradiata in response to acidification by $\mathrm{HCl}$, as measured by IPAM fluorometry. Maximum rate of photosynthesis $\left(\mathrm{P}_{\max }, \mathrm{A}\right)$, saturation irradiance $\left(\mathrm{I}_{\mathrm{k}}, \mathrm{B}\right)$, and photosynthetic efficiency $(\alpha, \mathrm{C})$ were calculated using an exponential waiting-in-line fit curve, $\mathrm{pH} 8.1$ (blue) and $\mathrm{pH} 7.6$ (red). Values are means $\pm \mathrm{SE}$, with $\mathrm{n}=5$ per time-point. 


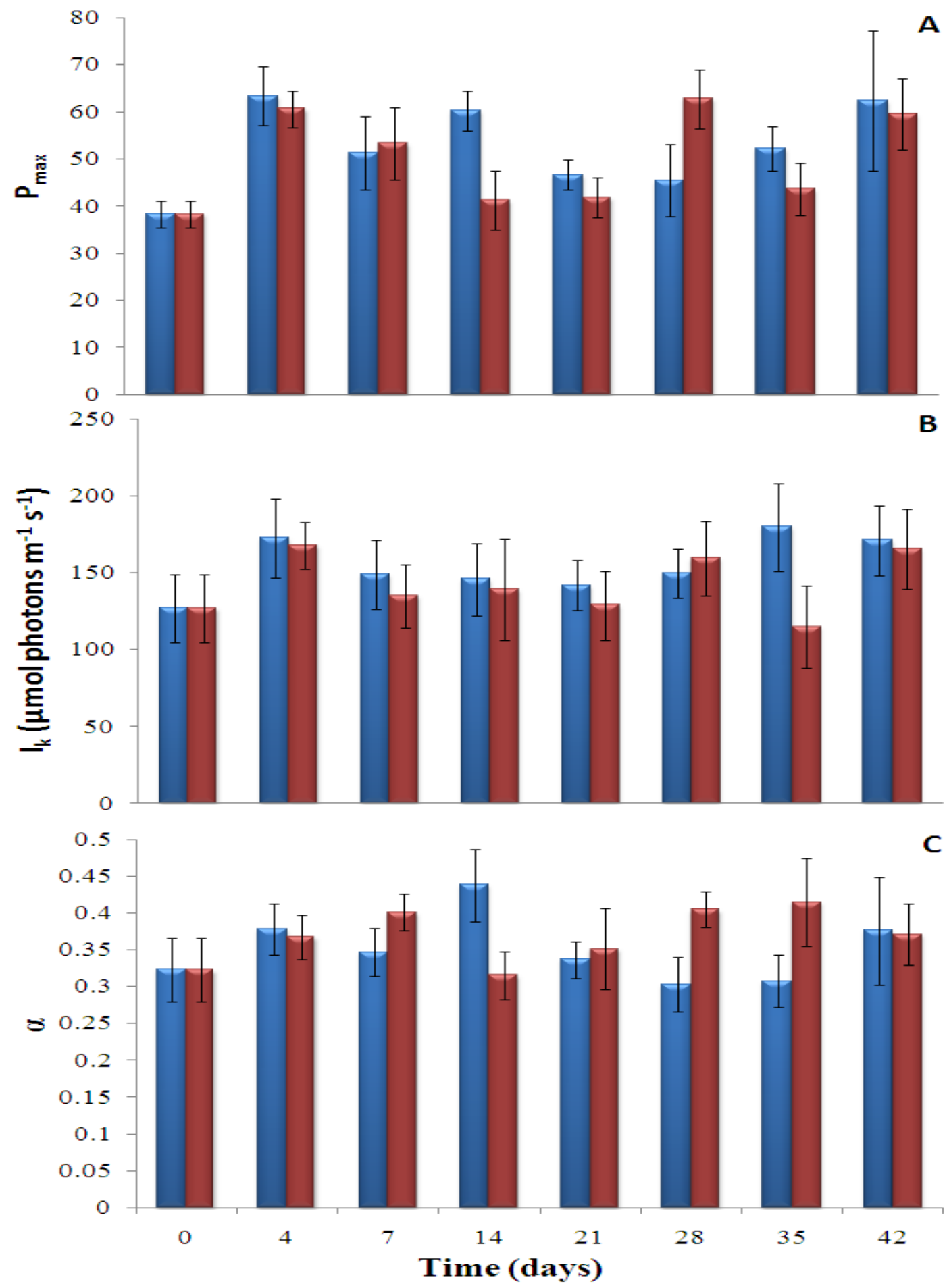

Figure 3.12: Photosynthetic parameters of Anthopleura aureoradiata in response to acidification by $\mathrm{CO}_{2}$, as measured by IPAM fluorometry. Maximum rate of photosynthesis $\left(\mathrm{P}_{\max }, \mathrm{A}\right)$, saturation irradiance $\left(\mathrm{I}_{\mathrm{k}}, \mathrm{B}\right)$, and photosynthetic efficiency $(\alpha, \mathrm{C})$ were calculated using an exponential waiting-in-line fit curve, $\mathrm{pH} 8.1$ (blue) and $\mathrm{pH} 7.6$ (red). Values are means $\pm \mathrm{SE}$, with $\mathrm{n}=5$ per time-point. 


\subsubsection{Photosynthesis in Anthopleura aureoradiata in response to acidification by $\mathrm{HCl}$ or $\mathrm{CO}_{2}$}

\section{Biomass-specific photosynthesis}

In the $\mathrm{HCl}$ experiment, total gross photosynthetic production $\left(\mathrm{P}_{\text {gross }}\right)$ declined significantly, by $40 \%$ and $70 \%$, between 0 and 42 days at $\mathrm{pH} 8.1$ and $\mathrm{pH} 7.6$ respectively (T-test, $\mathrm{p}<0.05$ for both treatments). This greater impact of $\mathrm{pH} 7.6$ meant that $\mathrm{P}_{\text {gross }}$ at 42 days was significantly lower in this acidified treatment than it was in the control (T-test, $p$ $<0.05$; fig 3.13A). In comparison, in the $\mathrm{CO}_{2}$ experiment, $\mathrm{P}_{\text {gross }}$ at both $\mathrm{pH} 8.1$ and 7.6 showed a decline, of about $50 \%$, between 0 and 42 days; this decline was significant in both cases (T-test, $p<0.05)$, but was not significantly different between treatments $(T$ test, $\mathrm{p}>0.05$; fig $3.13 \mathrm{~A})$.

\section{Cell-specific photosynthesis}

In the $\mathrm{HCl}$ experiment, gross photosynthesis per zooxanthella was not significantly different between 0 and 42 days, either at $\mathrm{pH} 8.1$ or $\mathrm{pH} 7.6$ (T-test, $\mathrm{p}>0.05$ for both treatments). However, the mean value declined sufficiently (by 62\%) in the $\mathrm{pH} 7.6$ treatment for the photosynthetic rate per zooxanthella to be significantly lower than in the control at this end time-point (T-test, $\mathrm{p}<0.05$; fig 3.13B). In comparison, in the $\mathrm{CO}_{2}$ experiment, gross photosynthesis per zooxanthella did not change in either $\mathrm{pH}$ treatment, nor was it significantly different between the $\mathrm{pH}$ treatments at the end of the experiment (T-test, $\mathrm{p}>0.05$; fig 3.13B). 


\section{Chlorophyll-specific photosynthesis}

In the $\mathrm{HCl}$ experiment, despite decreases in the average rate of gross photosynthesis per unit chlorophyll of $75 \%$ and $85 \%$ at $\mathrm{pH} 8.1$ and $\mathrm{pH} 7.6$, respectively, the declines were not significant (T-test, $\mathrm{p}>0.05$ ); this most likely results from the highly variable rates at Day 0 (fig 3.13C). In comparison, in the $\mathrm{CO}_{2}$ experiment, the chlorophyll-specific rate of gross photosynthesis remained the same between 0 and 42 days at both $\mathrm{pH} 8.1$ and $\mathrm{pH}$ 7.6, and the rates at these two $\mathrm{pH}$ levels were statistically similar at the end of the experiment (T-test, $\mathrm{p}>0.05$ for all comparisons; fig 3.13C).

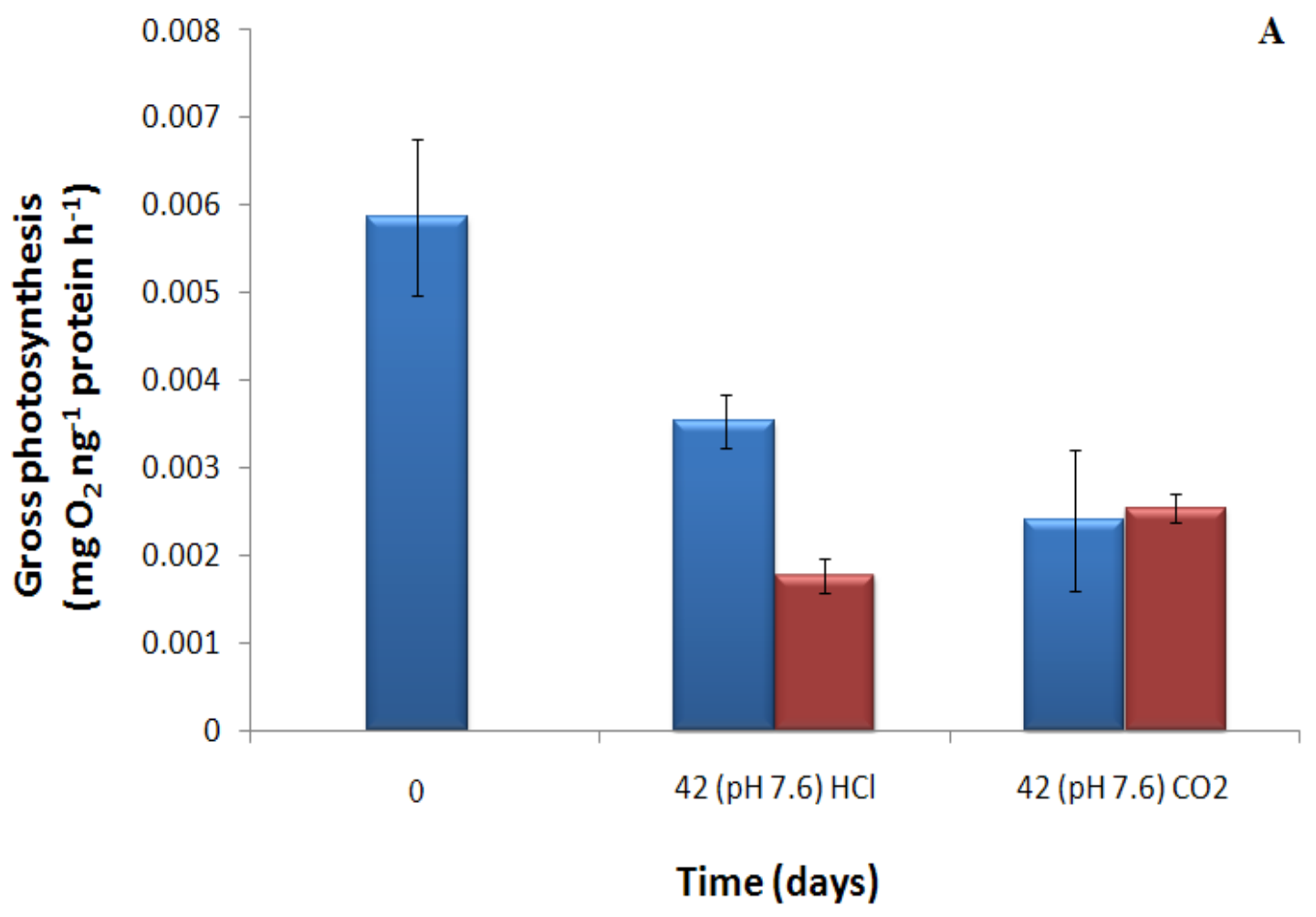



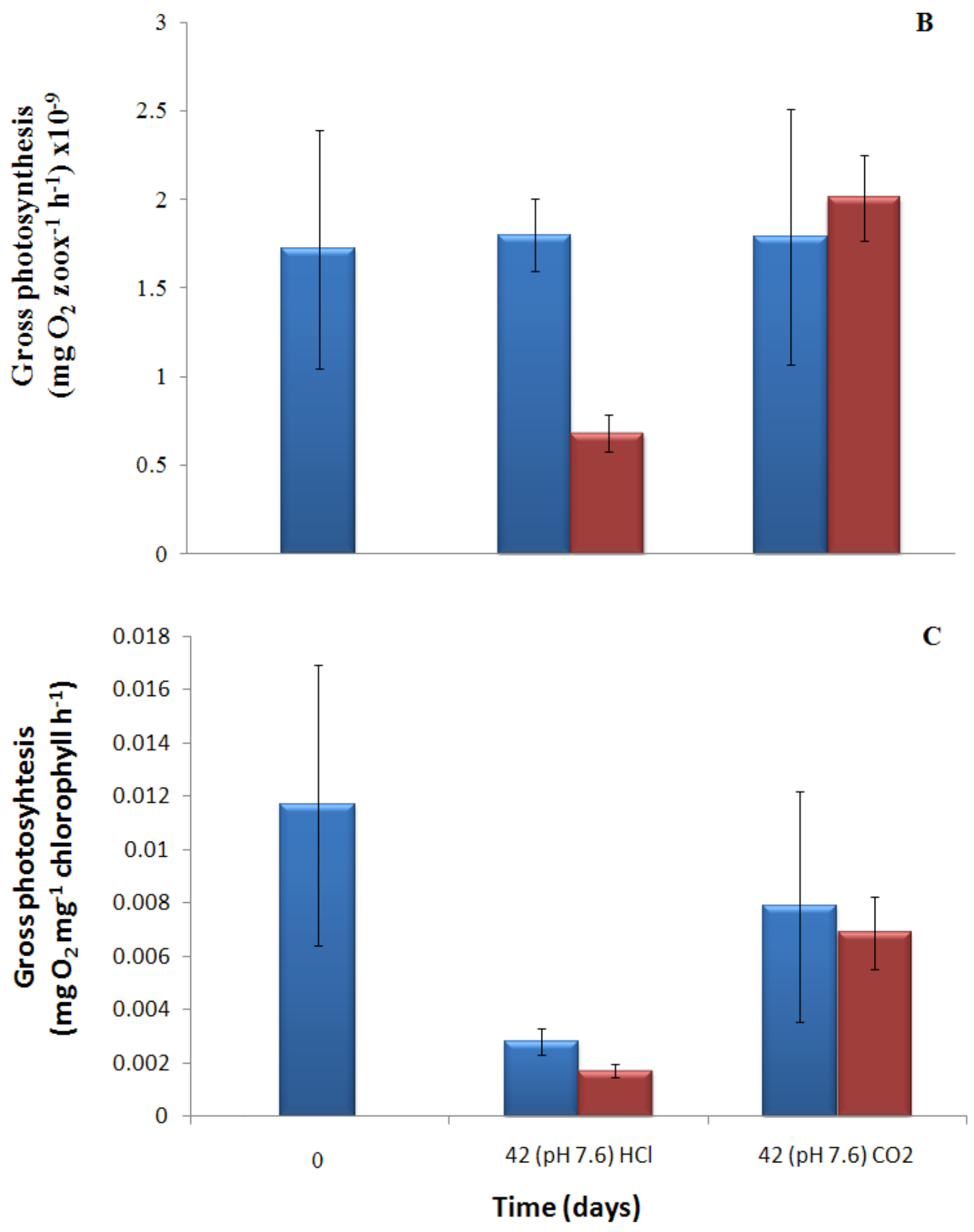

Figure 3.13: Photosynthesis in Anthopleura aureoradiata in response to acidification by $\mathrm{HCl}$ or $\mathrm{CO}_{2}$. A) Biomass-specific gross photosynthesis ( $\mathrm{mg} \mathrm{O}_{2} \mathrm{ng}^{-}$ $\left.{ }_{1} \mathrm{~h}^{-1}\right)$, B) Cell-specific gross photosynthesis (mg O $\left.\mathrm{O}_{2} \mathrm{zoox}^{-1} \mathrm{~h}^{-1}\right)$ and $\mathrm{C}$ ) Chlorophyll-specific gross photosynthesis (mg $\mathrm{O}_{2} \mathrm{mg}^{-1}$ chlorophyll $\mathrm{h}^{-1}$ ). Treatments were $\mathrm{pH} 8.1$ control (blue); $\mathrm{pH} 7.6$ generated with either $\mathrm{HCl}$ or $\mathrm{CO}_{2}$ (red). Note that anemones at Day 0 were removed from the same control $(\mathrm{pH} \mathrm{8.1)}$ stock tank and analysed, prior to further anemones being placed in either the control or two acidification treatments; hence there is only one bar at this first time-point. Values are means $\pm \mathrm{SE}, \mathrm{n}=5$ per time-point. 


\subsubsection{Respiration}

In the $\mathrm{HCl}$ experiment, respiration at $\mathrm{pH} 8.1$ remained constant between 0 and 42 days (T-test, $\mathrm{p}>0.05$ ), whereas respiration at $\mathrm{pH} 7.6$ dropped significantly between these time-points $(T$-test, $\mathrm{p}<0.05)$. This resulted in the respiration rate being significantly lower in the $\mathrm{pH} 7.6$ treatment than in the $\mathrm{pH} 8.1$ treatment at the end of the experiment (T-test, $\mathrm{p}<0.05$; fig 3.14). In comparison, in the $\mathrm{CO}_{2}$ experiment, the respiration rate did not decline significantly at either $\mathrm{pH} 7.6$ or 8.1 (T-test, $\mathrm{p}>0.05$ ), though it declined enough at $\mathrm{pH} 8.1$ for the rate at $\mathrm{pH} 7.6$ to be significantly higher $(40 \%$ higher $)$ at the end of the experiment (T-test, $\mathrm{p}<0.05$; fig 3.14).

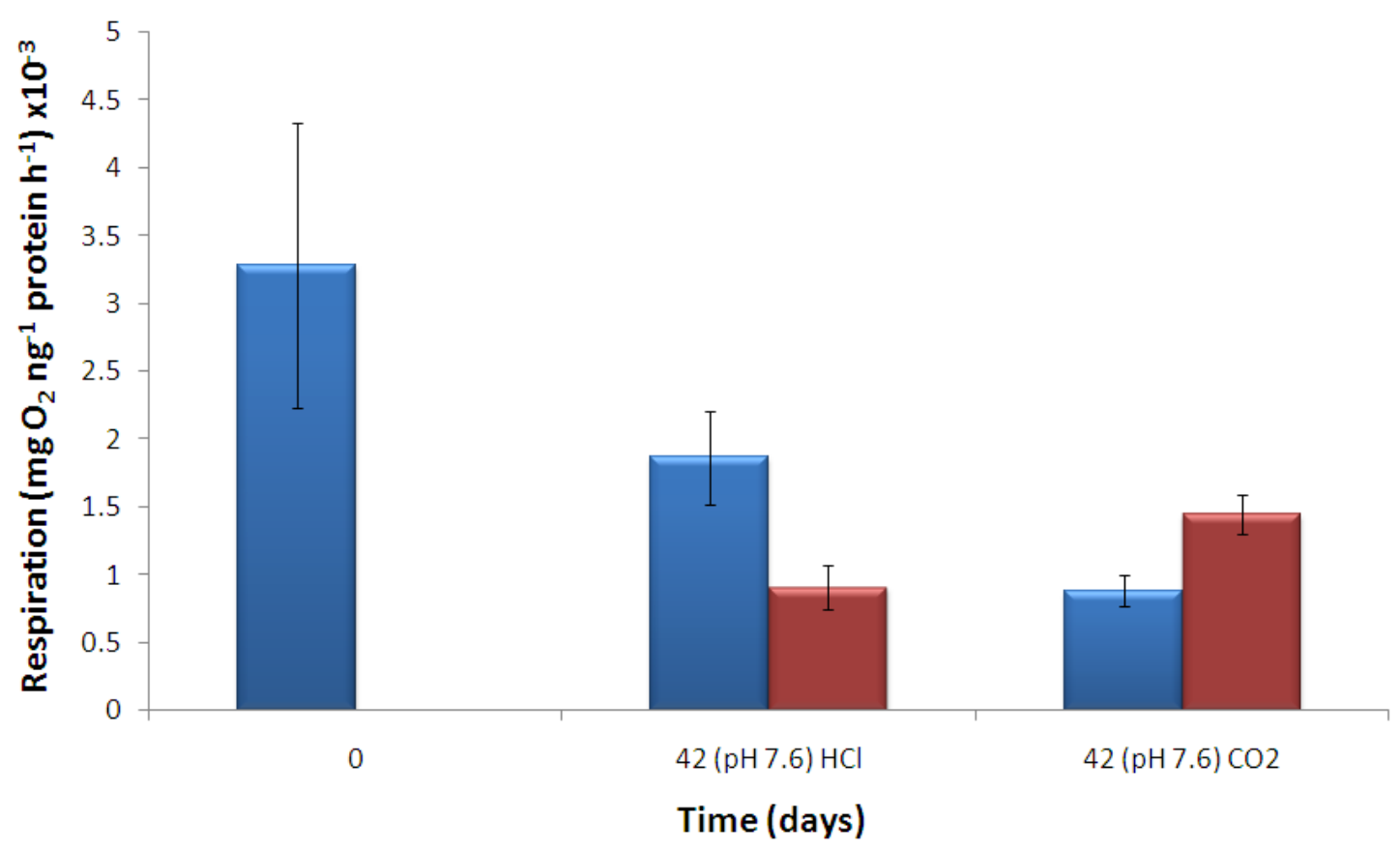

Figure 3.14: Respiration of Anthopleura aureoradiata in response to acidification of seawater by $\mathrm{HCl}$ or $\mathrm{CO}_{2}$. $\mathrm{pH} 8.1$ control (blue); $\mathrm{pH} 7.6$ generated with either $\mathrm{HCl}$ or $\mathrm{CO}_{2}$ (red). Note that anemones at Day 0 were removed from the same control $(\mathrm{pH} 8.1)$ stock tank and analysed, prior to further anemones being placed in either the control or two acidification treatments; hence there is only one bar at this first time-point. Values are means $\pm \mathrm{SE}, \mathrm{n}=5$ per time-point. 


\subsubsection{P:R}

In the $\mathrm{HCl}$ experiment, the ratio of total light-saturated gross photosynthesis to respiration (P:R) did not change between 0 and 42 days, either at $\mathrm{pH} 7.6$ or $\mathrm{pH} 8.1$ (T-test, $\mathrm{p}>0.05$, for both treatments); mean P:R at 42 days was virtually identical at both $\mathrm{pH}$ values (T-test, $\mathrm{p}>0.05$; fig 3.15). Likewise, in the $\mathrm{CO}_{2}$ experiment, there was no significant change in $P: R$ between 0 and 42 days at either $p H$ value (T-test, $p>0.05$ ). Furthermore, $P: R$ was not significantly different between $\mathrm{pH} 7.6$ and $\mathrm{pH} 8.1$ at the end of the experiment (T-test, $\mathrm{p}>0.05$; fig 3.15).

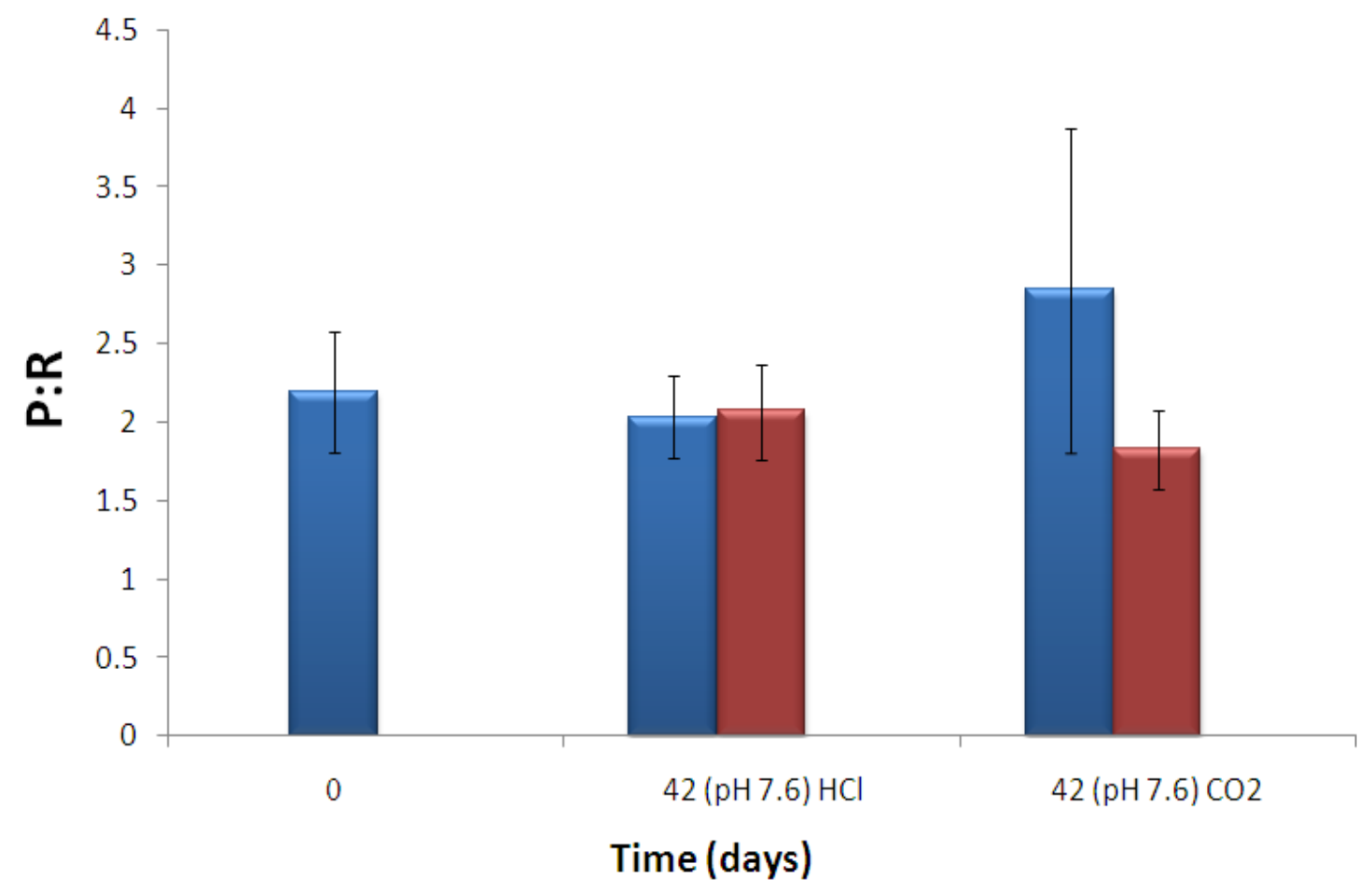

Figure 3.15: The ratio of gross photosynthesis $(\mathrm{P})$ to respiration $(\mathrm{R})$ of Anthopleura aureoradiata at the different $\mathrm{pH}$ values. $\mathrm{pH} 8.1$ (blue) were independent samples recorded at time 0 and twice at time 42 for both experiments. $\mathrm{pH} 7.6$, induced with either $\mathrm{HCl}$ or $\mathrm{CO}_{2}$ (red) was recorded at time-point 42 only, as indicated on the axis. Values are in means $\pm \mathrm{SE}, \mathrm{n}=5$ per time point. 


\subsection{Discussion}

Acidification by $\mathrm{HCl}$ caused no reduction in the density of zooxanthellae in $A$. aureoradiata beyond that seen in the controls. Yet total gross photosynthesis decreased, reflecting the reduced rate of gross photosynthesis per zooxanthellar cell; interestingly however, this decrease was not a direct response to reduced chlorophyll per cell, as this remained unchanged. Concurrent with the reduced rate of total gross photosynthesis was a drop in respiration, which meant that the anemone was still able to meet its metabolic requirements despite its lower productivity. In comparison, when seawater was acidified with $\mathrm{CO}_{2}$, the decline in zooxanthellar density was far less than that seen in the control, suggesting a stimulatory effect that counteracted a general stress response (most likely due to the artificial lighting used). The increase was reflected in an increased rate of total gross photosynthesis, though not in gross photosynthesis per cell or per unit chlorophyll. However, a concurrent increase in respiration rate meant that the P:R ratio remained the same. These results suggest that the seawater acidified using $\mathrm{CO}_{2}$ improves the photosynthetic performance of the symbiosis through increasing the density of symbiotic algae rather than the photosynthetic performance of the individual algal cells, while $\mathrm{HCl}$ is detrimental to photosynthetic function. However, the potential for autotrophy in the symbiosis is not altered due to proportional changes in respiratory demands.

Furthermore, this study supports recent claims that adjusting the $\mathrm{pH}$ with $\mathrm{HCl}$ does not accurately reflect the impacts of $\mathrm{CO}_{2}$ on seawater acidification (Kikkawa et al. 2003; Atkinson and Cuet 2008; Fabry 2008; Iglesias-Rodriguez et al. 2008). Using A. aureoradiata as a model organism, it was found that most physiological parameters were 
either more severely affected, or affected differently by $\mathrm{HCl}$ than they were by $\mathrm{CO}_{2}$. Indeed, of the eleven parameters recorded, seven were significantly different between the $\mathrm{HCl}$ and $\mathrm{CO}_{2}$ treatments.

The underlying mechanisms of these various photophysiological trends and their ecological implications, as well as the reasons for the different responses to $\mathrm{CO}_{2}$ versus $\mathrm{HCl}$, will be discussed here.

\section{Acidification via $\mathrm{HCl}$}

The loss of photosynthetic function when seawater was acidified with $\mathrm{HCl}$ strongly suggests cellular acidosis, which can affect a broad range of intracellular processes. For instance, in animals it has been shown that denaturation of protein in skeletal muscle and increased oxidation of amino acids, such as leucine, occurs when acidosis is induced (May et al. 1986; Reaich et al. 1992; Mitch et al. 1994 and May et al. 1996). Moreover, membrane function and repair may be hindered while at extreme levels of acidosis (Patel et al. 2001; Doerr et al. 2005) and the increased $\left[\mathrm{H}^{+}\right]$may cause lipid peroxidation (Hall et al. 1995). Further effects of acidosis have been reported in plants. For example, cytosolic acidification in plants triggers a reduction of carbon flow along the glycolytic pathway (Sakano 2001; Nocito et al. 2008). Acidosis in plants has also been found to affect the enzyme L-galactono-gamma-lactone dehydrogenase (GAL), which is important for the formation of ascorbic acid, which acts as an antioxidant in plants, removing free radicals and preventing cellular damage (Ostergaard et al. 1997; Blokhina et al. 2003). 
The loss of photosynthetic potential in the symbiosis was not due to loss of symbionts, but rather less photosynthesis per zooxanthellar cell. This suggests that the lowered $\mathrm{pH}$ may have an effect on the photosynthetic apparatus. Lowered $\mathrm{pH}$ can denature proteins and can affect the viability of membranes (May et al. 1986; Reaich et al. 1992; Mitch et al. 1994 and May et al. 1996; Patel et al. 2001; Doerr et al. 2005), meaning that the chloroplast, which contains ribulose-1,5-bisphosphate carboxylase (RuBisCO) and the thylakoid membranes, is likely compromised by a more acidic environment. Furthermore, even in less extreme cases, a lowered $\mathrm{pH}$ may not necessarily denature a protein but may move it out of its optimal range of efficiency, thus reducing its activity (Irwin et al. 1994; Laffey et al. 2000; Wildbrett et al. 2003); this could explain the witnessed reduction in photosynthetic efficiency, health and potential seen in A. aureoradiata in the $\mathrm{pH} 7.6 \mathrm{HCl}$ treatment. Similarly, Maury et al. (1981) induced stromal acidification of isolated spinach chloroplasts (a drop in stromal $\mathrm{pH}$ by $0.07-0.15 \mathrm{pH}$ units) by the addition of $\mathrm{Mg}^{2+}$. The study found that, despite only a small decrease in $\mathrm{pH}$, there was a significant decrease in $\mathrm{O}_{2}$ evolution, indicative of inhibition of photosynthesis. The authors suggested that increased acidity of the stroma causes photosynthesis to become more sensitive to internal phosphate levels, therefore for efficient photosynthesis to occur, the maximum desired levels of intracellular phosphate decrease with increasing cellular acidity (Maury et al. 1981 and Rutter and Cobb 2006). Therefore, while extracellular $\mathrm{pH}$ does not necessarily equilibrate exactly with intracellular levels (Boag et al. 1989), it has the potential to affect internal process, such as photosynthesis, directly. Similar effects most likely explain the reduced photosynthetic function seen here. 


\section{Acidification via $\mathrm{CO}_{2}$}

$\mathrm{CO}_{2}$ did not induce the same photophysiological responses that were witnessed in the $\mathrm{HCl}$ treatment. Indeed, the reduction in zooxanthellar density seen in the control treatment, which was likely a general stress response to artificial lighting, was dramatically slowed with the addition of $\mathrm{CO}_{2}$. This meant that total photosynthetic production was higher than that seen at the control $\mathrm{pH}$; there was no loss of photosynthetic function per zooxanthella. However, as photosynthesis was matched by a proportional increase in respiration rate, the anemone was no better off metabolically, i.e. its potential to meet its metabolic carbon demands by autotrophy remained unchanged. One possible reason for the different response to $\mathrm{HCl}$ versus $\mathrm{CO}_{2}$ is that $\mathrm{CO}_{2}$ counteracted the loss of function caused by cellular acidosis. With respect to this, it is important to note that zooxanthellae within their hosts do not have access to the vast amounts of dissolved inorganic carbon (DIC) stored as bicarbonate within the sea, as they are isolated from such reservoirs by their endosymbiotic habitat (Leggat et al. 2002; Weis and Reynolds 1999). Zooxanthellae must rely on a steady stream of $\mathrm{CO}_{2}$, inter-converted from bicarbonate by the host via carbonic anhydrase, in order to maximise photosynthesis; thus their carbon supply is under host control (Yellowlees et al. 1993; Weis 1993; Baillie and Yellowlees 1998; Leggat et al. 1999; Leggat et al. 2002). This $\mathrm{CO}_{2}$ demand is further supported via respiration of the host animal (Schwarz and Weis 2003). Together, DIC from the seawater and $\mathrm{CO}_{2}$ from host respiration contribute to the metabolic needs of the zooxanthellae, which are considerable. There is good evidence that, when in symbiosis, zooxanthellae are carbon-limited, reflecting both the controlled supply of DIC and the very high densities of zooxanthellae within the host. For example, Leggat et al. (2000) 
claimed that the host haemolymph of giant clams would be entirely depleted of $\mathrm{CO}_{2}$ within just 13 minutes as a result of the photosynthetic demands of the zooxanthellae. Given this demand, it is not surprising that competition for $\mathrm{CO}_{2}$ increases as zooxanthellar density increases (and vice versa). Davy and Cook (2001b) found that carbon was a limiting factor and a strong determinant in the density of zooxanthellae found within the sea anemone Aiptasia pallida. Host anemones were starved and the resultant decrease in zooxanthellar density (50\%) was correlated with increases in cellspecific rates of photosynthesis. This inverse relationship between zooxanthellar cell density and productivity resulted in the total quantity of photosynthetic carbon translocated to the host anemone remaining the same. Further evidence for in hospite carbon limitation comes from Harland and Davies (1995), who found that light-enhanced stimulation of gross photosynthesis in the zooxanthellate sea anemone Anemonia viridis led to a proportional increase in respiration, which in turn provided a $\mathrm{CO}_{2}$-rich intracellular environment which further enhanced the photosynthetic rate of the zooxanthellae. Results in the current study are consistent with carbon limitation, with the addition of $\mathrm{CO}_{2}$ increasing the total DIC content of the ambient seawater and so sustaining a more dense population of zooxanthellae. The more dense population and greater photosynthetic production appear to increase the respiration rate, which is likely to provide even more $\mathrm{CO}_{2}$ to the photosynthetic symbionts, so further supporting zooxanthellar photosynthesis in a positive feedback loop.

\section{Ecological implications of acidification for Anthopleura aureoradiata}

The carbon fixed by the zooxanthellae typically meets their metabolic requirements. When production of carbon exceeds this requirement a fraction is translocated to the 
animal host and can contribute significantly, and in some cases completely, to its metabolic needs (Muscatine et al. 1981; Iglesias-Prieto and Trench 1994; Verde and McCloskey 1996). The direct relationship between total gross photosynthesis and respiration meant that, irrespective of whether photosynthesis declined (with $\mathrm{HCl}$ ) or increased (with $\mathrm{CO}_{2}$ ) relative to the control, any potential advantage or disadvantage was countered by a proportional change in the respiratory rate. Indeed the P:R of $\sim 1.5-2.0$ suggests that, in all cases, not only can the zooxanthellae completely support host respiration but they can also contribute surplus carbon to host growth, reproduction and mucus production. This suggests that seawater acidification may have little impact on the survival and growth of $A$. aureoradiata.

It is important to recognise that the P:R ratios measured here were generated under optimal environmental conditions. In the field, most temperate symbioses are in fact exposed to highly variable light and temperature regimes, so $\mathrm{P}: \mathrm{R}$ ratios of $>1$ are rare and symbiotic cnidarians must rely heavily on heterotrophic sources of carbon (Davy et al. 1996). However, the results here still suggest that, whatever the autotrophic potential of $A$. aureoradiata in the field, it is still unlikely to be impacted by acidification, unless the quantity and identity of the translocated carbon products are altered. This is worthy of future investigation.

It is predicted that ocean acidification and its associated effects will first become apparent in the colder Southern Ocean due to $\mathrm{CO}_{2}$ being more readily absorbed by colder waters than warmer ones (Orr et al. 2005; Montenegro et al. 2007; Fabry et al. 2008). If, as Orr et al. (2005) and others suggest, the Southern Ocean and the Sub-Antarctic Pacific Ocean 
are the first to experience flow-on effects arising from ocean acidification, then the seas around New Zealand may become under-saturated with aragonite by 2100 . Literature is prevalent, and the effects well-publicised, on the consequences of oceanic undersaturation of aragonite and the effects that this may have on organisms which use $\mathrm{CaCO}_{3}$ to form integral physiological structures. While this may not affect A. aureoradiata directly, there are potential repercussions. On mudflats, which are perhaps the primary habitat of $A$. aureoradiata, the anemone is almost exclusively found on the cockle $A$. stutchburyi. Should the aragonite saturation horizon reach surface waters and hence impact on shell-forming molluscs such as A. stutchburyi, then A. aureoradiata populations on mudflats could be seriously impacted. If there is a positive note, then the current study at least suggests that those A. aureoradiata that inhabit rocky shores (where they are not reliant on cockles for substrate) may not be negatively impacted by acidification. More long-term experimentation is required, however, to confirm this. 


\section{Chapter IV}

\section{Photosynthetic health of THE TEMPERATE SEA ANEMONE ANTHOPLEURA AUREORADIATA IN RESPONSE TO INCREMENTAL INCREASES IN SEAWATER ACIDIFICATION}

\section{I Introduction}

Climate change, which is the shift in global climatic patterns arising from excessive amounts of atmospheric $\mathrm{CO} 2$, poses a real threat to the long term survival of coral reefs. $\mathrm{CO} 2$ acts like an insulator, heating the planet by trapping the Sun's energy. While this is an entirely natural process, mean global temperatures are, in a relative sense, increasing at a rate not seen before and to levels not seen in 10,000 or more years. This can largely be attributed to anthropogenic CO2 emissions (Petit et al. 1999; Epstein 2001). There is potentially an even greater threat to the world's coral reefs: ocean acidification. Not only is $\mathrm{CO} 2$ a greenhouse gas, but it also dissolves into the ocean. Therefore, as the rate at which it is being pumped into the atmosphere has intensified, so has the amount being absorbed by the world's oceans; this has overwhelmed natural systems. CO2, when dissolved in water, undergoes a chain of simple chemical reactions and, when combined with $\mathrm{H} 2 \mathrm{O}$, forms a carbonic acid which readily releases $\mathrm{H}+$ ions to the water, so making it more acidic (Royal Society 2005). 
As a result of the increased oceanic absorption of $\mathrm{CO} 2$, oceans have decreased 0.1 of a $\mathrm{pH}$ unit since the industrial and are predicted to drop further, to a $\mathrm{pH}$ of 7.6 by 2100 and beyond (Caldeira and Wickett 2003; Orr et al. 2005; Wood et al. 2008; Zeebe et al. 2008; Doney et al. 2009). This decrease in $\mathrm{pH}$ is likely to make it very difficult for marine calcifiers to form their calcium carbonate structures, and in most cases the organism depends on these structures for its survival (Orr et al. 2005; Hoegh-Guldberg et al. 2007). Ocean acidification was brought to the fore in a report by the Royal Society (2005), which highlighted numerous gaps in our knowledge of ocean acidification and the implications it may have. Ensuing research focused on these gaps, especially concerning marine calcification, meaning that we now know considerably more than we once did. However, as a result of this focus on calcification, other potential physiological impacts of acidification have remained somewhat understudied. There is, however, some evidence that acidification may in fact benefit primary production rather than harm it.

Increased levels of dissolved CO2 may lead to increases in photosynthesis. A unique in situ study by Hall-Spencer et al. (2008), using volcanic CO2 vents that locally acidified the water off the coast of Italy, found that seagrass production was highest in areas of $\mathrm{pH}$ 7.6. This evidence suggests that, not only was photosynthesis unaffected by increased levels of dissolved $\mathrm{CO} 2$, but also that it may have indeed been improved. Palacious and Zimmerman (2007) found that, in the short-term (45 days), elevated levels of dissolved $\mathrm{CO} 2$ were accompanied with increased photosynthetic rates in the seagrass Zostera marina. Given such positive effects on photosynthesis in seagrasses as well as brown algae (Riebesell 2008), and the fact that dissolved inorganic carbon is thought to be 
limiting for the symbiotic dinoflagellates (zooxanthellae) in hospite (Crawley et al. 2009), it stands to reason that the addition of $\mathrm{CO} 2$ may in fact improve photosynthesis in corals and other zooxanthellate invertebrates, though the evidence for this, from a very small number of relatively recent experiments, is equivocal.

Anthony et al. (2008) found detrimental effects on photosynthesis in the corals Acropora intermedia and Porites lobata and the crustose coralline alga Porolithon onkodes, but conversely Langdon and Atkinson (2005) found a positive effect on photosynthetic rate in the corals Porites compressa and Montipora verrucosa (capitata). Positive impacts on zooxanthellar photosynthesis, utilising $\mathrm{HCO} 3-$ as the primary source of carbon, are further supported by empirical studies using the corals Porites porites and Acropora sp. (Herfort et al. 2008) and Stylophora pistillata (Marubini et al. 2008). Langdon and Atkinson (2005) suggested that these positive effects could be related to the fact that the production of enzymes required to utilise $\mathrm{HCO} 3-$ as a source of carbon is energy expensive, and perhaps under conditions of increased CO2 (relative to available HCO3-) the energy-costly HCO3- mechanism could be deactivated with the zooxanthellae switching to $\mathrm{CO} 2$ as their primary source of carbon. However, any potential benefit ignores the fact that acidification of seawater may cause intracellular acidosis, leading to a disruption and possibly cessation of cell function. For example, denaturation of protein in skeletal muscle, increased oxidation of amino acids (May et al. 1986; Reaich et al. 1992; Mitch et al. 1994 and May et al. 1996), impaired membrane function and repair (Patel et al. 2001; Doerr et al. 2005), and lipid peroxidation (Hall et al. 1995) all result from cellular acidosis. Of these impacts, the denaturation of proteins is of particular interest here, as proteinaceous enzymes are a crucial component of the mechanism 
involved in the conversion of HCO3- to $\mathrm{CO} 2$ (Langdon and Atkinson 2005), and hence for creating a source of carbon for photosynthesis. In the previous experiments described in this thesis (Chapters 2 and 3) the impacts of acidification were very subtle, whether induced by $\mathrm{CO} 2$ or $\mathrm{HCl}$. This raises the question of: what seawater $\mathrm{pH}$ is actually required to induce significant acidosis and cellular dysfunction in cnidarian-dinoflagellate symbiosis?

While the impacts of acidification on tropical coral reefs are receiving ever-increasing amounts of attention, largely because of the critical role that calcification plays in reef accretion (Hoegh-Guldberg et al. 2007), the impacts on temperate systems have been considered far less. However, while far less diverse than their tropical counterparts, temperate cnidarian-dinoflagellate symbioses are still locally dominant and ecologically significant members of coastal benthic communities (Muller-Parker \& Davy 2001). Moreover, they provide an interesting contrast with tropical symbioses, as they are known to be more resistant to fluctuations in light and temperature, and to extremes in such environmental parameters (Muller-Parker \& Davy 2001; Muller-Parker et al. 2007). The impacts of acidification on temperate cnidarian-dinoflagellate symbioses are therefore worthy of our consideration.

Using the temperate zooxanthellate sea anemone Anthopleura aureoradiata, the aim of this study was to identify the impacts of acidification via $\mathrm{HCl}$ on its photosynthetic health. In particular, it aimed to identify the $\mathrm{pH}$ required to see a substantial loss of photosynthetic function, presumably as a result of cellular acidosis, without the confounding, potentially positive effects of $\mathrm{CO} 2$. It was hypothesised that a linear decline 
in photosynthetic health would be evident with decreasing $\mathrm{pH}$ levels, until a ' $\mathrm{pH}$ threshold' was reached where photosynthetic function suddenly ceased.

\subsection{Methods}

\subsection{Experimental organism}

A. aureoradiata is a common sea anemone found on mudflats throughout New Zealand; it also frequents rocky shores. Due to a lack of hard substrate on mudflats, the anemone attaches to the shells of common bivalves (fig 3.1), especially the cockle Austrovenus stutchburyi, a filter-feeding bivalve that can occur at very high densities (up to $200 \mathrm{~m}^{-2}$ ). A. aureoradiata can reach an average height of up to $2-3 \mathrm{~cm}$ when fully extended and attaches to the cockle using its basal disk; typically the cockle itself is more than $1 \mathrm{~cm}$ from the sediment surface, allowing the anemone's tentacles to reach the surface at high tide.

\subsubsection{Anemone collection and maintenance}

A. aureoradiata $(\mathrm{n}=50)$ was collected from Pauatahanui inlet (Latitude: $-41^{\circ} 05$ Min. 50 Sec. Longitude: $174^{\circ} 52 \mathrm{Min}$. $54 \mathrm{Sec}$; fig 3.2) at low tide during October 2008. Once brought back to Victoria University of Wellington, the anemones were housed in a $2 \mathrm{~L}$ specimen bowl, filled with $1-\mu \mathrm{m}$ filtered seawater (FSW). The anemones were maintained at $16 \pm 1{ }^{\circ} \mathrm{C}$ and an irradiance of $250-300 \mu$ mol photons $\mathrm{m}^{-2} \mathrm{~s}^{-1}$ on a $12 \mathrm{~h} \mathrm{light:}$ $12 \mathrm{~h}$ dark cycle in a standard incubator. The anemones were fed on a diet of Great Salt Lake Artemia sp. nauplii (MacKay Marine, USA), with feeding every 5 days. The 
anemones were acclimated to this environment for 10 days before the commencement of any experimentation.

\subsubsection{Experimental design}

This chapter details two similar experiments which were conducted one after the other. The first experiment utilised five different $\mathrm{pH}$ levels to determine whether there were any effects of acidification on the photosynthetic health of $A$. aureoradiata, and at what point

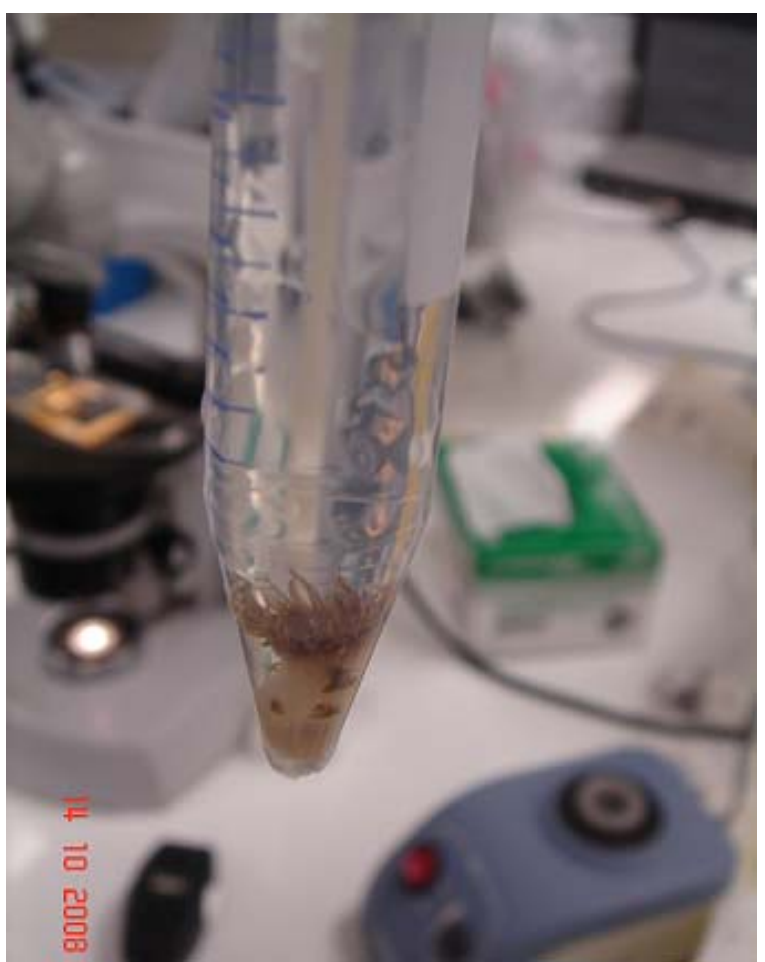

Figure 4.1: Anthopleura aureoradiata settled in a $15 \mathrm{ml}$ Falcon tube, in seawater of the desired $\mathrm{pH}$.

any major loss of function was observed.

The second experiment refined the protocol of the first: it again employed 5 $\mathrm{pH}$ levels, three of which duplicated those used in the first experiment, and two of which were lower. This refinement further increased the chances of establishing a 'pH threshold' at which photosynthetic function became unviable.

The $\mathrm{pH}$ levels used were based on the results in Chapter 3, where photosynthetic yield $\left(\mathrm{Y}_{\mathrm{i}}\right)$ was negatively impacted in the $\mathrm{pH} 7.6 \mathrm{HCl}$ treatment, yet $\mathrm{Y}_{\mathrm{i}}$ remained above a value of 0.4 so indicating reasonable health. The $\mathrm{pH}$ range chosen therefore extended considerably below $\mathrm{pH}$ 7.6, with the treatments in the first experiment being $\mathrm{pH} 8.1$ (control), 7.6, 7.25, 7.0, and 6.75. 
In the second experiment, the treatments were $\mathrm{pH} 8.1,7.25,6.75,6$, and 5. These ranges were deliberately overlapped to test for inconsistencies in the photosynthetic responses between the two experiments. In every other respect the two experiments were identical.

Five anemones were used per $\mathrm{pH}$ treatment, with the same five anemones being monitored across all time-points. Each anemone was placed singly into a $15 \mathrm{ml}$ Falcon tube (fig 4.1, previous page), which was then filled with FSW of the desired $\mathrm{pH}$. The $\mathrm{pH}$ of the FSW stock was adjusted by the addition of $10 \% \mathrm{HCl}$, with measurement by a $\mathrm{S} 30$ SevenEasy ${ }^{\mathrm{TM}}$ conductivity $\mathrm{pH}$ probe (Mettler-Toledo, Switzerland) that was calibrated daily. The tube was then sealed with parafilm and a plastic cap to prevent exchange with the air. It had previously been determined (data not shown) that the $\mathrm{pH}$ remained constant for approximately 35 hours under these conditions, so to ensure a constant $\mathrm{pH}$ throughout the experiment the $\mathrm{pH}$-adjusted FSW was replaced daily. 


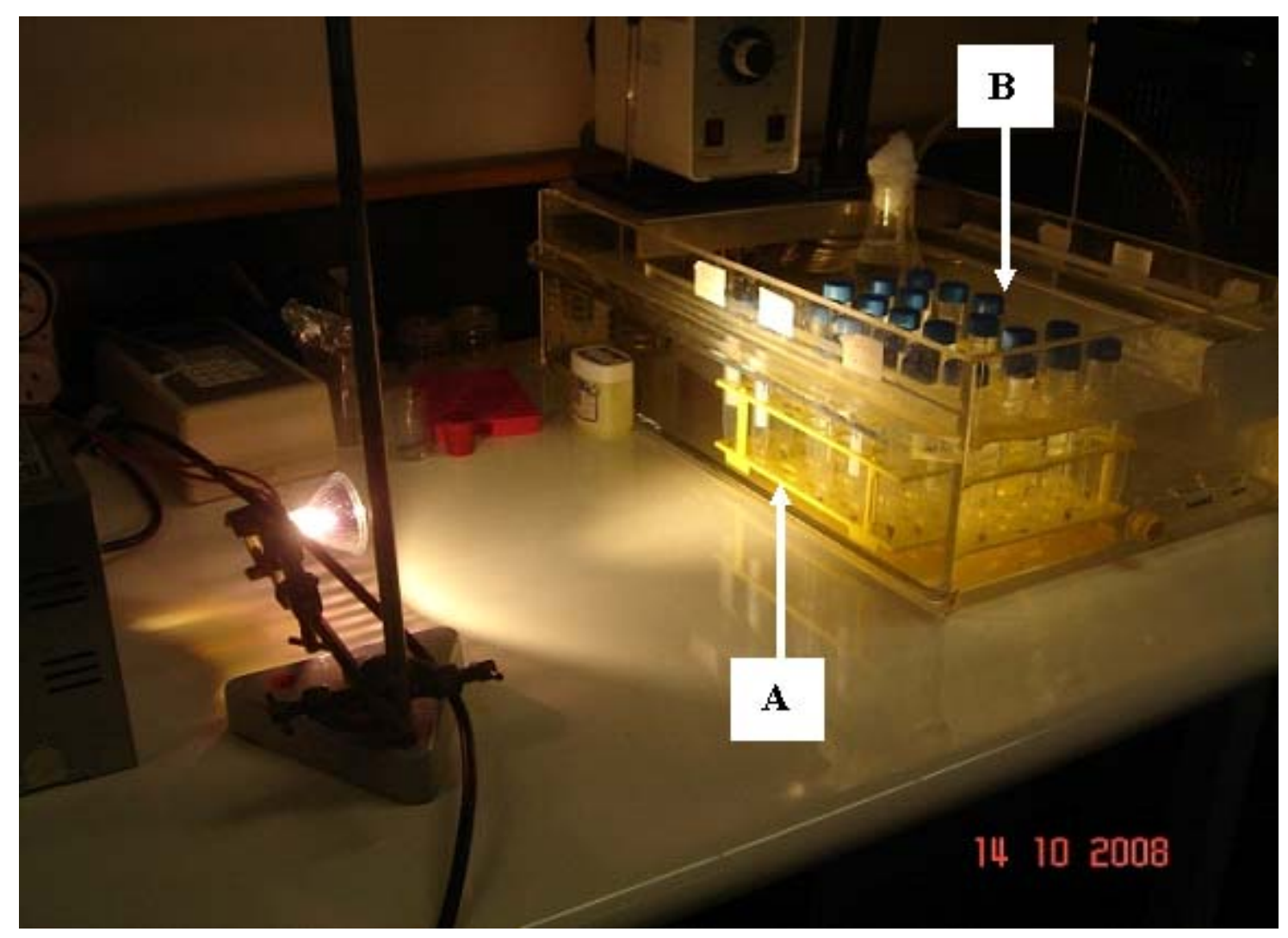

Figure 4.2: Experimental set-up, consisting of 25 treatment tubes placed in a waterbath at $16 \pm 1{ }^{\circ} \mathrm{C}$, and illuminated from the side by a halogen lamp. The position of the tubes was randomly re-assigned twice daily to prevent bias caused by the single light source.

The Falcon tubes were then placed into a test-tube rack, which in turn was placed into a transparent, Perspex waterbath (Fig. 4.2). The waterbath was set to $16 \pm 1^{\circ} \mathrm{C}$. Due to the lids of the Falcon tubes being opaque, a halogen lamp was used to illuminate the sea anemones from one side. Lights were operated on a $12 \mathrm{~h}$ light: $12 \mathrm{~h}$ dark regime at $275 \pm$ $25 \mu \mathrm{mol}$ photons $\mathrm{m}^{-2} \mathrm{~s}^{-1}$ (point $\mathrm{A}$ in fig 4.2) and as $150 \pm 25 \mu \mathrm{mol}$ photons $\mathrm{m}^{-2} \mathrm{~s}^{-1}$ (point $\mathrm{B}$ in fig 4.2). Due to the uneven light distribution, the tubes were randomly re-positioned 


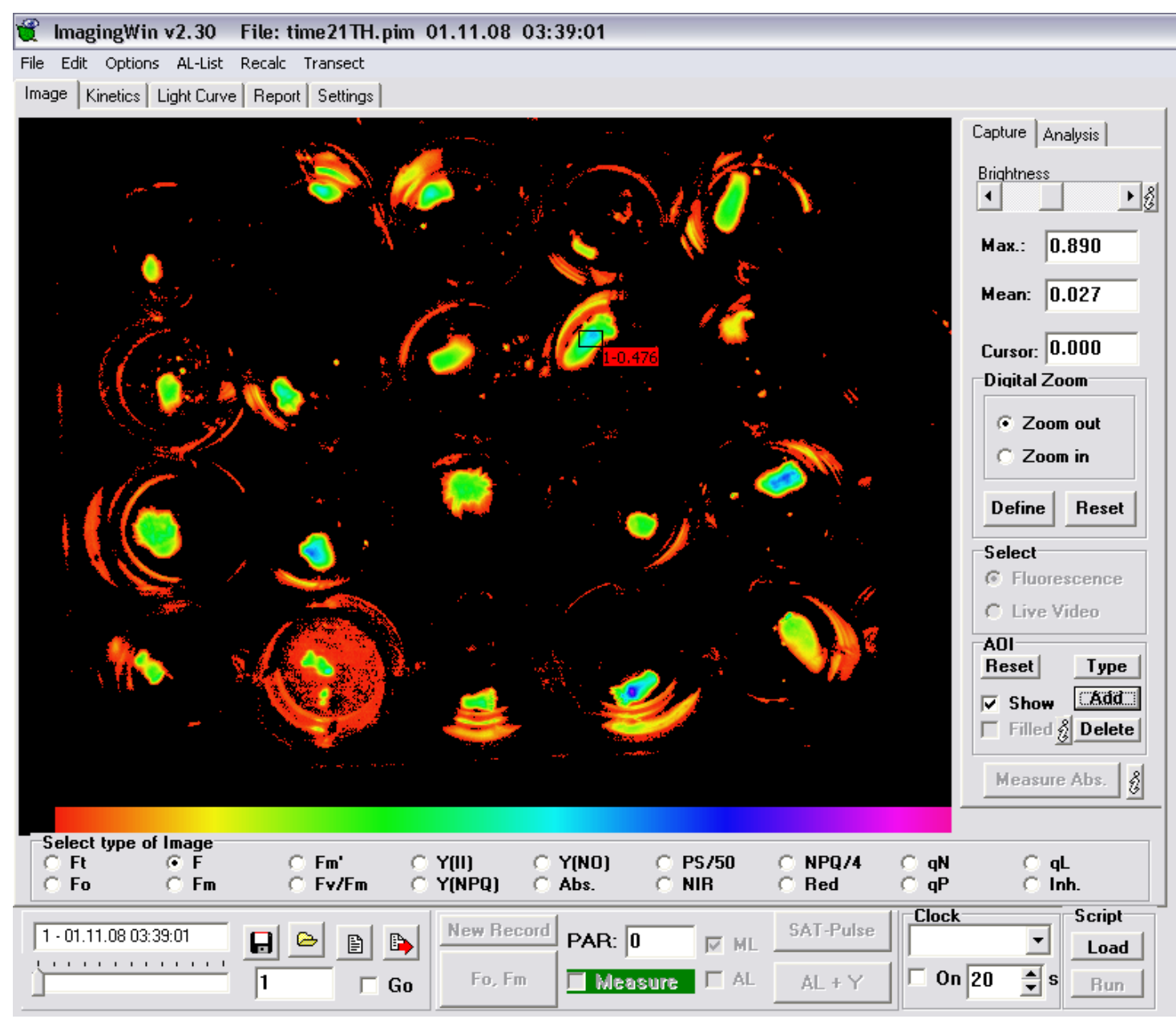

Figure 4.3: View of Anthopleura aureoradiata (20 of the total 25 anemones) under the IPAM fluorometer showing chlorophyll fluorescence (F). The black rectangle represents an 'area of interest'.

twice-daily to take account of the uneven light-field. To do this, numbers were assigned to each Falcon tube (1-25) and also to each space within the rack, and twice a day (at 9 am and again at $7 \mathrm{pm}$ ) for the duration of the experiment a random number generator on a Casio FX-115ES was used to assign each tube a position.

The experiment was run for a total of 21 days, with measurements being taken at $0,1,3$, 7, 14 and 21 days. At each time-point, each anemone was removed from its tube and placed into a plastic well-plate; each well was numbered to correspond to one of the 
tubes/anemones. To limit disturbance of the anemones and the time that the tubes were open to the air, this procedure coincided with the daily water change. Without darkadapting the anemones, the well-plate was then placed into the Imaging Pulse Amplitude Modulated (IPAM) fluorometer (Walz, model IAMG-MAX/1, Germany). The photosynthetic yield $\left(\mathrm{Y}_{\mathrm{i}}\right)$, a proxy of photosynthetic health for light-adapted cells, was then recorded (Fig. 4.3, previous page) before the anemones were returned to the waterbath. Imagaing PAM was set as follows: Measuring light intensity 2; Saturation Pulse Intensity 10; Gain 5; Damping 4 and 30 second intervals between measuring light pulses.

\subsubsection{Statistics}

Simple linear regression was used to analyse data with multiple time-points, to identify temporal trends and any differences between treatments. This was performed using the statistical software package $\mathrm{R}$, and diagnostic graphs were checked for normality and equal variance. T-tests were used to compare two means that were discrete from each other; these tests were performed by hand. 


\subsection{Results}

\subsection{Photosynthetic Health}

Experiment I - Despite a 13\% drop in photosynthetic yield $\left(\mathrm{Y}_{\mathrm{i}}\right)$ between Days 0 and 1, the $\mathrm{pH} 8.1$ treatment maintained constant photosynthetic health throughout the experiment (linear regression, $\mathrm{p}>0.05$ ), while $\mathrm{Y}_{\mathrm{i}}$ in all of the other treatments declined (linear regression, $\mathrm{p}<0.05)$. This meant that, by the last three time-points $(7,14,21$ days), $\mathrm{Y}_{\mathrm{i}}$ was up to $10 \%$ higher in the control than in the $\mathrm{pH} 7.6$ treatment (T-test, $\mathrm{p}<0.05$, for all pair-wise comparisons; fig. 4.4A). The difference was even bigger between the control and the other $\mathrm{pH}$ treatments $(\mathrm{pH} 7.25,7.0,6.75)$, where $\mathrm{Y}_{\mathrm{i}}$ was between 17 and $22 \%$ lower than at $\mathrm{pH} 8.1$ at the final three time-points (T-test, $\mathrm{p}<0.05)$. However, the trends in the various acidified treatments were not significantly different from one another (linear regression, $\mathrm{p}>0.05)$, and were only significantly different from the control $(\mathrm{p}<$ $0.05)$.

Experiment 2 - Simple linear regression identified 3 different trends in this experiment (fig. 4.4B; linear regression, $\mathrm{p}<0.01$ for all comparisons with the control, $\mathrm{p}<$ 0.05 for all other comparisons): 1) Constant $Y_{i}$ in the control; 2) slowly declining $Y_{i}$ at pH 7.25 and 6.75; and 3) rapidly declining $\mathrm{Y}_{\mathrm{i}}$ at $\mathrm{pH} 6$ and 5. After 21 days at $\mathrm{pH} 7.25$ and $\mathrm{pH} 6.75, \mathrm{Y}_{\mathrm{i}}$ was $23 \%$ and $27 \%$ lower than at $\mathrm{pH} 8.1$, respectively (T-test, $\left.\mathrm{p}<0.01\right)$. In comparison, after 21 days at $\mathrm{pH} 6$ and $\mathrm{pH} 5, \mathrm{Y}_{\mathrm{i}}$ was $48 \%$ and $63 \%$ lower than at $\mathrm{pH} 8.1$, respectively (T-test, $\mathrm{p}<0.01$ ); $\mathrm{Y}_{\mathrm{i}}$ at these same two acidic $\mathrm{pH}$ values was also at least $30 \%$ lower than at pH 7.25 and $\mathrm{pH} 6.75$ (T-test, $\mathrm{p}<0.01$ ). 

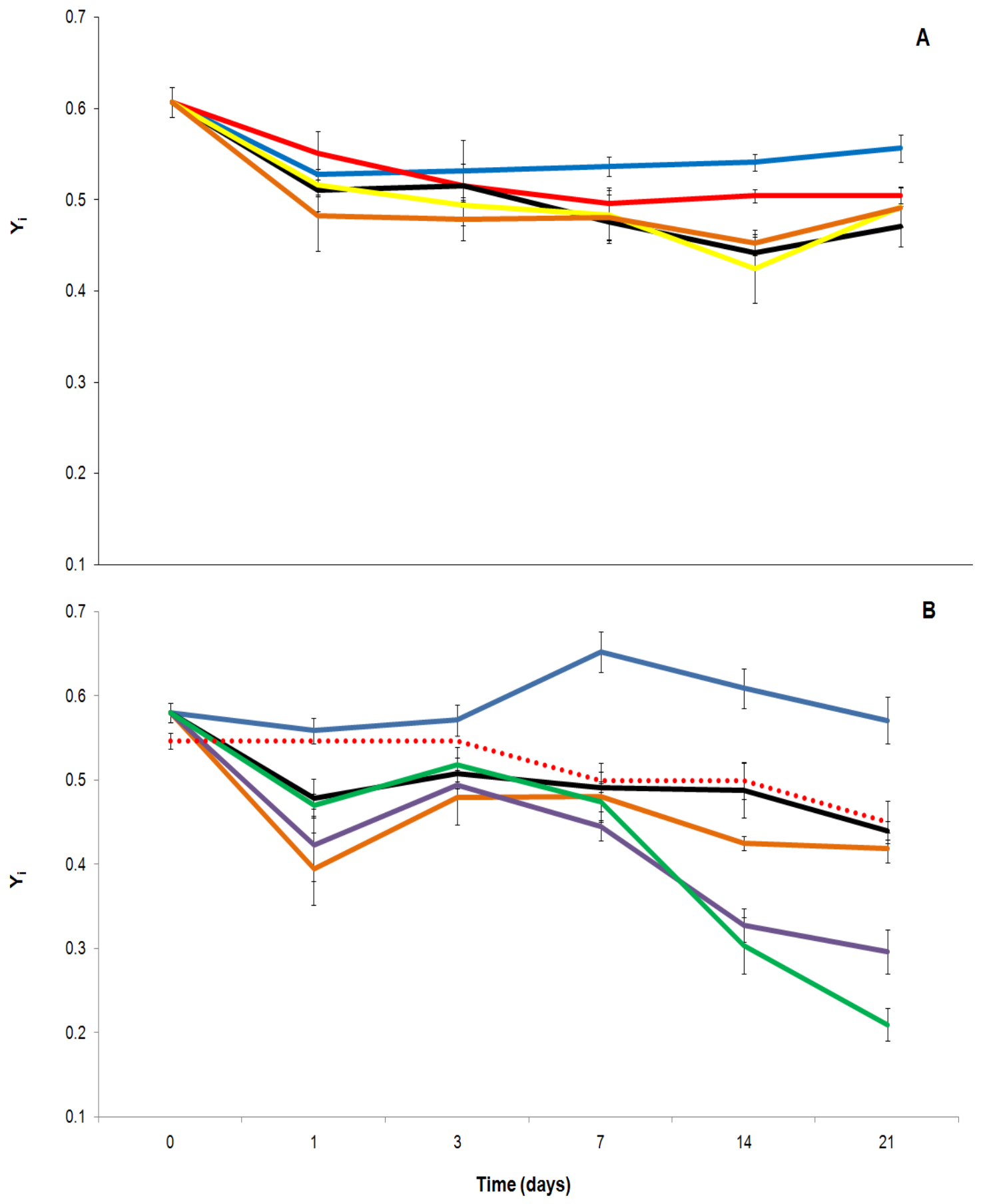

Figure 4.4: Photosynthetic health $\left(\mathrm{Y}_{\mathrm{i}}\right)$ of Anthopleura aureoradiata in response to seawater acidification. Treatments: A) pH 8.1 (blue); $\mathrm{pH} 7.6$ (red); $\mathrm{pH} 7.25$ (black); pH 7 (yellow); and pH 6.75 (orange). B) pH 8.1 (blue); $\mathrm{pH} 7.6$, as a reference from Chapter 3 results (red dash); $\mathrm{pH} 7.25$ (orange); $\mathrm{pH} 6.75$ (black); $\mathrm{pH} 6$ (purple); and $\mathrm{pH} 5$ (green). Treatments were acidified using 10\% $\mathrm{HCl}$. Values are means $\pm \mathrm{SE}, \mathrm{n}$ $=5$ per time-point, with the same anemones measured repeatedly throughout the experiment. 


\subsection{Discussion}

By Day 7, all acidified treatments in the first experiment ( $\mathrm{pH} \mathrm{7.6,7.25,} \mathrm{7,} \mathrm{and} \mathrm{6.75)}$ showed a negative impact on photosynthetic health when compared to the control. This negative impact continued until the end of the 21-day experiment, though the decline was very slight. However, the trends of declining photosynthetic health at these acidic $\mathrm{pH}$ levels were not different from one another, clearly indicating that no 'pH threshold' had been reached, at which cellular acidosis suddenly caused a massive loss of photosynthetic function (this finding corroborates the results of Chapter 3). Similar trends were seen in the second experiment, however at the two lower $\mathrm{pH}$ values ( $\mathrm{pH} 6$ and 5) there was a much more marked deterioration in photosynthetic health.

The results presented here for the less acidic treatments are consistent with those of Thornton (2009), who studied photosynthetic production of the marine planktonic diatom Chaetoceros muelleri. As in the current study, this author used $\mathrm{HCl}$ to acidify the seawater, to $\mathrm{pH}$ values of 7.9, 7.4 and 6.8; the control $\mathrm{pH}$ was 8.2. Thornton (2009) found that photosynthesis was unaffected at $\mathrm{pH} 7.9$, that there was a significant decrease in photosynthetic health at $\mathrm{pH} 7.4$ and $\mathrm{pH} 6.8$, and that the effect of these two lowest $\mathrm{pH}$ values was statistically similar. Thornton (2009) proposed that the reduction in photosynthetic health with acidification is due to less energy being available to fix carbon. The reduction in available energy can be linked to two potential mechanisms, operating either in concert or exclusively: 1) impacts of acidosis on mitochondrial function; and 2) impacts of acidosis on photosynthetic enzyme activity and thylakoid function. Under normal physiological conditions, and due to proton transport by the electron transport 
chain, mitochondria generate and maintain an alkaline $\mathrm{pH}$ in the mitochondrial matrix (Gursahani and Schaefer 2004). When proton generation by the mitochondrion is compromised (metabolic inhibition) this steady $\mathrm{pH}$ can be lowered causing mitochondrial acidification (Gursahani and Schaefer 2004). Acidification can result in inefficient protein translocation and membrane binding (Olsen et al. 1989), a decreased rate of net $\mathrm{Ca}^{2+}$ uptake, reduced electron transport chain integrity, and mitochondrial depolarisation - all of which act to impair the production of adenosine triphosphate (ATP) and the reduced form of nicotinamide adenine dinucleotide phosphate (NADPH) (Gursahani and Schaefer 2004; Wilson et al. 2006).

Hoefnagel et al. (1998) noted that the chloroplast generates insufficient ATP and NADPH from the light-dependent reactions to perform all cellular processes, therefore any impact on the capacity of the mitochondria to generate ATP is likely to impair photosynthetic performance, which in turn reduces the availability of energy-rich photosynthate for mitochondrial metabolism (Hoefnagel et al. 1998). Secondly, the pH may have moved out of the optimal range for the operation of mitochondrial/chloroplast enzymes. Enzymes require specific intracellular conditions to perform their function and, if these conditions are stable, enzymes are able to reduce the energy required (provide 'free energy') to initiate a chemical reaction. As a result, they can potentially catalyse a specific reaction up to $10^{19}$ times faster than if these stable conditions are absent (fig 4.5) (Albery and Knowles 1976; Kraut 1988; Garcia-Viloca 2004). In more extreme cases, acidosis can cause denaturation of enzymes (May et al. 1986; Reaich et al. 1992; Mitch et al. 1994 and May et al. 1996). Impacts on mitochondrial processes were discussed above, however the impacts that acidosis may directly have on the chloroplast are subtly 

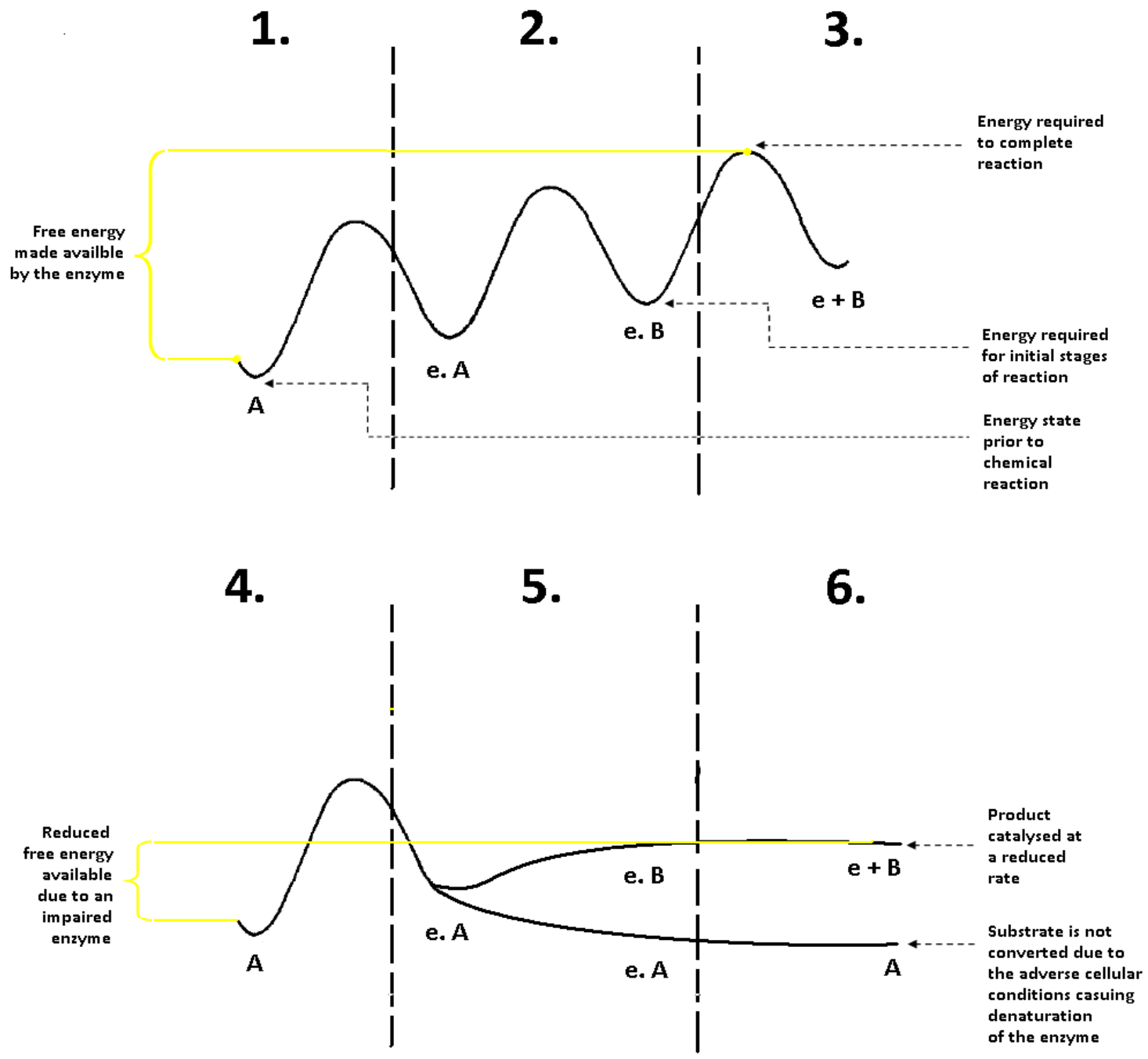

Figure 4.5: Free-energy profile of a typical enzymatic reaction. Points 1 (initial substrate); 2 (enzyme active site binds onto substrate and initial conversion); and 3 (enzyme and product at up to $10^{19}$ increased efficiency) represent optimal function of an enzyme under optimal conditions (for example, specific $\mathrm{pH}$, temperature and alcohol concentrations). The free energy made available by the enzyme (e) either allows the most efficient conversion rate of the substrate (A) to the product (B), or even permits the conversion to occur at all. Points 4 (initial substrate); 5 (enzyme binding on to substrate and initial conversion (e. B) or no binding occurs (e. A)); and 6 (enzyme and product catalysed at a reduced rate $(\mathrm{e}+\mathrm{B})$ or not at all $(\mathrm{A})$ represent what is likely to occur should an enzyme operate out of optimal conditions or become denatured. In the chloroplast, the substrate for the enzyme RuBisCO is $\mathrm{CO}_{2}$ or $\mathrm{O}_{2}$ combined with $\mathrm{H}_{2} \mathrm{O}$; if RuBisCO fixes $\mathrm{CO}_{2}$ the product produced is the intermediate photosynthetic product 3keto-2-carboxyarabinitol 1,5-bisphosphate. If RuBisCO decreased in efficiency or ceased to function there would be severe consequences for photosynthetic health.

Source: Adapted from Albery and Knowles (1976) and Kraut (1988) 
different, as acidosis may affect the proteinaceous enzyme ribulose-1,5-bisphosphate carboxylase (RuBisCO) or the enzymes involved in the conversion of $\mathrm{HCO}_{3}{ }^{-}$to $\mathrm{CO}_{2}$, and impair the membranes of the chloroplast, particularly the thylakoid membranes (Thornton 2009). Either working in concert with the reduced supply of ATP from the mitochondria, or exclusively on the basis of decreased chloroplast enzymatic/membrane efficiency, these hypotheses potentially account for the reduced photosynthetic health seen in $A$. aureoradiata. Clearly, at the more extreme $\mathrm{pH}$ values used in the current study $\mathrm{pH} 5$ and 6) such biochemical impacts will be more severe, and this is entirely consistent with the large decline in photosynthetic health seen at these levels of acidification.

The fact that the negative impacts of acidification, even at a $\mathrm{pH}$ of 6.75 , were only moderate and still allowed for reasonable photosynthetic function suggests that the zooxanthellae were somewhat buffered from the external $\mathrm{pH}$, or that they have adapted to function under these conditions. In terms of buffering from the ambient environment, not only are the zooxanthellae protected within the animal's cells, but it may be that the animal is somehow able to regulate its intracellular $\mathrm{pH}$ to avoid excessive acidification. Furthermore, it is possible that the cytosol of the zooxanthellae is somewhat resistant to changes in external pH. In support of this latter hypothesis, Smith and Raven (1979) concluded that the cytosol of plant cells is relatively insensitive to changes in the external $\mathrm{pH}$, and that changes in the internal $\mathrm{pH}$ are not directly proportional to changes in the external medium. Such a response could explain why the responses to the various $\mathrm{pH}$ treatments in the current study tended to occur in groups rather than as a continuum. The relative resistance to acidity, at least at the less acidic $\mathrm{pH}$ values, could result however from these $\mathrm{pH}$ values being closer to the $\mathrm{pH}$ inside the host's cells than initially suspected. 
Indeed, very recently the application of fluorescent $\mathrm{pH}$-sensitive probes and confocal microscopy has enabled the measurement of the $\mathrm{pH}$ at the interface between the zooxanthellae and the host's cytoplasm, with values of $\mathrm{pH}$ 7.01-7.41 being measured in a tropical coral (S. pistillata) and a temperate sea anemone (Anemonia viridis) (Venn et al. 2009). It therefore seems likely that zooxanthellae are adapted to living in conditions that are somewhat more acidic than the surrounding seawater, though if this is the case then it is perhaps surprising that photosynthetic health declined at all in A. aureoradiata at $\mathrm{pH} 7$ 7.65 .

Despite any buffering capacity of the host tissues or the algal cell itself, the results of this study suggested that eventually the $\mathrm{pH}$ was too low and the buffering system was overwhelmed, causing marked loss of photosynthetic function. Coleman and Colman (1981) studied photosynthetic $\mathrm{O}_{2}$ evolution and the intracellular $\mathrm{pH}$ of the cyanobacterium Coccochloris peniocystis, and noted that the intracellular $\mathrm{pH}$ did not change in proportion to the external $\mathrm{pH}$. For example, the intracellular $\mathrm{pH}$ was 7.6 and 7.9 when the external $\mathrm{pH}$ was 7.0 and 10 , respectively. However, when the external $\mathrm{pH}$ was reduced to $\mathrm{pH} 6.6$, the intracellular $\mathrm{pH}$ suddenly decreased to a value of 5.25 , and as a result photosynthetic production ceased entirely. Coleman and Colman's (1981) results therefore suggest a photosynthetic $\mathrm{pH}$ threshold of between $\mathrm{pH} 7.6$ and 6.6. This compares to an apparent 'tipping point' somewhere between 6.75 and 6 for $A$. aureoradiata, though further experimentation is required to confirm this and, if there is indeed such a threshold, at exactly what $\mathrm{pH}$ it occurs. 
It is important to note that the lower $\mathrm{pH}$ levels used in the current study are far more acidic than even the most extreme long-term predictions for oceanic $\mathrm{pH}$ (Caldeira and Wickett 2003). Furthermore, it is well established that the addition of $\mathrm{HCl}$ is not a good proxy for ocean acidification, due to it having different impacts on seawater chemistry than does $\mathrm{CO}_{2}$ (Kikkawa et al. 2003; Atkinson and Cuet 2008; Fabry 2008; IglesiasRodriguez et al. 2008). Nevertheless, these results provide insight into the $\mathrm{pH} /$ acidosis tolerance of zooxanthellae in A. aureoradiata without the confounding effects of $\mathrm{CO}_{2}$. It appears that these zooxanthellae suffer only a small decline in photosynthetic health with minor decreases in seawater $\mathrm{pH}(\sim 1 \mathrm{pH}$ unit). Given this, and the prediction of an oceanic $\mathrm{pH}$ of 7.6 by 2100 , it is unlikely that ocean acidification will have a major impact on zooxanthellar production in A. aureoradiata, which supports the evidence presented in Chapter 3. Further study is needed to assess whether other temperate symbiotic and freeliving algae behave in a similar manner, and how these compare to their tropical counterparts. However, it seems safe to assume from the data presented in this chapter and elsewhere in this thesis, that negative impacts of ocean acidification on zooxanthellar photosynthesis, in both corals and sea anemones, are not a major concern. This is in stark contrast to the potentially devastating impacts on coral calcification. 


\section{Chapter V}

\section{GENERAL DisCUSSION}

\section{Summary of Results}

This thesis aimed to detect any effect of seawater acidification on the photophysiology of symbiotic dinoflagellates (zooxanthellae). In particular, the effects on the zooxanthellae of a tropical coral and a temperate sea anemone were compared, as were the effects on zooxanthellae both inside and outside their coral host.

The response of various photophysiological parameters in the tropical coral Stylophora pistillata to acidification by $\mathrm{CO}_{2}$ was measured; unfortunately the data for the $\mathrm{HCl}$ trial were lost due to circumstances beyond the author's control. Over the 18-day experiment, zooxanthellae within acidified $S$. pistillata exhibited increased concentrations of chlorophyll when compared to zooxanthellae in corals at the control $\mathrm{pH}$. This did not, however, translate into increased levels of either gross photosynthesis per zooxanthella cell or total gross photosynthesis (i.e. photosynthesis per unit coral biomass), seemingly because there was a $22 \%$ (though non-significant) drop in gross photosynthesis per unit chlorophyll. After 18 days in the $\mathrm{pH} 8.1$ control treatment, S. pistillata exhibited a decreased respiration rate and this was reflected in a superior $P: R$ ratio (the ratio of biomass-specific gross photosynthesis to respiration) when compared to the $\mathrm{pH} 7.6 \mathrm{CO}_{2}$ treatment; both the respiration rate and $\mathrm{P}: \mathrm{R}$ ratio of $S$. pistillata in the $\mathrm{pH} 7.6 \mathrm{CO}_{2}$ 
treatment remained constant over the duration of the experiment. Despite the difference in $\mathrm{P}: \mathrm{R}$ responses between treatments, the $\mathrm{P}: \mathrm{R}$ ratio of $S$. pistillata remained at $>1$ in both treatments, indicating that complete autotrophy was maintained under both $\mathrm{pH}$ regimes. Photosynthetic health $\left(\mathrm{Y}_{\mathrm{i}}\right)$, zooxanthella density, and all other photosynthetic parameters (i.e. $P_{\max }, I_{k}$ and $\alpha$ ) remained unchanged for both treatments. While comparisons with $\mathrm{HCl}$ data were not possible, it is worth mentioning that alkalinity was an order of magnitude lower in the $\mathrm{pH} 7.6 \mathrm{HCl}$ treatment than in the control and $\mathrm{pH} 7.6 \mathrm{CO}_{2}$ treatments; these latter treatments had almost identical alkalinities. The variation in alkalinity may have explained why, at Day 17 (one day prior to the end of the experiment when over-acidification accidentally occurred) S. pistillata looked far less healthy (e.g. much paler, more mucus) than it did in the other treatments. Repetition of this experiment was not possible due to limited time at the Centre Scientifique de Monaco, but future studies should focus on the apparently different responses to $\mathrm{CO}_{2}$ versus $\mathrm{HCl}$, to better discriminate between the impacts of cellular acidosis and an increase in available Dissolved Inorganic Carbon (DIC) on the zooxanthellae of this, and other, tropical corals.

In addition to the experiments with in hospite zooxanthellae, zooxanthellae isolated and cultured from S. pistillata were also subjected to acidification with both $\mathrm{CO}_{2}$ and $\mathrm{HCl} . \mathrm{Y}_{\mathrm{i}}$ did not change in either $\mathrm{pH}$ treatment, while chlorophyll concentration per zooxanthella cell also remained unchanged. It is interesting that the coral and the zooxanthellae isolated from the coral exhibited similar increases in chlorophyll per zooxanthellae, with $25 \%$ and $33 \%$ increases respectively. These increases were narrowly insignificant and hence inconclusive, and could be interpreted as evidence against the theory that zooxanthellae are carbon limited while in hospite, however this is unlikely (see below) 
and further investigation will be required to confirm this. The difference between the isolated and in hospite zooxanthellae indicates that acidosis may impact on the animal host first, with consequent effects on the algal symbionts; a similar trend has been suggested with respect to thermal bleaching in some coral species (Ralph et al. 2001). Alternatively, the physiology of the zooxanthellae might change upon isolation from the host. Further work is required to elucidate the cellular basis of this difference.

Using the temperate sea anemone Anthopleura aureoradiata, and a longer-term experimental duration, similar acidification regimes were applied. The zooxanthella density declined slightly in the $\mathrm{pH} 7.6 \mathrm{HCl}$ treatment but this decline was not different from that in the $\mathrm{pH} 8.1$ control, suggesting that acidification itself had no impact on this parameter. However, total gross photosynthesis decreased in the $\mathrm{pH} 7.6 \mathrm{HCl}$ treatment as a result of a reduced photosynthetic rate per zooxanthella cell. This reduced rate in cellular productivity was not related to a change in chlorophyll per cell, which remained constant. Though both $Y_{i}$ and photosynthetic efficiency $(\alpha)$ did decline, suggesting a loss of photosynthetic function, the other photosynthetic parameters remained unchanged. Concurrent with the reduced rate of total gross photosynthesis in the $\mathrm{pH} 7.6 \mathrm{HCl}$ treatment was a drop in respiration, which meant that the anemone was potentially still able to meet its metabolic carbon requirements despite its lower overall photosynthetic production.

As in the $\mathrm{pH} 7.6 \mathrm{HCl}$ treatment, there was a decline in the zooxanthella density of $A$. aureoradiata in both the $\mathrm{pH} 8.1$ and $\mathrm{pH} 7.6 \mathrm{CO}_{2}$ treatments. Importantly though, the decline witnessed in the $\mathrm{pH} 7.6 \mathrm{CO}_{2}$ treatment was less marked than that seen in the $\mathrm{pH}$ 
8.1 control. This relative increase in zooxanthella density was reflected in an increased rate of total gross photosynthesis, though not in gross photosynthesis per cell or per unit chlorophyll. However, an increase in the respiration rate with acidification meant that the $P: R$ ratio was the same at the beginning and end of the experiment. Furthermore, $Y_{i}, P_{\max }$, $\mathrm{I}_{\mathrm{k}}$ and $\alpha$ did not change significantly throughout the experiment.

Finally, A. aureoradiata was subjected to graduated decreases in $\mathrm{pH}$ (with $\mathrm{HCl}$ ) to determine the $\mathrm{pH}$ threshold at which photosynthetic shut-down occurs; $\mathrm{pH} 7.6 \mathrm{HCl}$ had previously been shown to reduce photosynthetic health, $Y_{i}$, by $23 \%$. There was a positively-correlated relationship between declining $\mathrm{pH}$ and declining $\mathrm{Y}_{\mathrm{i}}$, though the responses to acidification clustered into three distinct groupings. The first 'grouping' contained $\mathrm{pH} 8.1$ only, at which $\mathrm{Y}_{\mathrm{i}}$ remained at control levels. The second grouping contained $\mathrm{pH} 7.25$ and $\mathrm{pH}$ 6.75, which had medium-level impacts on photosynthetic health that were comparable to those seen in the previously-described experiment. Lastly, the third grouping contained the extreme $\mathrm{pH}$ values of 6 and 5, both of which had severe impacts on the photosynthetic health of A. aureoradiata; indeed, $\mathrm{pH} 6$ induced photosynthetic shut-down and hence the threshold was somewhere between $\mathrm{pH} 6$ and $\mathrm{pH}$ 6.75. Further experiments are needed to pinpoint the exact $\mathrm{pH}$ at which shut-down occurs, however, and whether this threshold differs between different species.

With respect to the results described in this thesis, one broad question arises: are there likely to be any long-term effects of ocean acidification on photosynthesis by symbiotic cnidarians, and if so what are the ecological implications of such effects? This question is considered in detail here. 


\section{Long-Term Effects of Ocean Acidification on Photosynthesis}

The question of whether ocean acidification will have a long-term impact on photosynthetic production and ecosystem function has neither a single nor simple answer. A quick review of the current literature, both on symbiotic and non-symbiotic phototrophs, shows that ocean acidification could have: 1) a very positive effect on photosynthetic function (Palacious and Zimmerman 2007; Riebesell et al. 2007; HallSpencer et al. 2008; Iglesias-Rodriguez et al. 2008); 2) a moderately positive effect on photosynthetic function (Leonardos and Geider 2005; Hutchins et al. 2007); 3) a neutral effect on photosynthetic function (Rost et al. 2008); and 4) some loss of photosynthetic function (Anthony et al. 2008).

Anthony et al. (2008) found that the productivity of two coral (Acropora intermedia, Porites lobata) and one macroalgal species (Porolithon onkodes) reacted differently to a mixture of temperature and $\mathrm{pH}$ regimes: Porites lobata was much less negatively impacted than the other two species when maintained at temperatures and $\mathrm{pH}$ values similar to those used in this thesis. As the basic principles of photosynthesis are largely similar across all species, an important question remains as to why different photosynthetic organisms react differently to the same elevated DIC content and corresponding decrease in $\mathrm{pH}$ ? Rost et al. (2008) noted that acidification studies that find impacts on photosynthesis can only speculate as to the mechanisms behind the patterns observed, meaning that knowledge of these mechanisms is severely limited at present. However, one potential explanation for the variable responses to acidification relates to the supply of DIC to the algal cell and its subsequent utilisation. 
Unlike free-living microalgae, zooxanthellae are typically carbon limited when in hospite as a result of their high densities and endosymbiotic habitat (Yellowlees et al. 1993; Weis 1993; Baillie and Yellowlees 1998; Leggat et al. 1999; Leggat et al. 2002). This situation has led to carbon concentrating mechanisms (CCMs) in symbiotic cnidarians that aid the delivery of DIC to the algae for photosynthesis. Foremost among these CCMs is the enzyme carbonic anhydrase (CA), which inter-converts bicarbonate and $\mathrm{CO}_{2}$; $\mathrm{CA}$ is found both in the animal's tissues, on or near the surface of the algal cell, and within the alga (Weis 1993; Leggat et al. 1999). Once in the algal cell, the CCM serves to concentrate $\mathrm{CO}_{2}$ around the primary carboxylating enzyme, Ribulose-1,5-bisphosphate carboxylase ( $\mathrm{RuBisCO})$. RuBisCO is an ancient and highly conserved enzyme which evolved in times of elevated atmospheric $\mathrm{CO}_{2}$ and low $\mathrm{O}_{2}$ levels, and therefore is characterised by low affinities for its primary substrate $\mathrm{CO}_{2}$ and a susceptibility to perform a photorespiratory reaction with $\mathrm{O}_{2}$ (Rost et al. 2008). All photosynthetic organisms have developed methods to maximise the efficiency of RuBisCO. $\mathrm{C}_{3}$ plants have evolved highly efficient $\mathrm{RuBisCO}$, while $\mathrm{C}_{4}$ plants have evolved the structural and biochemical capability to concentrate carbon, though it is perhaps aquatic photosynthetic organisms that have developed the greatest diversity of strategies to improve the catalytic potential of RuBisCO (Badger et al. 1998; Giordano et al. 2005). $\mathrm{S}_{\text {rel }}$ ratios, or the relative specificity factor for the Rubisco to function as a carboxylase versus an oxygenase, provides insight into the ability of the $\mathrm{RuBisCO}$ to discriminate between $\mathrm{CO}_{2}$ and $\mathrm{O}_{2}$. Therefore if the $\mathrm{S}_{\text {rel }}$ ratio is low then there is likely a need for a CCM to create high internal concentrations of inorganic carbon (Badger et al. 1998; Leggat et al. 1999; Giordano et al. 2005). Evidence from Badger et al. (1998) suggests that there is considerable variation in the ability of photosynthetic organisms to use CCMs to create 
high intracellular concentrations of inorganic carbon. For example, the green alga Chlorella saccharophila can create up to a 180 -fold higher concentration than would be expected from passive diffusion alone, while the photosynthetic freshwater flagellate Peridinium gatunense can create concentrations up to 80-fold greater (Badger et al. 1998). At the opposite end of the scale are organisms such as the red alga Porphyridium cruentum and the coccolithophorid Emiliania huxleyi, which are capable of creating concentrations of only 1 - to 15 -fold greater than that expected through diffusion. To counter this, these organisms contain RuBisCO with relatively high $\mathrm{S}_{\text {rel }}$ ratios and therefore a relatively high affinity for $\mathrm{CO}_{2}$ (Badger et al. 1998). Dinoflagellates appear to be a unique case. For example, Leggat et al. (1999) illustrated that zooxanthellae (Symbiodinium sp.) from the giant clam Tridacna gigas have a similar ability to concentrate intracellular inorganic carbon to other marine algae, at around 40-fold the concentration expected from diffusion alone, yet their $\mathrm{RuBisCO}$ has an uncharacteristically low $\mathrm{S}_{\text {rel }}$ score. Likewise, the free-living dinoflagellate Amphidinium carterae has a similarly strong capacity to concentrate carbon, but when its $\mathrm{S}_{\text {rel }}$ score was compared with a range of other organisms, it ranked $4^{\text {th }}$ lowest out of 33 species (Badger et al. 1998). What makes dinoflagellates highly unusual is that they are the only group of organisms (along with anaerobic bacteria, where low $\mathrm{S}_{\text {rel }}$ values are of low physiological significance) to contain form II RuBisCO (Badger et al. 1998; Leggat et al. 1999; Giordano et al. 2005). This isoform has a maximum $\mathrm{S}_{\mathrm{rel}}$ score that is $40 \%$ lower than the lowest score of form I RuBisCO. The functional diversity of CCMs (in both symbiotic hosts and algae) and RuBisCO isoforms therefore provide a basis to explain the different responses of corals and other photosynthetic organisms to elevated levels of $\mathrm{CO}_{2}$, though 
far more work is needed to confirm the relationship between these cellular processes and the response to ocean acidification.

From the previous paragraph, it is a reasonable prediction that the susceptibility of a photosynthetic organism to ocean acidification will depend more upon its phylogeny rather than its latitudinal origin or habitat, with certain evolutionary groupings of organisms likely to benefit from elevated $\mathrm{CO}_{2}$ levels more than others (Giordano et al. 2005). Indeed, it is possible that any differences between the responses of S. pistillata and A. aureoradiata observed here are the result of phylogenetic differences rather than latitudinal ones, though a much broader survey of temperate versus tropical symbioses is needed to confirm this. According to Rost et al. (2008), species that rely solely on $\mathrm{CO}_{2}$ uptake by diffusion or those with inefficient $\mathrm{CCMs}$ are highly $\mathrm{CO}_{2}$ sensitive in photosynthesis, and thus may rapidly and directly benefit from any increases in ambient $\mathrm{CO}_{2}$ levels. Furthermore, this same author concludes that those species operating highly efficient $\mathrm{CCMs}$ are already at, or close to, rate-saturation under present day $\mathrm{CO}_{2}$ concentrations. Therefore, these algae are less likely to benefit from increases in $\mathrm{CO}_{2}$ in the short/medium-term but nevertheless may benefit in the future, since a downregulation of the $\mathrm{CCM}$ under elevated $\mathrm{CO}_{2}$ levels may allow for optimised energy and resource allocation. Given that the effects of $\mathrm{CO}_{2}$ supplementation in the current study were relatively minor, this could suggest that the zooxanthellae and their host possess a highly effective CCM that largely (though not wholly) counters the low affinity of form II RuBisCO. Alternatively though, it could indicate that the host tightly regulates the delivery of $\mathrm{CO}_{2}$ to its symbionts as a means of controlling their growth. Regulation of the symbiont population, as well as inter-partner signalling, is a characteristic of cnidariandinoflagellate symbioses (Smith and Muscatine 1986; Davy and Cook 2001b). This latter 
possibility could certainly explain why, even with the more efficient form I RuBisCO, a number of other free-living algae and seagrasses studied to date respond more dramatically to the addition of $\mathrm{CO}_{2}$ than did the symbiotic dinoflagellates in the current study (Palacious and Zimmerman 2007; Riebesell et al. 2007; Hall-Spencer et al. 2008; Iglesias-Rodriguez et al. 2008).

Most commonly, the literature reports neutral or positive impacts of ocean acidification on photosynthetic function (Riebesell et al. 2007; Guinotte and. Fabry 2008; Doney et al. 2009), which is consistent with the different CCMs and RuBisCO affinities discussed above. However, the negative impacts reported by Anthony et al. (2008) and in response to $\mathrm{HCl}$ in this thesis suggest that other detrimental physiological events must be occurring in these cases, presumably as a result of cellular acidosis. By 2100 , the $\mathrm{pH}$ of the oceans is predicted to decrease to 7.6 (Caldeira and Wickett 2003; Orr et al. 2005; Wood et al. 2008; Zeebe et al. 2008; Doney et al. 2009), representing an exponential increase in $\mathrm{H}^{+}$ ions present in the oceans. Dissolved $\mathrm{CO}_{2}$ is expected to increase to a greater extent than the decrease in carbonate ions meaning that total DIC is expected to be significantly higher than in pre-industrial times (Royal Society 2005; Caldeira 2007; Rost et al. 2008) (fig 5.1). It is apparent that, without the mitigating effects of elevated $\mathrm{CO}_{2}$ levels, acidification in the future has the potential to lead to physiological dysfunction in zooxanthellae, perhaps by removing the optimal intracellular conditions required for CA and/or RuBisCO function, or by denaturing these and other enzymes completely. However, with the predicted rise in DIC, events may be rather different, with higher rates of photosynthesis and greater productivity actually being seen. This suggests that enhanced $\mathrm{CO}_{2}$ availability somehow counters, either partially or wholly, the impacts of 
acidosis. While this would do little to save coral reefs given the changes in seawater carbonate availability for calcification, it could conceivably benefit non-calcifiers such as phototrophic sea anemones, and even assist the survival of coral polyps that may have lost their skeletons as a result of ocean acidification (Fine and Tchernov 2007). It is worth bearing in mind, though, that environmental factors such as temperature, light, inorganic nutrient supply and UV-B light can potentially impact upon the operation of CCMs and hence indirectly impact photosynthetic DIC supply, and that different algae have different susceptibilities to these factors (Giordano et al. 2005). Hence, in reality, the impacts of $\mathrm{pH}$ cannot be considered in isolation.

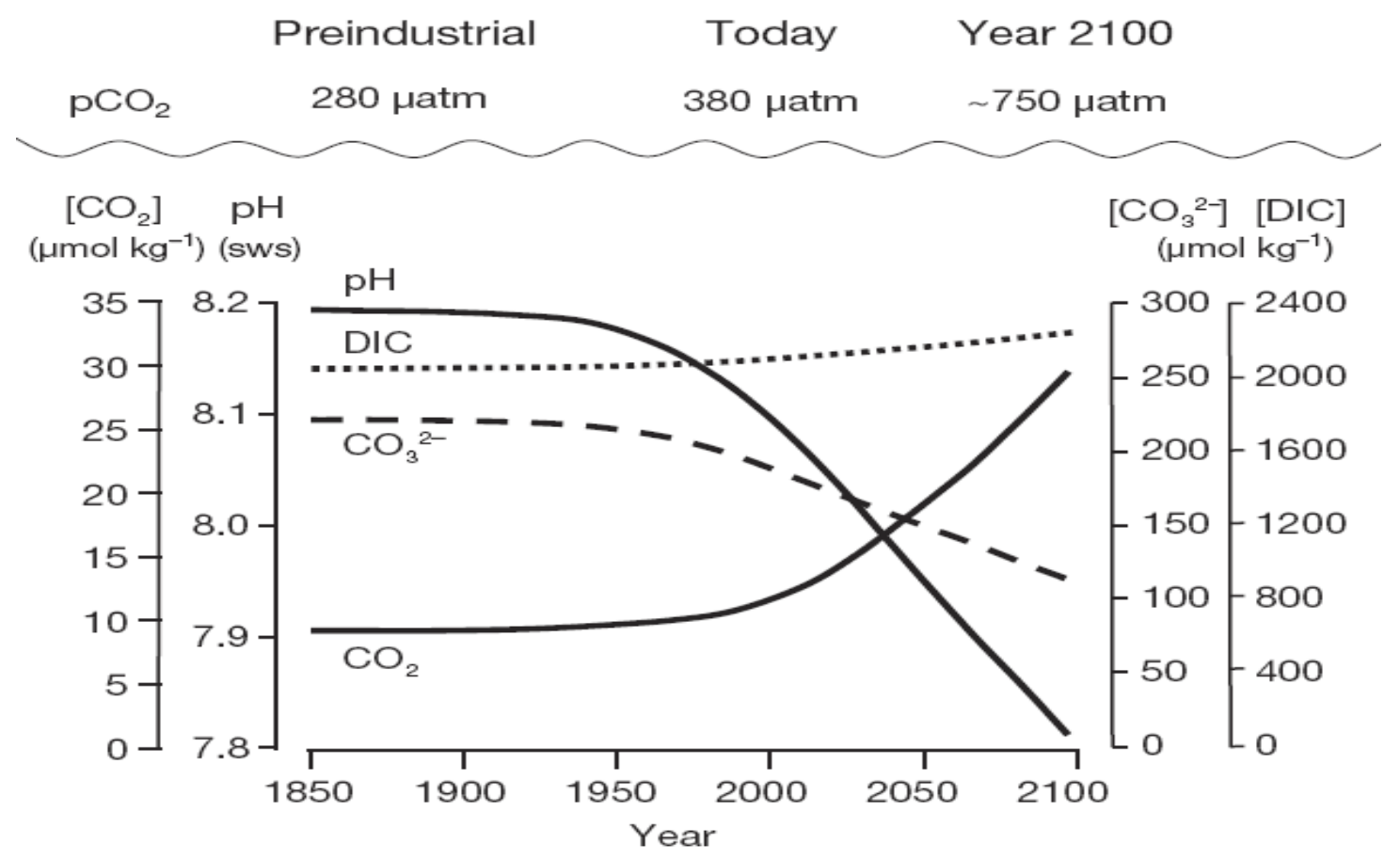

Figure 5.1: Key changes to carbon oceanic chemistry as a result of ocean acidification. Using information from the IPCC and assuming scenario IS92a, by $2100 \mathrm{pH}$ is predicted to fall to $7.8-7.6, \mathrm{CO}_{3}{ }^{2-}$ will drop by $50 \%$, there will be significantly increased dissolved $\mathrm{CO}_{2}$, and total DIC will increase.

(Source: Rost et al. 2008)

From the preceding discussion it is clear that the response to acidification is species specific. We therefore still need to know far more about how different species of corals 
and other symbiotic invertebrates respond to acidification and what the cellular bases are for any differences between species. Only then can we begin to accurately predict what the ecological implications of ocean acidification are. For instance, a comprehensive understanding of different cladal and intra-cladal responses of Symbiodinium spp. may allow us to predict which dinoflagellates will benefit or not as our oceans acidify, and consequently whether any symbiont community shifts might occur, as have been observed in responses to sea surface temperature fluctuations (Berkelmans and van Oppen 2006; Jones et al. 2008). Such shifts have been experimentally shown in freeliving diatom communities in the Ross Sea, Antarctica, where $\mathrm{CO}_{2}$ concentrations matching those of long term projections caused a change in the species composition in favour of larger chain-forming species (Tortell et al. 2008). Furthermore, we need to clarify the extent to which $\mathrm{HCl}$ can be trusted to isolate the effects of cellular acidosis from any positive effects of $\mathrm{CO}_{2}$ fertilisation, as the alkalinity of $\mathrm{HCl}$-acidified water is considerably below that of seawater acidified with $\mathrm{CO}_{2}$. Until then, the conclusions of comparative experiments, such as those presented here, should be treated with caution.

In general, however, it seems likely that the impacts of ocean acidification on the photophysiology of symbiotic dinoflagellates in corals and other cnidarians will, as a result of the positive effects of greater $\mathrm{CO}_{2}$ supply and reduced carbon limitation, be relatively minor when compared to the impacts on calcification or, potentially, other metabolic processes that are impacted by intracellular acidosis. However, the potential still exists for community shifts in both host and symbiont species, and further research is essential for us to better predict what these might be. 


\section{REFERENCES}

Albery, W. J., and Knowles, J. R. 1976. Evolution of enzyme function and the development of catalytic efficiency. Biochemistry 15(25): $5631-5640$

Allemand, D., Tambutté, E., Girard, J.-P., and Jaubert, J. 1998. Organic matrix synthesis in the scleractinian coral Stylophora Pistillata: role in biomineralization and potential target of the organotin tributyltin. The Journal of Experimental Biology 201: $2001-2009$

Allemand, D., Ferrier-Pagès, C., Furla, P., Houlbrèque, F., Puverel, S., Reynaud, S., Tambutté, E., Tambutté, S., and Zoccola, D. 2004. Biomineralisation in reefbuilding corals: from molecular mechanisms to environmental control. Comptes Rendus Palevol 3(6-7): 453 - 467

Anthony, K. R. N., and Hoegh-Guldberg, O. 2003. Kinetics of photoacclimation in corals. Oecologica 134(1): $23-31$

Anthony, K. R. N., Kline, D. I., Diaz-Pulido, G., Dove, S., and Hoegh-Guldberg O. 2008. Ocean acidification causes bleaching and productivity loss in coral reef builders. Proceedings of the National Academy of Sciences of the United States of America 105(45): $17442-17446$

Atkinson, M. J., and Cuet, P. 2008. Possible effects of ocean acidification on coral reef biogeochemistry: topics for research. Marine Ecology Progress Series 373: 249 256

Badger, M. R., Andrews, T. J., Whitney, S. M., Ludwig, M., Yellowlees, D. C., Leggat, W., and Price, G. D. 1998. The diversity and co-evolution of Rubisco, plastids, 
pyrenoids and chloroplast-based CCMs in the algae. Canadian Journal of Botany 76(6): $1052-1071$

Baillie, B. K., and Yellowlees, D. 1998. Characterization and function of carbonic anhydrases in the zooxanthellae-giant clam symbiosis. Proceedings of the Royal Society of London B: Biological Sciences 265(1395): 465 - 473

Baker, A. C. 2003. Flexibility and specificity in coral-algal symbiosis: diversity, ecology, and biogeography of Symbiodinium. Annual Review of Ecology, Evolution, and Systematics 34: $661-689$

Baker, C., Starger, C. J., McClanahan, T. R., and Glynn, P. W. 2004. Coral reefs: corals' adaptive response to climate change. Nature 430: 741

Barker, P. F., Barrett. P. J., Cooper, A. K., and Huybrechts, P. 1999. Antarctic glacial history from numerical models and continental margin sediments. Palaeogeography, Palaeoclimatology, Palaeoecology 150: 247 - 267

Barneah, O., Brickner, I., Hooge, M., Weis, V. M., LaJeunesse, T. C., Benayahu, Y. 2007. Three party symbiosis: acoelomorph worms, corals and unicellular algal symbionts in Eilat (Red Sea). Marine Biology 151: 1215 - 1223

Barnett, J., and Adger, W. N. 2003. Climate dangers and atoll countries. Climate Change, 61(3): $321-327$

Bavestrello, G., Arillo, A., Calcinai, B., Cattaneo-Vietti, R., Cerrano, C., Gaino, E., Penna, A., and Sara, M. 2000. Parasitic diatoms inside Antarctic sponges. Biological Bulletin 198: $29-33$

Beer, S., Ilan, M., Eshel, A., Weil, A., and Brickner, I. 1998. Use of pulse amplitude modulated (PAM) fluorometry for in situ measurements of photosynthesis in two Red Sea faviid corals. Marine Biology 131(4): 607 - 612 
Bell, P. R. F., and Elmetri, I. 1995. Ecological indicators of large-scale eutrophication in the Great Barrier Reef lagoon. Ambio 24(4): 208 - 215

Berkelmans, R., and van Oppen, M. J. H. 2006. The role of zooxanthellae in the thermal tolerance of corals: a 'nugget of hope' for coral reefs in an era of climate change. Proceedings of the Royal Society of London B: Biological Sciences 273(1599): $2305-2312$

Bijma, J., Honisch, B., and Zeebe, R. E. 2002. The impact of the ocean carbonate chemistry on living foraminiferal shell weight: Comment on "carbonate ion concentration in glacial-age deep waters of the Caribbean Sea" by W.S. Broecker \& E. Clark. Geochemistry. Geophysics. Geosystems. 3(11): 1064

Bil, K. Y., Kolmakov, P. V., and Muscatine, L. 1992. Photosynthetic products of zooxanthellae of the reef-building corals Stylophora Pistillata and Sereatopora Coliendrum from different depths of the Seychelles Islands. Atoll Research Bulletin 377: no pages specified

Blackford, J. C., Austen, M., Halloran, P., Iglesias-Rodriguez, D., Mayor, D., Pearce, D., and Turley, C. 2007. Modelling the response of marine ecosystems to increasing levels of $\mathrm{CO}_{2}$, Report to DEFRA arising from: Advances in Marine Ecosystem Modelling Research Workshop February 12 - 14, 2007. Plymouth, United Kingdom

Blank, R. J. 1987. Cell architecture of the dinoflagellate Symbiodinium sp. inhabiting the Hawaiian stony coral Montipora verrucosa. Marine Biology 94: 143 - 155

Blidberg, E., Elfwing, T., Plantman, P., and Tedengren, M. 2000. Water temperature influences on physiological behaviour in three species of giant clams (Tridacnidae). Proceedings 9th International Coral Reef Symposium, Bali, Indonesia 23-27 October 2000 
Blokhina, O., Virolainen, E., and Fagerstedt, K. V. 2002. Antioxidants, oxidative damage and oxygen deprivation stress: a review. Annals of Botany 91: $179-194$

Boag, S., Agostino, A., Furbank, R. T., and Hatch M. D. 1989. Effects of external $\sim$ g + and $\mathrm{pH}$ on the photosynthetic activities and stromal $\mathrm{pH}$ of intact chloroplasts isolated from C4 plants. Australian Journal of Plant Physiology 16: 379 - 90

Buddemeier, R. W., and Fautin, D. G. 1993. Coral bleaching as an adaptive mechanism. Bioscience 43(5): $320-325$

Buddemeier, R. W., Kleypas, J. A., and Aronson R. B. 2004. Coral reefs: potential contributions of climate change to stresses on coral reef ecosystems. Prepared for the Pew Center on Global Climate Change.

Burris, R. H. 1984. Nitrogen metabolism in the coral-algal symbiosis. Proceedings of the American Philosophical Society 128(1): 85 - 92

Caldeira, K., and Wickett, M. E. 2003. Anthropogenic carbon and ocean pH. Nature 425: 365

Caldeira, K. 2007. What corals are dying to tell us about $\mathrm{CO}_{2}$ and ocean acidification? Oceanography 20(2): 188 - 195

Carlos A. A., Baillie B. K., Kawachi M., and Maruyama T. 1999. Phylogenetic position of Symbiodinium (Dinophyceae) isolates from tridacnids (Bivalvia), cardiids (Bivalvia), a sponge (Porifera), a soft coral (Anthozoa), and a free living strain. Journal of Phycology 35: 1054 - 1062

Carte, B. K. 1996. Biomedical potential of marine natural products. BioScience 46: 271 286 
Chesnick, J. M., Morden, C. W., and Schmieg, A. M. 1996. Identity of the endosymbiont of Peridinium foliaceum (pyrrophyta): analysis of the rbcls operon. Journal of Phycology 32: $850-857$

Church, J. A., White, N. J., and Hunter, J. R. 2006. Sea-level rise at tropical Pacific and Indian Ocean islands. Global and Planetary Change 53(3): 155 - 168

Clark, P. U., Pisias, N. G., Stocker. T. F., and Weaver, A. J. 2002. The role of the thermohaline circulation in abrupt climate change. Nature 415: $863-869$

Coffroth, M. A., and Santos, S. R. 2005. Genetic diversity of symbiotic dinoflagellates in the genus Symbiodinium. Protist 156(1): $19-34$

Cohen, A. L., and T. A. McConnaughey, Geochemical perspective on coral mineralization. Reviews in Mineralogy and Geochemistry 54151 - 187

Coleman, J. R., and Colman, B., 1981. Inorganic carbon accumulation and photosynthesis in a blue-green alga as a function of external pH. Plant Physiology 67: 917 - 921

Constantz, B. R., and Weiner, S. 1988. Acidic macromolecules associated with the mineral phase of scleractinian coral skeletons. Journal of Experimental Zoology 248: $253-258$

Cook, C. B., Muller-Parker, G., and Orlandini, C. D. 1994. Ammonium enhancement of dark carbon fixation and nitrogen limitation in zooxanthellae symbiotic with the reef corals Madracis mirabilis and Montastrea annularis. Marine Biology 118(1): $157-165$

Cornish A. S., and DiDonato, E. M. 2004. Resurvey of a reef flat in American Samoa after 85 years reveals devastation to a soft coral (Alcyonacea) community. Marine Pollution Bulletin 48(7-8): 768 - 777 
Crawley, A., Kline, D. I., Dunn, S., Anthony, K., and Dove, S. 2009. The effect of ocean acidification on symbionts photorespiration and productivity in Acropora formosa. Global Change Biology. Received 4 February 2009; revised version received 31 March 2009 and accepted 3 April 2009 [as yet unpublished]

Crossland, C. J., Barnes, D. J., and Borowitzka, M. A. 1980. Diurnal lipid and mucus production in the staghorn coral Acropora acuminate. Marine Biology 60: 81 - 90

Davies, P. S. 1984. The role of zooxanthellae in the nutritional energy requirements of Pocillopora eydouxi. Coral Reefs 2(4): 181 - 186

Davies, P. S. 1991. Effect of daylight variations on the energy budgets of shallow-water corals. Marine Biology 108(1): 137 - 144

Davy, S. K., Lucas, I. A. N., and Turner, J. R. 1996. Carbon budgets in temperate anthozoan-dinoflagellate symbioses. Marine Biology 126: 773 - 783

Davy, S. K., Lucas, I., and Turner, J. R. 1997. Uptake and persistence of homologous and heterologous zooxanthellae in the temperate sea anemone Cereus pedunculatus (Pennant). The Biological Bulletin 192(2): 208 - 216

Davy, S. K., and Cook, C. B. 2001a. The influence of 'host release factor' on carbon release by zooxanthellae isolated from fed and starved Aiptasia pallida (Verrill). Comparative biochemistry and physiology. Part A, Molecular \& integrative physiology 129(2-3): $487-494$

Davy, S. K., and Cook, C. B. 2001b. The Relationship between nutritional status and carbon flux in the zooxanthellate sea anemone Aiptasia pallida. Marine Biology 139(5): $999-1005$ 
Davy, S. K., Trautman, D. A., Borowitzka. M. A., and Hinde, R. 2002. Ammonium excretion by a symbiotic sponge supplies the nitrogen requirements of its rhodophyte partner. The Journal of Experimental Biology 205: 3505 - 3511

Davy, S. K., and Turner, J. R. 2003. Early development and acquisition of zooxanthellae in the temperate symbiotic sea anemone Anthopleura ballii (Cocks). Biological Bulletin 205: $66-72$

D'Elia, C. F. 1977. The uptake and release of dissolved phosphorus by reef corals. Limnology and Oceanography 22(2): $301-315$

Dodds, W. K., Biggs, B. J. F., and Lowe, R. L. 1999. Photosynthesis-irradiance patterns in benthic microalgae: variations as a function of assemblage thickness and community structure. Journal of Phycology 35: $42-53$

Doerr, C. H., Gajic, O., Berrios, J. C., Caples, S., Abdel, M., Lymp, J. F., and Hubmayr, R. D. 2005. Hypercapnic acidosis impairs plasma membrane wound resealing in ventilator-injured lungs. American Journal of Respiratory and Critical Care Medicine 171: 1371 - 1377

Doney, S. C., Fabry, V. J., Feely, R. A., and Joan A. K. 2009. Ocean acidification: the other $\mathrm{CO}_{2}$ problem. Annual Review of Marine Science 1: 169 - 192

Epstein, P. R. 2001. Climate change and emerging infectious diseases. Microbes and Infection 3: $747-754$

Fabricius, K. E., Mieog, J. C., Colin, P. L., Idip, D., and Van open, M. J. H. 2004. Identity and diversity of coral endosymbionts (zooxanthellae) from three Palauan reefs with contrasting bleaching, temperature and shading histories. Molecular Ecology 13: 2445 - 2458 
Fabry, V. J. 2008. Marine calcifiers in a high- $\mathrm{CO}_{2}$ Ocean. Science 320(5879): 1020 1022

Fabry, V. J., Seibel, B. A., Feely, R. A., and Orr, J. C. 2008. Impacts of ocean acidification on marine fauna and ecosystem processes. ICES Journal of Marine Science 65(3): $414-432$

Falkowski, P. G., and Dubinsky, Z. 1981. Light-shade adaptation of Stylophora pistillata, a hermatypic coral from the Gulf of Eilat. Nature 289: 172 - 174

Falkowski, P. G., and La Roche, J. 1991. Acclimation to spectral irradiance in algae. Journal of Phycology 27(1): 8 - 14

Fine, M., and Tchernov, D. 2007. Scleractinian coral species survive and recover from decalcification. Science 315(5820): 1811

Fitt, W. K., and Cook, C. B. 2001. Photoacclimation and the effect of the symbiotic environment on the photosynthetic response of symbiotic dinoflagellates in the tropical marine hydroid Myrionema amboinense. Journal of Experimental Marine Biology and Ecology 256(1): 15 - 31

Furla, P., Galgani, I., Durand, I., and Allemand, D. 2000. Sources and mechanisms of inorganic carbon transport for coral calcification and photosynthesis. Journal of Experimental Biology 203(22): 3445 - 3457

Furla, P., Allemand, D., Shick, M. J., Ferrier-Pages, C., Richier, S., Plantivaux, A., Merle, P.-L., and Tambutte, S. 2005. The symbiotic anthozoan: a physiological chimera between alga and animal. Integrative and Comparative Biology 45: 595 - 604

Gantt, E. 1996. Pigment protein complexes and the concept of the photosynthetic unit: chlorophyll complexes and phycobilisomes. Photosynthesis Research 48: 47 - 53 
Garcia-Viloca, M., Gao, J., Karplus, M., and Truhlar, D. G. 2004. How enzymes work: analysis by modern rate theory and computer simulations. Science 303(5655): 186 $-195$

Garson, M. J., Flowers, A. E., Webb, R. I., Charan, R. D., and McCaffrey, E. J. 1998. A sponge/dinoflagellate association in the haplosclerid sponge Haliclona sp.: cellular origin of cytotoxic alkaloids by percoll density gradient fractionation. Cell and Tissue Research 293(2): 365 - 373

Gattuso, J.-P., Frankignoulle, M., Bourge, I., Romaine, S., and Buddemeier, R. W. 1998. Effect of calcium carbonate saturation of seawater on coral calcification. Global Planet Change 18: $37-46$

Gattuso, J.-P., Allemand, D., and Frankignoullej, M. 1999. Photosynthesis and calcification at cellular, organismal and community levels in coral reefs: a review on interactions and control by carbonate chemistry. American Zoologist 39: 160 183

Gattuso, J.-P., Reynaud-Vaganay, S., Furla, P., Romaine-Lioud, S., Jaubert, J., Bourge, I., and Frankignoulle, M. 2000. Calcification does not stimulate photosynthesis in the zooxanthellate scleractinian coral Stylophora pistillata. Limnology Oceanography 45: $246-250$

Gazeau, F., Quiblier, C., Jansen, J. M., Gattuso, J-P., Middelburg, J. J., and Heip, C. H. R. 2007. Impact of elevated $\mathrm{CO}_{2}$ on shellfish calcification. Geophysical Research Letters Vol. 34: L07603

Gierck, M. 2007. Warmer seas will stress coral. Eureka Street 17(17): 18 - 20

Giordano, M., Beardall, J., and Raven, J. A. 2005. $\mathrm{CO}_{2}$ concentrating mechanisms in algae: mechanisms, environmental modulation, and evolution. Annual Review of Plant Biology 56: 99 - 131 
Goh, B. P. L., and Chou, M. L. 1990. Corals in marine pollution monitoring. Essays in Zoology. Papers commemorating the $40^{\text {th }}$ anniversary of the Department of Zoology, National University of Singapore $465-476$

Goiran, C., Al-Moghrabi, S., Allemand, D., and Jaubert, J. 1996. Inorganic carbon uptake for photosynthesis by the symbiotic coral /dinoflagellate association I. photosynthetic performances of symbionts and dependence on sea water bicarbonate. Journal of Experimental Marine Biology and Ecology 199: 207-225

Gómez-Cabrera, M del C., Ortiz, J. C., Loh, W. K. W., Ward, S., and Hoegh-Guldberg, O. 2008. Acquisition of symbiotic dinoflagellates (Symbiodinium) by juveniles of the coral Acropora longicyathus. Coral Reefs 27: $219-226$

Goreau, T. F. 1959. The physiology of skeleton formation in corals. I. A method for measuring the rate of calcium deposition by corals under different conditions. Biological Bulletin (Marine biology Laboratory, Woods Hole) 116: 59-75

Grant, A. J., Rémond, M., and Hinde, R. 1998. Low molecular-weight factor from Plesiastrea versipora (Scleractinia) that modifies release and glycerol metabolism of isolated symbiotic algae. Marine Biology 130: 553 - 557

Guinotte, J. M., and Fabry, V. J. 2008. Ocean acidification and its potential effects on marine ecosystems. Annals of the New York Academy of Sciences 1134: 320 - 342

Gursahani. H. I., and Schaefer, S. 2004. Acidification reduces mitochondrial calcium uptake in rat cardiac mitochondria. American Journal Physiology: Heart and Circulation Physiology 287: H2659-H2665

Hall, N. C., Carney, J. M., Cheng, M. S., and Butterfield, D. A. 1995. Ischemia /reperfusion-induced changes in membrane proteins and lipids of gerbil cortical synaptosomes. Neuroscience 64(1): 81 - 89 
Hall-Spencer, J. M., Rodolfo-Metalpa, R., Martin, S., Ransome, E., Maoz, F., Turner, S. M., Rowley, S. J., Tedesco, D., and Maria-Cristina B. 2008. Volcanic carbon dioxide vents show ecosystem effects of ocean acidification. Nature 454: 99 - 99

Harland, A. D., and Davies, P. S. 1995. Symbiont photosynthesis increases both respiration and photosynthesis in the symbiotic sea anemone Anemonia viridis. Marine Biology 123: 715 - 722

Hauck, L. L. 2007. Molecular investigation of the cnidarian-dinoflagellate symbiosis and the identification of genes differentially expressed during bleaching in the coral Montipora capitata. A dissertation submitted to Oregon State University in partial fulfilment of the requirements for the degree of Doctor of Philosophy. Presented March 20, 2007 Commencement June 2007

Hawkins, J. P., and Roberts, C. M. 1994. The growth of coastal tourism in the red sea: present and future effects on coral reefs. Ambio 23(8): $503-508$

Herfort, L., Thake, B., and Taubner, I. 2008. Bicarbonate stimulation of calcification and photosynthesis in two hermatypic corals. Journal of Phycology 44(1): 91 - 98

Hoefnagel , M. H. N., Atkin, O. K., and Wiskich, J. T. 1998. Review Interdependence between chloroplasts and mitochondria in the light and the dark. Biochimica et Biophysica Acta (BBA) - Bioenergetics 1366(3): 235 - 255

Hoegh-Guldberg, O. 1999. Climate change, coral bleaching and the future of the world's coral reefs. Marine and freshwater research 50: 839 - 866

Hoegh-Guldberg, O., Mumby, P. J., Hooten, A. J., Steneck, R. S., Greenfield, P., Gomez, E., Harvell C. D., Sale, P. F., Edwards, A. J., Caldeira, K., Knowlton, N., Eakin, C. M., Iglesias-Prieto, R., Muthiga, N., Bradbury, R. H., Dubi, A., and Hatziolos M. 
E. 2007. Coral reefs under rapid climate change and ocean acidification. Science 318(5857): $1737-1742$

Houghton, J. T., Ding, Y., Griggs, D. J., Noguer, M., van der Linden, P. J., Dai, X., Maskell, K., and Johnson, C. A. 2001. Climate Change 2001: the scientific basis, Contribution of Working Group I to the Third Assessment Report of the Intergovernmental Panel on Climate Change Published for the Intergovernmental Panel on Climate Change

Houlbrèque, F., Tambutté, E., Allemand, D., and Ferrier-Pagès, C. 2004. Interactions between zooplankton feeding, photosynthesis and skeletal growth in the scleractinian coral Stylophora pistillata. Journal of Experimental Biology 207: $1461-1469$

Hughes, T. P., Baird, A. H., Bellwood, D. R., Card, M., Connolly, S. R., Folke, C., Grosberg, R., Hoegh-Guldberg, O., Jackson, J. B. C., Kleypas, J., Lough, J. M., Marshall, P., Nyström, M., Palumbi, S. R., Pandolfi, J. M., Rosen, B., and Roughgarden, J. 2003. Climate Change, human impacts, and the resilience of coral reefs. Science 301(5635): 929 - 933

Hulme, P. E. 2005. Adapting to climate change: is there scope for ecological management in the face of a global threat? Journal of Applied Ecology 42: $784-794$

Horiguchi, T., and Takano, Y. 2006. Serial replacement of a diatom endosymbiont in the marine dinoflagellate Peridinium quinquecorne (Peridiniales, Dinophyceae). Phycological Research 54: 193 - 200

Hutchins, D. A., Fu, F.-X., Zhang, Y., Warner, M. E., Feng, Y., Portune, K., Bernhardt, P. W., and Mulholland, M. R. 2007. $\mathrm{CO}_{2}$ control of Trichodesmium N2 fixation, photosynthesis, growth rates, and elemental ratios: implications for past, present, and future ocean biogeochemistry. Limnology and Oceanography 52(4): 1293 1304 
Inagaki, Y., Dacks, J. B., Doolittle, W. F., Watanabe, K. I., and Ohama, T. 2000. Evolutionary relationship between dinoflagellates bearing obligate diatom endosymbionts: insight into tertiary endosymbiosis. International Journal of Systematic and Evolutionary Microbiology 50: 2075 - 2081

Ishikura, M., Adachi, K., Maruyama, T. 1999. Zooxanthellae release glucose in the tissue of a giant clam, Tridacna crocea. Marine Biology 133: 665 - 673

Iglesias-Prieto', R., and Trench, R. K. 1994. Acclimation and adaptation to irradiance in symbiotic dinoflagellates. I. Responses of the photosynthetic unit to changes in photon flux density. Marine Ecology Progress Series 113: 163 - 175

Iglesias-Rodriguez, D. M., Halloran, P. R., Rickaby, R. E. M., Hall, I. R., ColmeneroHidalgo, E., Gittins, J. R., Green, D. R. H., Tyrrell, T., Gibbs, S. J., von Dassow, P., Rehm, E., Armbrust, V. E., and Boessenkool, K. P. 2008. Phytoplankton calcification in a high- $\mathrm{CO}_{2}$ world. Science 320 (5874): 336 - 340

Irwin, R. P., Lin, S.-Z., Long, R. T., and Paul, S. M. 1994. V-methyl-D-aspartate induces a rapid, reversible, and calcium-dependent intracellular acidosis in cultured fetal rat hippocampal neurons. The Journal of Neuroscience 14(3): 1352 - 1357

Jakob, T., Wagner, H., Stehfest, K., and Wilhelm, C. 2007. A complete energy balance from photons to new biomass reveals a light- and nutrient-dependent variability in the metabolic costs of carbon assimilation. Journal of Experimental Botany Research Paper.

Jones, R. J., and Hoegh-Guldberg, O. 1999. Effects of cyanide on coral photosynthesis: implications for identifying the cause of coral bleaching and for assessing the environmental effects of cyanide fishing. Marine Ecology Progress Series 177: 83 $-91$ 
Jones, R. J., Kildea T., and Hoegh-Guldberg, O. 1999. PAM chlorophyll fluorometry: a new in-situ technique for stress assessment in scleractinian corals, used to examine the effects of cyanide from cyanide fishing. Marine Pollution Bulletin 38(10): $864-874$

Jones, A. M., Berkelmans, R., van Oppen, M. J. H., Mieog, J. C., and Sinclair, W. 2008. A community change in the algal endosymbionts of a scleractinian coral following a natural bleaching event: field evidence of acclimatization. Proceedings of the Royal Society. London B: Biological Sciences 275(1641): 1359 - 1365

Kikkawa, T., Kitaa, J., and Ishimatsub, A. 2003. Comparison of the lethal effect of $\mathrm{CO}_{2}$ and acidification on red sea bream (Pagrus major) during the early developmental stages. Marine Pollution Bulletin 48(1-2): 108 - 110

Kleypas, J. A., Buddemeier, R. W., Archer, D., Gattuso, J.-P., Langdon, C., and Opdyke, B. N. 1999 Geochemical consequences of increased atmospheric carbon dioxide on coral reefs, Science $284: 118-120$

Knowlton, N. 2001a. Coral reef biodiversity--habitat size matters. Science 292: 1493 1495

Knowlton, N. 2001b. The future of coral reefs. Proceedings of the National Academy of Sciences 98(10): $5419-5425$

Kraut, J. 1988. How do enzymes work? Science 242(4878): 533 - 540

Laffey, J. G., Engelberts, D., and Kavanagh, B. P. 2000. Buffering hypercapnic acidosis worsens acute lung injury. American Journal of Respiratory and Critical Care Medicine 161(1): 141 - 146

LaJeunesse, T. C. 2002. Diversity and community structure of symbiotic dinoflagellates from Caribbean coral reefs. Marine Biology 141(2): 387 - 400 
LaJeunesse T. C., Loh, W. K. W., van Woesik, R., Hoegh-Guldberg, O., Schmidt, G. W., and Fitt, W. K. 2003. Low symbiont diversity in southern Great Barrier Reef corals relative to those of the Caribbean. Limnology and Oceanography 48(5): $2046-2054$

Langdon, C., Broecker, W. S., Hammond, D. E., Glenn, E., Fitzsimmons, K., Nelson, S. G., Peng, T.-H., Hajdas, I., and Bonani, G. 2003 Effect of elevated $\mathrm{CO}_{2}$ on the community metabolism of an experimental coral reef. Global Biogeochemical Cycles 17: 1011

Langdon, C., and Atkinson, M. J. 2005. Effect of elevated $\mathrm{pCO}_{2}$ on photosynthesis and calcification of corals and interactions with seasonal change in temperature/irradiance and nutrient enrichment. Journal of Geophysical Research 110: C09S07

Leclercq, N., Gattuso, J.-P., and Jaubert, J. 2000. $\mathrm{CO}_{2}$ partial pressure controls the calcification rate of a coral community. Global Change Biology. 6(3): 329 - 334

Lee, M. J., Ellis, R., and Lee, J. J. 1982. A comparative study of photoadaptation in four diatoms isolated as endosymbionts from larger foraminifera. Marine Biology 68: $193-197$

Leggat, W., Badger, M. R., and Yellowlees, D. 1999. Evidence for an inorganic carbonconcentrating mechanism in the symbiotic dinoflagellate Symbiodinium sp.. Plant Physiology 121: 1247 - 1255

Leggat, W., Rees, T. A. V., and Yellowlees, D. 2000. Meeting the photosynthetic demand for inorganic carbon in an alga-invertebrate association: preferential use of $\mathrm{CO}_{2}$ by symbionts in the giant clam Tridacna gigas. Proceedings of the Royal Society. London B: Biological Sciences 267: 523 - 529 
Leggat, W., Marendy, E. M., Baillie, B., Whitney, S. M., Ludwig, M., Badger, M. R., and Yellowlees, D. 2002. Dinoflagellate symbioses: strategies and adaptations for the acquisition and fixation of inorganic carbon. Functional Plant Biology 29: 309 322

Leonardos N., and Geider R. J. 2005. Elevated atmospheric carbon dioxide increases organic carbon fixation by Emiliania huxleyi (Haptophyta), under nutrient-limited high-light conditions. Journal of Phycology 41: 1196 - 1203

Lipschultz, F., and Cook, C. B. 2002. Uptake and assimilation of N-15-ammonium by the symbiotic sea anemones Bartholomea annulata and Aiptasia pallida: conservation versus recycling of nitrogen. Marine Biology 140: 489 - 502

Lirman, D. 2001. Competition between macroalgae and corals: effects of herbivore exclusion and increased algal biomass on coral survivorship and growth. Coral Reefs 19: $392-399$

Long, S. P., Humphries, S., and Falkowski, P. G. 1994. Photoinhibition of photosynthesis in nature. Annual Review of Plant Physiology and Plant Molecular Biology 45: $633-662$

Lough, J. M. 2008. 10th Anniversary Review: a changing climate for coral reefs. Journal of Environmental Monitoring 10(1): 1-148

Lovejoy, T. E. 2006. Protected areas: a prism for a changing world. Trends in Ecology and Evolution 21(6): 329 - 333

Major, K. M., and Dunton, K. H. 2002. Variations in light-harvesting characteristics of the seagrass, Thalassia testudinum: evidence for photoacclimation. Journal of Experimental Marine Biology and Ecology 275(2): 173 - 189 
Marlow H. Q., and Martindale, M. Q. 2007. Embryonic development in two species of scleractinian coral embryos: Symbiodinium localization and mode of gastrulation. Evolution \& Development 9(4): 355 - 367

Marubini, F., Ferrier-Pagès, C., Furla, P., and Allemand, D. 2008. Coral calcification responds to seawater acidification: a working hypothesis towards a physiological mechanism. Coral Reefs 27(3): 491 - 499

Maury, W. J., Huber, S. C., and Moreland, D. E. 1981. Effects of magnesium on intact chloroplasts. Plant Physiology 68: 1257 - 1263

May, R. C., Kelly, R. A., and Mitch, W. E. 1986. Metabolic acidosis stimulates protein degradation in rat muscle by a glucocorticoid-dependent mechanism. The Journal of Clinical Investigation 77: $614-621$

May, R. C., Bailey, J. L., Mitch, W. E., Masud, T., and England, B. K. 1996. Glucocorticoids and acidosis stimulate protein and amino acid catabolism in vivo. Kidney International 49: 679 - 683

Mazel, C. H., Lesser, M. P., Gorbunov, M. Y., Barry, T. M., Farrell, J. H., Wyman, K. D., and Falkowski P. G. 2003. Green-fluorescent proteins in Caribbean corals. Limnology and Oceanography 48(1, part 2): $402-411$

McClanahan, T. R. and Mutere, J. C. 1994. Coral and sea urchin assemblage structure and interrelationships in Kenyan reef lagoons. Hydrobiologia 286: $109-124$

McCloskey, L. R., and Muscatine, L. 1984. Production and respiration in the Red Sea coral Stylophora pistillata as a function of depth. Proceedings of the Royal Society of London B: Biological Sciences 222: 215 - 230 
McConnaughey, T. A. 1991. Calcification in Chara corallina: $\mathrm{CO}_{2}$ hydroxylation generates protons for bicarbonate assimilation. Limnology and Oceanography 36: $619-628$

McConnaughey, T. A., and Whelan, J. F. 1997. Calcification generates protons for nutrient and bicarbonate uptake. Earth-Science Reviews 42(1-2): 95 - 117

Meyer, J. L., Schultz, E. T., and Helfman, G. S. 1983. Fish schools: an asset to corals. Science 220(4601): $1047-1049$

Miles, H., Widdicombe, S., Spicer, J. I., and Hall-Spencer, J. 2007. Effects of anthropogenic seawater acidification on acid-base balance in the sea urchin Psammechinus miliaris. Marine Pollution Bulletin 54: 89 - 96

Miller, D. J., and Yellowlees, D. 1989. Inorganic nitrogen uptake by symbiotic marine cnidarians: a critical review. Proceedings of the Royal Society of London. Series $B$ 37: $109-125$

Mitch, W. E., Medina, R., Grieber, S., May, R. C., England, B. K., Russ Price, S., Bailey, J. L., and Goldberg, A. L. 1994. Metabolic acidosis stimulates muscle protein degradation by activating the adenosine triphosphate-dependent pathway involving ubiquitin and proteasomes. The Journal of Clinical Investigation 93: $2127-2133$

Montenegro, A., Brovkin, V., Eby, M., Archer, D., and Weaver, A. J. 2007. Long term fate of anthropogenic carbon. Geophysical Research Letters, 34: L19707

Mous, P. J., Pet-Soede, L., Erdmann, M., Cesar, H. S. J., Sadovy, Y., and Pet, J. S. 2000. Cyanide fishing on Indonesian coral reefs for the live food fish market - what is the problem? SPC Live Reef Fish Information Bulletin 7: 20 - 26 
Muller-Parker, G., and Davy, S. K. 2001. Temperate and tropical algal-sea anemone symbioses. Invertebrate Biology 120(2): 104 - 123

Muller-Parker, G., Pierce-Cravens, J., and Bingham, B. L. 2007. Broad thermal tolerance of the symbiotic dinoflagellate Symbiodinium muscatinei (dinophyta) in the sea anemone Anthopleura Elegantissima (cnidaria) from northern latitudes. Journal of Phycology 43(1): $25-31$

Muscatine, L. 1967. Glycerol excretion by symbiotic algae from corals and Tridacna and its control by the host. Science 156: $516-519$

Muscatine, L., and D'Elia, C. F. 1978. The uptake, retention, and release of ammonium by reef corals. Limnology and Oceanography 23(4): 725 - 734

Muscatine, L., McCloskey, L. R., and Marian, R. E. 1981. Estimating the daily contribution of carbon from zooxanthellae to coral animal respiration. Limnology and Oceanography 26(4): $601-611$

Muscatine, L., Falkowski, P. G., Porter, J. W., and Dubinsky, Z. 1984. Fate of photosynthetic fixed carbon in light- and shade-adapted colonies of the symbiotic coral Stylophora pistillata. Proceedings of the Royal Society of London B: Biological Sciences 222: $181-202$

Muscatine, L., Gates, R.D., La Fontaine, I. 1994. Do symbiotic dinoflagellates secrete lipid droplets? Limnology and Oceanography 39: 925 - 929

Muscatine, L., Goiran, C., Land, L., Jaubert, J., Cuif, J.-P., and Allemand, D. 2005. Stable isotopes $(\delta 13 \mathrm{C}$ and $\delta 15 \mathrm{~N})$ of organic matrix from coral skeleton. Proceedings of the National Academy of Science of the United States of America 102(5): $1525-1530$ 
Nicholls, R. J., Wong, P. P., Burkett, V., Woodroffe, C. D., and Hay, J. 2008. Climate change and coastal vulnerability assessment: scenarios for integrated assessment. Sustainability Science 3(1): 89 - 102

Nocito, F. F., Espen, L., Crema, B., Cocucci, M., and Attilio, S. G. 2008. Cadmium induces acidosis in maize root cells. New Phytologist 179(3): $700-711$

Nyström, M., Folke, C., and Moberg, F. 2000. Coral reef disturbance and resilience in a human-dominated environment. Trends in Ecology \& Evolution 15(10): 413 - 417

Olsen, L. J., Theg, S. M., Selman, B. R., and Keegstra, K. 1989. ATP is required for the binding of precursor proteins to chloroplasts. The Journal of Biological Chemistry 264: $6724-6729$

Orr, J. C., Fabry, V. J., Aumont, O., Bopp, L., Doney, S. C., Feely, R. A., Gnanadesikan, A., Gruber, N., Ishida, A., Joos, F., Key, R. M., Lindsay, K., Maier-Reimer, E., Matear, R., Monfray, P., Mouchet, A., Najjar, R. G., Plattner, G. K., Rodgers, K. B., Sabine, C. L., Sarmiento, J. L., Schlitzer, R., Slater, R. D., Totterdell, I. J., Weirig, M. F., Yamanaka, Y., and Yool, A. 2005. Anthropogenic ocean acidification over the twenty-first century and its impact on calcifying organisms. Nature 437: $681-686$

Ostergaard, J., Persiau, G., Davey, M. W., Bauw, G., Van Montagu, M. 1997. Isolation of a cDNA coding for L-galactono-gamma-lactone dehydrogenase, an enzyme involved in the biosynthesis of ascorbic acid in plants. Purification, characterization, cDNA cloning, and expression in yeast. Journal of Biological Chemistry 272: $30009-30016$

Palacios, S. L., and Zimmerman, R. C. 2007. Response of eelgrass Zostera marina to $\mathrm{CO}_{2}$ enrichment: possible impacts of climate change and potential for remediation of coastal habitats. Marine Ecology Progress Series 344: 1 - 13 
Palardy, J. E., Grottoli, A. G., and Matthews, K. A. 2006. Effect of naturally changing zooplankton concentrations on feeding rates of two coral species in the Eastern Pacific. Journal of Experimental Marine Biology and Ecology 331: 99 - 107

Patel, A. J., Lazdunski, M., and Honoré, E. 2001. Lipid and mechano-gated 2P domain $\mathrm{K}+$ channels. Current Opinion in Cell Biology 13: 422 - 427

Pearse, V. B. 1971. Sources of carbon in the skeleton of the coral Fungia scutaria. In: Experimental Coelenterate Biology pp. 239-245. Honolulu: University of Hawaii Press (1971).

Pearse, V. B., and Muscatine, L 1971. Role of symbiotic algae (zooxanthellae) in coral calcification. Biological Bulletin 141: 350 - 363

Pelejero, C., Calvo, E., McCulloch, M. T., Marshall, J. F., Gagan, M. K., Lough, J. M., and Opdyke, B. N. 2005. Preindustrial to modern interdecadal variability in coral reef pH. Science 309: $2204-2207$

Petit, J. R., Jouzel, J., Raynaud, D., Barkov, N. I., Barnola, J.M., Basile, I., Bender, M., Chappellaz, J., Davis, J., Delaygue, G., Delmotte, M., Kotlyakov, V. M., Legrand, M., Lipenkov, V., Lorius, C., Pe'pin, L., Ritz, C., Salzman, E., and Stievenard, M. 1999. Climate and atmospheric history of the past 420000 years from the Vostok ice core, Antarctica. Nature 399: 429 - 436

Pomerance, R. 1999. Coral bleaching, coral mortality, and global climate change. Report presented by Deputy Assistant Secretary of State for the Environment and Development to the US Coral Reef Task Force, 5 March 1999, Maui, Hawaii. [accessed online 26/08/2009] http://www.state.gov/www/global/global_issues/coral_reefs/990305_coralreef_rpt .html 
Porto, I., Granados, C., Restrepo, J. C., and Sánchez J. A. 2008. Macroalgal-associated dinoflagellates belonging to the genus Symbiodinium in Caribbean Reefs. Public Library of Science ONE 3(5): e2160

Ralph, P. J., Gademann, R., and Larkum, A. W. D. 2001. Zooxanthellae expelled from bleached corals at $33^{\circ} \mathrm{C}$ are photosynthetically competent. Marine ecology progress series 220: $163-168$

Reaich, D., Channon, S. M., Scrimgeour, C. M., and Goodship, T. H. 1992. Ammonium chloride-induced acidosis increases protein breakdown and amino acid oxidation in humans. American Journal of Physiology - Endocrinology and Metabolism 263(4): E735 - E739

Rees, T. A. V. 1986. The green hydra symbiosis and ammonium. I. The role of the host in ammonium assimilation and its possible regulatory significance. Proceedings of the Royal Society of London B: Biological Sciences 229: 299 - 314

Rees, T. A. V., and Ellard, F. M. 1989. Nitrogen conservation and the green hydra symbiosis. Proceedings of the Royal Society of London B: Biological Sciences 236: $203-212$

Reimer, J. D., Shusuke, O., Furoshima, Y., and Tsukahara, J. 2007. Seasonal changes in morphological condition of symbiotic dinoflagellates (Symbiodinium spp.) in Zoanthus sansibaricus (Anthozoa: Hexacorallia) in southern Japan. South Pacific Studies 27(2): pages not specified

Renegar, D. A., and Riegl, B. M. 2005. Effect of nutrient enrichment and elevated $\mathrm{CO}_{2}$ partial pressure on growth rate of Atlantic scleractinian coral Acropora cervicornis. Marine Ecology Progress Series 293: 69 - 76

Richmond, R. H. 1993. Coral reefs: present problems and future concerns resulting from anthropogenic disturbance. American Zoologist 33(6): 524 - 536 
Ridley, C. P., Bergquist, P. R., Harper, M. K. D., Faulkner, J., Hooper J. N. A., and Haygood, M. G. 2005. Speciation and biosynthetic variation in four dictyoceratid sponges and their cyanobacterial symbiont, Oscillatoria spongeliae. Chemistry \& Biology 12: 397 - 406

Riebesell, U., Zondervan, I., Rost, B., Tortell, P. D., Zeebe, R. E., and Morel. F. M. M. 2000. Reduced calcification of marine plankton in response to increased atmospheric $\mathrm{CO}_{2}$. Nature 407: $364-367$

Riebesell, U. 2004. Effects of $\mathrm{CO}_{2}$ enrichment on marine phytoplankton. Journal of Oceanography 60(4): 719 - 729

Riebesell, U., Schulz, K. G., Bellerby, R. G. J., Botros, M., Fritsche, P., Meyerhofer, M., Neill, C., Nondal, G., Oschlies, A., Wohlers, J., and Zollner, E. 2007. Enhanced biological carbon consumption in a high $\mathrm{CO}_{2}$ ocean. Nature 450(7169): 545 - 548

Riebesell, U. 2008. Climate change: acid test for marine biodiversity. Nature 454: 46 47

Riegl, B., and Brancha, G. M. 1995. Effects of sediment on the energy budgets of four scleractinian (Bourne 1900) and five alcyonacean (Lamouroux 1816) corals. Journal of Experimental Marine Biology and Ecology 186(2): 259 - 275

Roberts, C. M., Hawkins, J., Schueler, F. W., Strong, A. E., and McAllister, D. E. 1998. The distribution of coral reef fish biodiversity: the climate-biodiversity connection. Sea Wind 12(4): $14-28$

Rodriguez-Lanetty, M., Chang, S.-J., and Song, J.-I. 2003. Specificity of two temperate dinoflagellate-anthozoan associations from the north-western Pacific Ocean. Marine Biology 143: 1193 - 1199 
Rodriguez-Lanetty, M., Loh, W., Carter, D., and Hoegh-Guldberg, O. 2001. Latitudinal variability in symbiont specificity within the widespread scleractinian coral Plesiastrea versipora. Marine Biology 138(6): 1175 - 1181

Rogers, C. S. 1990. Responses of coral reefs and reef organisms to sedimentation. Marine Ecology Progress Series 62: 185 - 202

Rost, B., Zondervan, I., and Wolf-Gladrow, D. 2008. Sensitivity of phytoplankton to future changes in ocean carbonate chemistry: current knowledge, contradictions and research directions. Marine Ecology Progress Series 373: 227 - 237

Rowan, R., and Knowlton, N. 1995. Intraspecific diversity and ecological zonation in coral-algal symbiosis. Proceedings of the National Academy of Sciences of the United States of America 92: 2850 - 2853

Royal Society 2005. Ocean acidification due to increasing atmospheric carbon dioxide. Policy Document. The Royal Society

Rutter, J. C., and Cobb, A. H. 2006. Photosynthesis by isolated Codium Fragile chloroplasts of varying internal phosphate status. New Phytologist 95(4): 549 557

Saffo, M. B. 1992. Invertebrates in endosymbiotic associations. American Zoologist 32(4): $557-565$

Sakano, K. 2001. Metabolic regulation of $\mathrm{pH}$ in plant cells: role of cytoplasmic $\mathrm{pH}$ in defense reaction and secondary metabolism. International Review of Cytology 206: $1-44$

Sale, P. F. 2008. Management of coral reefs: where we have gone wrong and what we can do about it. Marine Pollution Bulletin 56 (5): 805 - 809 
Salih, A., Larkum, A., Cox, G., Kuhl, M., and Hoegh-Guldberg, O. 2000. Fluorescent pigments in corals are photoprotective. Nature 408: $850-853$

Savage, A. M., Goodson, M. S., Visram, S., Trapido-Rosenthal, H., Wiedenmann, J., and Douglas. A. E. 2002. Molecular diversity of symbiotic algae at the latitudinal margins of their distribution: dinoflagellates of the genus Symbiodinium in corals and sea anemones. Marine Ecology Progress Series 244: 17-26

Schuhmacher, H., and Zibrowius, H. 1985. What is hermatypic? Coral Reefs 4(1): 1 - 9

Scott, A., and Harrison, P. 2007. Broadcast spawning of two species of sea anemone, Entacmaea quadricolor and Heteractis crispa, that host anemonefish. Invertebrate Reproduction and Development 50(3): 163 - 171

Shick, J. M and Dykens, J. A 1985. Oxygen detoxification in algal-invertebrate symbioses from the Great Barrier Reef. Oecologia 66: 33 - 41

Schneider, K. and Erez, J. 2006. The effect of carbonate chemistry on calcification and photosynthesis in the hermatypic coral Acropora eurystoma. Limnology and Oceanography 51(3): $1284-1293$

Schwarz, J. A., and Weis, V. M. 2003. Localization of a symbiosis-related protein, Sym32, in the Anthopleura elegantissima-Symbiodinium muscatinei association. Biological Bulletin 205: 339 - 350

Sebens, K. P. 1994. Biodiversity of coral reefs: what are we losing and why? American Zoologist 34(1):115 - 133

Sheppard, C. 2008. A marine nutcracker. Marine Pollution Bulletin 56(5): $799-800$

Smith, A. F., and Raven, J. A. 1979. Intracellular pH and its regulation. Annual Review of Plant Physiology 30:289 - 311 
Smith, G. J., and Muscatine, L. 1986. Carbon budgets and regulation of the populationdensity of symbiotic algae. Endocytobiosis and Cell Research 3: 213 - 238

Smith, D. C., and Douglas A. E. 1987. The biology of symbiosis London: Edward Arnold, (1987)

Spero, H. J., Bijma, J., Lea, D. W., and Bemis, B. E. 1997. Effect of seawater carbonate concentration on foraminiferal carbon and oxygen isotopes. Nature 390: 497 500

Stambler, N., and Dubinsky, Z. 2005. Corals as light collectors: an integrating sphere approach. Coral Reefs 24(1): 1 - 9

Stimson, J. S. 1987. Location, quantity and rate of change in quantity of lipids in tissue of hawaiian hermatypic corals. Bulletin of Marine Science 41(3): 889 - 904

Stonik, V. A., Mikhailov, V. V., Bulgakov, V. P., and Zhuravlev, Y. N. 2007. Biotechnological studies in the far-eastern region of Russia. Biotechnology Journal 2(7): $818-825$

Suggett, D. J., le FlocH, E., Harris, G. N., Leonardos, N., and Geider, R. J. 2007. Different strategies of photoacclimation by two strains of Emiliania huxleyi (Haptophyta). Journal of Phycology 43: 1209 - 1222

Streamer, M., McNei1, Y. R., and Yellowlees, D. 1993. Photosynthetic carbon dioxide fixation in zooxanthellae. Marine Biology 115(2): 195 - 198

Strychar. K., Coates, M., and Sammarco, P. W. 2004. Loss of Symbiodinium from bleached Australian corals (Acropora hyacinthus, Favites complanta and Porites solida). Marine and Freshwater Research 55: 135 - 144 
Sundquist, E. T. 1993. The global carbon dioxide budget. Science 259(5097): 934 - 941

Tanner, J. E. 1995. Competition between scleractinian corals and macroalgae: an experimental investigation of coral growth, survival and reproduction. Journal of Experimental Marine Biology and Ecology 190(2): 151 - 168

Thornton, D. C. O. 2009. Effect of low pH on carbohydrate production by a marine planktonic diatom (Chaetoceros muelleri). Research Letters in Ecology. Received 5 November 2008; Accepted 28 January 2009 [as yet unpublished]

Titlyanov, E. A., Titlyanova, T. V., Yamazatoc, K., van Woesikd, R. 2001. Photoacclimation of the hermatypic coral Stylophora pistillata while subjected to either starvation or food provisioning. Journal of Experimental Marine Biology and Ecology 257: 163 - 181

Titlyanov, E. A., and Titlyanova T. V. 2002. Reef-building corals—symbiotic autotrophic organisms: 1. general structure, feeding pattern, and light-dependent distribution in the shelf. Russian Journal of Marine Biology 28(S1): S1 - S15

Tortell, P. D., Payne, C. D., Li, Y., Trimborn, S., Rost, B., Smith, W. O., Riesselman, C., Dunbar, R. B., Sedwick, P., DiTullio, G. R. 2008. $\mathrm{CO}_{2}$ sensitivity of Southern Ocean phytoplankton. Geophysical Research Letters L04605

Trench, R. K. 1993. Microalgal-invertebrate symbioses: a review. Endocytobiosis and Cell Research 9: 135 - 175

Turley, C. M., Roberts, J. M., and Guinotte, J. M. 2007. Corals in deep-water: will the unseen hand of ocean acidification destroy cold-water ecosystems? Coral Reefs 26: $445-448$

Usher, K. M., Bergman, B., and Raven, J. A. 2007. Exploring cyanobacterial mutualisms. Annual review of ecology, evolution, and systematics 38: 255 - 273 
van Alstyne, K., Wylie, C. R., Paul, V. J., and Meyer, K. 1992. Antipredator defenses in tropical pacific soft corals (Coelenterata: Alcyonacea). I. sclerites as defenses against generalist carnivorous fishes. Biological Bulletin 182: $231-240$

van Oppen, M. J. H., Mieog, J . C., Sánchez C. A., and Fabricius K. E. 2005. Diversity of algal endosymbionts (zooxanthellae) in octocorals: the roles of geography and host relationships. Molecular Ecology 14: 2403 - 2417

Venn, A. A., Tambutté, E., Lotto, S., Zoccola, D., Allemand, D., and Tambutté, S. 2009. Imaging intracellular $\mathrm{pH}$ in a reef coral and symbiotic anemone. Proceedings of the National Academy of Sciences of the United States of America 106(39): 16574 $-16579$

Verde, A. E., and McCloskey, L. R. 1996. Carbon budget studies of symbiotic cnidarian anemones-evidence in support of some assumptions. Journal of Experimental Marine Biology and Ecology, 195: 161 - 171

Wagner, H., Jakob, T., and Wilhelm C. 2006. Balancing the energy flow from captured light to biomass under fluctuating light conditions. New Phytologist 169(1): 95 108

Wakefield, T. S., and Kempf, S. C. 2001. Development of host- and symbiont-specific monoclonal antibodies and confirmation of the origin of the symbiosome membrane in a cnidarian-dinoflagellate symbiosis. Biological Bulletin 200: 127 143

Walther, G.-R., Post, E., Convey, P., Menzel, A., Parmesan, C., Beebee, T. J. C., Fromentin, J.-M., Hoegh-Guldberg, O., and Franz, B. 2002. Ecological responses to recent climate change. Nature 416: 389 - 395 
Wang, J. T., and Douglas, A. E. 1998. Nitrogen recycling or nitrogen conservation in an alga-invertebrate symbiosis? Journal of Experimental Biology 201: 2445 - 2453

Weis, V. M. 1993. Effect of dissolved inorganic carbon concentration on the photosynthesis of the symbiotic sea anemone, Aiptasia pulchella Carlgren: role of carbonic anhydrase. Journal of experimental marine biology and ecology 174(2): $209-225$

Weis, V. M., and Reynolds, W. S. 1999. Carbonic anhydrase expression and synthesis in the sea anemone Anthopleura elegantissima are enhanced by the presence of dinoflagellate symbionts. Physiological and Biochemical Zoology 72(3): 307 - 316

Weis, V. M. 2008. Commentary - Cellular mechanisms of cnidarian bleaching: stress causes the collapse of symbiosis. The Journal of Experimental Biology 211: 3059 $-3066$

Weis, V. M., Davy, S. K., Hoegh-Guldberg, O., Rodriguez-Lanetty, M., and Pringle, J. R. 2008. Cell biology in model systems as the key to understanding corals. Trends in Ecology \& Evolution 23(7): 369 - 376

Wildbrett, P., Oh, A., Naundorf, D., Volk, T., and Jacobi C. A. 2003. Impact of laparoscopic gases on peritoneal microenvironment and essential parameters of cell function. Surgical Endoscopy 17: 78 - 82

Wilson, C. H., Brook, N. R., and Talbot, D. 2006. Preservation Solutions for Solid Organ Transplantation. Mini-Reviews in Medicinal Chemistry 6: 1081 - 1090

Wood, H. L., Spicer, J. I., and Widdicombe, S. 2008. Ocean acidification may increase calcification rates, but at a cost. Proceedings of the Royal Society B: Biological Sciences 275: $1767-1773$ 
Woodroffe, C. D. 1990. The impact of sea-level rise on mangrove shorelines. Progress in Physical Geography 14: 483 - 520

Yellowlees, D., Dionisio-Sese, M., Masuda, K., Maruyama, T., Abe, T., Baillie, B., Tsuzuki, M., and Miyachi, S. 1993. The role of carbonic anhydrase in the supply of inorganic carbon to the giant clam-zooxanthellae symbiosis. Marine Biology 115: $605-611$

Zeebe, R. E., Zachos, J. C., Caldeira, K., Tyrrell, T. 2008. Carbon emissions and acidification. Science Perspectives 321: $51-52$

Zondervan, I., Zeebe, R., Rost, B., and Riebesell, U. 2001. Decreasing marine biogenic calcification: a negative feedback on rising atmospheric $\mathrm{pCO}_{2}$. Global Biogeochemical Cycles 15: 507 - 516

Zondervan, I., Rost, B., and Riebesell, U. 2002. Effect of $\mathrm{CO}_{2}$ concentration on the $\mathrm{PIC/POC}$ ratio in the coccolithophore Emiliania huxleyi grown under lightlimiting conditions and different daylengths. Journal of Experimental Marine Biology and Ecology 272(1): 55 - 70 